FORSCHUNGSERGEBNISSE DER WIRTSCHAFTSUNIVERSITÄT WIEN

Ingrid Zechmeister

\title{
Mental Health Care Financing in the Process of Change
}


FORSCHUNGSERGEBNISSE DER

WIRTSCHAFTSUNIVERSITÄT WIEN

Ingrid Zechmeister

\section{Mental Health Care Financing in the Process of Change}

While mental health care has undergone substantial reforms, little attention has been paid to financing issues. This book addresses this shortcoming and brings more transparency into the complex relationship between mental health care reform, service provision and financing. Additionally, it provides rich information about the characteristics of mental health care financing in Western Europe. The author analyses the recent mental health care reform discourse against the backdrop of broader political economic developments and demonstrates the role of financing arrangements herein. The book vividly shows how financing is related to specific effects for service users and their relatives in the process of change. In the final part practitioners, planers and policy makers find useful guidelines for developing alternative financing approaches including support to improve understanding of financing issues amongst those involved in mental health care.

Ingrid Zechmeister was born in Upper Austria in 1972. After several years of practical experience in the area of ultrasound sonography at the Department of Gynaecology/Vienna General Hospital she moved to research in the field of (mental) health economics and health policy. Since 2000 she has been involved in research projects at the Department of Social Policy/Vienna University of Economics and Business Administration and at the Vienna University Clinic of Psychiatry, and additionally in teaching activities at several Austrian Universities. 
Mental Health Care Financing in the Process of Change 


\section{Forschungsergebnisse der Wirtschaftsuniversität Wien}

Band 8

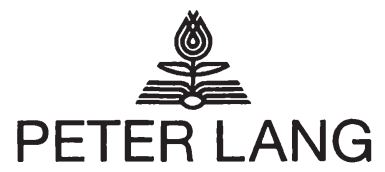

Frankfurt am Main · Berlin · Bern · Bruxelles · New York · Oxford · Wien 
Ingrid Zechmeister

\section{Mental Health Care Financing in the Process of Change}

Challenges and Approaches for Austria

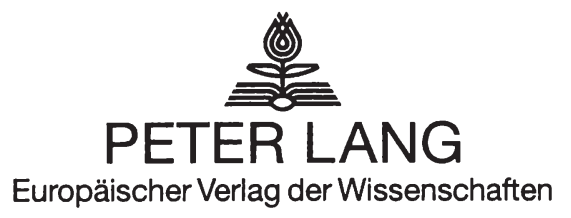

Ingrid Zechmeister - 978-3-631-75434-4

Downloaded from PubFactory at 01/11/2019 04:56:41AM

via free access 


\title{
Bibliographic Information published by Die Deutsche Bibliothek
}

Die Deutsche Bibliothek lists this publication in the Deutsche Nationalbibliografie; detailed bibliographic data is available in the internet at <http://dnb.ddb.de>.

Open Access: The online version of this publication is published on www.peterlang.com and www.econstor.eu under the international Creative Commons License CC-BY 4.0. Learn more on how you can use and share this work: http://creativecommons. org/licenses/by/4.0.

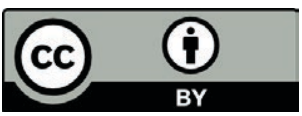

This book is available Open Access thanks to the kind support of ZBW - Leibniz-Informationszentrum Wirtschaft.

Zugl.: Wien, Wirtschaftsuniv., Diss., 2004

Printed with support of Wirtschaftsuniversität Wien.

\author{
ISSN 1613-3056 \\ ISBN 3-631-54338-7 \\ US-ISBN 0-8204-7775-3 \\ ISBN 978-3-631-75434-4(eBook) \\ (c) Peter Lang GmbH \\ Europäischer Verlag der Wissenschaften \\ Frankfurt am Main 2005 \\ All rights reserved.
}

All parts of this publication are protected by copyright. Any utilisation outside the strict limits of the copyright law, without the permission of the publisher, is forbidden and liable to prosecution. This applies in particular to reproductions, translations, microfilming, and storage and processing in electronic retrieval systems.

$$
\begin{gathered}
\text { Printed in Germany } 124567 \\
\text { www.peterlang.de }
\end{gathered}
$$




\section{ACKNOWLEDGEMENT}

I would like to thank my supervisor Prof. August Österle for his very helpful, sometimes quite challenging but intellectually stimulating comments, his permanent assistance in the research process and the confidence he has put in me. Additionally, I would like to thank my co-supervisor Prof. Manfred Lueger for his encouraging statements. With both of them I have experienced a very supportive climate and a well working co-operation which I appreciate very much.

I am especially grateful to my friend Elisabeth Hammer for stimulating and creative debates, for constantly motivating me and giving me advice; to my British friend Liz Petrovitch who has spent a lot of time helping me to improve the language of the thesis; to Thomas Wasner for discussing my thoughts and supporting me in many ways and to all my friends and colleagues who have given me a lot of mental support.

I am also grateful to the participants of the 'Mental Health Economics European Network' who shared their knowledge with me and helped me to get access to important data; in particular I want to thank Claire Curran and Reinhold Killian for their very helpful comments. Not least, I would like to thank all the interviewees who have generously shared their thoughts with me and to anyone who has spoken openly about their experiences. Without their effort I couldn't have written many important parts of this thesis. 
Ingrid Zechmeister - 978-3-631-75434-4 Downloaded from PubFactory at 01/11/2019 04:56:41AM via free access 


\section{TABLE OF CONTENTS}

LIST OF FIGURES

LIST OF TABLES.

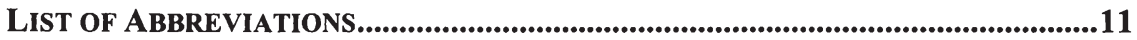

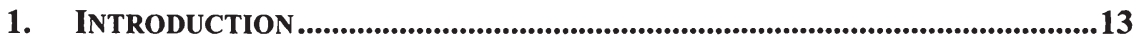

1.1. BACKGROUND AND MOTIVATION OF RESEARCH....................................................13

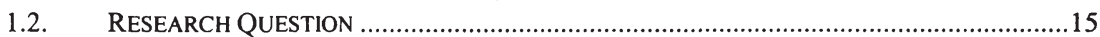

1.3. METHODS, METHODOLOGY AND EPISTEMOLOGICAL BACKGROUND …........................16

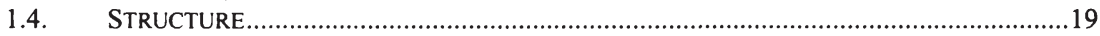

2. PERSPECTIVES OF MENTAL ILLNESS ...........................................................

2.1. CONCEPTS OF MENTAL ILLNESS FROM A HISTORICAL PERSPECTIVE...............................21

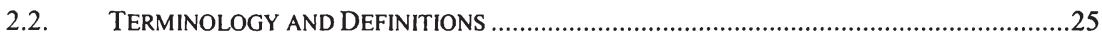

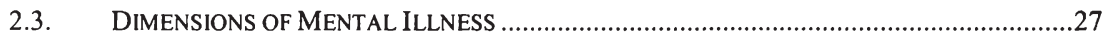

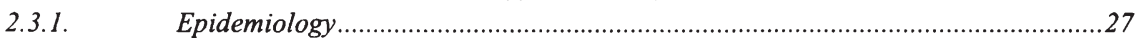

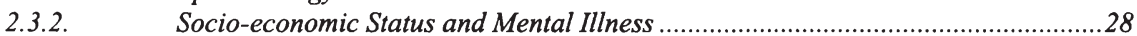

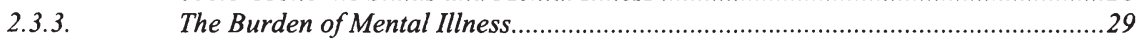

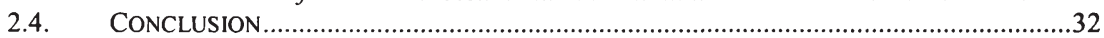

3. Mental health Care Structures in Austria ....................................33

3.1. Mental Health Care Service Categories: AN OVERVIEW ....................................33

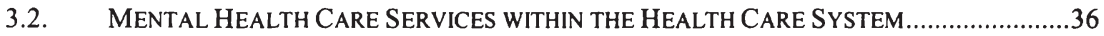

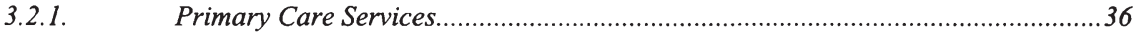

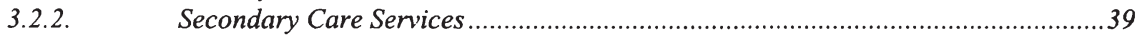

3.3. MENTAl Health CARE SERvices outside the Health CARE SySTEM ......................40

3.3.1. Mobile and Ambulatory Psychiatric Services (MAPS), Social Day Structure

Services and Employment Related Services ............................................................................

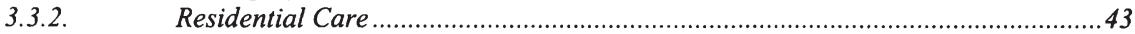

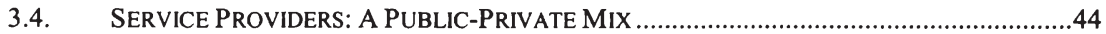

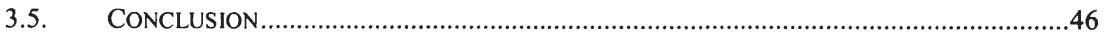

4. Mental Health Care Financing .............................................................47

4.1. AN OVERVIEW OF MENTAL HEALTh CARE FINANCING IN WESTERN EUROPEAN

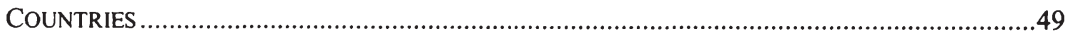

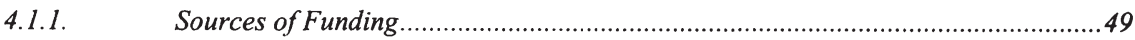

4.1.1.1. Funding Mental Health Care Services within the Health Care System......................... 49

4.1.1.2. Funding Mental Health Care Services outside the Health Care System ..........................53

4.1.2. Transfer of Funds and Resource Allocation Processes ..........................................53

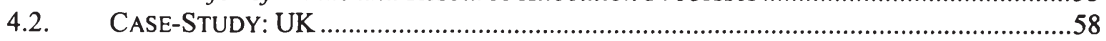

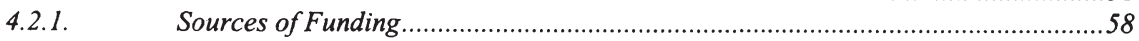

4.2.1.1. Funding Mental Health Care Services within the Health Care System......................... 58

4.2.1.2. Funding Mental Health Care Services outside the Health Care System ...........................59

4.2.2. Transfer of Funds and Resource Allocation Processes ..........................................60

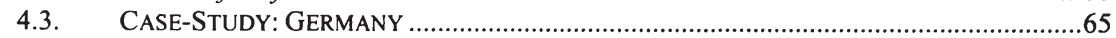

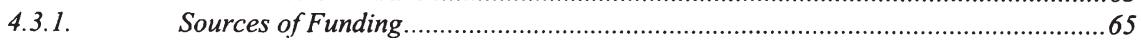


4.3.1.1. Funding Mental Health Care Services within the Health Care System .....................65

4.3.1.2. Funding Mental Health Care Services outside the Health Care System....................68

4.3.2. Transfer of Funds and Resource Allocation Processes.......................................69

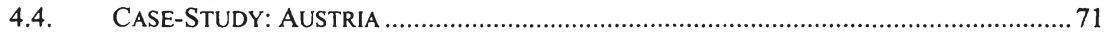

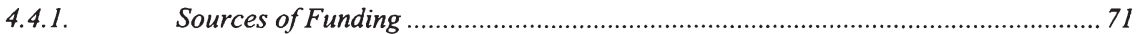

4.4.1.1. Funding Mental Health Care Services within the Health Care System ..................... 71

4.4.1.2. Funding Mental Health Care Services Outside the Health Care System................... 73

4.4.2. Transfer of Funds and Resource Allocation Processes....................................74

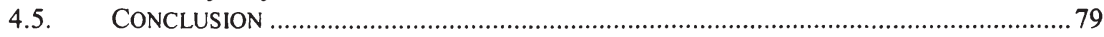

5. Paradigm Shift in Mental Health Care: An Exploration of Mental Health CARe Reform OBJectives ANd Reform Processes ........83

5.1. CENTRAL FEATURES OF ChANGE FROM AN INTERNATIONAL PERSPECTIVE..................83

5.2. MENTAL Health CARE Reform AND Reform Discourse In Austria: A Critical

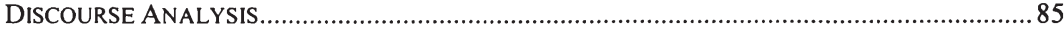

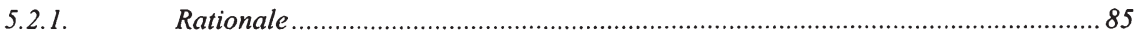

Excursus: Theoretical and Methodological Considerations of a 'Critical Discourse Analysis'.....86

5.2.2. Empirical Data, Method and Analytical Framework........................................ 92

5.2.3. Mental Health Care Policy in Austria since the 1960s: A Brief Historical Overview.

5.2.4. Mental Health Care Plans in Austria: Development and Contents ......................97

5.2.5. Analysis of Reform Discourses and Processes.............................................100

5.2.5.1. The Different Faces of Community Mental Health Care ...................................... 100

5.2.5.2. Actor-relationships and Discourse Struggles .................................................. 103

5.2.5.3. Mental Health Care between Economisation and Changing Patterns of

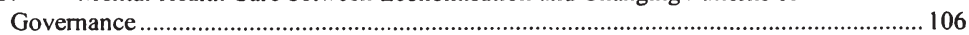

5.2.5.4. Towards a Liberal Model of Mental Health Care?.................................................. 116

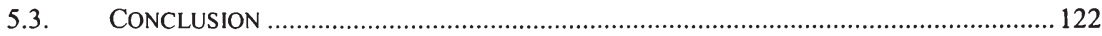

\section{Mental Health Care Financing in the Light OF Reform}

OBJECTIVES AND DISCOURSE .......................................................................125

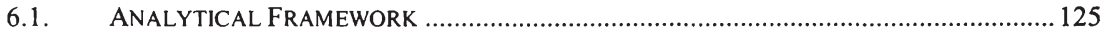

6.2. MENTAL HEALTH CARE FINANCING AND IMPACTS ON THE MACRO LEVEL................. 128

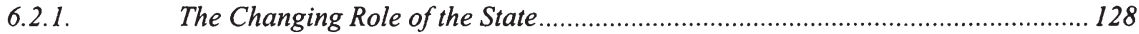

6.2.2. The Rising Position of the 'Market' .............................................................. 133

6.3. MENTAL HEALTH CARE FINANCING AND IMPACTS ON THE MICRO LEVEL.................138

6.3.1. Shifting of the Financial Burden on the Individual Level ................................. 138

6.3.2. 'Consumers' of Mental Health Care: Opportunities and Pitfalls ......................... 142

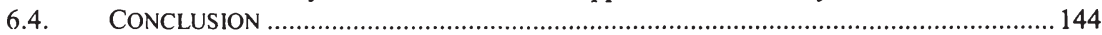

7. Concluding Remarks: What Financing for Mental Health

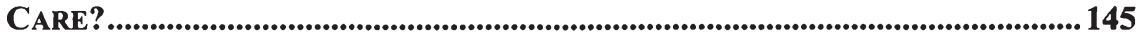

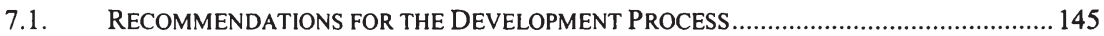

7.2. GUIDELINES FOR DISCUSSING FINANCING OPTIONS .............................................. 149

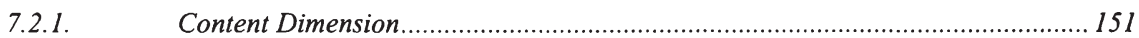

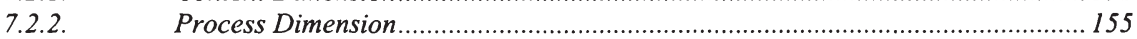

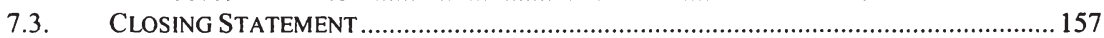

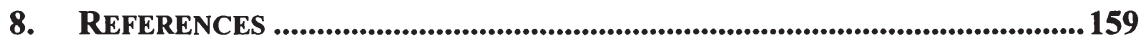




\section{List of Figures}

Figure 1: Changes in days of absenteeism in percentages 1993-2002.................31

Figure 2: Annual changes in days of absenteeism in percentages 1993-2002.......31

Figure 3: Changes in early retirement cases due to inability/reduced ability to

work in percentages 1993-2002.

Figure 4: Mental health care services continuum from non-institutional to institutional care

Figure 5: Number of psychiatrists with and without social security contract .......36

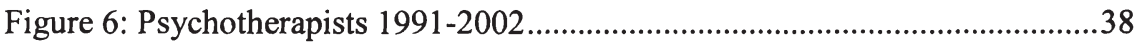

Figure 7: Beds in psychiatric hospitals and in psychiatric departments of general hospitals

Figure 8: Primary source of funding mental health care services within the health care sector 52

Figure 9: Mental health care financing structures in England .............................66

Figure 10: Mental health care financing structures in Germany ...........................72

Figure 11: Prescription of psychotropic medication 1995-2002 ...........................77

Figure 12: Costs of outpatient prescriptions of psychotropic medication 2002

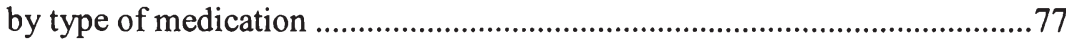

Figure 13: Mental health care financing structures in Lower Austria ....................80

Figure 14: Quantification of monetary flows from public payers in Lower

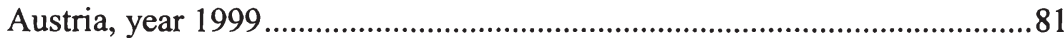

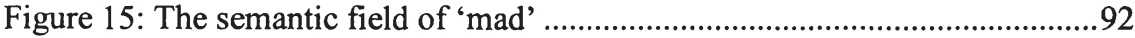




\section{List of Tables}

Table 1: Mental health care services in the health care and social care sector...... 35

Table 2: Distribution of psychiatrists in Austria ..................................................37

Table 3: Distribution of psychotherapists in Austria.............................................38

Table 4: Distribution of health- and/or clinical psychologists in Austria...............39

Table 5: Mobile and ambulatory psychiatric services, year 1998 ......................... 41

Table 6: Social day structure services for mentally ill persons, year 1998 ........... 42

Table 7: Sheltered employment for mentally ill persons, year 1998 ..................... 42

Table 8: Employment related services for mentally disabled people ..................... 43

Table 9: Living arrangements for mentally ill persons, year 1998........................44

Table 10: Mental health care providers in Austria ..................................................45

Table 11a: Funding of mental health care services outside the health care

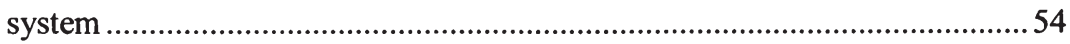

Table 11b: Funding of mental health care services outside the health care

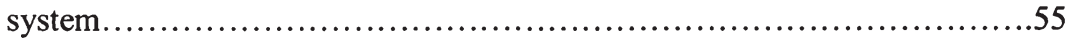

Table 12: PCT allocation to clinical areas in England ...........................................62

Table 13: Commissioners and providers of mental health care in the UK.............65

Table 14: Costs for hospital mental health care 1990-1995 ................................... 75

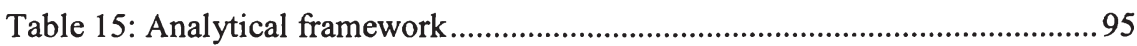

Table 16: Mental Health Care Reform documents since 1990_............................98

Table 17: Analytical framework ........................................................................... 127

Table 18: Interdependency between financing and mental health policy ............151 


\section{List of Abbreviations}

$\begin{array}{ll}\text { AOT } & \text { Assertive Outreach Team } \\ \text { ASVG } & \text { Allgemeines Sozialversicherungsgesetz } \\ \text { AWBZ } & \text { Exceptional Medical Expenses Act } \\ \text { CDA } & \text { Critical Discourse Analysis } \\ \text { CFISSA } & \text { Centrally Funded Initiative and Services and Special Allocation } \\ & \text { Fund } \\ \text { CMHT } & \text { Community Mental Health Teams } \\ \text { DALY } & \text { Disability Adjusted Life Years } \\ \text { DoH } & \text { Department of Health } \\ \text { DRG } & \text { Diagnosis Related Groups } \\ \text { DSM } & \text { Diagnostic and Statistical Manual } \\ \text { EU } & \text { European Union } \\ \text { FHS } & \text { Family Health Service } \\ \text { GDP } & \text { Gross Domestic Product } \\ \text { GMSCL } & \text { General Medical Services Cash Limited } \\ \text { GP } & \text { General Practitioner } \\ \text { HA } & \text { Health Authority } \\ \text { HCHS } & \text { Hospital and Community Services } \\ \text { ITL } & \text { Italian Lire } \\ \text { KWNS } & \text { Keynesian Welfare National State } \\ \text { LTC } & \text { Long Term Care } \\ \text { MAPS } & \text { Mobile and Ambulatory Psychiatric Services } \\ \text { MINI } & \text { Mental Illness Needs Index } \\ \text { NHS } & \text { National Health Service } \\ \text { NPM } & \text { New Public Management } \\ \text { ÖBIG } & \text { Österreichisches Bundesinstitut für Gesundheitswesen } \\ \text { OECD } & \text { Organisation of Economic Cooperation and Development } \\ \text { PCG } & \text { Primary Care Groups } \\ \text { PCT } & \text { Primary Care Trusts } \\ \text { PSD } & \text { Psychosozialer Dienst } \\ \text { PSS } & \text { Personal Social Service } \\ \text { Psych-PV } & \text { Psychiatrie Personalverordnung } \\ \text { RAWP } & \text { Resource Allocation Working Party } \\ \text { SWPR } & \text { Schumpeterian Workfare Post-national Regime } \\ \text { UK } & \text { United Kingdom } \\ \text { US(A) } & \text { United States of America } \\ \text { WHO } & \text { World Health Organisation } \\ & \end{array}$


Ingrid Zechmeister - 978-3-631-75434-4 Downloaded from PubFactory at 01/11/2019 04:56:41AM via free access 


\section{Introduction}

\subsection{Background and Motivation of Research}

From around 1960 onwards, provision of mental health care in most of the 'Western societies' has undergone substantial changes (Bauer, Engfer and Rappl 1991; Bennett 1995; Goodwin 1997). In many countries these processes are still under way. The common idea of the developments has been to reorganise and reshape mental health care from centralised asylum based care to decentralised and deinstitutionalised community based mental health care. Central characteristics of the transformation process have been that firstly, the concept of mental illness has changed from the hitherto normal-pathological dualism to the concept of illness development on a continuum, ranging from normal to pathological. Secondly, the causes for mental illness and the factors for progression of the illness have been recognised as being multiple including biological, psychological and social aspects. Thirdly, the location and organisation of service provision has been characterised by the replacement of asylums with decentralised structures of services. And, finally, the number of involved occupational groups has increased. Treatment or care are carried out by multiprofessional teams and they are characterised by a less paternalistic relationship with the patient (Forster 1997).

As a consequence of the ongoing restructuring processes, current mental health care issues are associated with several challenges. Thus, after a period in which mental health care reform was very much focusing on removing the worst conditions, e.g. by closing several large asylums (Goodwin 1997; Haug and Rössler 1999), more differentiated questions about adequate service provision have arisen. With shifting paradigms in mental health care, new approaches in service provision are required (e.g. Balk 1998; Thornicroft 2001). Notably, various actors have postulated a change from so-called supply-oriented to individual person-oriented and needs-based mental health care (e.g. Bundesministerium für Gesundheit 1999; Kruckenberg 2000).

Apart from restructuring, further challenges are posed by the fact that mental health care ranges beyond the health care system, as it is understood in a traditional sense. Thus, it is very common that mental illness is associated with social isolation, homelessness and accommodation problems or unemployment. Both, the characteristics and aims of the ongoing restructuring processes in mental health care as well as the difficulties linked with mental illness per se imply that reorganising mental health care not only requires medical discussions but has to be embedded in the broader context of economic and social policy issues.

At the same time, overall conditions within which needs and service provision are being discussed, have changed. Concerning health and social policy, a greater emphasis has been put on issues of efficiency, effectiveness and quality of services, the more so, as expenditure limits within the social and health care sector 
have become increasingly tight. This, once again, makes clear that mental health care implies more than 'psychiatry' in a narrow sense. Warner $(1994, x i)$ emphasises: "To understand [mental illness] we need to step outside psychiatry. We have to venture into the territory of the sociologists, the anthropologists and the historians; we must enter the province of epidemiologists, social psychiatrists, economists and political scientists". I believe that this is equally true for understanding mental health care. In addition to multidisciplinary perspectives, I consider it important to address different levels of mental health care. That is to take into account content as well as context and actors as well as structures of mental health care, whichever the specific areas of interests are. These viewpoints are reflected in the approach of the thesis which attempts to address mental health care from a multi-level and interdisciplinary perspective.

Since the project is a one-person undertaking it would, obviously, be impossible to integrate all disciplines which might be relevant. Hence, this thesis will be guided by a social policy perspective, whereby social policy is understood in an interdisciplinary manner as the intersection of economics, sociology and political science. This perspective has been found important for two reasons. Firstly, it has been rather neglected in research so far. For example, despite growing awareness of the costs of mental illness from a macro-economic point of view (e.g. Rice et al. 1992), mental health care has rarely been addressed in health policy and related health care economics research. Research on specific topics has mainly been conducted in Anglo-American countries (e.g. Frank and Manning 1992; Knapp 1995; Netten and Beecham 1993; Williams and Doessel 2001). In continental Europe, as for example in Germany (e.g. Frick, Rehm and Cording 2001; Rössler 2001; Salize 2001) and in Austria, a discourse is only at the beginning.

Apart from the research area, a thorough social policy perspective has secondly been neglected in the more practical field of mental health care planning. This observation is not least based on my own experience when I was involved in the evaluation of the 'Lower Austrian Mental Health Care Plan' (Katschnig, Denk and Weibold 2003) and in the 'Upper Austrian Mental Health Care Planning Project' (Landesregierung Oberösterreich 2003). While numerous debates have taken place concerning the adequate type and level of mental health care, little attention has been drawn to the challenges these issues imply for social policy measures. Or otherwise, where social policy aspects have been addressed, the debates have either taken place rather isolated from general debates on reforming mental health care provision or relevant social policy issues have not been covered in detail. Hence, one central personal interest of the thesis is to further integrate the fields of mental health care and social policy in an interdisciplinary manner for the Austrian context. This, I believe, is not only a challenge from an academic point of view but, as mentioned above, should also shed some more 
light to issues concerned with mental health policy in general and mental health care planning, service provision and financing in particular.

\subsection{Research Question}

The thesis focuses on one major aspect in the field of overall social and specific mental health policy, that is financing mental health care. The term 'financing' is to be understood in a very broad manner, including financing structures such as sources of financing and resource allocation issues as well as actors involved. This subject has been chosen because it is assumed that mental health care financing plays a central role within any (successful) restructuring process in mental health care and because financing issues have been broadly neglected in reform discussions so far. Yet, a challenge for addressing the financing question is provided by the fact that the reform process often appears rather incoherent and is characterised by ambiguous strategies, interests and objectives. Based on that initial situation, the central research interest is firstly, to identify the overall content of mental health care reforms and the political economic context, reforms are embedded in and to, secondly, explore the challenges for mental health care financing with respect to its interdependency with service provision in the process of change.

Via more specific sub-questions I am, firstly, exploring current mental health care financing structures both, nationally and internationally. Secondly, I am going to address what the aims of the reforms are, how they have changed over time and how they are interwoven with mental health care financing. In that respect, I will additionally explore the role of the broader political economic context in the relation between mental health reform and financing structures. Thirdly, I seek to examine the current mental health care financing system according to its impact at the micro-level and at the macro-level of service provision against the backdrop of ongoing changes. Based on these results and experiences, I will, finally, attempt to develop cornerstones for a mental health care financing approach in Austria.

The entire thesis will be characterised by a dialectic approach shifting between analysing the political economic context where reform initiatives and financing systems are embedded, and analysing specific elements of either mental health care or financing issues. Overall, the thesis is based on the results of a twoyear research project which was funded by the Austrian federal bank from October 2002 to July 2004 (Zechmeister and Österle 2004). 


\subsection{Methods, Methodology and Epistemological Background}

As it has become clear from the research question and the subject of research, the thesis focuses on understanding historical developments and processes as well as the dialectic interplay between specific single issues and the overall context of the object under scrutiny. The purpose of the research is not primarily to find causes for the phenomena which are analysed but it aims at better understanding the nature of a phenomenon via an exploratory approach. Thus, concerning the method, it seemed reasonable to choose a qualitative approach. In detail, the study focuses on a combination of qualitative approaches. Using multiple methods, which is known under the term 'triangulation', is at the same time a way of assuring reliability in qualitative research, since weaknesses of single methods can be overcome and the in-depth understanding of the phenomenon under evaluation is enhanced (Denzin 1989).

Qualitative methods which will be applied are, firstly, a discourse analysis in order to evaluate Austrian reform documents, secondly, the interpretation of qualitative interviews of relevant key actors and, thirdly, case-studies of national and international mental health care financing processes. Overall, the methods employed can be summarised under the so-called 'interpretative social science research', described in detail by Lueger (2001).

From an epistemological point of view, every scientific method implies a specific methodological framework which reflects epistemological positions. Thus, in following a qualitative approach, the study is based on the constructivist theoretical assumption that reality is constructed via (inter)active social processes and that the sense of phenomena is socially constructed. This position dismisses the notion of objectivism, since any (apparently objective) facts of reality are nothing else than subjectively constructed expressions of reality and are therefore relative. Consequently, the constructivist epistemological position contrasts with the prevailing Popperian Critical Rationalism and its positivist epistemological approach ${ }^{1}$. From that perspective, 'subjectivist constructionism' and 'objectivist positivism' are two contrasting theories which both reflect a form of dualism. However, as has been pointed out, a study which is based exclusively on either of these concepts inevitably ends up in some shortcoming (e.g. Novy 2002). Objectivism, on the one hand, tends to reduce complex social realities to social regularities or 'social laws'. On the other hand, in the case of subjectivism, the existence of any social order is denied entirely due to the argument that anything is relative. In the latter case, research simply tries to explore independently constructed 'micro-realities' without relating them to an overall context.

\footnotetext{
${ }^{1}$ Positivism, as a form of objectivism and rationalism claims that reality exists outside of our subjective mind. As human subjects we are situated opposite this objective and autonomous social reality. With correct empirical methods, it is argued, this reality can be grasped. Studies which follow this approach are aiming at identifying causal relationships and social functions.
} 
Consequently, an entirely subjectivist constructivist approach was found inadequate for the following study. In that respect, the epistemological background of this study does not exclusively rest on constructivism but on a synthesis of the subjectivism-objectivism dualism. Thus, it disagrees with the hypothesis that social reality can entirely be explained via formalised laws and the related notion of 'objectivity' as much as it disagrees with a restrictive focus on subjectivity, where individual constructions of reality are analysed independently of the interrelations with the overall context. Central to the present research approach is the dialectic interrelation between the acting subject and her/his social and physical world and the associated perspective that interacting individuals are within and not opposite their social world.

It follows from these assumptions that as a researcher, I am myself part of the social reality I am exploring. Secondly, I am, consequently, constructing reality via the research process and during that process I am, furthermore, influenced by my social and physical environment. In that context, the epistemological position is influenced by Hegel's dialectic concept of processes as well as by the 'Critical Theory' (Schülein und Reitze 2002).

The methodological principles of qualitative research do not only reflect specific epistemological theories but the concepts of these theories have, moreover, consequences for the entire research process. This concerns the organisation and procedure of the research process, the sampling strategies and, not least, the selection of theories for the theoretical framework of the thesis.

Firstly, following the principles of qualitative research, flexibility within a defined research framework will be allowed, thus adapting the research process to its specific requirements.

Secondly, the actual empirical research process has to be understood as circular and will be characterised by recurring phases of data collection and analyses and phases of reflection in between which will finally lead to "theoretical saturation.' This reflects a sampling strategy which is different from conventional 'statistical sampling.' Hence, the qualitative approach is not necessarily defined by using qualitative data but by a distinct procedure and attitude which pervades the entire research process. Consequently, where relevant and where possible to acquire, also quantitative data will be used for description and evaluation.

Finally, concerning the selection of theory throughout the thesis, some thoughts have been spent on the interrelation between epistemological approach and theories of a discipline. Since 'financing' (as it has been defined) is an economic subject and social policy (which has been chosen as primary

\footnotetext{
2 This term is related to the so-called, theoretical sampling' which is a central strategy of ,grounded theory'. It is based on the concept that through circular processes of data collection, coding and analysing, gradually a theoretical framework is constituted. The data collection process is directed by the emanating theory and is continued until no further categories of the generated theory can be found via additional data (Glaser and Strauss 1998).
} 
perspective) has been dominated by the discipline of economics in the German speaking area (Kaufmann 2003), a brief analysis of mainstream economic theory from an epistemological point of view was found to be important: Theoretical concepts of disciplines are, on the one hand, concerned with the subject matter of the discipline. Beyond that they, additionally, reflect specific epistemological and methodological approaches which are apparent in their premises and their historical developments. Weintraub $(2002,2)$ has described the former issues as the "discipline's knowledge" whilst the latter ones concern the "image of knowledge". The discipline of economics has been dominated by orthodox neoclassical theory for several decades. This is particularly the case for the core normative and behavioural assumptions, the sub-discipline 'health care economics' is predicated on (Mannion and Small 1999; Schulenburg 2000). Orthodox neoclassical economic theory and its derivatives are for the most part contradictory to the methodological foundation and the related epistemological background of the qualitative approach. This is due to the logic of those theories and the premises which are underlying them.

The model of human behaviour, which is used in orthodox neoclassic is the 'homo oeconomicus'. As a simple construct of the mind, the concept of individual utility maximising is put at the centre of this model. The according theoretical meta-concept is named 'methodological individualism' which attempts to make explanations exclusively in terms of individuals. This logic has been applied for different issues of 'the social', be it the family (e.g. Becker 1991), the health care system or any other social issue. Additionally, it has been pointed out that the neoclassical school has transformed economic processes into rational theoretical models to be analysed via formalised and mathematical methods. Empirical research has, correspondingly, been focussed on quantitative methods. This theoretical and empirical approach should convey objectivity and should, not least, transform economics into a discipline of natural sciences (e.g. Michalitsch 2000).

As stated by Schülein (1994), scholars have accused this concept for ideological bias and theoretical inadequacy and have explained this as follows. First of all, economics cannot be reduced to mathematical formulas. Secondly, the focus on individual action neglects the influence of social structures and dependencies on human action. Thirdly, complex social realities cannot solely be explained via utility maximisation and fourthly, the assumption that every person acts rationally is inappropriate to improve understanding of specific situations and constellations. Overall, the prevalent theorems mask micro- and macro-social contexts and understand human action within a specific and rather restrictive form of logic. Most significantly, they do not allow questions which address the embedding of single phenomena within an overall context, because this context is usually externalised in traditional economic models via 'ceterus paribus' clauses. Although orthodox economics may have broadened its approaches to study 
rational choice, as for example the rise of behavioural economics shows, critics have argued that in their very essence, these approaches are a continuation of the neoclassical tradition (Rothschild 2002).

The subject of the thesis questions orthodox economics in a threefold manner. First of all, the research question addresses complex social circumstances which can only to a marginal extent be answered via 'restricted ceterus paribus conditions' and formalised economic laws. Secondly, according to Williams and Doessel (2001), the subject of mental health and/or mental illness is in itself a challenge for the concept of the homo oeconomicus as one has to ask to which degree the theorems are useful when 'Homo Oeconomicus' has a mental disorder. Thus, mental illness poses a fundamental problem for prevailing economic methodology, in particular for the assumption about economising behaviour. This is even more of relevance, as struggles against discrimination and stigmatisation have been significant issues for mental health issues for several decades. The concept of the homo oeconomicus which represents human beings as subjects without culture, history, tradition and social relation (Michalitsch 2000) externalises variables which are related to discrimination or stigmatisation and does, therefore, not allow to adequately address fundamental issues of mental health care. One of the major shortcomings in that context is the absence of power in contemporary economic theory (Rothschild 2003). Thirdly, orthodox neoclassical theorems are based on a positivist epistemological position. Yet, in the in-depth genealogical analysis 'Madness and Society', Foucault (1973) has indicated that positivism plays an equivocal role in context with mental illness. Noticeably, he showed interesting parallels between the development of positivism and the construction of 'madness' which was linked to the rise of the asylums in the late $19^{\text {th }}$ century.

On the whole, these considerations have made clear that for answering the research question an orthodox (positivist) economic approach concerning the theoretical concepts used would be inadequate. In this respect, I shall call the theoretical focus which will be followed 'socio-economic' which once more reflects the interdisciplinary approach I seek to undertake. Not least, this theoretical focus will allow for conceptualising mental health care financing in such a way as to capture the social and political economy within which it is embedded.

\subsection{Structure}

The remainder of the thesis is divided into seven chapters. In chapter 2, I will outline different perspectives of mental illness, including a brief historical overview about the concepts of mental illness, the relationship between socio- 
economic factors and mental illness as well as data about the epidemiology and the (economic) burden of mental illness.

In chapter 3, Austrian mental health care structures will be portrayed in terms of types and number of available services and categories of service providers. In addition to the current service landscape, developments over the last years will be addressed.

Chapter 4 will focus on mental health care financing issues from a descriptive perspective. The chapter covers an overview about financing arrangements in Western Europe, followed by three case studies from the UK, Germany and Austria where financing structures and processes will be addressed in more detail.

In chapter 5, I will provide an in-depth analysis of mental health care reform objectives. Starting with a summary of mental health care reform processes in Western Europe since the $60 \mathrm{ies}$, the analysis subsequently focuses on mental health care reform objectives and processes in Austria. This contains a discourse analysis of different Austrian reform documents and interview transcripts. The results of this exploration will be used as contextual background and as an indicator of change for the analysis in chapter 6 .

In chapter 6 , the results from the discourse analysis in chapter 5 and the empirical data from chapter 4 will be linked to study the role of mental health care financing in the context of reform processes. In particular, implications from financing structures and processes will be addressed. This includes firstly, an analysis on the macro-level looking at the role financing plays in shaping the relations between overall societal structures; secondly this part provides an analysis on the micro-level which concentrates on the impacts of financing issues on affected individuals and their relatives.

The final chapter 7 summarises the results and attempts to conclude the thesis with some criteria for financing approaches and some cornerstones for future financing scenarios. 


\section{Perspectives of Mental Illness}

\subsection{Concepts of Mental Illness from a Historical Perspective}

"There is still much to be learned about the specific causes of mental and behavioural disorders" (WHO 2001, 10).

To develop an understanding of mental health care I shall, first of all, consider how conditions of mental illness have been understood historically. Overall, aetiology as well as treatment and therapies of mental illness have always been subject to discussions. Essentially, assumed causes for mental illness have changed considerably over the last two centuries (Prior 1993). The notion that 'madness' is a form of illness has not always existed as such which is mostly mirrored in the absence of any form of specific treatment up to the $19^{\text {th }}$ century. As Ingleby $(1985,146)$ interprets Foucault, "up to the mid- $17^{\text {th }}$ century, the mad had been allowed to remain in the open, either cared for by their families or set loose to roam the countryside." From that time onwards until the end of the $18^{\text {th }}$ century, the 'insane', the criminals and the poor were ascribed a kind of similar status and were usually kept in custodial care as a heterogeneous group in some sort of asylum (Foucault 1973; Goodwin 1997).

With the beginning of the industrial age, separate places such as prisons for punishment, 'working-houses' and mental asylums were established. From then on, the mentally ill where kept separately from other groups on the social margins. For example, in 1784, the Viennese 'Narrenturm' was built for that purpose under Joseph II (Döcker 1994). According to Busfield $(1999,59)$ "the new asylums [were] standing in an institutional space somewhere between hospitals for the sick, prisons or penitentiaries for criminals, and workhouses for paupers, just as insanity, a lay more than a medical concept, stood in the conceptual and practical space between deviance, sickness, poverty and normality". During that period, regulations of admission and discharge were judicial rather than medical ones and reasons for confinement can be summarised as having been mainly moral ones. "Thus it was the particular conception of sanity embraced by the 'age of reason' that constitutes, by opposition, the category of madness" (Foucault 1965 in Ingleby 1985,147$)$.

At the beginning of the $19^{\text {th }}$ century, mainly triggered by the proceeding secularisation, madness was increasingly believed to be curable (Döcker 1994). Hence, the status of asylums began to change. Supported by a wave of therapeutic optimism, inmates were freed from chains, straitjackets and other physical instruments of restraints (Busfield 1999). A regime based on 'morale treatment' (in German 'psychische Kurmethode') was introduced which was viewed as a 'more humanitarian' approach to lunatics. Asylums were no longer solely regarded as places for custody and care but also as places of treatment and retreat 
away from encumbering places of dirt and chaos in town centres (Lesky 1978). Notably, a separation between the 'curable' and the 'uncurable' mad took place. Due to the changing requirements a number of asylums were newly built or adapted.

In the geographic area of what is now Austria, reforms only took place selectively. Thus, in Vienna, the first asylum for 'traitement morale' was established in 1819, when Bruno Goergen was authorised to open a private 'Heilund Irrenanstalt' in Gumpendorf which was transferred to Döbling in 1831 (Jetter 1982). Only in 1853, the first public 'Heil- und Pflegeanstalt' which operated according to 'no-restraint principles' was established 'auf dem Bründelfelde' (Lesky 1978). Although the fact that a form of therapy was carried out mirrors a notion of illness, the concept has not been a medical one in an orthodox sense. Rather, it can be described as a form of pedagogical behavioural therapy which was influenced by a mixture of patriarchal, romantic and enlightenment ideas (Dörner 1974). Marxist writers have argued that what is described as humanitarian approach, was in fact the 'reprogramming' of the insane in order to function as productive members of society (e.g. Scull 1985). Overall, attempts of improving conditions had limited effects and the situation was still more custodial than therapeutic in character (Goodwin 1997). Not least, analysts have emphasised that during that period new forms of repression replaced the old ones (e.g. Döcker 1994).

The $19^{\text {th }}$ century was also the time when the epistemological positivist revolution led to the development of medicine as a natural science, which brought about the rise of the medical profession. During the second half of the $19^{\text {th }}$ century, psychiatrists (who had so far specialised in the caring of mentally ill patients) became increasingly eager to adopt the medical model, hence, turning psychiatry into a medical science. With the entering of psychiatry into medical science, mental illness became an illness of the brain. The origin of this concept in the German-speaking area can be traced back to the psychiatrist Wilhelm Griesinger who's biological concept was published in 1845 in 'Pathologie und Therapie der psychischen Krankheit' (Lesky 1978; Gröger 1999). In the positivist climate his ideas became increasingly accepted whilst other, more holistic approaches by so-called 'philosophical doctors', won little recognition. This development was accompanied with the psychiatrists' claims to base psychiatry at university teaching hospitals which led to a separation between university psychiatry and 'non-clinical asylum-psychiatry'. The separation persisted for numerous decades, with university psychiatrists gaining increasing reputation (Lesky 1978).

Within the developing medical psychiatric approach, several discrepancies emerged. While some psychiatrists followed an anatomical-physiological approach of explaining mental illnesses with (sometimes keen) brain-physiological hypotheses, others held the view that psychiatry had to be restricted to a merely descriptive science. In Austria, a well-known dispute in that context 
emerged between Theodor Meynert, who was a representative of the former opinion and Richard Krafft-Ebing, who adopted the latter view. When Julius Wagner-Jauregg researched the interrelations between physiological processes in the body and mental illness, another important development within the medical model of mental illness appeared, which can be described as scientific shift from research of physiology and pathology of the brain to physiology and pathology of the body (Gröger 1999; Lesky 1978). What all of these approaches had in common was that they based the causes for and/or treatment of mental illness on a biological concept of illness.

In the early $20^{\text {th }}$ century, some further and rather rivalling concepts of mental illness emerged which have significantly influenced today's psychiatry. One of these concepts was developed by Emil Kraeplin, who followed the biological strand and the related concept of mental illness as a disease of the brain. His observations resulted in a new type of classification which differentiates between manic-depressive and schizophrenic forms of mental illness (Andreasen and Black 2001; Katschnig 1998). This classification is still valid in modern psychiatry, albeit in a more elaborate form.

The second person, who has significantly contributed to our current concept of mental illness was Sigmund Freud. According to his theory, mental illness is a disease of the mind. In his well-known publication about hysteria which he had written together with Joseph Breuer, he argued that some types of trauma that occur early in life can lead to manifest pathologies of the mind which later on cause irritations (Bolognese-Leuchtmüller 1994; Lesky 1978; Prior 1993). After a period of biological-dominated theories, this model added a completely new dimension to mental illness. Undeniably, it has shaped psychiatry and its concepts and theories.

Finally, a third model was the 'social model'. Thus, influences of the social environment on mental health and illness became an important issue with respect to aetiology and therapy. Although interests in the association between social issues and mental illness cannot be traced back to one point of origin, one significant contribution for that approach has been made by Émile Durkheim. He developed his concept out of the results of an empirical analysis where he discovered a strong correlation between high suicide rates and bad social conditions (Katschnig 1998). Unlike previous theories, in this view, mental illnesses are 'social illnesses'.

Although the outlined arguments have become a lot more differentiated over the last decades, these three styles of thoughts, namely the biological, psychological and sociological principle, have considerably influenced today's theories of mental illness ${ }^{3}$. Thus, according to the WHO (2001), modern science is

\footnotetext{
${ }^{3}$ Although it will not be addressed in the thesis, it has to be noted that during the period of ,Nationalsozialismus', psychiatry entered a disastrous period; the concept of mental illness in that period resulted in killing of thousands of people due to eugenic practices.
} 
still showing that mental disorders have an organic, a social and a psychological base. The relationship of these factors is, however, complex and multidimensional. For example, while genetic risk factors for mental illness have been identified which has enforced biological arguments, more recent research has shown that it is predominately the interaction of multiple risk genes with environmental factors which leads to the onset of some disorders (WHO 2001). Influences of postmodernity have, furthermore changed the perception of mental illness from being a single fact at a point in time to the understanding of mental illness as a process. This requires addressing different factors such as predisposition, onset and proceeding of the illness. Additionally, the scale of what is regarded as mental health problem has grown. An increased range of behaviour patterns, such as substance abuse, is nowadays seen as product of a mental disorder.

On the whole, the complexity of causes of mental illness is still unclear. None the less, knowledge about treatment methods has increased considerably including biological, psychotherapeutic and socio-therapeutic approaches. In summary, 'modern Western' psychiatry is a rather eclectic field notwithstanding the overall domination of the biological medical model in treatment and therapy (Pilgrim and Rogers 1994). Apart from professionals' concepts of mental illness, one should bear in mind that patients and lay people usually define their own individual concepts of mental illness. These are likely to differ from expert ones due to different perspective and different personal concerns. These fragmented sets of perspectives show that diverse concepts are not merely a matter of terminology but also reflect different types of reality.

While the positions summed up so far emphasise the factual reality of mental illness, some researchers have raised a rather contrasting perspective. Thus, some sociologists and also psychiatrists themselves have argued that the whole concept of mental illness is nothing else than a social fabrication which is scientifically worthless and socially harmful (e.g. Szasz 1974). An additional critical approach is provided by the so-called 'labelling-theory'. It is mainly concerned with how individuals react to and categorise deviance, the associated negotiation and maintenance of the patient's role and the way symptoms become diagnosed as mental illness (e.g. Goffman 1973). These theories are either entirely or at least partly based on a social constructivist position. Some of the critics mentioned have also specifically addressed the role of professionals in context with concepts of mental illness. While conventional historiography by psychiatrists describes medicalisation of psychiatry as revolutionary breakthrough, other writers have contrasted this view with the argument that mental illness has been constructed and used by professionals to legitimise their position. Thus, the rising profession of psychiatrists gradually discovered the 'insane' as their clientele, only to finally replace old places of social control with new ones, which were the mental hospitals (e.g. Dörner 1974). In the critics' view, the beginning of the medical treatment of mental illness was neither due to an altruistic motive nor was it the 
result of available effective treatment methods but it was rather due to the selfinterests of medical professionals.

What these critical positions have in common is that they draw attention to the issue that what has been defined as mental illness has also to be seen in the light of various forms of social control and norms. Although the theories have somehow fallen out of fashion nowadays, similar topics have also been raised in more recent work. For example, Astbury $(2002,149)$ remarks that "all diagnostic criteria and assessments of mental health depend on the theoretical constructs of human behaviour, on what is believed to constitute the normal, and how this can be clearly distinguished from the pathological."

To conclude, this thesis is based on the notion of a factual reality of mental illness. Nevertheless, the critical arguments are particularly valuable to maintain a reflective approach concerning value-judgements and tacit cultural knowledge which may constantly shape this reality.

\subsection{Terminology and Definitions}

The previous chapter has shed some light on the historical developments in psychiatry. In the following paragraphs this information will be applied in order to define terms which will be used in the remainder of the text. Hence, I am going to outline what I mean by 'mental illness' and 'mental health care' and which terms will be used for people who are affected by a mental illness.

As I have shown in the previous part, rather than being based on a single concept, markedly different perspectives and frameworks of the nature of mental illness exist. When referring to 'mental illnesses' ${ }^{4}$, the definition according to the 'International Statistical Classification of Diseases and Related Health Problems (ICD-10) will be used (Dilling 2000). This classification includes a wide range of categories of mental disorders and, thus, reflects a very broad concept of mental illness. The definition I am using does not include mental disability. I am aware that nosologies to classify mental ailments are arbitrary in essence and that they have also been subject to criticism. It has, for example, been debated whether the instruments which are used for data collection and classification reflect the actual entities of mental disorders or whether they reflect biased constructions of mental diseases (e.g. Cermele, Daniels and Anderson 2001; Copeland 1981). Prior (1993, $110)$ has put it this way: "They [instruments] could only produce the phenomena which they were supposedly designed to discover and measure." These critical voices need to be remembered.

If it is not completely understood what 'mental illness' is, the definition of what does or does not constitute 'mental health care' is similarly difficult to

\footnotetext{
${ }^{4}$ Although a differentiation can be made between mental 'disorder', 'illness' or 'disease', for the purpose of this thesis these terms will be used synonymously.
} 
determine. Indeed, concepts of mental illness have changed considerably over the centuries and, not surprisingly, so has the organisation and provision of mental health care. According to Prior $(1993,12)$, "in any event, it is clear that what people think and believe about mental disorder is invariably reflected in some manner in the conceptual, material and bureaucratic tools which they use to organize such conditions." In other words, with changing concepts and theories for mental illness the organisation of mental health care changes. However, Prior (1993) argues that the changing practice of care is not exclusively a direct reaction to an objectively given nature of specific disorders (which is to be discovered by the development of medical knowledge) but practice of treatment and care also implies a constructivist element of 'creating and inventing', that is a socially conditioned knowledge which is influenced by structural factors of society. The quote also makes clear that current perceptions of mental health care have been influenced by preceding historical styles of thought about mental disorders.

These processes need to be remembered when outlining the 'modern' definition of mental health care which will be followed in this thesis. The analysis in the following chapters will illuminate the current concept of mental health care in more detail. For the purpose of definition at this stage 'mental health care' is understood in a very broad manner, including various institutions and being related to manifold policy sectors. Thus it includes acute as well as long-term care and health care as well as social (care) issues. Apart from services which specifically address the mentally ill, mental health care is also regarded as being part of more general social and economic policy. It is clear that this understanding mirrors a specific concept of aetiology and treatment of mental illness which, in correspondence to the concept of illness discussed earlier, can be summarised as multidimensional.

Finally, it needs to be considered which term to use for people who receive services. History has shown that different interest groups have claimed their right to define these terms. In the recent past such claims have increasingly been made by user groups. This has not necessarily resulted in a consensus on which vocabulary to use. On the contrary, terminology remains a controversial issue in that context. For example, the term 'mentally ill' has been rejected by some persons of the anti-psychiatric movement whereas others regard it as appropriate way of understanding their distress (Barnes and Bowl 2001; Mueser et al. 1996). Meanwhile, a great variety of terms exists ranging from 'users', 'ex-patients', or 'survivors' to 'patients', 'consumers', 'clients' or 'customers'. As Sayce (2000, 14) points out: "No term is without pitfalls." In chapter 0 , particular attention will be drawn to these issues. For the overall thesis, where possible, I refer to people by the terms they choose themselves. Since the thesis argues for a factual reality of mental illness, in the remaining cases people who are affected by such an illness will be termed 'mentally ill persons', 'patients' or 'users'. 


\subsection{Dimensions of Mental Illness}

The following parts will provide a rough picture of mental disorders from an epidemiological and socio-economic point of view.

\subsubsection{Epidemiology}

Mental illness belongs to the most prevalent and disabling diseases world-wide. The World Health Organisation has recognised the importance of mental health and illness for a long time and has dedicated the World Health Report 2001 to this issue (WHO 2001). According to results of their literature surveys, on average more than $25 \%$ of individuals worldwide develop one or more mental or behavioural disorders during their entire lifetime. Intercountry variations are, however, wide and range from a lifetime prevalence rate of $12.2 \%$ in Turkey to $48.6 \%$ in the US (WHO 2000). According to Katschnig et al. (2001), large epidemiological studies in the EU and USA have detected a one-year prevalence of mental disorders of $30 \%$. Hence, within a period of one year, around one third of the population is affected by a mental disorder. The overall lifetime prevalence rates are similar for men and women, notwithstanding marked gender differences for specific disorders and the process of illness. Most commonly diagnosed distresses among women are depression and anxiety disorders, while men most frequently suffer from substance abuse and dependencies. For severe conditions such as schizophrenia and bipolar disorder, lifetime prevalence rates are much lower $(0.1 \%$ to $3 \%$ for schizophrenia and $0.2 \%$ to $1.6 \%$ for bipolar disorder) and gender differences have not been detected (Astbury 2002). However, gender differences exist in other dimensions of severe mental illness. For example, women have later onsets of schizophrenia than men (Piccinelli and Homen 1997) and are more likely to develop rapid cycling forms of bipolar disorders than men (Leibenkuft 2000).

In Austria, large-scale epidemiological studies of mental illness have not been undertaken so far. In 1993, a survey asking for mental well-being was carried out using a representative sample of 1,408 persons aged over 14. Calculated 4-week prevalence rates for depression, anxiety disorders and psychosomatic disorders were $17.5 \%$ for women and $15.1 \%$ for men (Katschnig et al. 1993).

One form of mental disorder which - due to demographic changes - has received increasing attention over the last years is dementia. For the year 2000, Wancata, Kaup and Krautgartner (2001) calculated a prevalence rate of $5.41 \%$ among the Austrian population aged 60 and over. The prevalence for the population which was older than 65 years was $6.93 \%$, whereas for the over 80 years old it was $18.5 \%$. In absolute figures, in 200090,500 people suffered from dementia. This figure has been estimated to rise 2.58 times by the year 2050 to 
233,800 persons with Dementia in the Austrian population (Krautgartner, Berner and Wancata 2001).

On the whole, incidence and prevalence rates of mental illness have risen considerably over the last decades. It is, however, unclear whether this can be explained by factual rises of illnesses or by higher detection rates of formerly hidden cases.

\subsubsection{Socio-economic Status and Mental Illness}

The relationship between socio-economic factors and mental illness is a multidimensional one. While several studies have shown a correlation between poverty (associated with low socio-economic categories) ${ }^{5}$ and mental disorders, the direction of these relationships is unclear. Thus, according to the social causation explanation, poverty is a risk factor for the development of mental illness. On the other hand, the so-called social selection or social drift argument goes on the assumption that higher rates of mental illness in lower social classes are a consequence of the drift of the mentally ill into lower social classes.

In a US comorbidity survey, six-month prevalence of any DSM-III ${ }^{6}$ disorder was calculated to be 2.86 times higher in the lowest socio-economic status category than in the highest, controlling for age and gender (Kessler et al. 1994). Furthermore, Saraceno and Barbui (1997) have summarised several studies on poverty and mental illness and outline that people with the lowest socio-economic status have 8 times more relative risk for suffering from schizophrenia than those with the highest socio-economic status. Compared to people without a mental disorder, people who suffer from schizophrenia are 4 times more likely to be unemployed or partly employed and 3 times more likely not to have graduated from high school. Mörchen et al. (2002) showed for two German areas that 38\%, respectively $31.9 \%$ of mentally ill patients lived under conditions of material poverty. Only up to one third were regularly employed. With regard to gender, studies have shown a correlation between female gender, low education and poverty and mental disorders (Patel et al. 1999). However, gender differences related to the socio-economic status are usually difficult to analyse, since gender disaggregated income-data are hardly available?

Apart from social causation and social drift hypotheses, the socio-economic status is also a predictor for the outcome of treatment. Thus, Warner (1994) has shown that recovery from psychosis with regard to time spent in hospitals and

\footnotetext{
${ }^{5}$ Low socio-economic categories are defined according to the WHO $(2001,40)$ as conditions of unemployment, low education, deprivation and homelessness.

${ }^{6}$ DSM denotes the 'Diagnostic and Statistical Manual'.

${ }^{7}$ Usually family or household income is used as a proxy-variable to substitute the sum of the income of each family member.
} 
number of admissions is worse in the lower socio-economic groups. However, from a cross-country perspective, people suffering from psychosis in developing countries have a better outcome than their counterparts in developed countries (Jablensky et al. 1992).

\subsubsection{The Burden of Mental Illness}

In Europe mental disorders account for $20 \%$ of disability adjusted life years $(\mathrm{DALY})^{8}$ and $43 \%$ of all years lived with a disability (WHO 2001). Among the group aged 15 to 44 years, mental illness accounts for seven out of ten leading causes for DALYS. The greatest disability related to mental illness is imposed by depression. Depression is, moreover, the most frequent cause for DALYs among women, whereas the most frequent cause for DALYs among men is alcohol dependency (Murray and Lopez 1996). Overall, mental and behavioural disorders are estimated to account for $12 \%$ of the global burden of disease (WHO 2001).

From an economic point of view, mental illness is associated with high economic costs. These include direct costs for treatment and care but also indirect costs such as loss of productivity or costs for relatives involved in caring. Rice, Kelman and Miller (1992) have estimated that in 1985 in the US the total economic costs of mental illness were $\$ 103.7$ billion. A more recent study from the UK estimated total costs of mental illness up to $£ 32.1$ billion (1996/97 prices) of which one third was due to lost employment and lost productivity from suicide (Patel and Knapp 1998). Schizophrenia is considered to be the most costly mental illness. Thus, in the US total economic costs of schizophrenia were estimated to be 65 billion $\$$ in 1991 (Salize, Rössler and Reinhard 2001). In Germany, expenditure for schizophrenia in 1994 was estimated to account for $2 \%$ of the total health care budget which is higher than the percentage spent on dementia or depression (Salize 2001). Tarricone et al. (2000) showed that the annual mean costs of schizophrenia in Italy were nearly 50 million ITL, of which $70 \%$ were for indirect costs. On the whole, indirect costs for schizophrenia are higher than direct costs, although calculations vary considerably. For example, Launois, Tourni and Reboul-Marty (1998) showed that indirect costs account for $81 \%$ of the total costs, whereas Guest and Cookson (1999) calculated a percentage of $49 \%$ for indirect costs in relation to $51 \%$ for direct costs.

\footnotetext{
${ }^{8}$ DALY (disability adjusted life years) is an indicator which has been developed for large scale cross country epidemiological studies to measure disability which results from illness. Overall, the indicator reflects the burden of non-lethal diseases and combines life years lived with a disability with lost life years due to premature death. The latter are measured according to standardised life expectancies. Years lived with disability are transformed into standardised time losses via a mathematical formula.
} 
Apart from schizophrenia, cost-studies for single forms of illness are mainly related to depressive disorders. In Portugal, costs associated with depressive disorders were estimated to be 50 million $€$ (at 1992 prices) of which $80 \%$ were due to losses in productivity due to a temporary incapacity to work (Ramos et al. 1996). In Germany it has been investigated that in 2002, 18 million workdays were lost due to depression with total cost to employers of around 1.59 billion $€$ (Gesundheitsreport der Techniker Krankenkasse 2002).

In Austria, costs of illness have solely been estimated for dementia in a study by Krautgartner, Berner and Wancata (2001). Depending on the method of calculation, for the year 2000 the costs for dementia were estimated to have accounted for 569 million $€$ or 1.24 billion $€$ respectively.

Overall, Salize (2001) has emphasised that cost studies hardly ever address entire costs of illness. Very often, the figures are restricted to direct costs and do not include indirect costs such as costs for informal care and secondary illnesses which may result from it, nor do they usually include intangible costs such as loss of quality of life. That costs falling on caregivers can be significant is for example shown in a Belgium study which compared average earnings after tax for the Flemish population with that of families with psychiatric patients. While the former were earning $30,474 €$ on average, the average earning for the latter were 23,302 € (De Rick et al. 2000).

A rough picture about the economic dimensions of mental illness in Austria may be provided by absenteeism and early retirement statistics. While overall days of absenteeism decreased by $13 \%$ between 1993 and 2002, days of absenteeism due to mental illness increased by $56 \%$. The length of absenteeism for male employees with a mental illness increased by $37 \%$, for female employees it rose by $72 \%$ (figure 1). It needs to be questioned whether the changes are the result of factual increase of mental illness, increasing awareness of mental illness or whether they are simply the result of technical changes in registration. Since the yearly variation is quite irregular (figure 2), both, registration differences and epidemiological changes seem to be most likely.

Similarly, total number of early retirement entrants decreased by around $1 \%$ between 1993 and 2002. By comparison, in the same period new early retirement cases due to mental illness increased by $84 \%$. The rate for male persons increased by $64 \%$, whereas the rate for females increased by $115 \%$. In 1993 , new entrants due to mental illness accounted for roughly $12 \%$ of all entrants. In 2002, their percentage rose to $22 \%$. Compared to other forms of illness, new entrants due to mental illness are on the second highest rank. Additionally, total cases of early retirement increased by $13 \%$ between 1993 and 2002, while total early retirement cases due to mental illness rose by roughly $50 \%$ (figure 3 ). 


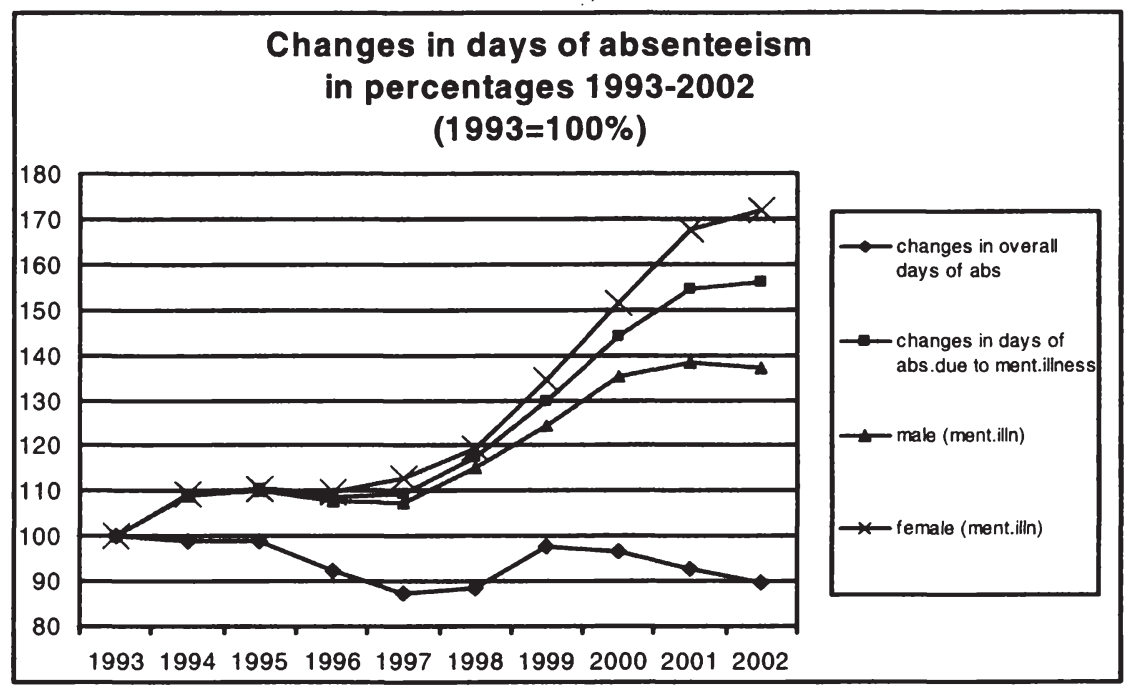

Figure 1: Changes in days of absenteeism in percentages 1993-2002; Source: Social Insurance Statistics

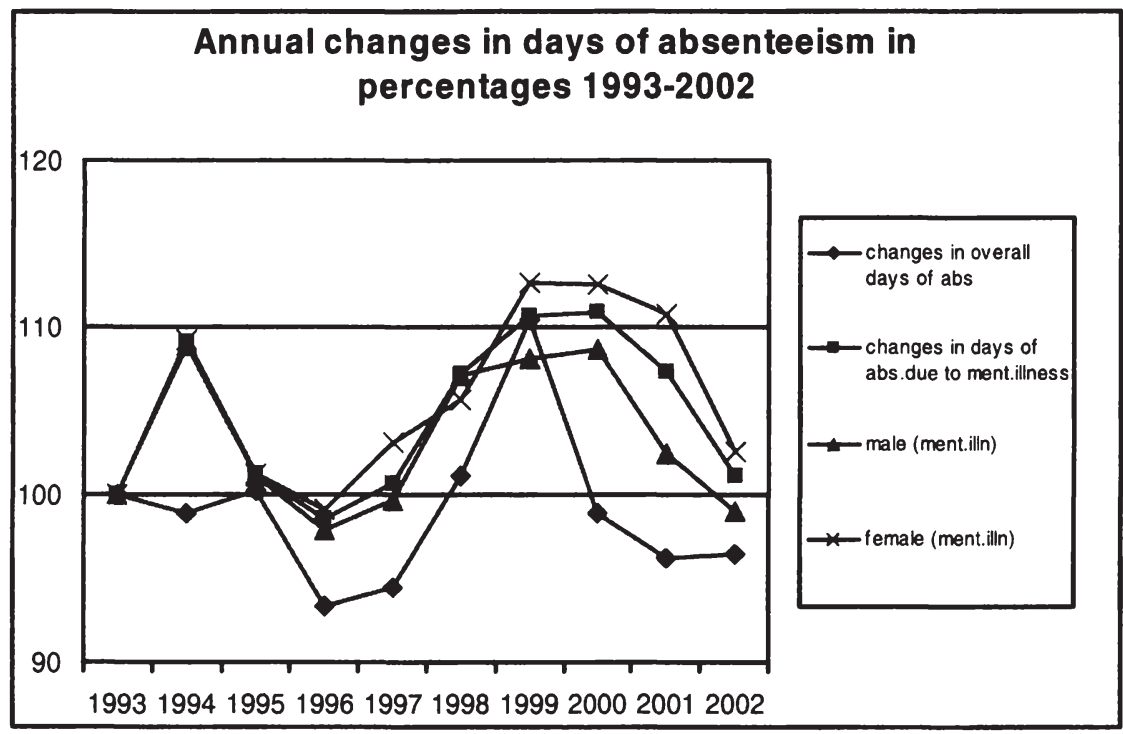

Figure 2: Annual changes in days of absenteeism in percentages 1993-2002; Source: Social Insurance Statistics 


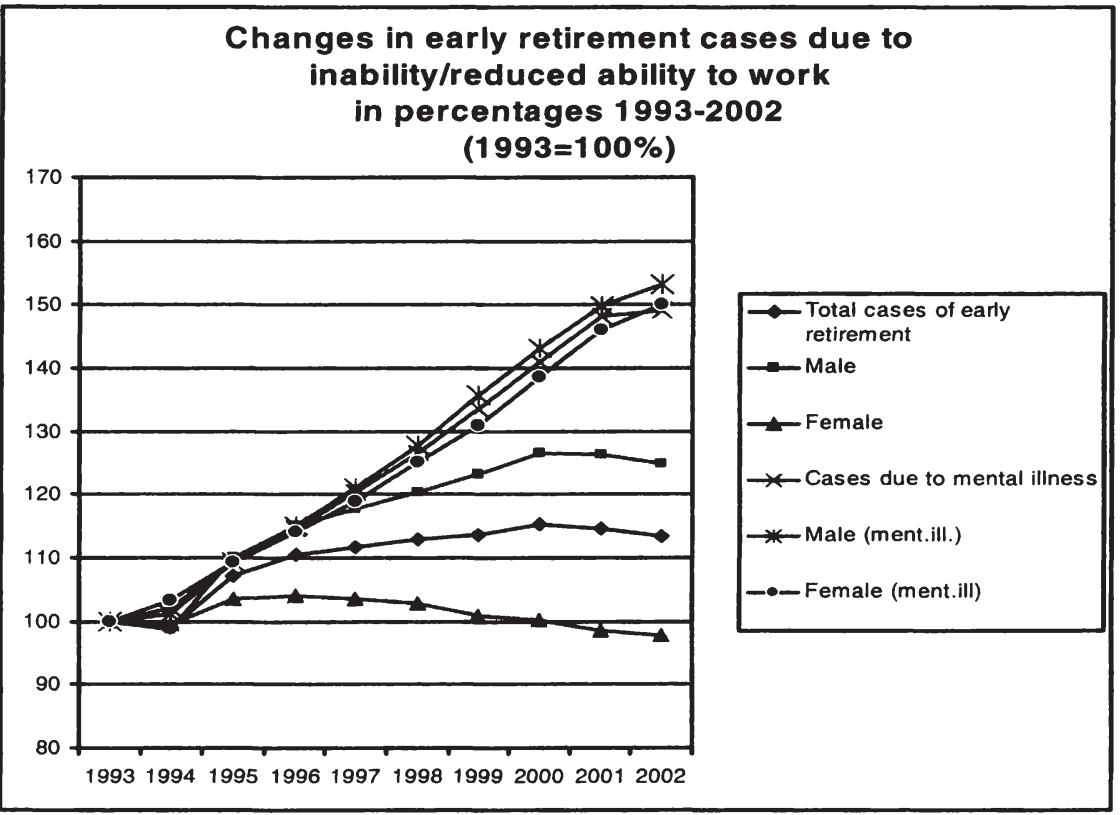

Figure 3: Changes in early retirement cases due to inability/reduced ability to work in percentages 1993-2002; Source: Social Insurance Statistics

\subsection{Conclusion}

The previous paragraphs have opened the scene with some features and facts about mental illness and a brief historical overview about the stages in development of the concept of illness and treatment up to the $21^{\text {st }}$ century. To arrive at a conclusion, the most significant issues seem to be the obvious controversies which have accompanied those developments. On the one hand, these controversies make it difficult to follow a straight line of argument. On the other hand, however, they make clear that the terms and definitions used are the result of negotiation processes between different interest groups. Not least, they add to an understanding of the complex processes which have shaped our perception of mental health and illness. This information is thus valuable for exploring subsequent questions of mental health care financing from a multi-level perspective. In the following chapters the focus moves to more recent processes of change with the main emphasis on mental health care service structure, mental health care financing, recent reform processes and reform objectives. 


\section{Mental Health Care Structures in Austria}

This chapter describes the mental health care structures in Austria. It starts with a general categorisation of service elements, followed by a portrayal of different types of services and their historical development from a specific Austrian perspective. In the final part the Austrian scenery of mental health care providers will be outlined. The overall purpose of this chapter is to demonstrate the broad variety of service components and the numerous actors involved in providing mental health care services in Austria.

\subsection{Mental Health Care Service Categories: An Overview}

Mental health care is multifaceted and consists of a large variety of services which makes systemising a challenging task. The problem is exaggerated by the fact that terms used do not necessarily have identical meanings in different provinces. Thus, every classification will have its shortcomings. Principally, existing services can be systemised according to different criteria.

One useful criterion of categorisation - particularly in context with ongoing reform processes - seems to be the grade of institutionalisation based on Goffman's theory of social institutions (Schülein 1987). Goffman defines social institutions as rooms, places of residence, buildings or enterprises where activities are carried out on a regular basis. Total institutions - as a maximum form of institutionalisation - represent an exclusive world of living where all parts of a person's life which usually are separated from each other are unified in one place. Visualised on a continuum, mental health care services range from 'noninstitutional' mobile services to 'total institutions' of long-term care (see figure 4). The least institutionalised services are the so-called 'go-structures' where providers are going to the people with disorders, such as crisis teams and mobile psychiatric services. Secondly, there are services which can be described as lowgrad institutionalised. These are the numerous community based 'come structures' where people with mental disorders come to a local institution without, however, 'living' there. They include ambulatory psychiatric services, employment-related services, day structure institutions and several health care providers such as psychiatrists in solo-practices, general practitioners and psychotherapists. Additionally, differently staffed residential arrangements ranging from sheltered accommodation to 24-hour care exist. They reach from little to highly institutionalised forms of care. Finally, high-grade institutionalised services such as hospital care and institutional long-term care are provided, where all parts of the person's life are unified in one place and people basically live in the institution (at least for a certain period of time). 


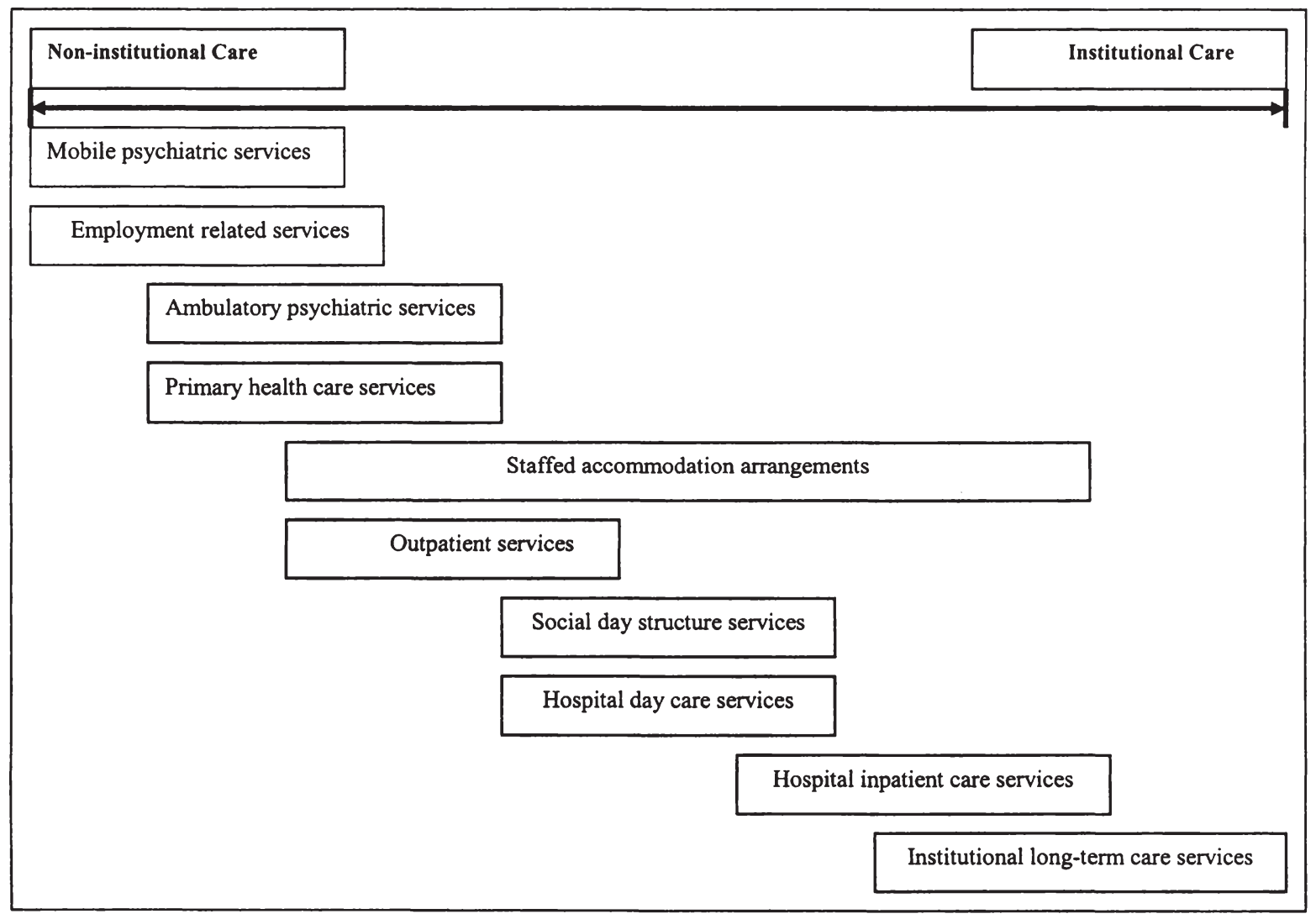

Figure 4: Mental health care services continuum from non-institutional to institutional care; own figure 
Secondly, for the specific Austrian situation services can be categorised according to the traditional division into health care and social care sector services ${ }^{9}$, which is demonstrated in table 1.

\begin{tabular}{|l|l|}
\hline \multicolumn{2}{|c|}{ Mental health care services in the health care and social care sector } \\
\hline \multicolumn{1}{|c|}{ Sector } & \multicolumn{1}{c|}{ Services } \\
\hline Health care & $\begin{array}{l}\text { Psychiatric specialist mental health care (Psychiatrists) } \\
\text { Psychotherapists, psychologists and other professionals } \\
\text { General practitioners (GP) }\end{array}$ \\
\hline Primary & $\begin{array}{l}\text { Hospital inpatient care } \\
\text { Hospital outpatient care } \\
\text { Hospital day care }\end{array}$ \\
\hline Secondary & $\begin{array}{l}\text { Mobile and ambulatory psychiatric services (MAPS) } \\
\text { Social day structure services } \\
\text { Employment related services } \\
\text { Residential care } \\
\text { - Accommodation arrangements } \\
\text { - Institutional long-term care }\end{array}$ \\
\hline
\end{tabular}

Table 1: Mental health care services in the health care and social care sector; own table

For the purpose of the thesis it is necessary to use a type of classification which enables me to reasonably address the research question and at the same time allows for a consistent application throughout the remaining chapters. While the previous classification is useful for the Austrian case it may be problematic within an international context. The term 'social care sector' and the applied definition in particular might be misleading because of different contexts or legislative structures. Thus, it has been decided to use a slightly different classification which differentiates between 'services within the health care system' and 'services outside the health care system'. Although these categories may be sub-optimal in a semantic sense (see chapter 5), they will be used for pragmatic reasons.

\footnotetext{
${ }^{9}$ Health and social care sector are here defined according to legislative criteria of public financial responsibility. Services which are (primarily) funded by health insurance according to the General Social Security Act are attributed to the health care sector, whereas services which are funded by other public sources (taxes, pension or unemployment insurance) are attributed to the social care sector.
} 


\subsection{Mental Health Care Services within the Health Care System}

\subsubsection{Primary Care Services}

According to table 1, the primary mental health care sector includes psychiatrists in solo-practices, psychotherapists, clinical and health psychologists, general practitioners and - to a smaller extent - services provided by professionals such as occupational therapists, music therapists or physiotherapists. Since there are large overlaps between all those professionals, their number cannot simply be added up, hence, a total number of professionals cannot be calculated. For example, a lot of psychiatrists are also registered as psychotherapists.

The number of psychiatrists has continuously increased over the last 30 years. By the end of 2002, 893 certified psychiatrists were registered. This corresponds to roughly 1 psychiatrist per 9,000 inhabitants. Two third of psychiatrists worked in solo-practices but only 98 or 0.12 per 10,000 inhabitants had a contract with the health insurance (BMFG 2003) (figure 5). In other words, patients of psychiatrists without a health insurance contract have to pay for the service privately and can apply for a partial refund from health insurance. On the contrary, services of 'contract psychiatrists' are paid for by health insurance, while private contributions are limited to a small out-of pocket payment.

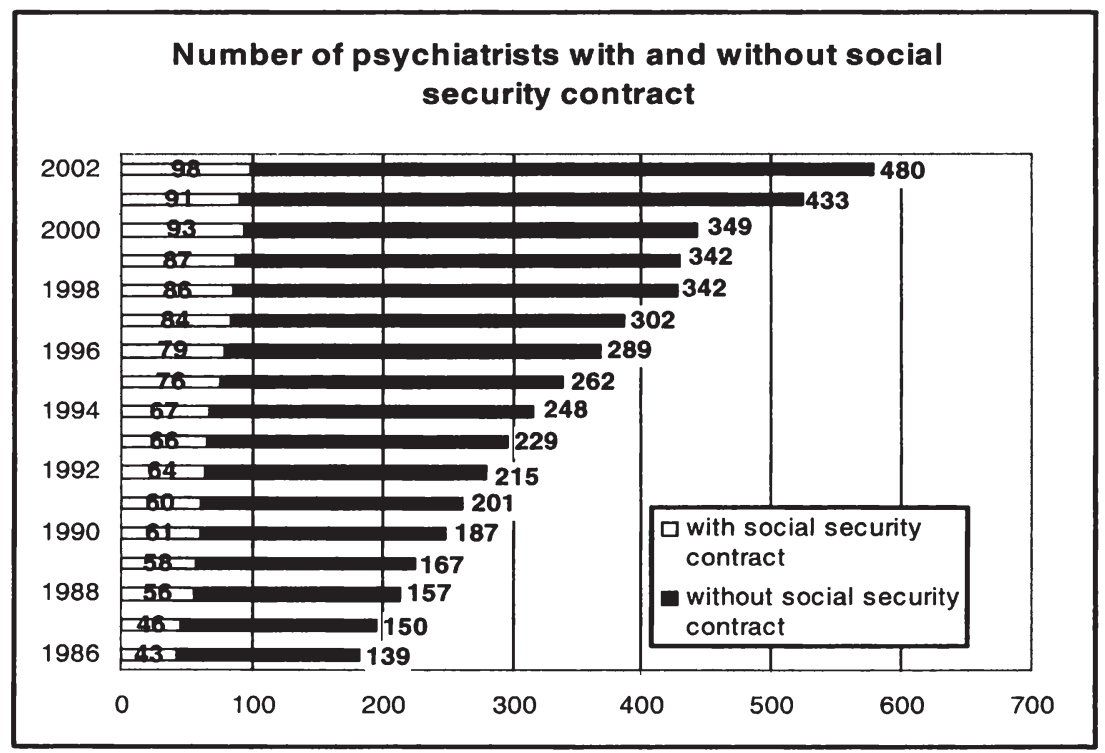

Figure 5: Number of psychiatrists with and without social security contract; Source: BMGF (2003) according to the Austrian Chamber of Doctors 
Availability of psychiatrists varies considerably in different provinces (table 2). Contrasted with the number of inhabitants in the provinces, in 2000, the highest density of psychiatrists existed in the very western parts of Austria, the lowest one in Upper Austria.

\begin{tabular}{|l|l|c|c|c|}
\hline \multicolumn{5}{|c|}{ Distribution of psychiatrists in Austria, year 2000} \\
\hline \multicolumn{1}{|c|}{ Province } & $\begin{array}{c}\text { Total } \\
\text { number of } \\
\text { psychiatrists }\end{array}$ & $\begin{array}{c}\text { Number of } \\
\text { psychiatrists } \\
\text { with contract }\end{array}$ & $\begin{array}{c}\text { Percentage of } \\
\text { psychiatrists } \\
\text { with contract }\end{array}$ & $\begin{array}{c}\text { Number per } \\
\mathbf{1 0 0 , 0 0 0} \\
\text { inhabitants }\end{array}$ \\
\hline Burgenland & 7 & 4 & $57.1 \%$ & 1.4 \\
\hline Carinthia & 21 & 8 & $38.1 \%$ & 1.4 \\
\hline Lower Austria & 46 & 13 & $28.3 \%$ & 0.8 \\
\hline Upper Austria & 26 & 5 & $19.2 \%$ & 0.4 \\
\hline Salzburg & 26 & 7 & $26.9 \%$ & 1,4 \\
\hline Steiermark & 26 & 10 & $38.5 \%$ & 0.8 \\
\hline Tyrol & 31 & 12 & $38.7 \%$ & 1.8 \\
\hline Vorarlberg & 28 & 10 & $35.7 \%$ & 2.9 \\
\hline Vienna & 231 & 24 & $10.4 \%$ & 1.5 \\
\hline Total & $\mathbf{4 4 2}$ & $\mathbf{9 3}$ & $\mathbf{2 1 . 0 \%}$ & $\mathbf{1 . 1}$ \\
\hline
\end{tabular}

Table 2: Distribution of psychiatrists in Austria; Source: Katschnig et al. (2001)

Similar to psychiatrists, the number of registered psychotherapists has also increased considerably over the last few years. By the end of 2002, 5,632 psychotherapists were registered which corresponds to 7 therapists per 10,000 inhabitants (figure 6). In 1991, the 'Psychotherapy Act' (Psychotherapiegesetz) was implemented which regulates the training of psychotherapists in Austria. Training is delegated to 19 psychotherapy associations, representing different 'schools' (BMFG 2003). Services are provided in solo-practices, in institutions or as part of multi-professional treatment in other types of services such as ambulatory psycho-social services. Similarly to psychiatrists, availability of psychotherapy services varies considerably between the provinces. Table 3 shows the variation of self-employed psychotherapists in the primary care sector.

The third group of professionals which - in addition to being employed in institutions - offer services in private practices, are the health and/or clinical psychologists. Some of them also are registered as psychotherapists. Total number of registered health and/or clinical psychologists rose from 2,925 in 2000 to 3,902 in 2003. For self-employed psychologists there are also considerable regional differences with the highest number of professionals working in Vienna and Salzburg and the lowest number of psychologists working in Burgenland (table 4). 


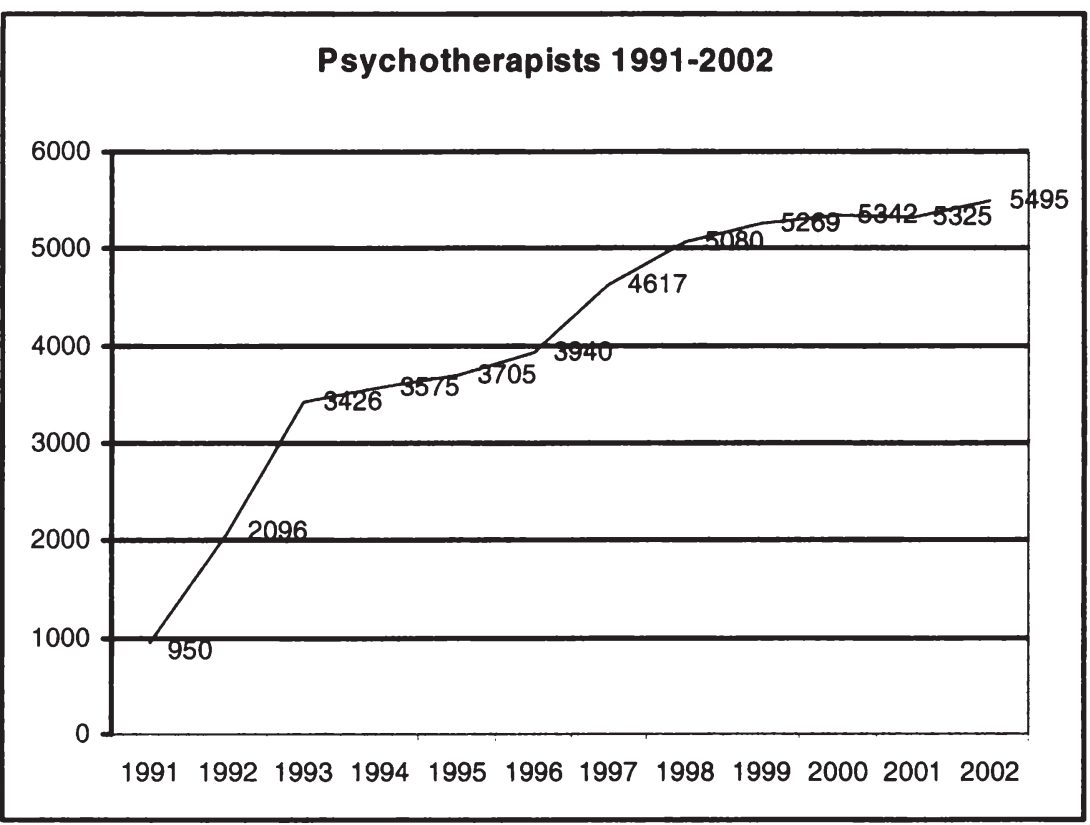

Figure 6: Psychotherapists 1991-2002; Source: BMGF (2003)

\begin{tabular}{|l|c|c|}
\hline \multicolumn{3}{|c|}{ Distribution of psychotherapists in Austria, year 2000} \\
\hline \multicolumn{1}{|c|}{ Province } & $\begin{array}{c}\text { Number of self-employed } \\
\text { therapists }\end{array}$ & $\begin{array}{c}\text { Number/10,000 } \\
\text { inhabitants }\end{array}$ \\
\hline Burgenland & 42 & 1.51 \\
\hline Carinthia & 180 & 3.19 \\
\hline Lower Austria & 357 & 2.33 \\
\hline Upper Austria & 387 & 2.81 \\
\hline Salzburg & 450 & 8.76 \\
\hline Styria & 404 & 3.56 \\
\hline Tyrol & 334 & 5.03 \\
\hline Vorarlberg & 163 & 4.71 \\
\hline Vienna & 1948 & 12.18 \\
\hline Total & $\mathbf{4 , 2 6 5}$ & 5.28 \\
\hline
\end{tabular}

Table 3: Distribution of psychotherapists in Austria; Source: Katschnig et al. (2001) 
Distribution of health- and/or clinical psychologists in Austria, year 2000

\begin{tabular}{|l|c|c|}
\hline \multicolumn{1}{|c|}{ Province } & \multicolumn{1}{c|}{$\begin{array}{c}\text { Self-employed } \\
\text { psychologists }\end{array}$} & $\begin{array}{c}\text { Number/10,000 } \\
\text { inhabitants }\end{array}$ \\
\hline Burgenland & 25 & 0.90 \\
\hline Carinthia & 101 & 1.79 \\
\hline Lower Austria & 160 & 1.04 \\
\hline Upper Austria & 131 & 0.95 \\
\hline Salzburg & 246 & 4.79 \\
\hline Styria & 183 & 1.52 \\
\hline Tyrol & 148 & 2.23 \\
\hline Vorarlberg & 45 & 1.30 \\
\hline Vienna & 818 & 5.12 \\
\hline Total & $\mathbf{1 , 8 5 7}$ & $\mathbf{2 . 3 0}$ \\
\hline
\end{tabular}

Table 4: Distribution of health- and/or clinical psychologists in Austria; Source: Katschnig et al. (2001)

\subsubsection{Secondary Care Services}

Until the early 1970 s, inpatient mental health care was provided by ten large mental hospitals and three small university departments. Altogether they had 12,000 beds. Six of them had more than 1,000 beds and three had more than 1,500 beds. Meanwhile, psychiatric hospital beds have decreased to below 5,000 beds or 6 beds per 10,000 inhabitants (BMFG 2003). In 2001, the number of beds actually in use was 4,696 (figure 7). These beds were distributed over 29 psychiatric hospitals and departments in general hospitals. Then, only two psychiatric hospitals had more than 500 beds. Meanwhile, the trend towards smaller psychiatric units has continued. While the mental health report from 2001 mentioned the existence of 6 psychiatric departments in general hospitals (Katschnig et al. 2001), currently 13 additional departments are in planning stage, or shortly before implementing (Katschnig, Denk and Scherer 2004). However, the overall development has not been evenly distributed across the country.

In addition to inpatient care, mental health care has increasingly been provided in day-hospital settings. In 1999, 16 day hospitals existed. 


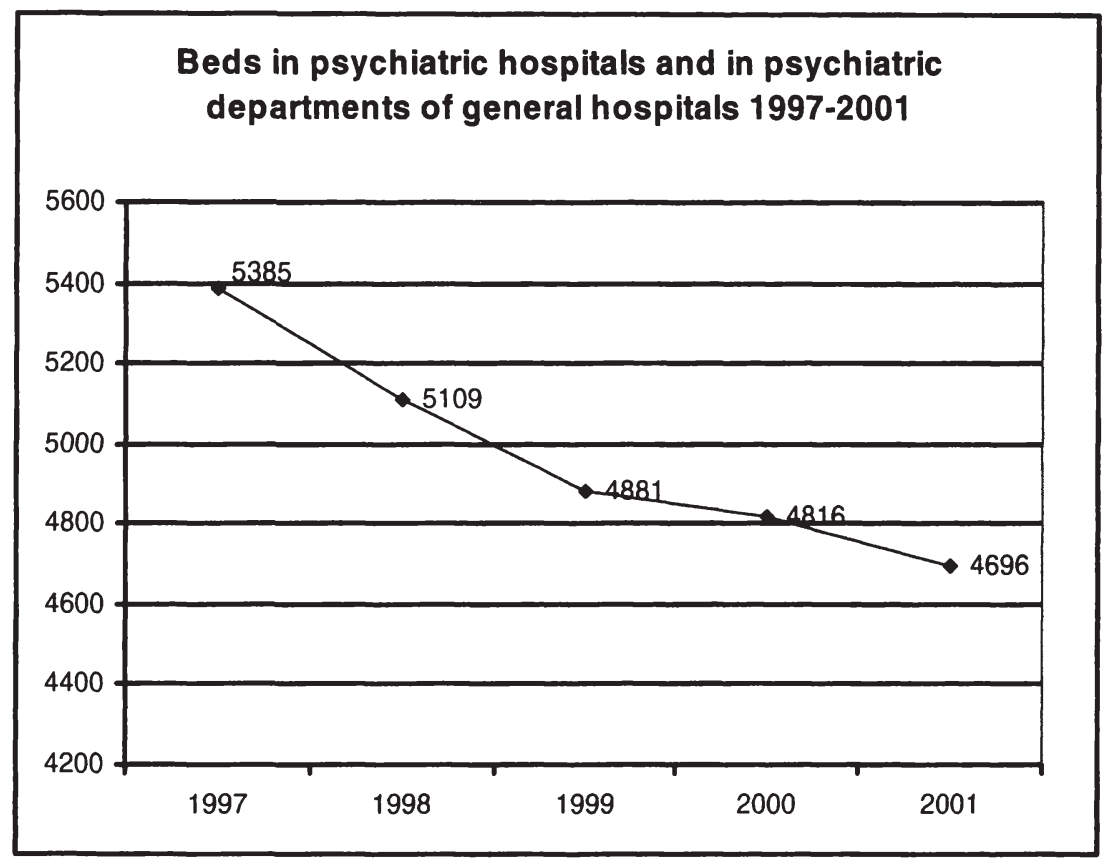

Figure 7: Beds in psychiatric hospitals and in psychiatric departments of general hospitals; Source: BMFG (2003)

\subsection{Mental Health Care Services outside the Health Care System}

The number of services for the mentally ill outside the health care system has steadily increased over the last years. However, in analogue to the situation within the health care system, there exist considerable provincial and even regional differences. Services are not well systemized and cannot easily be compared to each other. Furthermore, some of the services are firmly established, while others are temporary projects (BMFG 2003). In a recent survey, 1,041 services and/or projects which are provided by roughly 250 providers were counted in Austria (BMFG 2003). In several areas, for example in Lower Austria, the common picture is that a high number of services are provided by very few dominant providers whereas the remaining providers offer only small scale services which address very specific type of user group (e.g. homeless people with alcohol problems). 


\subsubsection{Mobile and Ambulatory Psychiatric Services (MAPS), Social Day Structure Services and Employment Related Services}

In terms of MAPS, social day structure and employment related services, the Austrian Mental Health Report (Katschnig et al. 2001) provides a rough mapping for specific mental health services on the community level in single provinces. The data is from the year 1998 and shows services from eight out of nine Austrian provinces. Tables 5-8 list availability of mobile and ambulatory psychiatric services, social day structure services, living arrangements and sheltered employment which are provided for people with mental disorders.

\begin{tabular}{|l|c|c|c|}
\hline \multicolumn{5}{|c|}{ MAPS, year 1998} \\
\hline \multicolumn{1}{|c|}{ Province } & Number of MAPS & $\begin{array}{c}\text { Full-time } \\
\text { equivalent }\end{array}$ & $\begin{array}{c}\text { Employees/100,000 } \\
\text { inhabitants }\end{array}$ \\
\hline Burgenland & 7 & 10.5 & 3.8 \\
\hline Carinthia & 17 & 37.2 & 6.6 \\
\hline Niederösterreich & 24 & 29.4 & 1.9 \\
\hline Oberösterreich & 27 & 94.1 & 6.9 \\
\hline Salzburg & 2 & 14.5 & 2.8 \\
\hline Steiermark & 18 & 71.9 & 6.0 \\
\hline Tirol & 12 & 52.8 & 8.0 \\
\hline Vorarlberg & 9 & 42.2 & 12.3 \\
\hline Total & $\mathbf{1 1 8}$ & $\mathbf{3 6 4 . 4}$ & 4.5 \\
\hline
\end{tabular}

Table 5: Mobile and ambulatory psychiatric services, year 1998; Source: Katschnig et al. (2001)

In 1998, 118 mobile and ambulatory psychiatric services were available in eight out of nine Austrian provinces relating to a personnel rate of 4.5 per 100,000 inhabitants (table 5). Additionally, 904 places for social day structure were provided which is equivalent to 11.2 places per 100,000 persons (table 6 ). Finally, 1,262 places or 15.6 places per 100,000 inhabitants for sheltered employment were provided (table 7). Notably, services varied considerably across the provinces. For example, in Burgenland, availability of most of the services was very low while in other provinces such as in Upper Austria service supply was much higher.

Concerning employment related services, additionally, the 'Ministry of Social Security and Generations' (BMSG 2003) has only recently established a database of available services for labour market integration of disabled people in Austria. Services are categorised into 'occupation-related counselling and orientation', 'training and qualification' and 'occupation/employment'. According to the data- 
base, 59 services aim primarily at mentally disabled people (table 8 ), whereas the remaining 348 services are available for people with different types of disabilities including mentally disabled people. Thus, all together around 407 services for labour market integration are available for mentally disabled people.

\begin{tabular}{|l|l|c|c|}
\hline \multicolumn{4}{|c|}{ Social day structure services for mentally ill persons, year 1998 } \\
\begin{tabular}{|l|c|c|c|}
\hline \multicolumn{1}{|c|}{ Province } & $\begin{array}{c}\text { Social day } \\
\text { structure services }\end{array}$ & $\begin{array}{c}\text { Number of } \\
\text { available places }\end{array}$ & $\begin{array}{c}\text { Places/100,000 } \\
\text { inhabitants }\end{array}$ \\
\hline Burgenland & 0 & 0 & 0.0 \\
\hline Carinthia & 4 & 108 & 19.1 \\
\hline Niederösterreich & 6 & 124 & 8.1 \\
\hline Oberösterreich & 17 & 269 & 19.6 \\
\hline Salzburg & 1 & 25 & 4.9 \\
\hline Steiermark & 2 & 30 & 2.5 \\
\hline Tirol & 13 & 324 & 48.9 \\
\hline Vorarlberg & 0 & 0 & 0.0 \\
\hline Total & 44 & $\mathbf{9 0 4}$ & 11.2 \\
\hline
\end{tabular}
\end{tabular}

Table 6: Social day structure services for mentally ill persons, year 1998;

Source: Katschnig et al. (2001)

Sheltered employment for mentally ill persons, year 1998

\begin{tabular}{|l|c|c|c|}
\hline \multicolumn{1}{|c|}{ Province } & $\begin{array}{c}\text { Number of } \\
\text { services }\end{array}$ & $\begin{array}{c}\text { Number of } \\
\text { available places }\end{array}$ & $\begin{array}{c}\text { Places/100,000 } \\
\text { inhabitants }\end{array}$ \\
\hline Burgenland & 0 & 0 & 0.0 \\
\hline Carinthia & 5 & 204 & 36.1 \\
\hline Niederösterreich & 4 & 105 & 6.8 \\
\hline Oberösterreich & 22 & 330 & 24.0 \\
\hline Salzburg & 2 & 32 & 6.2 \\
\hline Steiermark & 11 & 234 & 19.4 \\
\hline Tirol & 1 & 36 & 5.4 \\
\hline Vorarlberg & 4 & 76 & 22.4 \\
\hline Total & 54 & $\mathbf{1 , 2 6 2}$ & $\mathbf{1 5 . 6}$ \\
\hline
\end{tabular}

Table 7: Sheltered employment for mentally ill persons, year 1998; Source: Katschnig et al. (2001) 
Employment related services for mentally disabled people, 2003

\begin{tabular}{|l|c|c|c|c|}
\hline \multicolumn{1}{|c|}{$\begin{array}{c}\text { People from } \\
\text { province }\end{array}$} & $\begin{array}{c}\text { Counselling/ } \\
\text { Orientation } \\
\text { services }\end{array}$ & $\begin{array}{c}\text { Training/ } \\
\text { Qualification } \\
\text { services }\end{array}$ & $\begin{array}{c}\text { Employment/ } \\
\text { Occupation } \\
\text { services }\end{array}$ & Total \\
\hline Burgenland & 2 & 2 & 1 & 5 \\
\hline Carinthia & 1 & 2 & & 3 \\
\hline Niederösterreich & 4 & 2 & 1 & 7 \\
\hline Oberösterreich & 3 & 1 & 2 & 6 \\
\hline Salzburg & & 3 & 3 & 6 \\
\hline Steiermark & 5 & 7 & 2 & 14 \\
\hline Tirol & 2 & 2 & 1 & 3 \\
\hline Vorarlberg & 2 & & 2 & 4 \\
\hline Wien & 3 & 4 & 4 & 11 \\
\hline $\begin{array}{l}\text { Total number of } \\
\text { services }\end{array}$ & $\mathbf{2 0}$ & $\mathbf{2 3}$ & $\mathbf{1 6}$ & $\mathbf{5 9}$ \\
\hline
\end{tabular}

Table 8: Employment related services for mentally disabled people; Source: BMSG (2003)

\subsubsection{Residential Care}

As mentioned under 3.1., residential care is provided in several different forms ranging from sheltered accommodation arrangements to 24-h staffed and institutional long-term care. Concerning available accommodation arrangements, 1,232 places were counted in 1998 relating to 15.2 places per 100,000 inhabitants (Table 9).

Concerning institutional long-term care, this has always played a significant role in mental health care. Initially, it has primarily been provided in mental hospitals. Due to the process of decentralisation and the closure of large mental hospitals and, not least, because of the introduction of a new hospital reimbursement system (see chapter 4), long-term care has been transferred to traditional long-term care institutions in provinces. Overall, in 2000, 761 longterm care institutions existed in Austria (BMSG 2001; Nam 2003). Many of them serve persons with mental disorders, however, no comprehensive Austrian-wide survey about mental health care in long-term care institutions has been carried out so far. As an exceptional example, data concerning this issue exist for the province of Lower Austria (Denk and Weibold 2002). According to the results of the conducted survey, in 2002, 90 out of 105 long-term care institutions in Lower 
Austria served 5,130 persons with a psychiatric diagnosis ${ }^{10}$. Those persons accounted for more than $50 \%$ of all residents. The percentage of residents with a psychiatric diagnosis correlated positively with the size of the institutions. $65 \%$ of them lived in institutions with more than 100 beds. Three quarters of residents with psychiatric diagnosis were women. Residents were on average 82.47 years old. Only in two institutions which specialised in mental illness, the average age was 60 and 68.22 years respectively. The highest proportion $(57.2 \%)$ of residents suffered from psycho-organic disorders, followed by functional disorders (28.1\%), substance dependencies $(7.43 \%)$ and mental disability $(7.02 \%)$. The average costs per day for residents with mental disorders were $66.44 €$. In the two specialised institutions daily costs were $92.47 €$ and $81.04 €$ respectively.

\begin{tabular}{|l|l|c|c|}
\hline \multicolumn{4}{|c|}{ Living arrangements for mentally ill persons, year 1998 } \\
\begin{tabular}{|l|c|c|c|}
\hline \multicolumn{1}{|c|}{ Provinces } & $\begin{array}{c}\text { Living } \\
\text { arrangements }\end{array}$ & $\begin{array}{c}\text { Number of } \\
\text { available places }\end{array}$ & $\begin{array}{c}\text { Places/100,000 } \\
\text { inhabitants }\end{array}$ \\
\hline Burgenland & 0 & 0 & 0.0 \\
\hline Carinthia & 5 & 46 & 8.1 \\
\hline Niederösterreich & 14 & 175 & 11.4 \\
\hline Oberösterreich & 38 & 624 & 45.4 \\
\hline Salzburg & 4 & 44 & 8.6 \\
\hline Steiermark & 8 & 40 & 3.3 \\
\hline Tirol & 23 & 117 & 17.7 \\
\hline Vorarlberg & 13 & 139 & 40.3 \\
\hline Total & $\mathbf{1 0 8}$ & $\mathbf{1 , 2 3 2}$ & 15.2 \\
\hline
\end{tabular}
\end{tabular}

Table 9: Living arrangements for mentally ill persons, year 1998; Source: Katschnig et al. (2001)

\subsection{Service Providers: A Public-Private Mix}

With respect to the type of service providers, mental health care consists of a public-private mix (table 10). Although mental health care has always been provided by a mix of public and private providers, before the reform process state owned providers and the family used to play the most dominant role. The reform process has changed the public-private relation concerning service provision. Mental health care has become a more 'mixed economy', involving the state, the

\footnotetext{
${ }^{10}$ The number includes mentally disabled people.
} 
private for-profit and non-profit sector, the voluntary sector and the family in service provision, with the state's role decreasing. The number and scope of private non-profit services in mental health care has increased considerably over the last years.

\begin{tabular}{|c|c|c|c|c|}
\hline \multicolumn{5}{|c|}{ Mental health care providers in Austria } \\
\hline Type of service & $\begin{array}{c}\text { Public } \\
\text { providers }\end{array}$ & $\begin{array}{c}\text { Private } \\
\text { non-profit } \\
\text { providers }\end{array}$ & $\begin{array}{c}\text { Private } \\
\text { for-profit } \\
\text { providers }\end{array}$ & $\begin{array}{l}\text { Voluntary/ } \\
\text { Family }\end{array}$ \\
\hline $\begin{array}{l}\text { MAPS, social day structure } \\
\text { services and employment } \\
\text { related services }\end{array}$ & $\mathrm{x}$ & $\mathrm{x}$ & & \\
\hline \multicolumn{5}{|l|}{ Residential care } \\
\hline $\begin{array}{l}\text { - Institutional long- } \\
\text { term care }\end{array}$ & $\mathrm{x}$ & $\mathrm{x}$ & $\mathrm{x}$ & \\
\hline $\begin{array}{ll} & \begin{array}{l}\text { Accommodation } \\
\text { arrangements }\end{array} \\
\end{array}$ & $\bar{x}$ & $\bar{x}$ & & \\
\hline Primary care & $\mathrm{x}$ & & $\mathbf{x}$ & \\
\hline \multicolumn{5}{|l|}{ Hospital care } \\
\hline - $\quad$ Mental hospital & $\mathrm{x}$ & & & \\
\hline - General hospitals & $\mathbf{x}$ & $\mathrm{x}$ & & \\
\hline Family care (formal) & & & & $\mathrm{x}$ \\
\hline Informal care & & & & $\mathrm{x}$ \\
\hline
\end{tabular}

Table 10: Mental health care providers in Austria; own table

Currently, MAPS, social day structure and employment-related services are mainly provided by private non-profit providers. Only in very few cases (e.g. in Vienna), providers of these community services are also public authorities such as municipalities. However, with constant restructuring of the public sector, for example the recent foundation of the 'Viennese Social Fund' (Fonds Soziales Wien), the role of private providers is likely to increase. Institutional long-term care providers are either public or private organisations. The latter can be both, for-profit or non-profit organisations with non-profit organisations playing a considerably more important role. Public long-term care providers usually reside on the provincial or community level. Similar to institutional long-term care, hospital services are either provided by public authorities or by private providers. While mental hospitals are publicly owned, hospital mental health care in general 
hospitals is provided by both, public and private non-profit institutions. Concerning the governmental level of public hospital providers, services are supplied by provinces or communities. Providers in the primary care sector are generally private for-profit-practices except for some services, which are provided by the social insurance fund.

Apart from professional services, family based service provision on a formal basis (Familienpflege) has been promoted in several regions (e.g. Styria and Upper Austria). In those cases, families receive a pre-determined amount of money for taking care of a person with mental illness. Finally, a considerable amount of care is provided informally by relatives. In both of these caring arrangements, service provision falls within the family/voluntary sector.

\subsection{Conclusion}

The description of the current mental health care structures in Austria demonstrates a variegated picture of different services supplied by a mix of service providers. Over the last decades substantial changes have taken place which has been indicated in this chapter by data about re-dimensioning of hospital care, the establishment of new services and the expansion of services which are provided outside the hospital. Although new services have been created, the construction of a comprehensive community psychiatric service system continues to be incomplete with substantial regional variation. This is associated with the fact that no nation-wide mental health policy exists and legislation which impacts on mental health care is to a large extent based on the provincial level. Furthermore, institutional care plays an important role as demonstrated by the example of Lower Austria especially with regard to former long-stay patients. Having outlined the rich and complex pattern of service provision, it will be shown in the following chapter how these service elements are financed. For that purpose, financing structures on the European level as well as the specific characteristics of the Austrian mental health care financing system will be addressed. 


\section{Mental Health Care Financing}

It has been outlined in the previous part that mental health care in Austria includes elements which are covered within and outside the health care system. Furthermore, historical issues and traditions as well as the federalist structure have led to the development of a specific scenery of public and private sector involvement. This is not only the case in Austria, but it is the traditional pattern in Western European countries. Given this complexity, it is not surprising that the financing structures of mental health care are also particularly complex.

In none of the Western European states there exists an explicitly defined mental health care financing system. Thus, mental health care financing always occurs within the context of the overall welfare state financing system and to a large extent within the context of general health care systems and financing arrangements. This might suggest that there is no point in specifically addressing mental health care financing. However, there are several reasons why the focus on mental health care financing is warranted.

Firstly, as Frank and McGuire (1999) point out, the spending on mental health care displays a different pattern than that found in the health care sector overall. When studying the situation in the USA they found that the most important difference is the role of government as direct funder of care. State and local government allocate more resources for mental health $(41.1 \%)$ than for health services generally $(23.3 \%)$. On the other hand, the federal government funds over $25 \%$ of health spending but less than $20 \%$ of mental health expenditures. Additionally, private spending for private health insurance and private out-of pocket spending differ between health care and mental health care. Although European health care systems vary considerably from the US system, it is likely that European mental health care financing systems equally display specific patterns, simply because mental health care covers a wider range of services than general health care. Moreover, Dixon (2002) remarks that as a result of the shift away from institutionalised psychiatric to community care a diversification in mental health care financing has taken place in most of the countries. These specific characteristics may not least have implications for service delivery and for the individuals affected by mental disorders.

Secondly, even in domains where mental health care financing is identical with general health care financing, it is important to address financing arrangements. It has been outlined in the previous chapters that mental disorders differ from somatic illness in terms of aetiology, diagnosis and treatment as well as in terms of various social consequences which are related to mental illness. Serious disorders are associated with social disorders that can severely impair quality of life, including isolation from social networks, homelessness or inappropriate accommodation placements. Severe and chronic mental health problems are associated with unemployment and low income. Due to this specific nature of 
illness and its consequences, the general health care financing system may have different implications for persons with mental disorders compared to those with somatic illnesses, for example in terms of (re-)distributional effects of a financing system or access to care.

Thirdly, since around 1980, all across Western Europe health care reforms have taken place. The majority of them were either directly or indirectly concerned with financing issues. Usually, implications of those changes for mental health care service provision and individuals affected by mental disorders have not been taken specifically into account in reform formulation and implementation processes. In other cases, mental health care has definitely been excluded from reforms. Both situations may have specific impacts for mental health care in general and for affected individuals in particular.

The purpose of this chapter is to describe mental health care financing in EU member states. Following this introduction is an overview about mental health care financing in Western European countries which is completed by three casestudies including the UK, Germany and Austria. The non-Austrian cases have been chosen according to the criteria of maximum similarity and maximum difference to the Austrian situation in terms of health care system type. In Germany, the overall financing principle is very similar to Austria, however, several specific arrangements (for mental health care financing) exist which differ from the Austrian case. It will be of interest to explore the effects of differences in details within overall similar systems in the subsequent parts of the thesis. In the $\mathrm{UK}$, on the other hand, the general health care financing principle is different from Austria. The relationship between this type of financing and mental health care will also be an interesting issue, the more so, as considerable progress in the mental health care reform process in the UK can be observed.

The chapter will be of descriptive nature and provides an empirical source for the in-depth analysis in chapter 6 as well as for identifying alternative approaches to mental health care financing in chapter 7. In theory, this would include describing the overall health, social care and even other sectors' financing system. However, due to the great variety of funding arrangements between countries and even within countries and regions, I will mainly restrict the description of financing arrangements to selected core-services for mentally ill rather than covering the sectors entirely. Particularly for the case studies the portrayal includes financing of hospital inpatient care, psychiatric specialist mental health care, residential care and mobile/ambulatory psychiatric services (MAPS). This raises terminological problems. Although terms used might be identical, they may cover different types of treatment/care in various countries or even within one country. Vice versa, providers offering similar types of activities may be termed differently. For the purpose of comparability I use the following definitions: 'Hospital inpatient care' relates to inpatient medical treatment, while 'psychiatric specialist mental health care' means psychiatric services offered by psychiatrists. 'Residential care' corresponds to all types of accommodation arrangements 
ranging from 24-hour staffed nursing homes to sheltered housing. Finally, the term 'mobile/ambulatory psychiatric services' stands for multidisciplinary teams which provide 'come or go-structures' for people with mental illness excluding employment related services. Only in the Austrian case, due to the Austrian focus of the thesis, the description of financing structures will cover some further elements of service provision. Furthermore, in the UK case, slightly more attention will be drawn to the financing procedure, as this will be of relevance for the remainder of the thesis.

\subsection{An Overview of Mental Health Care Financing in Western European Countries ${ }^{11}$}

In the following, an overview about financing mechanisms in Western European countries which are relevant for mental health care services will be provided. This will firstly, include an overview about health care financing in Europe including sources of funding and resource allocation processes. However, similar to Austria, a lot of mental health care services are not provided within the health care system (as the term 'mental health care' might suggest) but in parallel sectors such as social care. In those cases, methods of financing and entitlement to services may differ considerably. Thus, the chapter also addresses the balance between health and social sector in mental health care and financing methods for core-services which are traditionally covered outside the health care sector in many countries. Empirical data for this description has been obtained via the 'Mental Health Economics European Network (MHEEN)' where research representatives from various European countries have collected information on financing mental health care (MHEEN 2004).

\subsubsection{Sources of Funding}

\subsubsection{Funding Mental Health Care Services within the Health Care System}

Sources of financing are relevant for several issues. Firstly, different sources can have different distributional effects. As Wendt (2003) remarks, individuals and their standard of living are considerably influenced by the way the health service is financed. Secondly, sources of financing often determine who makes decisions about resource allocation and broader planning aspects in the health care system (Wendt 2003).

\footnotetext{
"The countries include Austria, Belgium, Denmark, Finland, France, Germany, Greece, Ireland, Italy, Luxembourg, The Netherlands, Portugal, Spain, Sweden and the UK.
} 
Usually, mental health care services within the health care system are funded in the same fashion as other health care services. Although there are many differences and variations between individual systems, there are four primary mechanisms for collecting funds for European health care systems which are taxation, social health insurance, out-of-pocket payments/user charges and private insurance. Taxes or social insurance money are public sources while user charges and payments by private insurances (which may be complementary or a substitute for public services) are private sources. Concerning public sources, each country tends to be dominated by one pattern, according to the general principle of organising and providing health services. 'Beveridge-countries' (e.g. UK, Scandinavian countries) base their health service financing on general taxation while the primary source of 'Bismarck-countries' (e.g. Germany and Austria) is social insurance money.

The sources can take different forms. Thus, taxation systems vary according to the source of taxes used (direct, indirect) and the collection level (national, local). Moreover, taxation can be earmarked or not. Social insurances, on the other hand, are based on pooling revenue through compulsory contributions by employees and (usually) employers. In some 'social insurance-countries' there exists an optingout possibility for high-income groups which is the case in Germany. In the Netherlands, higher income groups are generally privately insured. Revenues can be collected by national or individual health insurance funds or by associations of funds. Usually, contributions are not risk-rated but dependent on income-levels. Contribution rates may either be uniform or they may vary according to funds. In some countries, individuals are able to choose between sickness funds, such as in Germany (Knapp et al. 2003).

Private health insurance plays a limited role for mental health care financing in all of the Western EU-countries. It can take a complementary form (such as in Germany or the Netherlands) or a supplementary form (such as in Austria or France). In most countries the majority of policies are bought at the discretion of an employer on behalf of the individual. Premiums are usually risk-rated (i.e. based on an assessment of individual risk), but may also be community-rated (based on an assessment of the average risk in a defined subgroup of the population) or group-rated (based on an assessment of average risk among the employees of a firm) (Mossialos and Thomson, 2002). Where supplemental insurance is available, coverage for mental health related services is often very limited. Due to the chronic nature and high cost of mental health treatments and interventions private insurers are likely to exclude mental health interventions from the benefits offered to enrolees. Psychiatric care and mental health problems are explicitly excluded in some European Union member states (Mossialos and Thomson, 2002). For instance the sole provider of private health insurance in Luxembourg does not cover mental health. Where treatments are covered, premia are likely to be high. In some cases private insurers are beginning to provide limited cover for some mental health problems, and in some countries this is 
becoming significant. For example, employers may provide private health insurance as a non pecuniary employment benefit. A new phenomenon are insurance schemes providing employment protection. While these may not directly pay for mental health care, insurers can provide a cash benefit should an individual have to give up work because of a mental health related problem. In the UK such insurance schemes have funded counselling and other treatment for workers who have stress related disorders such as teachers.

Private contributions from users vary. In general, they play a minor role compared to public sources. However, trends can be observed which show a considerable increase in private contributions in some countries (Hofmarcher and Röhrling 2003a). User charges can be a percentage of cost or they can be a fixed amount. It is very common that user charges are levied on certain health services such as pharmaceuticals or primary care consultation. Introducing user charges can either be a way of raising revenue or a mean to discourage excessive or inappropriate utilization of services. Usually, specific groups are exempted from charges. Exemptions may be based on age, income, disease or functional status. For example, in Italy people with mental health problems are exempted from charges for using outpatient services. In Portugal exemptions to user charges have been applied for those with low family incomes, individuals with exceptional need for health care consumption such as the disabled and those with certain chronic conditions and for a range of special patient groups (e.g. pregnant women, children, drug addicts on recovery programs, chronic mental patients, etc.) (Pereira et al. 1999). In some cases private insurance may cover the cost of user charges.

OECD data indicate that public funding is the dominant source of health care financing in the countries observed. Concerning mental health care, this relates to those mental health care services which are provided within the health care system. Results from a global survey of mental health financing from the WHO (2001a) show that in the majority of Western European countries the primary source of financing mental health care within the health care system are taxes (figure 8).

There are only few situations where mental health care services within the health care system are financed differently from other health care sector services concerning sources of funding. One unusual case among social insurance based countries are the Netherlands. They have a separate insurance fund for long-term illness, as primary social health insurance only covers a one year period of either inpatient care and/or rehabilitation. After this period the 'Exceptional Medical Expenses Act' (AWBZ) comes into effect. The AWBZ is concerned with very severe financial burdens as a result of serious long-term illnesses or disorders. This insurance scheme is obligatory even for those with high income enrolled in private insurance schemes. Typically, long-term mental health problems are funded under this scheme. Overall, about $85 \%$ of the cost of mental health care 
facilities is paid by the AWBZ, while $11 \%$ come directly out of the national budget. Additionally, there are out-of-pocket contributions for inpatient treatment, sheltered accommodation and psychotherapy which cover $4 \%$ of the costs of mental health care. Coverage under the AWBZ includes admission and stay in general hospitals, psychiatric hospitals and rehabilitation centres after the first 365 days, as well as funding nursing home care, home care, sheltered accommodation, counselling and outpatient psychiatric care (Ministry of Health, Welfare and Sports (VWS) and T. Institute 2000).

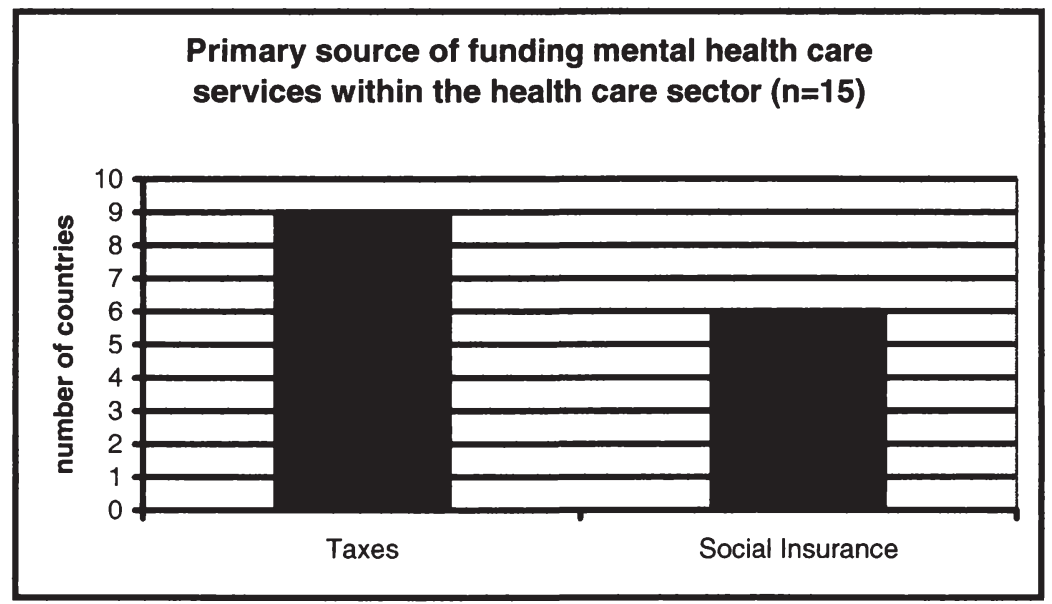

Figure 8: Primary source of funding mental health care services within the health care sector; Source: WHO (2001a)

Another special case is Belgium with respect to home care services for people with mental health problems as well as child and adolescent mental health outreach services. Although these services lie within the health care system they are not funded by social insurance but directly by the federal government, as these services currently operate on a pilot experimental basis.

Finally, some services for instance in Luxembourg, Spain and the UK may be supported by charitable groups. In some cases this type of funding is intended to supplement statutory services, in others it fills a gap where public funding is not available. 


\subsubsection{Funding Mental Health Care Services outside the Health Care System}

As has been stated before, it is required to additionally investigate which core mental health care services are not part of the health care sector and may thus be funded in different ways. This is even more relevant as mental health care reforms have aimed at shifting mental health care from hospital based to community-based deinstitutionalised care and services of the latter are likely to be classified as 'nonhealth care system' services.

In general, there is much variation concerning which range of services are covered within or outside the health care system. Overall, few countries provide a fully comprehensive range of services within the health care system and even where they do the boundaries of responsibility and financing between the health and other sectors may be blurred. In the majority of countries, key services such as vocational rehabilitation or residential care are covered outside the health care system. Tables $11 \mathrm{a} / \mathrm{b}$ present an overview of financing methods of those particular mental health care services.

Commonly, the primary sources of funding are taxes. In general, they are levied and/or administered on the regional or local level rather than on the national level. Notably, only in Sweden full public cost-coverage is provided. In any other country at least some forms of means-testing and out of pocket payment exist. Private payments can range from covering 'hotel costs' only such as in Denmark, Finland and Norway to high rates of private contributions according to the principle of subsidiarity. In the latter case, private money is used as the primary source of financing such as for some services in Portugal, Greece or Austria (MHEEN 2004a). Additionally, financing for services which are covered outside the health care sector is very often restricted to specific user groups in terms of access. For example, in Germany, access to several services depends on the severity of the illness and/or the grade of disability.

\subsubsection{Transfer of Funds and Resource Allocation Processes}

In this chapter a brief overview on the methods used in Western European countries to distribute mental health care resources is provided. In that respect, two processes can be distinguished. On the one hand, there is the process of resource distribution to different sectors and/or geographical areas of the mental health care system. On the other hand, resources are allocated to different providers of the mental health care system which takes place according to various reimbursement methods. The two processes are in some way dependent on each other. For example, the reimbursement method chosen may to a large extent determine the criteria for distributing overall resources. 


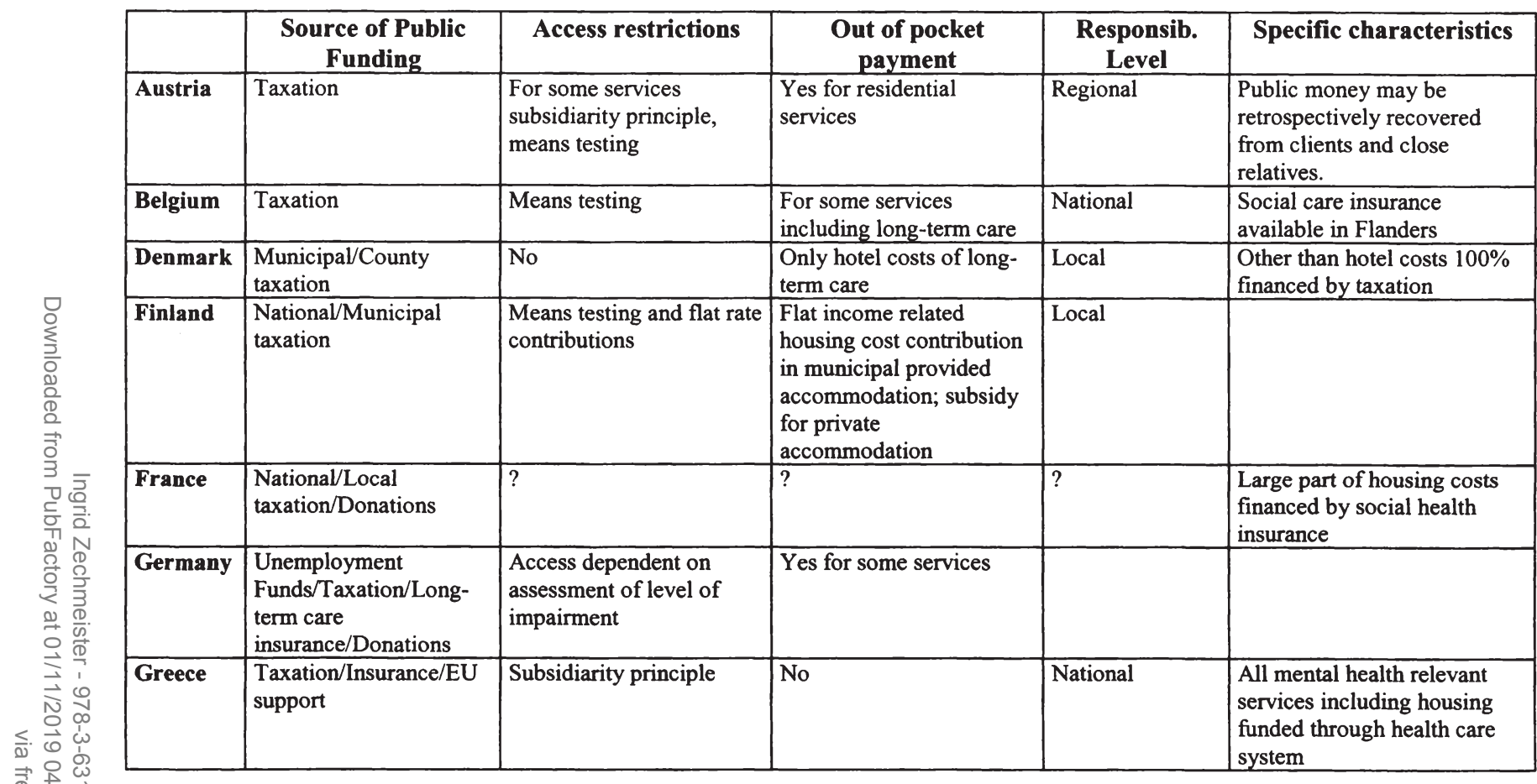

Table 11a: Funding of mental health care services outside the health care system adapted from MHEEN (2004a) 


\begin{tabular}{|c|c|c|c|c|c|}
\hline & $\begin{array}{c}\text { Source of Public } \\
\text { Funding }\end{array}$ & Access restrictions & $\begin{array}{c}\text { Out of pocket } \\
\text { payment }\end{array}$ & $\begin{array}{l}\text { Responsib. } \\
\text { Level }\end{array}$ & Specific characteristics \\
\hline Ireland & Taxation/Donations & Means testing & Yes for most services & Regional & \\
\hline Italy & Taxation & $?$ & $?$ & Local & $\begin{array}{l}\text { Services largely provided in } \\
\text { partnership with health care } \\
\text { system }\end{array}$ \\
\hline $\begin{array}{l}\text { Luxem- } \\
\text { bourg }\end{array}$ & Taxation & $\begin{array}{l}\text { Housing requires referral } \\
\text { from medical sector }\end{array}$ & $?$ & $?$ & $\begin{array}{l}\text { Specialist housing provided } \\
\text { through general taxation }\end{array}$ \\
\hline $\begin{array}{l}\text { Nether- } \\
\text { lands }\end{array}$ & $\begin{array}{l}\text { National taxation/Other } \\
\text { sources }\end{array}$ & $?$ & $?$ & Local & $\begin{array}{l}\text { Long-term care is funded } \\
\text { through the AWBZ }\end{array}$ \\
\hline Portugal & Taxation/Donations & Subsidiarity principle & Yes & National & $\begin{array}{l}\text { Attempts to standardise } \\
\text { payments for service } \\
\text { providers; health related } \\
\text { aspects of long-term care } \\
\text { covered by health system }\end{array}$ \\
\hline Spain & Regional taxation & $\begin{array}{l}\text { Certificate of disability } \\
\text { required to access } \\
\text { services/Discretionary } \\
\text { provision }\end{array}$ & $?$ & Regional & \\
\hline Sweden & $\begin{array}{l}\text { Local taxation/National } \\
\text { equalisation }\end{array}$ & No & No & Local & $\begin{array}{l}\text { National system to equalise } \\
\text { revenues received from } \\
\text { municipalities }\end{array}$ \\
\hline UK & Taxation/Donations & Subsidiarity principle & Yes for some services & $\begin{array}{l}\text { Devolved } \\
\text { administrations/ } \\
\text { Local }\end{array}$ & $\begin{array}{l}\text { Wide variation in access to } \\
\text { services; personal and } \\
\text { nursing costs of long-term } \\
\text { care free in Scotland }\end{array}$ \\
\hline
\end{tabular}


According to Rice and Smith (2002) four main modes of distributing overall health care funds can be found in Western European health care systems. Firstly, budgets can be set according to the size of a bid from providers. Secondly, the budget can be mainly based on political negotiation. Thirdly, the funds may be set according to historical patterns and, finally, they may be based on some independent measure of health care needs. Most Western European countries have introduced some type of needs based resource allocation method, mainly in the form of risk adjusted capitation formulae. In their empirical study, Rice and Smith (2002) found that from the Western European health care systems they analysed, only Austria, Greece, Ireland and Luxembourg had no elements of capitation. However, in most cases capitated budgets are still influenced by political negotiations and historical precedents, as it is for example evident in Portugal.

With respect to provider reimbursement within the health care system, three main methods of provider reimbursement can be envisaged along a spectrum of various arrangements. Firstly, providers can be reimbursed according to full retrospective reimbursement for all expenditure incurred. Secondly, reimbursement can be activity based according to a fixed schedule of fees as for example in the case of diagnosis related group systems. Finally, reimbursement may take place according to prospective funding based on a fixed budget which is determined on the basis of expected future expenditure. The main difference between method one and three is that the financial risk shifts increasingly from the payer to the provider of services. Rice and Smith (2002) point out that, not least because of increasing concerns with expenditure control, the trend within European health care systems has been a shift to the latter model. Particularly with the introduction of new forms of overall resource allocation such as needs based capitation, the 'full retrospective reimbursement method' has inevitably had to be abolished. However, very often explicit mechanisms of reimbursement may be influenced retrospectively by implicit mechanisms such as hidden subsidies. A case in point is the Austrian system where the prospective hospital budget combined with a diagnosis-related reimbursement of hospitals is traditionally subsidised in retrospect by taxes from provinces (see 4.4.). Not least, with changing reimbursement methods, particularly from retrospective to activity based and prospective reimbursement, the relationship between purchasers and providers has changed into a contractual relationship where various types of performance based contracts have been introduced.

Concerning the question whether specific characteristics in terms of resource allocation and reimbursement for mental health care services within the health care sector exist, some differences to somatic services can be envisaged. Most importantly, psychiatric hospital care may be exempted from the overall reimbursement scheme as for example in Germany, where psychiatric hospital services have been excluded from the diagnosis related group reimbursement system when it was introduced in January 2004 (see 4.3.). 
Given that the majority of countries use risk adjusted capitation formulae for allocating resources, a crucial question is whether the factors used in the formulae account in any way for mental illness. There is hardly any information available on that matter. As Rice and Smith $(2002,258)$ note: "The selection of factors to be included in calculating health care capitation has been highly complex and controversial...". Furthermore, once factors have been selected, weights must be attached in order to reflect the differences in needs. They are either based on individual data (e.g. age, sex, disability status etc.) or on aggregate data (e.g. demography, mortality etc.). Comprehensive individual data are hardly available. Thus statisticians are often forced to restrict weighing to very few individual criteria such as 'age' in France or they use aggregate data such as in Belgium or a hybrid model. With respect to mental illness, some of the factors (such as morbidity) may take specific needs more into account than others. In some cases, there may even be an explicit 'mental illness factor' which takes into account specific resource requirements for providing mental health care. An example for that will be described in more detail under 4.2.

Overall, allocations to mental health care are difficult to quantify. Some countries operate with a 'ring fenced' mental health care budget, while in others, the mental health care budget cannot be separated from the overall health care budget. According to a WHO (2001a) data base, twelve out of the fifteen Western European countries report that a specified mental health care budget exists. Out of these countries, seven have provided a percentage of mental health care spending. In one case (France) this accounts for $5 \%$ of the total health care spending. Four countries (Belgium, Ireland, The Netherlands, UK) commit between 5.1 and $10 \%$ of their budget to mental health care, whereas only two (Luxembourg, Sweden) spend slightly more than $10 \%$ of total health care expenditure on mental health care. ${ }^{12}$

With respect to transferring funds and resource allocation for mental health services outside the health care system, even less detailed information is available. Principally, many of the described modes of distributing funds and reimbursing providers can also be found outside the health care system. However, funds for financing those services are more likely to be determined according to political negotiations and historical patterns. With respect to reimbursement, retrospective reimbursement has traditionally been used for various providers. More recently, reimbursement has shifted to activity based types of reimbursement and prospectively determined budgets, which is closely related to the shift from public subsidies to performance based contracting. Finally, it is common that similar to sources of funds, resource allocation and reimbursement processes for services outside the health care system differ within countries.

12 The accuracy of the data depends on the definition of mental health care adopted in each country. In some countries the figure may also include financial resources for financing services outside the health care sector. 


\subsection{Case-Study: UK}

\subsubsection{Sources of Funding}

\subsubsection{Funding Mental Health Care Services within the Health Care System}

From the services under investigation, hospital inpatient care, psychiatric specialist services and MAPS ${ }^{13}$ are covered within the health care system in the UK. Core elements of the latter are for example Community Mental Health Teams $(\mathrm{CMHT})^{14}$ or Assertive Outreach Teams (AOT) ${ }^{15}$. In the following paragraphs sources for financing these services will be described.

The UK health care system belongs to the so-called 'Beveridge-countries' where the primary sources of health care funding are taxes and access to health care is universal (based on residency). The majority of health care in the UK is provided by the Department of Health $(\mathrm{DoH})$ through the National Health Services (NHS). Apart from taxation, a small proportion of NHS expenditure is covered by national insurance contribution. For example, in England consolidated funds (general taxation) accounted for $77.7 \%$ of the NHS spending in 2000/2001 while $11.9 \%$ of the NHS spending was met by the national insurance (Department of Health 2002). It is worth noting that in 2003 hypothecated national insurance contributions for health care were introduced which increased insurance contributions for employers and employees by $1 \%$. Concerning general taxation, direct taxes account for $44 \%$ (Wendt 2003). Overall, in 1995, taxes made up $84 \%$ of total health care expenditure while only $9.8 \%$ of the expenditure was financed through other public sources. On the whole, the public share of health care expenditure is high. In 2002, total expenditure on health accounted for $7.7 \%$ of the GDP from which $83.4 \%$ were publicly financed (OECD 2004).

\footnotetext{
${ }^{13}$ With re-structuring mental health care, the separation between health and social care has become increasingly blurred; thus, some resources (e.g. personnel) in MAPS may also be part of the traditional social sector. For example, formerly separate social work teams are merged with health teams to form 'integrated services'. However, services are still regarded as health service led and mainly funded from health sector resources.

${ }_{14}$ Community mental health teams are multidisciplinary teams which are responsible for coordinated service provision. The average size of those teams is 11 full-time equivalents which relates to 15 team members on average. The occupational group mostly represented are community psychiatric nurses (CPN) followed by social workers, medical personnel, psychologists and occupational therapists. The clientele are to a large extent people with serious mental disorders (57\%) (Becker 1999).

${ }^{15}$ Assertive Outreach teams are responsible for a specific target group, who have had frequent hospital admissions, present a substantial risk to themselves or others and have not engaged well with community mental health teams. The team works in patients' living places (Johnson, Zinkler and Priebe 2001).
} 
Private payments in the form of co-payments, self-payment or private insurance used to make up a relatively small contribution. In 1996, approximately $£ 7,474$ million (or $14.6 \%$ of total spending) were spent privately (Robinson and Dixon 1999). With respect to mental health care within the health care sector, copayments only exist for prescriptions and, thus, play a role for services which are provided outside the hospital only. In terms of private insurance, private insurers are beginning to provide limited coverage for some mental health problems. However, these products have been criticised for being overly complex and variable which makes it difficult for the individual person to find out what is covered. For example of a sample of 203 policies available to a 50 year old provided by 7 insurance companies, 101 offered some inpatient psychiatric cover and 80 some outpatient psychiatric cover. Importantly, pre-existing conditions and treatment for 'chronic conditions' tend to be excluded from private health insurance coverage (Office of Fair trading 1996). While the number of individuals who purchase private insurance is small, private health insurance is increasingly offered by employers as an employment benefit.

Not least, the opportunity to provide services through private insurance rises with the increasing provision of mental health care by private companies (McDaid et al. 2004). As a recent market survey suggests, mental health is the fastest growing independent private health care sector, not least because the NHS increasingly outsources acute psychiatric care. For example, independent psychiatric hospital revenues were $£ 336$ million in total in 2001 which demonstrates an increase by $117 \%$ between 2000 and 2001 (Laing and Buisson 2003).

Furthermore, coverage with private health insurance is strongly income related. Data from a recent survey showed that $40 \%$ of those in the highest income decile have private insurance compared to just under $5 \%$ of those persons in the poorest four deciles. The correlation with high income also relates to the likelihood of an insurance paid for by an employer (Emmerson, Frayne and Goodman 2002).

Finally, in terms of self-payment, it may be relevant that the private sector is an important provider of psychological treatment such as psychotherapy (Johnson, Zinkler and Priebe 2001).

\subsubsection{Funding Mental Health Care Services outside the Health Care System}

Several core elements of community mental health care, namely residential care, employment support and leisure support are not covered within the NHS. Overall, Lien (2003) points out that in contrast to inpatient care where $96 \%$ of costs are covered within the NHS, for community care, over $50 \%$ fall on local health authorities, housing and education, voluntary organisations, social security, families of sufferers and other informal carers. For example, (financing) 
responsibility for long-term care in residential or nursing homes and other accommodation arrangements is shared between several agencies such as local governments, the social services department and the NHS.

To a large extent, the provision of services outside of the NHS is the responsibility of Local Authorities (LAs). Funding for these social care services is through the Personal Social Services (PSS) scheme. In contrast to the NHS, in the PSS locally raised revenues play a more important role while central DoH-money only accounts for a marginal proportion. In 2000/2001, spending by local authorities on PSS from DoH sources was $£ 974$ million (10\%), while $£ 9,752$ $(90 \%)$ million were funded from other sources (Department of Health 2002). Furthermore, many people have their residential care funded by housing benefits. While health care benefits available under the NHS are universal and free at the point of use, social care benefits are means tested and often subject to cost sharing. Thus, in the PSS-scheme, co-payments are common. For example, in $2002 / 2003$, from £ 920 million total expenditure for the group 'mentally ill adults', private contributions from individuals accounted for $£ 80$ million (approx. 9\%) in the English social service scheme (Department of Health 2004). As Goodwin (1997) points out, local authorities are increasingly using means tests for social care services in an attempt to control demand and raise resources.

Notably, the boundary between health and social care is blurred in mental health care. A person with a mental health problem who has accessed the system is assigned a care coordinator who is responsible for providing services based on the individual's need. Services may be provided by the NHS but also by the social sector or other agencies. According to Dixon (2002), the shift to community mental health care has generally transferred responsibility for financing mental health care services from NHS budget to local social services budgets. Furthermore, the degree of integration between NHS mental health and social services varies. Although government policy requires plans to be made for social workers employed by local authority to work in joint teams with NHS mental health professionals, there is considerable variation in the extent to which these plans have been implemented so far (Johnson, Zinkler and Priebe 2001).

\subsubsection{Transfer of Funds and Resource Allocation Processes}

Since 1991, the structure of the UK health care system has been constantly changing which has particularly affected the resource allocation procedures in health and social care. Furthermore, the process of devolution has resulted in differences between England, Wales and Scotland. The following description should reflect the current situation as accurately as possible. Where relevant, the example of England is used. Additionally, figure 9 provides a graphical scheme of the financial structures and flows. 
In the UK, the DoH budget is set annually in the overall political public expenditure planning process. It consists of a long-term fixed and a short-term (more flexible) treasury grant. Resources are allocated to the NHS and the PSS. In $2000 / 2001$ total DoH Budget was $£ 45,550$ million from which $97 \%$ were allocated to the NHS and only 3\% were allocated to the PSS (Department of Health 2002). The NHS budget is further broken down into funding for hospital and community care services (HCHS), family health services (FHS) and Central and Miscellaneous Services (CHMS) and is then transferred to the district level. To ensure that equity and efficiency goals are met, HCHS budgets are ideally set according to risk adjusted capitation methods. This means that allocation takes place according to a formula which was originally developed by the Resource Allocation Working Party (RAWP) in the 1970s. The formula takes into account the number of inhabitants, composition in terms of age and gender and weighted health status. Statistical methods of calculation have become increasingly sophisticated since then (Department of Health 2003). However, in several cases (especially when allocation is made to smaller catchment areas) budget allocation has mostly relied on historical patterns of costs and activity (Robinson and Dixon 1999). In contrast to the HCHS budget, allocation of the FHS budget has traditionally taken place according to historical patterns. Yet, with the development of new primary care structures, the establishment of formulae for primary care budget allocation seems to be under way.

Dixon (2002) points out that it has been recognised to include mental health as a separate risk factor in some resource allocation formulae. For example, in England the RAWP introduced specific needs indices for psychiatric hospital and community care in 1994 (Bindman et al. 2000). The commonly used index is the 'Psychiatric Needs Index'. Some further allocation formulae for mental health care have been developed in the academic field. For example, Glover et al. (1998) developed the Mental Illness Needs Index (MINI) for special mental health care needs which is based on mathematical/statistical data on service utilisation, on socio-demographic variables and on expert interviews. The MINI is, however, not applied in practice.

Within the HCHS scheme of the NHS, England has an earmarked budget for mental health. It consists of a 'general allocation for mental health' and some smaller 'special allocations' such as the 'old long stay allocation', the 'drug misuse allocation' and the 'mental health challenge fund'. While the 'general allocation budget' seems to be related to the Psychiatric Needs Index, such a relation is not observable with the 'old long stay allocation' indicating that the latter is mainly allocated on the basis of historical patterns (Bindman et al. 2000). On average, since 1997 around 12\% of the HCHS budget has been allocated to mental HCHS (see table 12 for England). This corresponded to $£ 2,911$ million in 1996/1997 (Bindman et al. 2000) and to £ 5,368 million in 2003/2004 (Glover 2002). 


\section{Total amount and maximum/minimum proportion of PCT allocation to clinical areas in England for 2003/2004}

\begin{tabular}{|l|r|r|r|r|}
\hline Clinical areas & Overall \% & Max. \% & Min. \% & $\begin{array}{l}\text { Total Allocation for } \\
\text { England (£ 1000) }\end{array}$ \\
\hline Acute HCHS & 70.87 & 73.14 & 64.04 & $32,112,793$ \\
\hline Mental HCHS & $\mathbf{1 1 . 8 5}$ & $\mathbf{2 0 . 1 3}$ & $\mathbf{8 . 0 4}$ & $\mathbf{5 , 3 6 7 , 5 9 6}$ \\
\hline Prescribing & 14.01 & 16.81 & 9.02 & $6,346,694$ \\
\hline GMSCL & 2.59 & 3.32 & 2.02 & $1,174,531$ \\
\hline HIV/AIDS & 0.69 & 5.79 & 0.07 & 311,217 \\
\hline Total & 100 & & & $45,312,830$ \\
\hline
\end{tabular}

Table 12: PCT ${ }^{10}$ allocation to clinical areas in England; Source: Glover (2002)

Additionally, mental health receives a share of a dedicated budget for "Clinical Priorities' which is funded through the 'Centrally Funded Initiatives and Services and Special Allocation Fund' (CFISSA). It is primarily spent on public mental health campaigns (Department of Health 2002).

Finally, within the PSS, mental health has a specific DoH grant. In 1999/2000, $5.3 \%$ (or $£ 677$ million) of local authority gross expenditure was spent for mentally ill adults (Department of Health 2002). In addition to these 'earmarked' allocations, money for mental health care is also allocated via other benefits (e.g. housing benefits), yet without addressing people with mental health problems in particular. Although overall government funding for social services has increased in recent years, the amounts available for mental health care have been constrained and the mental health grant given by central government to local authorities has not been raised at all in the latest period (Sainsbury Centre of Mental Health 2003).

Furthermore, with the process of devolution, significant differences in funding are beginning to appear within the UK. For instance in Wales all out of pocket charges for prescriptions are being phased out, while in Scotland personal as well as nursing costs of long-term care are now funded by the state. Incidentally, since devolution the amount of per capita resources devoted to mental health in Scotland is considerably higher than that in England (MHEEN 2004a).

Finally, resource allocation of the central budget is only one important matter. Another key issue is how resources are actually spent by the purchasing bodies. In other words, even if the allocation process is equitable, resources may not be invested in mental health care. In the UK, the expenditure procedure works as

\footnotetext{
${ }^{16}$ PCT is the abbreviation for Primary Care Trusts (see p. 63 for more details).
} 
follows: Once broken down, the HCHS sub-budget is allocated to different bodies which function as purchasers of services. At first, the budget is transferred to Health Authorities (former District Health Authorities). Health Authorities (HA) transfer parts of the budgets further on to Primary Care Groups (PCG) with 'Trust-status' (PCT). The latter are groupings around GP practices in a geographical area which cover a population ranging from 50,000 to $250,000^{17}$. Both, Health Authorities and PCTs are responsible for commissioning and purchasing services from the providers based on the needs of the population. More recently, the function of HA has started to shift towards strategic planning, as PCGs increasingly move towards trust-status and assume responsibility for commissioning. The FHS sub-budget, on the other hand, is used for GP reimbursement and other primary care services.

Reimbursement for service providers is based on contracting arrangements which differ in detail between service types. Concerning methods of hospital funding, a contracting system was introduced under the 1991 reform. Providers of hospital services which have been given 'Trust-status' are expected to conclude performance based contracts with the purchasers. Contracts specify the type of service to provide and the terms on which they are to be supplied. The type of contract varies and has initially ranged from 'block contracts' to 'cost-and-volume contracts' and 'cost-per-case contracts'. While block contracts define a sum of money for a range of services, cost-and-volume contracts specify a given number of treatments or cases at an agreed price. Cost-per-case contracts, on the other hand, link expenditure and activity explicitly on the individual patient level. Because of considerable transaction costs, the latter type was only used for specific arrangements. In practice, a new form of contract emerged which was called 'sophisticated block contract'. Since 1998, the former short-term contractual relationship between purchasers and providers has been replaced by long-term service agreements emphasising collaboration rather than competition (Robinson and Dixon 1999).

In the field of mental health care, some specific service supply characteristics exist. Notably, some 'Mental Health Trusts' have been founded. 'Mental Health Trusts' are characterised as "large organisations with a range of local authority and PCT partners, operating from a multiplicity of sites" (Commission for Health Improvement 2003, 7). The foundation of 'Mental Health Trusts' enabled integration of health and social care through the delegation of social care services to NHS trusts. Thus, 'Mental Health Trusts' not only provide hospital care but also specialised community care services such as 'Assertive Outreach' or 'Crisis Resolution' (see 4.2.1.1.). They represent a collaboration between community mental health providers, hospital care providers and a range of voluntary and independent providers (Stevens et al. 2001). According to the Commission for

\footnotetext{
${ }^{17}$ PCT only exist in England. In Wales and Scotland these bodies are called 'Local Health Groups' and 'Local Health Care Cooperatives/Trusts' respectively.
} 
Health Improvement (2003), 'Mental Health Trusts' are at very different stages of development concerning the range of collaborating providers. Additionally, while trusts are formally established collaborations, mental health care services can also be provided through some flexible forms of health and social care integration. Furthermore, fairly recently 'Care Trusts' have been established. These are organisations that work in both health and social care. Local authorities can delegate health-related functions in order to provide integrated health and social care to their local communiities. Care Trusts may carry out a range of services, including social care and mental health services. There are presently just four Care Trusts in England, however discussions are underway to set up more in the future (Henderson and Knapp 2003).

General practitioners are reimbursed via contracts with the NHS. The conditions of the contract are negotiated between the 'General Medical Service Committee' and the DoH. Reimbursement is made according to a mixture of fixed allowances, capitation fees and fees for a number of specific services (Robinson and Dixon 1999). With respect to mental health care on the primary level, primary health care teams providing social services, voluntary sector services and independent sector services exist which are commissioned by PCTs.

Mental health care services which have not been delegated to NHS trusts may be commissioned by PCTs in collaboration with local authority and commissioning teams of health authorities. Table 13 summarises the different types of commissioning and provision of mental health care services.

Viewed from a longitudinal perspective, it has been argued that the spending on adult mental health care has increased slower than spending in the general health and social care (Sainsbury Centre for Mental Health 2003). Adjusting for the effects of pay and price rise, expenditure on mental health services are estimated to increase at less than half the rate of total spending in the NHS and social services over the two years 2002/03 and 2003/04. Despite its status as a priority service, the share of mental health budgets is falling. This causes considerable pressures on budgets the more so, as government targets and new policies are to be implemented requiring substantial amount of service redesign and re-organisation. Since there are no savings available, a transitional problem exits, as setting up new services would require some additional funding in the short run.

Furthermore, Bindman et al. (2000) have shown that the ratio of actual expenditure to initial allocation varies considerable between the different spending bodies. This suggests that, given the allocation process is equitable, resources are not necessarily invested in mental health care by purchasers and providers. Indeed, the authors found that areas with greater levels of need tend to spend less than their allocation on mental health services. It appears that the redistributive nature of the psychiatric index has not been drawn to the attention of purchasing bodies. "They may fail to spend resources in line with the $[\ldots]$ formula because it 
has never been suggested that they should do so. Even if the implications of the formula have become apparent, they might be reluctant to divert resources to psychiatry from high-profile acute services" (Bindman et al. 2000, 272). Since it is national policy that the use of local resources is at the discretion of purchasing bodies, this issue can only be addressed locally.

\begin{tabular}{|l|l|l|}
\hline \multicolumn{3}{|c|}{ Commissioners and providers of mental health care in the UK } \\
\hline \multicolumn{1}{|c|}{ Service } & \multicolumn{1}{|c|}{ Commissioners } & \multicolumn{1}{c|}{ Providers } \\
\hline $\begin{array}{l}\text { Mental health provision } \\
\text { in primary care }\end{array}$ & $\begin{array}{l}\text { PCG/Ts responsible to } \\
\text { health authorities }\end{array}$ & $\begin{array}{l}\text { Primary care team with } \\
\text { social services, voluntary } \\
\text { sector and independent } \\
\text { sector }\end{array}$ \\
\hline $\begin{array}{l}\text { Secondary and } \\
\text { specialised community } \\
\text { care }\end{array}$ & $\begin{array}{l}\text { PCG/Ts in collaboration } \\
\text { with health authority } \\
\text { commissioning teams }\end{array}$ & $\begin{array}{l}\text { Community mental } \\
\text { health trusts and a range } \\
\text { of voluntary and } \\
\text { independent providers }\end{array}$ \\
\hline Social care & $\begin{array}{l}\text { PCG/Ts in collaboration } \\
\text { with local authority and } \\
\text { health authority } \\
\text { commissioning teams }\end{array}$ & $\begin{array}{l}\text { Local authority services, } \\
\text { housing associations and } \\
\text { private and voluntary } \\
\text { sector }\end{array}$ \\
\hline
\end{tabular}

Table 13: Commissioners and providers of mental health care in the UK; Source: Stevens et al. $(2001,63)$

\subsection{Case-Study: Germany}

\subsubsection{Sources of Funding}

\subsubsection{Funding Mental Health Care Services within the Health Care System}

In the German system, from the selected core-services only hospital inpatient and psychiatric specialist services are covered within the health care system. With respect to health care system type, Germany belongs to the so-called 'Bismarckgroup' of countries where health care financing is based on social health insurance. Employers and employees have to pay mandatory 'earmarked' contributions into particular health insurance funds. Since the reforms in 1996, insurees have been free to choose between different sickness funds. With respect to freedom of choice between insurance funds, concern arose for two reasons, 


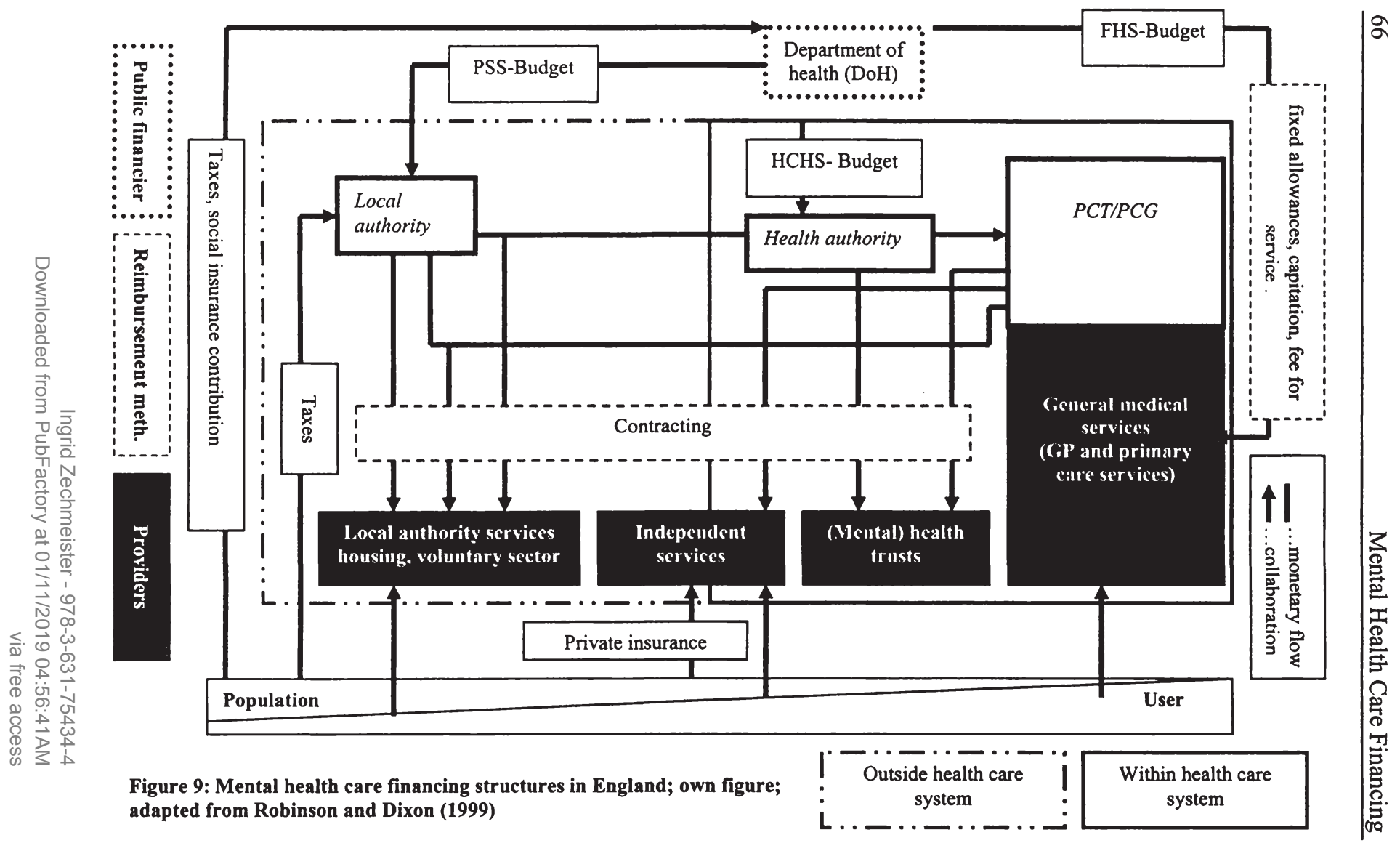


firstly, the lack of mobility of chronically ill between funds and, secondly, the disincentive funds had to provide high quality care. According to Dixon (2002), of the 1.2 million people who changed funds in 2000 only 800 were chronically ill. Although social health insurance funds in Germany are required to accept all applicants, they may participate in more covert forms of risk selection such as exclusive internet marketing, which may deter certain patient groups. Since January 2002, funds that offer better care have received higher allocation through the 'Risk Compensation Scheme' for every member enrolled in a disease management programme. However, it has been criticised that there has not been put enough attention to the specific policy impact for mentally ill persons.

Contributions to the health insurance funds represent a percentage of the income up to a certain income ceiling. Persons whose income exceeds this ceiling are free to opt for full coverage via private health insurance. Currently, approximately $9 \%$ of the population has a full-cover private health insurance. Another $9 \%$ have taken out supplementary private health insurance in addition to social health insurance. According to the Verband der privaten Krankenkassen (2002), in $2001,6 \%$ of the private health insurances' expenditure was spent on mental health care. Overall, in 2002 around two thirds of the health care expenditures were financed by social insurance resources. The contribution of private health insurances was $8.4 \%$.

In addition to the social and private insurance sources of health care, sources of funding are taxes which accounted for $7.9 \%$ in 2002 and, finally, private payments which covered a proportion of $12.16 \%$ of total health care expenditure (Statistisches Bundesamt 2002). In terms of private payments, co-payments have had a long tradition within the German health care system. With respect to mental health care, user charges particularly apply for inpatient care (fixed fee of $€ 9$ per day for maximally 14 inpatient days per year), rehabilitation services (fixed fee of $€ 9$ per day), prescription drugs (fixed fee of $€$ 4-5 depending on package size for each drug prescribed) and primary care services (fixed fee of $€ 10$ for visiting GPs or specialist psychiatrists). However, exemptions exist for persons under 18 years, for persons whose income is below $€ 500$ and the maximal amount of user charges is limited to $2 \%$ of the p.a. gross income.

In social insurance systems, entitlements to health care is theoretically related to contributions made, however, the German system has been driven towards near universal coverage including the unemployed, non-working relatives, or people living on welfare benefits. Yet, for people with mental health problems entitlement is restricted in another sense: Only persons with acute conditions are entitled to hospital care. Once, long-term needs are detected, people are excluded from health care system and shifted to the social welfare system, the financing mechanisms of which will be described below. 


\subsubsection{Funding Mental Health Care Services outside the Health Care System}

Several core-services of mental health care are not covered within the health care system in Germany. For the services under investigation, this relates to residential care. Furthermore, although MAPS (Sozialpsychiatrischer Dienst) legally belong to the health care system in some provinces, they are financed by different sources and methods which is why I also address them under 'outside the health care system'. It needs to be noted that for many services outside the health care sector legal responsibility rests with the provinces. Due to the federalist structure, details of financing arrangements can vary considerably between provinces (Länder) or even within provinces.

Sources for residential care depend on the type of residence. The main public sources of funding long-term care for the mentally ill in nursing homes are resources from long-term care insurance and tax based social benefits. Long-term care insurance is organised as a compulsory insurance system (Nam 2003a). Thus, people who are covered under the social insurance system in health care and their employers pay income-related premia into the social long-term insurance system. Persons with a private health insurance need to complete a contract for long-term care with a private insurer. Other residential care facilities, such as sheltered accommodation are financed via tax based social benefits. Like in the British case, utilisation of these services is usually subject to cost-sharing (Con_sens 2000). Furthermore, access to living arrangements depends on the grade of impairment which is assessed by a public medical officer. The system differentiates between two levels of impairment. The first level is related to a $30 \%$ reduction of physical, intellectual or mental functioning while on the second level ('severe impairment'), functioning is reduced by $50 \%$. Most services are limited to persons with at least $30 \%$ impairment.

MAPS are usually funded by a mixture of sources. Rössler (1992) provides an overview about these sources which include tax-based subsidies from provinces, tax-based resources from communities, shares from private non-profit organisations and in some cases taxes from specific federal programs. Until recently, a small proportion of funding used to come from health insurances. However, the introduction of 'Soziotherapie' as a new service element has resulted in 'earmarking' social security money for 'Soziotherapie'. This has reduced the resources for traditional activities of MAPS (Deutscher Berufsverband für Soziale Arbeit 2003). Additionally, some provinces have reduced their level of financing in the recent past and communities are expected to follow the same route. According to an expert in the field, the future existence of MAPS in Germany is rather at risk (Salize 2004). Overall, MAPS are entirely publicly funded, however, access is restricted to persons with severe mental illness only, as outlined in the directive of the German Social Ministry (Sozialministerium 2002). 


\subsubsection{Transfer of Funds and Resource Allocation Processes}

Available data from Germany do not allow for quantifying the resources which are allocated to mental health care. Nevertheless, allocation processes will be described in a qualitative manner. For an overview of monetary flows see figure 10. For services which are covered within the health care system, a fundamental characteristic in terms of resource allocation is the sharing of decision making between the federal government, the provinces and the social insurance bodies. Germany does not have one budget for funding health care, but there are several tax-based budgets and several hundred sub-budgets from sickness funds. Tax based budgets are determined by individual parliaments acting on a proposal from their respective government (Busse and Riesberg 2000). Health care funds do not have predetermined health budgets but budgets depend on total contributions, which in turn are related to contribution rates, employment rate and other economic parameters. Funds have to cover all the expenses of their insured members. Theoretically, if income does not match expenditure, contribution rates have to be adjusted. In order to avoid constantly rising contribution rates, sectoral budgets or spending cups were introduced. This measure should limit expenditure growth to the growth rate of contributory income. In contrast to the former case of the UK, budgets for hospital and primary care are mainly based on activity and historical patterns rather than on some kind of needs formulae.

Regarding hospital reimbursement, historically, reimbursement took place according to per diem flat rates which were paid in retrospect for each hospital. Over the last ten years several reforms have taken place which changed the reimbursement methods considerably. Since January 2004, reimbursement has taken place according to a diagnosis-related-group principle (DRG). This method links administered diagnoses with a prospectively determined lump sum of money which should reflect different costs for treating different diagnoses. However, psychiatric hospital reimbursement has been excluded from the DRG system. Thus, psychiatric hospital services are still reimbursed by a two-tier per diem system. It consists of a hospital-wide flat rate covering non-medical costs and a department specific charge covering medical costs (Busse and Riesberg 2000). The flat rate is based on calculations from the 'Federal directive on staffing in inpatient psychiatric services' (Psychiatrie Personalverordnung). This was introduced in 1991 in order to increase the number of personnel and, thus, quality of mental health care in hospitals (Aktion Psychisch Kranke 1998). The method calculates personnel needs according to the number and type of patients in an institution multiplied with a defined time requirement.

There have been discussions in Germany whether mental health care should be included into the DRG system in future. While there are proponents of the inclusion strategy, others have started to discuss an alternative reimbursement method which is based on the 'Federal directive on staffing in inpatient 
psychiatric services'. The idea is to generally allocate the 'psychiatric budget' according to results of the calculation. In other words, the criterion for resource allocation would be time and personnel requirements for different types of treatment and care rather than diagnoses (as in the DRG system).

DRG-fees and per diem fees are all part of the budget of the hospitals. However, these budgets are not budgets in the sense of prospective budgets. They are rather based on predetermined targets established in negotiations between the sickness funds and the hospitals. If the activity of the hospital is above or below the target, some financial adjustments are made.

Payment of specialist psychiatrists is subject to a two-tiered process of physician reimbursement. The physicians association receives an overall budget based on capitation which is distributed to the members of the physician association according to a 'Uniform Value Scale'. At the end of each quarter physicians invoice the association for the total number of service points delivered (Busse and Riesberg 2000). Actual reimbursement is subject to several controlmechanisms which should prevent excess utilisation and false claims.

Resource allocation of taxes for services which are covered outside the health care system is primarily based on political negotiations and historical spending patterns and is, thus, subject to the public budget process. Long-term care insurance benefits are allocated according to the person's needs. However, unlike the health insurance, long-term care insurance benefits are restricted to a maximum level. Cost differences and 'hotel costs' have to be borne privately or may be borne by social assistance after means testing (Nam 2003a). Furthermore, reimbursement for mental health services outside the health care system varies considerably between the regions. The most common reimbursement method for MAPS and residential arrangements are annual public subsidies and daily flat rates respectively.

Apart from these general financing arrangements some new forms of financing have been introduced on an experimental base in Germany. Firstly, in some regions, people are allocated a 'Personal Budget' (derived from tax based social assistance sources). In some cases people can spend the money completely freely and need not necessarily buy professional services. In other areas, the arrangement resembles a 'voucher principle' where people receive a cash benefit which is valid for using services from accredited service providers and, thus, allows them to choose freely between different service providers (Hagelskamp 2004; Schröder 2004). Usually, the overall service package involves different service elements from various providers. The level of the personal budget is based on an individual needs assessment procedure (Krüger and Kunze 2004). In some cases the level of the budget is determined by multiplying the individual service needs (expressed in professional caring hours) with the wages/hour from the cheapest service provider. This has been termed 'cold benefit in kind' (kalte Sachleistung) 
(Speicher 2004). Overall, this financing model demonstrates a shift from benefit in kind to cash benefit.

Secondly, a 'Regional Budget for Clinical Psychiatry' has been introduced on a 5-year project base in the region of Schleswig-Holstein. The budget integrates sources from all health insurance funds in the region in a 'Managed Care ${ }^{17}$, approach. The size of the budget is based on historical spending patterns for hospital mental health care and outpatient mental health care according to the number of treated patients. The aim of the regional budget is to allow a more flexible choice between various treatment settings which include 'inpatient care', 'outpatient care' and 'medical home treatment' in the first stage. In the long run the goal is to reduce hospital care and, additionally, to reduce costs (Deister, Zeichner and Roick 2004). The project is being evaluated and may be extended to covering the whole range of mental health care services and payers in a second phase.

\subsection{Case-Study: Austria}

Similar to the former two countries, the financing structures of the Austrian mental health care are complex (figure 11). In resemblance to Germany, legal competence for services covered outside the health care system mainly rests with the provincial levels. Hence, differences in financing structures between the provinces occur. Where this is the case, the situation in the province of Lower Austria will be referred to. In terms of types of services, the portrayal will be slightly more detailed than the previous ones as it is the Austrian situation which will be paid primary attention to in the remainder of the thesis.

\subsubsection{Sources of Funding}

\subsubsection{Funding Mental Health Care Services within the Health Care System}

From the services under investigation, hospital inpatient care and psychiatric specialist services are covered within the health care system. Additionally, the Austrian description will include psychotherapy which is also attributed to the

\footnotetext{
17 'Managed Care' is a management concept for health care system which transfers leadership and control to payers (Arnold, Lauterbach and Preuß 1997).
} 


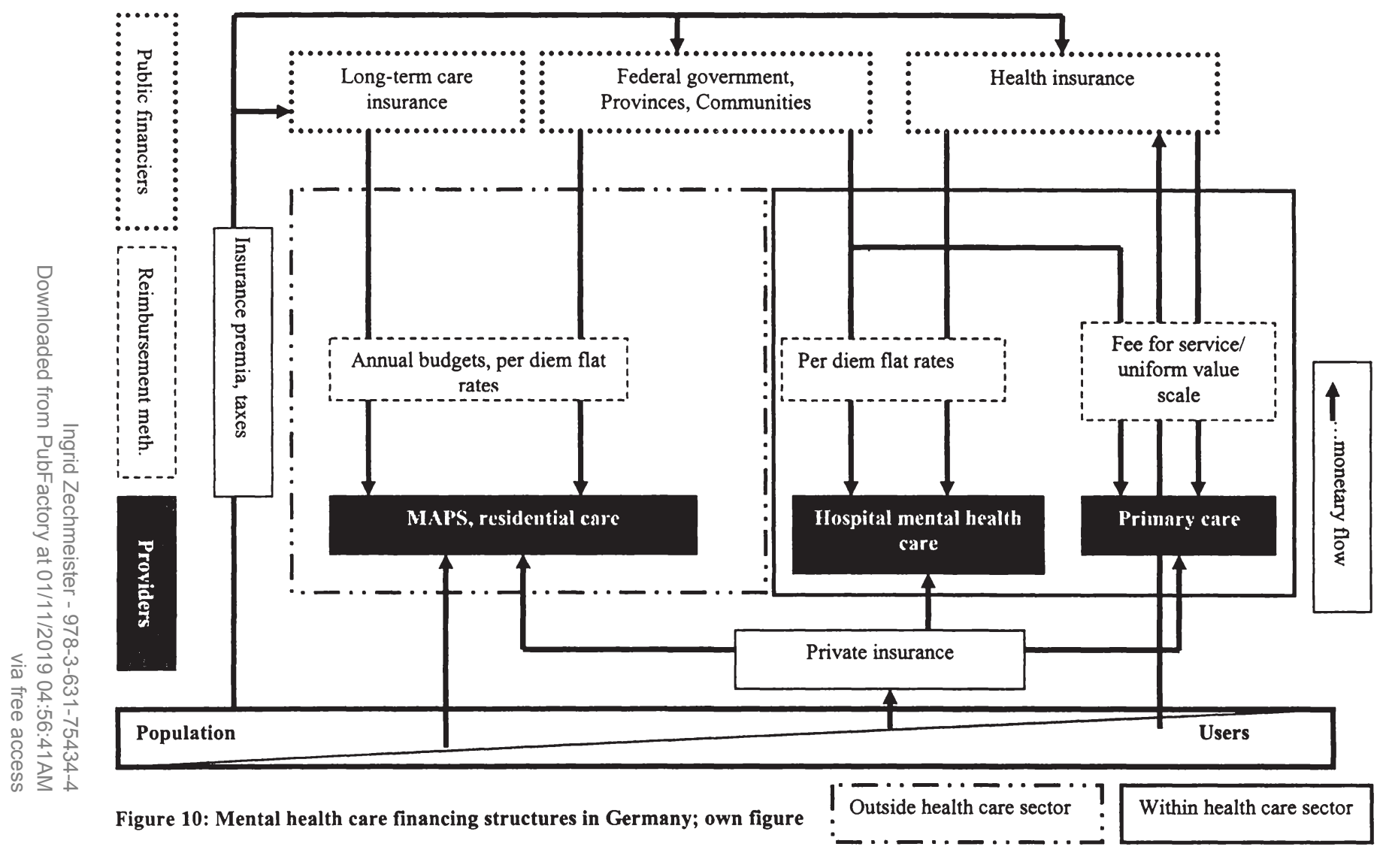


health care system. Like Germany, Austria belongs to the so-called 'Bismarck group' of countries where health care financing is based on health insurance. Austrian employers and employees as well as the self-employed and pensioners have to pay mandatory 'earmarked' payments into particular health insurance funds. Yet, in contrast to Germany, the number of existing funds is considerably lower. In Austria, these funds finance about $42 \%$ of the health care system, with most of the rest coming from tax funds invested by the federal and provincial governments $(27 \%)$ and from out-of-pocket payments $(30 \%)$ in the form of copayments (e.g. prescription fees, daily flat rates for hospital stays), private payments for certain services (e.g. private specialist psychiatrists), or private insurance. Private insurance takes a complementary form in Austria. Nevertheless, private insurance coverage is rather high with around $32 \%$ of the population covered in 1999 (Badelt and Österle 2001). In the year 2000 overall expenditure for health care in Austria came to $8.2 \%$ of GDP (OECD 2002). While public expenditure is on the decline (corresponding to $67.3 \%$ of total health care expenditure in 2001), private expenditure has risen over the last years with an average annual increase of $4.5 \%$ since 1997 (Hofmarcher and Röhrling 2003).

Similar to Germany, the premium for Austrian health insurance funds is adjusted to one's income level up to a certain income ceiling and it is independent of the payer's health status. Moreover, access to health care and the type of service to which individuals are entitled bear no relation to the premium paid. However, unlike Germany, people cannot choose between insurance funds and opting out to private insurance is only possible for a very small minority of the population. Nevertheless, eligibility to health care is organised similarly to Germany. It depends strongly on the definition of illness according to the 'General Social Security Act' (Allgemeines Sozialversicherungsgesetz, ASVG) which takes a curative approach (Resch 2001). Thus, the potential for cure via medical intervention is the prerequisite for service payment by the health insurance fund. By implication, mentally ill people who develop chronic illnesses are excluded from the health insurance system.

\subsubsection{Funding Mental Health Care Services Outside the Health Care System}

In contrast to medical services, responsibility for residential care and MAPS rests with provincial governments whereas for employment related services (which are also included in the Austrian case study) it rests partly with the provincial and partly with the federal government. The legal basis of the former is constituted by provincial 'Social Assistance Acts' (Sozialhilfegesetze) which stipulate that financing of social services is based on the principle of subsidiarity. For the provision of several services, pensions and long-term care allowances, according to the 'Federal and Provincial Long-Term Care Allowance Acts' (Bundespflege- 
geldgesetz, Landespflegegeldgesetze) are the primary source of financing. The difference with respect to full coverage of costs is financed via taxes, and may in retrospect be re-covered from the private savings of clients and of close relatives. The laws allow a rather broad interpretation which results in a considerable variety as to the implications for individual patients even within the same province (Pfeil 2001). Mental health care services which are funded via these financing arrangements are nursing homes and other forms of residential care. MAPS, on the other hand, belong to the very few specific social services which are entirely publicly funded. In these cases the financier is the provincial government using tax-money. For employment related services (which are publicly funded) financiers are the federal and the provincial government, the employment insurance fund and the supranational European Social Fund. Current availability of data does not allow for a quantification of total funding for mental health care. To get a rough overview of overall social care expenditure for social services and living arrangements, in 1998 from 1.4 billion $€$ gross expenditure by provinces, private payments made up 481.1 million $€$ which corresponds to $34 \%$. In 2001 , the private share was $37 \%$, rising to $39 \%$ in 2002 . In total, private payments in 2002 accounted for 698.1 million $€$ (Statistische Nachrichten 2000; Statistische Nachrichten 2004).

\subsubsection{Transfer of Funds and Resource Allocation Processes}

Like in Germany, resource allocation within the health care system is separated between hospital and primary care. In the 1997 reform, central provincial institutions were established in each of the nine provinces which are allocated a prospectively determined global budget for financing all publicly funded hospitals. All public financiers pay into these provincial funds (in Lower Austria the 'Niederösterreichischer Gesundheits- und Sozialfonds/Bereich Gesundheit'). Around $40 \%$ is covered by the health insurance funds in the form of a prospectively determined flat rate which is based on the annual growth rate of social insurance income. In addition, predetermined payments are made by the federal government, the local governments and the communities via turnover taxes. Their contribution is determined legally as a fixed percentage of tax income. The procedure for negotiating overall aggregates of the hospital budget is linked with the periodic negotiations on intergovernmental transfers between the federal government and the provinces (Hofmarcher and Rack 2001). Any hospital-deficit which arises due to expenditure that exceeds the allocated budget is borne by the providers. Thus, the hospital reform has transferred the financial risk from the payer to the provider. Since provinces and communities are major providers of hospital services, they often have the final financial responsibility.

The reimbursement of providers is organised in rather variegated fashions. Hospitals are reimbursed via a diagnosis-related hospital reimbursement system 
(Leistungsorientierte Krankenanstaltenfinanzierung). It was introduced in 1997 in order to limit further increase in costs and replaced the retrospective reimbursement that was based on flat rates per day. In the Austrian DRG-system, hospitals 'earn points' for every diagnosis they administer and some specific specialised services they provide. The monetary value of each point is determined in retrospect and depends on the total points earned by all hospitals in a province. In contrast to Germany, psychiatric hospital interventions are reimbursed via the DRG system.

According to the Austrian audit court (Rechnungshof 1998), total costs for hospital mental health care accounted for around 291 million $€$ in 1990 and rose to roughly 400 million $€$ in 1995 . In other words, costs for inpatient care rose by $37.5 \%$ between 1990 and 1995. The average cost per beds accounted for around $33,430 €$ in 1990 and rose to $81,394 €$ in 1995 which reflects an increase of more than 70 percent (table 14). In relation to the overall expenditure for health care, mental hospital care costs accounted for around 3\% of the total health care expenditure in 1995. In addition to the general Austrian situation, data from the province of Lower Austria show that the amount of money which was allocated to hospital mental health care in 1999 has been estimated to roughly 32.3 million $€$ (figure 14).

It needs to be noted that none of these figures include expenditure for those people with a psychiatric diagnosis who were treated in non-psychiatric wards. As Katschnig et al. (2001) have shown, these patients account for a rather high proportion of discharged persons. For example, in 1997, almost half of the persons with a psychiatric diagnosis were discharged from non-psychiatric wards in Austria. Thus, actual expenditure for hospital mental health care will in fact be considerably higher than the figures presented.

\begin{tabular}{|c|c|c|c|c|}
\hline \multicolumn{5}{|c|}{ Costs for hospital mental health care $1990-1995$} \\
\hline & 1990 & 1994 & 1995 & $\begin{array}{c}\text { Increase } 1990 \text { to } \\
1995 \text { in } \%\end{array}$ \\
\hline $\begin{array}{l}\text { Total cost (in } \\
\text { million } € \text { ) }\end{array}$ & 291 & 385 & 400 & 37.5 \\
\hline $\begin{array}{l}\text { Cost per bed } \\
\text { occupied (in } € \text { ) }\end{array}$ & 33,430 & 74,126 & 81,394 & 72.3 \\
\hline
\end{tabular}

Table 14: Costs for hospital mental health care 1990-1995; Source: Rechnungshof (1998)

For General Practitioners (GPs) and psychiatric specialists who usually work in solo practices, separate regulations exist. Negotiations on a corporatist basis are 
the common norm. The medical association and the health insurance funds agree on fees for those GPs and specialist doctors who are in a contractual relationship with the health insurance funds. Remuneration follows a mixed reimbursement system with a combination of flat rates and fee-for-service. For services rendered by private, non-contract specialists patients pay on an out-of-pocket basis and are partially refunded by health insurance funds or private insurance (Hofmarcher and Rack 2001). While figures of total expenditure for primary mental health care treatment by psychiatrists and general practitioners are not available, costs for medication show at least a proportion of the expenditure. Between 1995 and 2002, the total number of prescriptions which concerned psychotropic medication paid for by health insurance rose from 4.77 million to 6.5 million prescriptions (or $7 \%$ of all prescriptions) (figure 11). In 2002, they cost 167.3 million $€$ and accounted for $9.4 \%$ of total public drug expenditure. Then, over $50 \%$ of the prescriptions were for antidepressants, less then $25 \%$ for tranquilizers and $15 \%$ for antipsychotics. Prescriptions for antidepressants and antipsychotics have risen while costs for tranquilizers are on the decline (BMFG 2003) (figure 12). Antipsychotics accounted for one quarter of the total costs. On the contrary, tranquilizers, making up $25 \%$ of prescriptions, accounted for only $4 \%$ of the costs. In total, in 2003 costs for psychotropic medication were three times higher than in 1995 (Katschnig, Denk and Scherer 2004).

Psychotherapy has, until recently, been mainly privately financed by patients. They have been able to apply for a partial refund ( $21.80 €$ /hour of therapy; $5.09 €$ for a group therapy session) from the social insurance. Over the last years, a variety of financial arrangements for publicly funded psychotherapy has been established on provincial level with the social insurance bodies and the provinces being the public funding bodies. Contracts differ considerably between the nine provinces and resource-allocation as well as selection of patients are intransparent (Zechmeister, Meichenitsch and Hagleitner 2004). A recent study shows that there exist seven different types of financing arrangements in Austria (ÖBIG 2004). Resource allocation and reimbursement arrangements are, thus, subject to individual negotiations between providers and financiers. Consequently, access to services for users varies considerably.

In 1999, social insurance expenditure for psychotherapy services was 27.3 million $€$. Two third (17.4 million $€$ ) from those were paid in the form of partial refunds and around 9.9 million $€$ were allocated to full-cost funded psychotherapy provided either by medical doctors ( 4.3 million $€$ ), by provincial organisations (4.6 million $€$ ) or by ambulatories owned by the social insurance fund ( 1 million $€$ ) (Katschnig et al. 2001). Financial resources from health insurance slightly increased to roughly 28.8 million $€$ in 2001 (ÖBIG 2004). Furthermore, public resources for provincial organisations were estimated to roughly 12.21 million $€$ in 2003. Nevertheless, despite rising public expenditure for psychotherapy, these make up only around one fifth of the expenditure for pharmacotherapy. 


\section{Prescriptions of psychotropic medication 1995-2002}

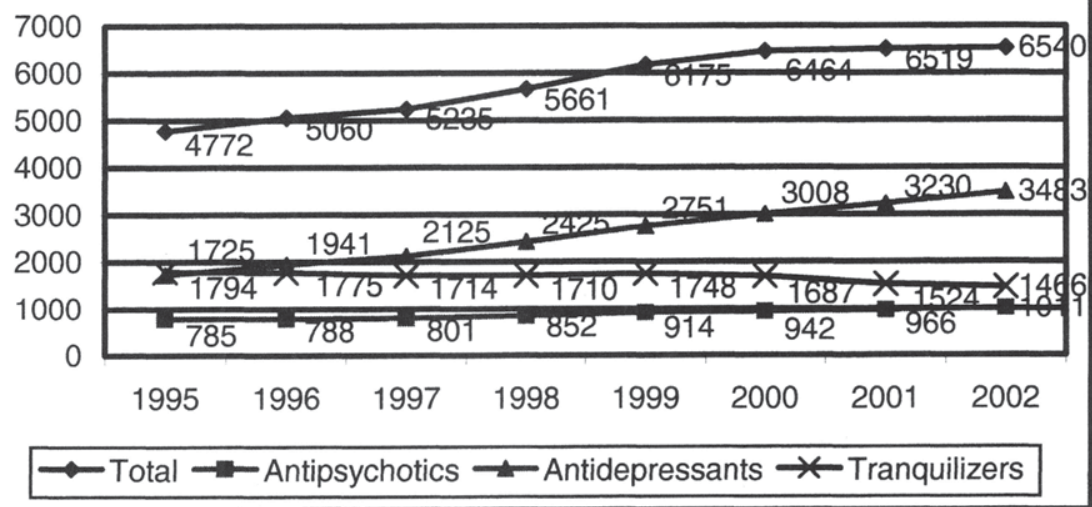

Figure 11: Prescription of psychotropic medication 1995-2002; Source: BMFG (2003)

Costs of out-patient prescriptions of psychotropic medication 2002 by type of medication, $100 \%=167,331 €$

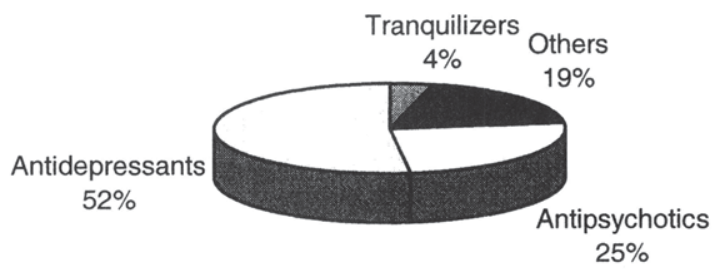

Figure 12: Costs of outpatient prescriptions of psychotropic medication 2002 by type of medication; Source: BMFG (2003) 
Compared to public expenditure, private expenditure is rather high for psychotherapy services. In 2001, overall private expenditure was estimated to approximately 47.5 million $€$. This is more than 1.5 times higher than total psychotherapy expenditure by the social insurance funds (ÖBIG 2004).

As it has been outlined earlier, residential care and MAPS are financed via the social care system where responsibility rests on the provincial level. The total amount of resources allocated to the services varies between the nine provinces and is usually subject to annual public expenditure planning processes. Negotiations are mainly based on former costs and activity. Mental health care plans which have been established in all of the nine provinces serve as an additional basis for negotiations. For example, in Lower Austria extension of MAPS including their scope of financing is based on the 'Lower Austrian Mental Health Care Plan'.

For financing social care services in Lower Austria, the provincial 'Social Care Fund' (Niederösterreichicher Gesundheits- und Sozialfonds/ Bereich Soziales) acts as a counterpart to the provincial 'Health Care Fund'. However, financial flows are much more complex in social care (see figure 14). For each type of social service provision there are specific funding mechanisms that result in segregated monetary flows. Hence, the role of the provincial 'Social Care Fund' as a central institution for resource distribution and allocation for social service providers has so far been rather marginal. Major regulatory competence rests with different departments in the provincial government. Quantitative figures on resource allocation can only be roughly estimated. According to figure 14, the highest amount of money has been allocated to public nursing homes (160.4 million $€$ ), followed by other forms of residential care (23.4 million $€$ ) and MAPS/crisis phone (547,672 €). However, it needs to be taken into account that the public share from provinces and communities for public nursing homes and other forms of residential care is much lower in reality, as the figure includes private sources from the users. Furthermore, with respect to nursing homes the figure shows gross expenditure for all nursing home residents, because a separation between mentally ill and other residents in terms of expenditure is not possible. Consequently, the figures overestimate factual public expenditures for these types of mental health services.

As with the overall resource allocation, considerable provincial variations exist with respect to reimbursement of services. In Lower Austria, nursing homes are reimbursed via flat rates per day and expenditure is then recovered from residents and close family members. Other types of residential care, such as staffed group homes or sheltered housing as well as day structure centres are financed via flat rates per patient and year. MAPS, on the other hand are financed via annual budgets. Finally, services promoting employment and labour market integration are funded via a combination of annual budgets and subsidies from the federal and provincial governments and by the Labour Market Service (Arbeitsmarktservice) 
(Zechmeister and Österle 2001). Not least, recently, performance based contracting between private providers and public payers have become an increasingly prominent issue in the financing discussions. Equally to the UK, this means that resources are allocated according to the results of negotiations between providers and the public payers. Concluded contracts stipulate the quantity and quality of services that are to be provided (Schneider and Trukeschitz 2003).

\subsection{Conclusion}

This chapter has provided descriptive data on mental health care financing in Western Europe with some detailed information for Austria, Germany and the UK. It has been shown that financing arrangements for mental health care services are rather complex involving various actors and being based on different regulations. Furthermore, it has been demonstrated that mental health care financing displays a different pattern than that found in the health care sector overall. The main reasons for that are the special characteristics of mental illness which require provision of several core-services of mental health care outside the health care sector or which have led to specific financing regulations for mental health care services within the health care sector. Compared to somatic illness, financing of mental health care is often related to another government level where revenues for financing are raised or administered and/or to a different share of funding for payers. Additionally, resource allocation and reimbursement methods in mental health care differ from those of general health care either because specific methods have been determined for mental health care or simply because processes of allocation and reimbursement outside the health care sector are different from those within the health care sector. The chapter has also shown that exact quantitative data are not always available. Especially the Austrian data illustrate rough dimensions of financing rather than correct figures. Concerning qualitative dimensions, information on financing regulations for services within the health care system has been available in more detail than for those outside the health care system where the regulations often vary between different regions within one country.

In the following chapter the focus shifts to reform processes and reform objectives and attempts to analyse the broader reform discourse within mental health care planning initiatives with a focus on the Austrian situation. The results will be linked with the empirical data on financing from this chapter in the final analysis in chapter 6 . 


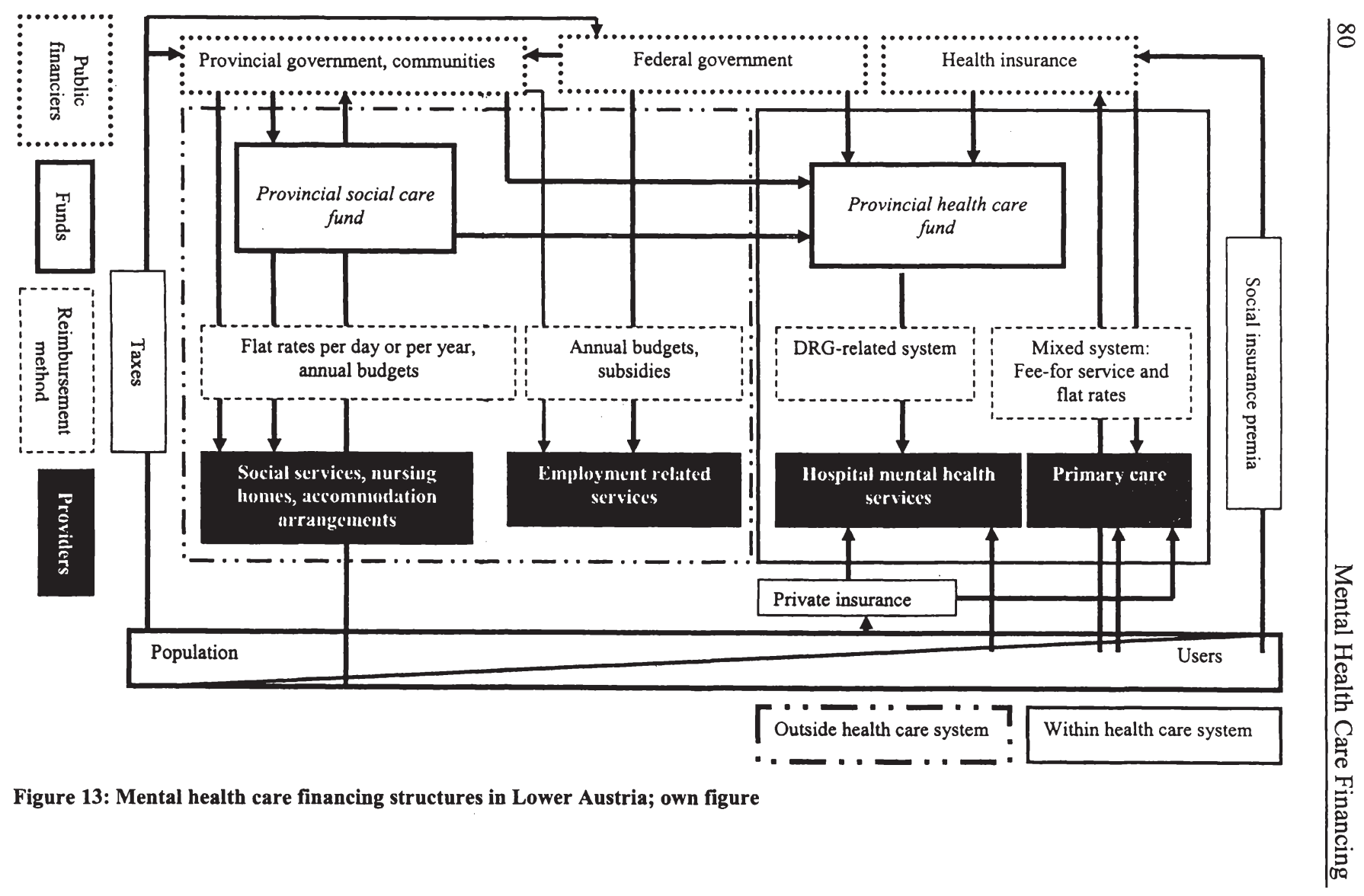



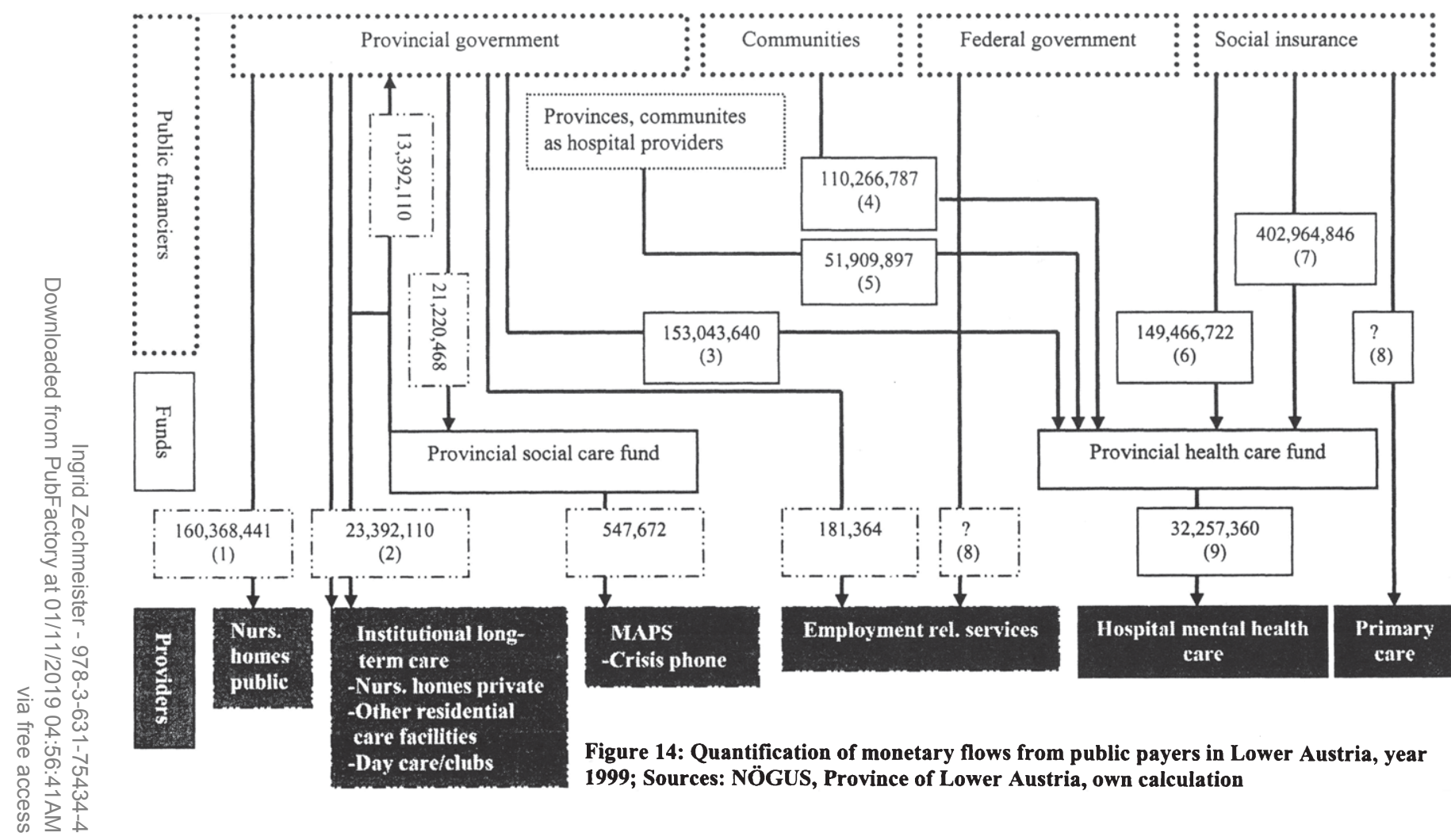

hospital providers

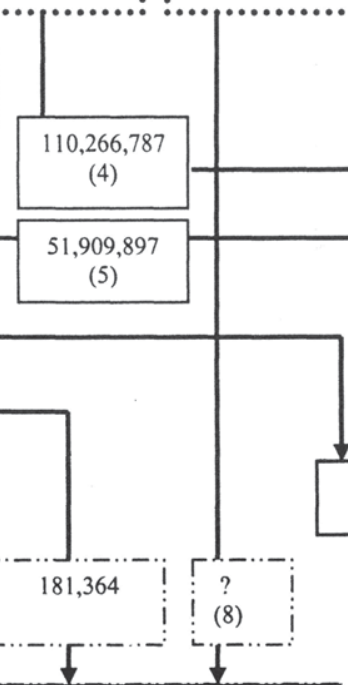

\section{MAPS \\ -Crisis phone}

Employment rel. services

Hospital mental health care

Primary care

Figure 14: Quantification of monetary flows from public payers in Lower Austria, year 1999; Sources: NÖGUS, Province of Lower Austria, own calculation 
Legend to Figure 14

1) Amount for total number of residents including private payments (amount for mentally ill only and for private proportion not available)

2) Amount includes private and public sources (private proportion not available)

3) Legally determined sources from provinces

4) Legally determined sources from communities

5) Sources from hospital providers including deficit spending

6) Legally determined federal sources

7) Legally determined social insurance sources

8) Amount not available

9) Calculated, according to administered LKF-points; amount only includes treatment in mental hospitals and in psychiatric departments in general hospitals; figures for treatment of people with diagnosis of mental illness in other departments not available

Health Care System 


\section{Paradigm Shift in Mental Health Care: An Exploration of Mental Health Care Reform Objectives and Reform Processes}

\subsection{Central Features of Change from an International Perspective}

From the middle of the $19^{\text {th }}$ century onwards, institutional systems for the mentally ill had grown rapidly. As a consequence, large asylums with sometimes several thousand hospital beds dominated the psychiatric landscape (Goodwin 1997). With the exception of the Second World War-period where thousands of mentally ill people were killed or died due to starvation, growing institutionalisation lasted for around one century until the 1950s, when mental hospital bed space reached a peak in the majority of countries. Since the 1960 s, across Western Europe and North America major changes in mental health services have taken place. The reforms have been characterised by two significant features of change. Firstly, there has been a shift from centralised care to decentralised service provision. Secondly, institutional and asylum-based care have been substituted by or have at least been supplemented with non-institutional services which has been termed deinstitutionalisation. These procedures can be summed up under the term 'community mental health care'. Put differently, the objective has been to provide acute and long-term care on the community level, preferably in non-institutional settings. As shown in the Austrian example in chapter 3, a variety of facilities such as residential homes, day structure centres, mobile treatment services and services to support employment have been established. Usually, these settings are run by multidisciplinary teams.

Overall, these processes had substantial consequences for patients. Lengths of hospital stays have decreased and treatment and/or care have partly been undertaken in non-hospital settings or in psychiatric wards in general hospitals. Although hospital beds have been reduced significantly, in many cases overall hospital admission rates have risen sharply due to higher turnover-rates and increased voluntary admissions (Goodwin 1997). Principally, decarceration has been a universal process, yet substantial variations within that process can be identified across countries which has resulted in different forms and characteristics of community care systems (Fakhoury and Priebe 2002). Thus, in several countries, such as the UK or Italy, the systematic establishment of community services has been paralleled by reducing the number of hospital beds considerably (Rothbard and Kuno 2000). There is some different evidence, for example from the Netherlands, that the shift to community care has been accompanied by a considerable expansion of mental health care, since community-based care 
increased several times more than hospital-care was reduced. Empirical data have shown that the increase of services is mainly due to increased treatment of new and less severely ill persons (Pijl et al. 2000).

Despite numerous reform activities, deficiencies are still reported. In several countries, for example in Germany or in Austria, rather than deinstitutionalisation, transinstitutionalisation of former long-stay patients into nursing homes has taken place (Forster 2000). For example, it has already been shown in chapter 3 that mentally ill persons account for a high number of nursing home residents in Lower Austria. Equally, in Germany, especially until the 1990s, many discharged patients were transferred into nursing homes. According to Cooper and Bauer (1987), in the mid-1980s, there were around 50,000 to 60,000 people with mental problems to be found in nursing homes. A more recent survey has estimated that officially approximately $16 \%$ of places in nursing homes are occupied by mentally ill persons. Yet, in reality the figure is likely to be much higher (Von Cranach 2000). Additionally, people were transferred to other types of institutions. For example, Rössler et al. (1994) showed that parallel to the decrease of beds in mental hospitals, there was an increase in 'drug abuse hospital beds' which are predominately supplied by private and voluntary providers.

Additionally, evidence has shown that in some areas deinstitutionalisation has affected access to acute hospital care (Wilson 2000). Major deficiencies have, moreover, been reported with respect to co-ordination of services and services for people with multiple needs (Bundesministerium für Gesundheit 1996 and 1999).

In addition to broader structural changes, the new philosophy of care also implied a shift to a more individualised type of care. While at the beginning of the reform the focus was very much on providing alternative and different service elements, more recent discussions have stressed that rather than the servicestructure, the individual person in need should be put at the centre of interest. This development can be described as a shift from supply-oriented to person-oriented or needs-based mental health care (Bundesministerium für Gesundheit 1999).

For explaining the policy shifts, different factors of explanation have been identified. According to Goodwin (1997), existing explanations can be classified into orthodox and radical accounts. The orthodox view, which stresses the positive and beneficial aspects of the reform process, explains the shift with pluralistic arguments. Common explanations are the developments of new types of treatments, the development of the sub-discipline of social psychiatry combined with the anti-psychiatric movement, poor conditions within old asylums and increasing community tolerance as well as institutional structures and funding arrangements which provided an incentive for community care. Radical writers have focused on a more general nature of social and economic arrangements and their possible implications for mental health policy. In their view, the emergence of community care is the result of measures to cut public costs and to reduce deficit spending. Additional attention has been paid to the relation between 
unemployment and deinstitutionalisation where, for example, high demand for labour was found to correlate with early onset for deinstitutionalisation (Warner 1994).

These results indicate that there are no mono-causal explanations for reform processes and the related policy shift. Instead, we can identify complex transformation processes which have been influenced by dialectic interplays between structures and actors. In the following part, I will focus on the Austrian policy context where recent reform processes and main characteristics of the changes will be analysed. Rather than finding causal relationships and factors of explanation for why changes have taken place, the aim is to improve the understanding of the complexity of ongoing processes, patterns and trends and to draw a rich picture of the Austrian case, in particular of the reform objectives and their embedding in broader socio-economic transformation processes.

\subsection{Mental Health Care Reform and Reform Discourse in Austria: A Critical Discourse Analysis}

\subsubsection{Rationale}

Objectives and trends in Austrian mental health care reform initiatives have been similar to those in other countries. Hence, establishing a community mental health care system is the broad tenure within reform initiatives throughout the country. While core aims of the reform seem to be clear and identical in different Austrian provinces, a closer look at reform documents shows ambiguities and differences. This is particularly the case for key terms used where, at second glance, documents lack consensus and clarity concerning definitions of terms and concepts and, subsequently, concerning perceptions of the status of actors within the system. From a financing point of view, this raises difficulties for discussing financing questions. In other words, if it is not known exactly what various key concepts of mental health care mean, it will become a tricky task to discuss ways and modes of implementation and financing. This initial situation is one reason why it was found to be important to carry out an analysis of reform objectives. However, apart from this rather technical appearing problem, drawing attention to discourse was found to be important in another context. That is to say that controversies and ambiguities are not only mirroring a terminological dispute but that discourse in psychiatric reform has a deeper significance: Health or social care reforms are inevitably linked with structural and/or legislative changes which, in turn, have various implications on the individual and on the macro-level of a health care system. Not least they impact on the power and authority of institutions and individuals and their associated interests. Hence, those reforms are 
political processes even if this is not always obviously observable. As the given case shows, although implementation of mental health reform goals are accompanied with substantial changes, the subject has hardly appeared on the social policy agenda in general, nor on the financing agenda. In that respect, reform documents and their inherent discourse as well as the overall reform discourse and the actors involved become a significant source for analysing the political dimension of the reform processes. Analysing mental health care reform through that lens means that various implicit links to financing questions will be identified, not least because any social-policy agenda is eventually a budgetary, hence a financing agenda. The underlying assumption is that reform aims and objectives as well as the discourses of actors is partly explicitly, but even more often implicitly linked with financing issues. It is assumed that through deconstructing the reform agenda, both, obvious and more subtle links between reform and financing aspects should become transparent. This is of even more interest, as mental health care plan development falls within the period of substantial restructuring processes in the Austrian welfare state and considerable changes in economic policy. Taking these considerations into account, it was decided to approach questions of mental health care financing with an in-depth analysis of the Austrian reform discourse and the recent reform processes.

The overall goal of this research design is twofold. Firstly, the research activity should enhance the understanding of mental health care reform processes and reform objectives within a broader historical and political-economic context. Herein, it should particularly make clearer the changing role and status of actors within the welfare state as reflected through discourse. Secondly, the analysis should make visible the contexts and modes of argumentation and its significance for issues of mental health care financing. This means that the focus of the analysis will continuously shift from the actual contents of empirical material to a broader socio-political and economic discussion aiming at eventually addressing relevant questions of mental health care financing.

\section{Excursus:}

\section{Theoretical and Methodological Considerations of a 'Critical Discourse} Analysis'

The following analysis will be approached via a so-called 'Critical Discourse Analysis' (CDA). The method applied is based on the definition of CDA suggested by Fairclough (1995), who distinguishes sharply between CDA and 'Critical Linguistics'. CDA, in a Faircloughian sense (1995), is an analysis of discourse from a sociological and philosophical perspective and as such, not only considers the actual language of discourse, but also text interpretation and text production processes as well as the overall context where the discourse is 
embedded. The approach seems to have some elements in common with the discourse theoretical strand defined by Laclau and Mouffe, who emphasise that discourse analysis goes beyond the linguistic level and who particularly address the socio-political level (Torfing 1999). On the whole, at the centre of interest are not only manifest contents as they appear in texts, but the analysis is also concerned with reality beyond language, in particular with the economic and political reality which is manifested in the texts. The central consideration underlying this approach is that texts are sensitive indicators of social processes and vice versa also shape social processes.

As Meyer (2001) points out, theoretical components of different origin have been adopted for CDA. In that respect, CDA works eclectically and is not based on a strict normative theoretical framework. Hence, prior to the empirical analysis it is required to outline the theoretical construct which will guide the analysis. Firstly, as 'critical' in 'Critical Discourse Analysis' suggests, the method implies a critical dimension. The critical approach can be traced back to influences of the Frankfurt School and Jürgen Habermas's claim that language is a medium of domination and social force which serves to legitimise relations of organised power (Habermas in Wodak 2001). CDA is therefore based on the thoughts of 'Critical Theory'. Weiss and Wodak $(2003,2)$ have put it this way: "This approach [CDA] is essentially based on a critical-dialectic concept of theory that is not limited to formulating and examining general statements about the laws of social reality." Critical evaluation in CDA focuses on how social identities, roles, attitudes and value systems are transported via discourse, whilst users of discourse are not necessarily conscious of those processes.

At the heart of the CDA-approach are the concepts of 'power', 'history' and 'ideology'. Roughly speaking, CDA is conducted with the notion that "discourse is structured by dominance, that every discourse is historically produced and interpreted ... and that dominant structures are legitimated by ideologies and powerful groups" (Wodak 2001, 3).

Concerning the concept of 'history', CDA pays particular attention to social changes as triggers of discourse changes and vice versa. These changes are usually gradual processes. For example, people do not abruptly begin using certain terms but new terms slowly replace other terms, with replacement taking place consciously as well as unconsciously (Herles 1996). Of vital interest for the analysis is that any changes in discourse take place within existing power relations, be it within an institutional context or within a broader political or societal context.

The definition of the term 'discourse' in CDA is not to be understood in its broadly used meaning of 'conversation'. Rather, the etymological origin of 'discourse' can be traced back to the Latin term 'discursus' meaning 'moving away, moving back and forwards' (Nünning in Bargetz 2002). In Habermas's sense discourse can be illustrated as the locus of constructive and public debate 
and, in Foucauldian terms, as an element of power-relations and even as an instrument of repression (Foucault 1991; Habermas 1977). Jäger (2001, 34) has further exemplified discourse as "the flow of knowledge - and/or all societal knowledge stored - throughout all time, which determines individual and collective doing and/or formative action that shapes society, thus exercising power." Although focussing on different levels, what these definitions have in common is that they indicate the mutual link between text, conversation or communication and the societal, the political or the cultural sphere. Thus, discourse is not only 'talking about different issues', but discourses also create and construct issues as much as these issues construct the discourse itself. Importantly, at this point the central concepts of 'ideology' and 'power' come into play.

The relationship between language and ideology can be traced back to thoughts by Althusser and Pecheux (Wodak 2001). However, while for Althusser and Pechaux discourses are the result of deterministic and separate elements of hegemonic formations within the public state (Hauck 1992), others have integrated the relationship between language, power and ideology within a more dialectic theoretical framework. This can also be regarded as an attempt to shift from structuralism to a more constructionist and relationist perspective (Torfing 1999). Fairclough (1995), whose approach is followed here, has incorporated the Gramscian concept of hegemony with its central characteristic of integrating economy, politics and ideology. Hegemony, in a Gramsican sense, is a mode where those who are in power gain common consent within society including suppressed or discriminated groups or individuals (Eagleton 2000). This is based on the consideration that specific 'Weltanschauungen' are becoming the collective will and are, thus legitimated within society as a whole. Thus, ideology works through becoming 'naturalised'. It is, consequently, left increasingly unquestioned because it becomes invisible. Hegemony, therefore, extends structuralist concepts of ideology to the notion of ideology as collective habit of social practice (Eagleton 2000, 136). As Torfing $(1999,27)$ quotes Gramsci: "Hegemony is won, when the ruling class has succeeded in eliminating the oppositional forces, and in winning the active or passive consent of its allies, and thereby has managed to become a state." Hegemony is sustained via culture, politics and economy including non-discursive and discursive practices. In that respect, the concept of hegemony is linked to the concept of discourse.

CDA investigates the mutual relationship between extra-discoursal structures and discourse, thereby aiming at dismantling taken-for-granted knowledge. It goes on the assumption that each discourse contains a specific knowledge base which in turn embodies certain ideologies. Concerning mental health care reform documents, for example, the reform objectives stated are based on certain assumptions about the nature of medicine, the social roles and identities of mentally ill persons, etc. However, rather than reading off ideologies from the text 
directly, the emphasis is on evaluating the imprints that ideological processes have on texts. Nonetheless, as Fairclough $(1995,82)$ emphasises, "this does not...imply that all discourse is irredeemably ideological" which, firstly, means that ideological investment may vary across different types of discourse and, secondly, that individuals are capable of transcending ideology. As a practical consequence, constant reflection concerning this issue has to accompany the analysis.

In rejecting the perception that language simply reflects social structures and the related notion of a deterministic relation between language and the social, for CDA, language and the social are mutually determined. These processes necessarily include the acting individual. As Fairclough $(1995,65)$ puts it: "It is important...to be sensitive to how discourse is shaped by and helps to shape social structures and relations and...to be sensitive to how social structures and relations are instantiated in the fine detail of daily social practices, including discourse". Language is regarded as a receptor for and constructor of social praxis. CDA is therefore interested in "the social processes and structures which give rise to the production of a text, and [in] the structures and processes within which individuals or groups as social historical subjects, create meanings in their interaction with texts" (Fairclough and Kress in Wodak 2001, 3). In doing so, the concept links action and structure by taking into account the subjects' action, the social and physical structures as well as the interrelation between these dimensions. Put differently, the approach can be described as a dialectic relationship between a structuralist and individualist theoretical tradition. In the given case, this relationship is specifically reflected in the notion that documents represent a form of communication. The link between written documents and communication was established in the 1960s, when Garfinkel (1967) pointed out that documents are similar to conversation. Even if participants in this type of conversation do not know each other, they will mutually understand insinuations or intentions. Not least is every text written with a specific readership in mind. It follows from this theoretical assumption that the production of a document as well as its use (reading, quoting etc.) is a mode of social interaction. This interaction, on the one hand presupposes social structures, in particular language codes or norms of language use. On the other hand, these actions reproduce structure. This interconnectedness is usually not obviously visible. It is one central objective of CDA to make these relations visible.

The concept of power does, in context with CDA, not necessarily mean coercion, domination or control. According to one of the central assumptions of CDA, power can, just as much, be inherent in consensus. It can as well be expressed as the direction of the free will of individuals to act in someone's interests (Foucault 1982), or, according to Weber (1980), as getting a person to do something or to accept the existing order of things through shaping a person's wants. In 'Orders of Discourse' Foucault (1991) has linked the power-category with discourse. Foucault argues that the production of discourse is controlled, 
selected, organised and canalised in every society. As such, discourse is the result of a social process and therefore the result of power relations. The most visible procedures are prohibition, confinements or explicit taboos in the sense that various norms officially restrict the use of language.

An additional procedure, which Foucault considers at least as significant, is the (linguistic) construction of boundaries. Mental illness is a good example of that. Since the middle ages the constructed demarcation between 'reason and madness' has discriminated against the discourse of the mentally ill. These specific demarcations may not be valid anymore but, according to Foucault, demarcations are still produced and they still exist, albeit in other forms. In that context it becomes clear that for CDA it is not only interesting what is said but also what is not said in a specific context and why.

The theoretical assumptions have been developed further by the Foucauldian concept of 'Dispositive'. A dispositive is to be understood as an established discursive practice including various discourses which are in a certain way related to each other and, thereby result in an integrating order. For the genealogy of dispositives, scientific discourse plays a significant role, because the dispositive is a form of power relation which is sustained by knowledge and which, in turn, sustains knowledge (Weiß 1995). Additionally, the mass media, the education system and think tanks are important factors within those processes (Novy 2002). Specific terms which are used in written and spoken texts are, in that respect, discursive categories within knowledge/power formations. CDA engages in 'denaturalising' ideologies and dispositives. It questions taken for granted knowledge-bases via integrating the dominant discourse into a broader historical and contextual analysis. It searches for the genealogy of terms and their demarcations and boundaries which are inherent in their definitions and it investigates their development and their contexts of use. It asks how terms shape discourse and on which immanent presuppositions they are founded on.

It follows from these theoretical assumptions that the analysis is not restricted to manifest text but, as Mautner $(2000,47)$ stresses, has to take into consideration "opaque intertextuality" which goes beyond the actual text and takes into account other texts as well as social structures of text production and consumption. In this respect, CDA typically follows an interdisciplinary approach. The aim in the given case is to go beyond the level of mental health care planning and to address the broader political economic level of reform processes which is manifested in discourse. In addition, it will be reflected whether the reform discourse reproduces or challenges and transforms existing orders of discourse practices. The focus of interest in that respect is to unveil 'discourse struggles' which may be observed between different interest groups. This underlines the process orientation of the method.

Having outlined the theoretical concepts of history, power and ideology underlying the method chosen, some final theoretical issues need to be addressed. 
First of all, from a constructivist epistemological perspective, documents reflect constructed forms of social reality. "... all texts, e.g. physics textbooks, do-ityourself manuals, novels, children's books, biographies, histories, speeches and conversations ... are discursive constructions of some world" (Fowler 1991, 208; original emphasis). According to Wolff (2000), documents are products of human activity and thus can be defined as standardised artefacts with a certain format or outer appearance. Hence, as much as to text and context, attention needs also to be drawn to formal features, frames, schema or style of a text. Beyond their manifested form of appearance, documents express and indicate a social logic. They allow conclusions about their authors, their purposes and intentions and about the institutions or organisations they have been produced in. In other words, they are representatives of a broader social context, in particular of socially organised practices of producing and processing. As a practical consequence of this constructivist perspective, the analysis needs to focus on the original texts including the original language used in the text and, furthermore, content features as well as formal features need to be addressed.

If one takes a look beyond the recent past, it is noticeable that the interest in psychiatric discourse is not a novel issue. Critics of mental health care, such as Dörner (1969), Scull (1979) or Foucault (1973/1991) have particularly addressed, among other issues, the significance of discourse within context of discrimination of the mentally ill. Additionally, mental illness is one of the most striking examples of diachronic language transformation ${ }^{18}$ within medicine. In many cases, this has again happened in conjunction with increasing awareness of the discriminating or stigmatising effects of specific terms. Hughes (1988) has shown that the semantic field of synonyms for 'mad' is quite large. Figure 1 gives an overview of the multiple terms which have been used in that context.

Also more recently, the mental health discourse has been under scrutiny. For example, as Strouhal (1989) has shown in his hermeneutic analysis of a psychiatric report, discriminating processes within mental health care may be closely linked to the institutional language of bureaucracy. Similar forms of discrimination may still happen, albeit in different ways. Furthermore, feminist scholars have shown that psychiatric discourse has contributed to pathologise, individualise and medicalise women's psychological and emotional suffering in various ways, thereby providing another example of the ambiguous relationship between discourse and mental health care (Stoppard 2000). A Swiss female psychiatrist has summarised the relationship of discourse and psychiatry in the following way: "With language we exercise enormous power. The secret nature of medical discourse has a particularly uncontrollable potential for the misuse of power." (Der Standard 24-02-2003, 18; interview excerpt; I.Z. translation)

18 'Diachronic' refers to the chronological change of language. 


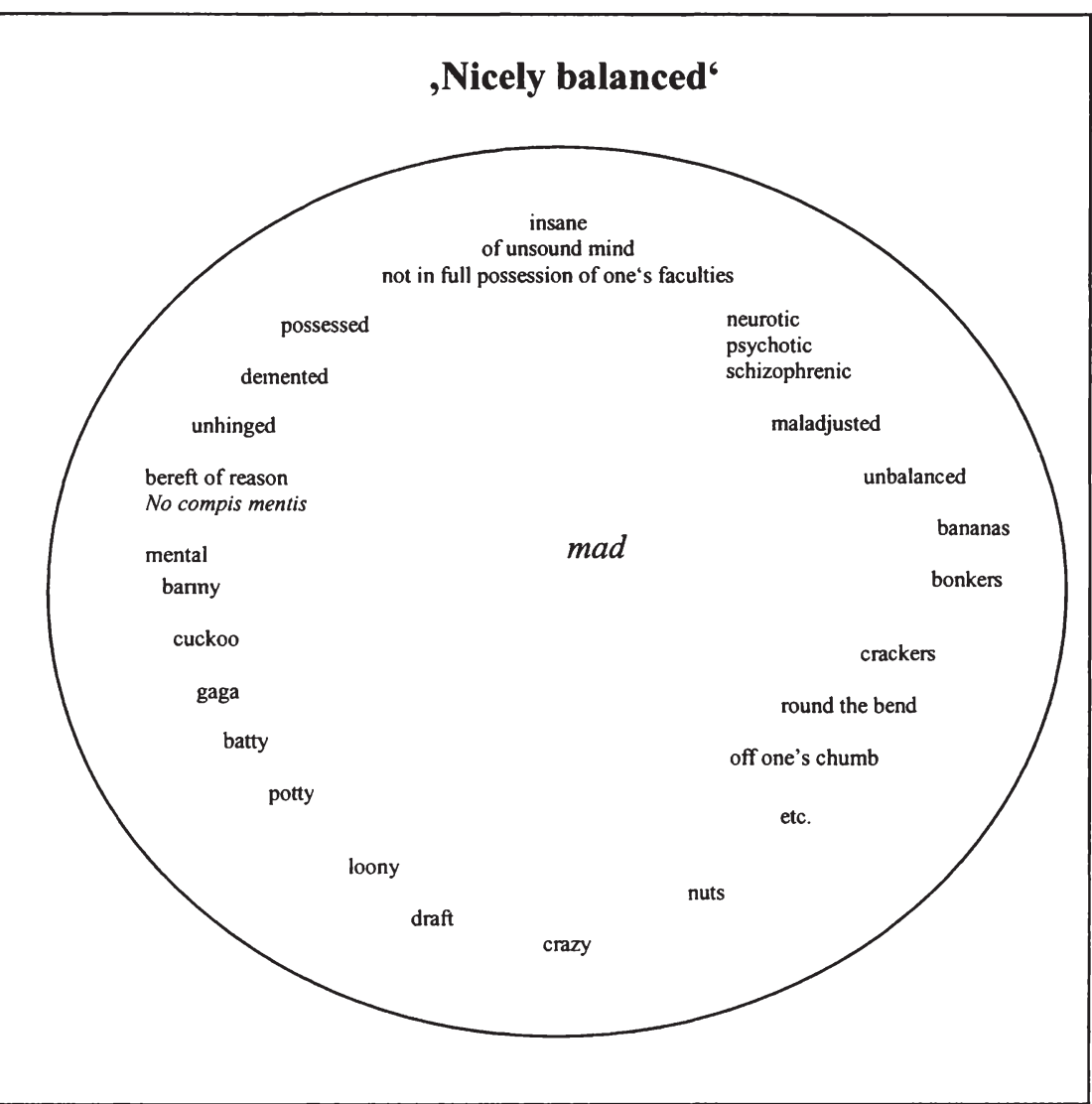

Figure 15: The semantic field of 'mad'; Source: Hughes $(1988,19)$

\subsubsection{Empirical Data, Method and Analytical Framework}

Researchers have drawn attention to the difficulties of applying discourse theory to an empirical analysis which is primarily due to the highly abstract level of the theory (Torfing 1999). Nevertheless, the theory has been used to guide analyses of different social phenomena (e.g. Atzmüller and Redak 2000; Bargetz 2002; Mautner 2000; Fairclough 1995; Reichert 2003; Wodak 1989). The specific design for the empirical analysis is usually characterised by a triangular interrelation between theory, data corpus and method (Mautner 2000; Meyer 2001). For the present study, the empirical data for the analysis are, first of all, the 
official mental health care reform plans of different Austrian provinces which have been published since 1990. The date has been chosen because it marks the beginning of intensified reform discussions in Austria and because prior to that date, reform documents of that type hardly existed.

In addition to reform documents, results of qualitative interviews supplement the empirical data sources. Different sources of empirical data are, not least, important for reliability purposes. Furthermore, while documents show products of (discursive) processes, interviews have been conducted to learn more about these processes themselves, in particular about perspectives and perceptions of the process among different interest groups. For that purpose, seven representatives of various groups of actors within mental health care, namely service-users, their relatives, providers of services and payers have been interviewed via semistructured interviews using slightly varying open questions (Kvale 1996). Contacts from former projects have helped to select key-actors within every group of actors. The selection-criterion was that the person had to be involved in the mental health care reform process. Interviews were carried out in different provinces and interviewees were of different age and gender. The interviews were recorded and subsequently transcribed into texts. Overall, analytical tools according to Froschauer and Lueger (1992) have guided the interview analysis. Identified discursive categories and distinct discursive features should supplement and differentiate hypotheses and interpretation results from the reform-text analysis, thus adding another dimension of interpretation. In general, the paragraphs for the detailed analysis of documents and interview texts have not been translated prior to the analysis and where possible, the documents used have not been manipulated or transformed in their original appearance.

Following the method of Fairclough (1995), the analysis is employed on three dimensions. Firstly, properties of the text themselves are looked at. Secondly, from the perspective of processes, the practice of text production and interpretation is addressed. Finally, the socio-cultural practice within which the discourse is embedded in the immediate situation, at the wider institutional or organisational level and at the societal level is analysed. This corresponds to three practical procedures. First of all, a linguistic description, secondly, an interpretation of the relation between discursive processes and the text and, thirdly, an explanation of the relationship between discursive processes and social processes are required. It has to be noted that these three dimensions do not necessarily relate to a chronological order but they are addressed variably throughout the analysis.

For addressing this different dimension, several analytical categories and questions have been defined in order to guide the analysis (see table 15). For the text/language level, categories have been adopted from Mautner (2000). They can be divided into categories addressing a) the formal level and categories addressing b) the content level of the language. Concerning the formal language level, 
categories for the analysis are, firstly, the text itself (e.g. definition of the type of text, structuring, themes, perspectives of the author) secondly, lexis ${ }^{19}$ (e.g. use of metaphors $^{20}$, metonyms ${ }^{21}$ and synonyms ${ }^{22}$ ) and, thirdly, non-verbal modes (e.g. emphases, graphical design, illustrations, symbols). Concerning the content level of language, the analytical categories are 'strategies' (subordinate discursive aims which are manifested in the text) and 'motives' (single content features which constitute strategies). For the dimension of 'text production/interpretation' questions cover the processes of producing and 'consuming' the texts, the actors involved and the immediate contexts of these processes. Concerning the third dimension which has been named 'discourse-society relationship', the focus of the questions shifts from mental health care texts and interview transcripts to broader political-economic and societal transformation processes. It particularly addresses how developments in the mental health care discourse are related to developments in the overall welfare state. At this point, the analysis particularly aims to identify implicit financing arguments in the discourse. Although the stated categories are not applied for every single feature, they represent the entire analytical pool which has been compiled for the analysis. Illustrated on a 'language-societal continuum', the overall analysis predominately focuses on the latter features.

For a qualitative analysis, the data-base is fairly huge. Hence, the material is not analysed to full extent, but selected topics have been defined for specific "case studies'. Features for the text analyses are selected according to the criterion of a) being particularly salient in one text by comparison with other texts and according to the criterion of b) appearing as a key term and/or dominant feature. Obviously, this selection is subjective because it is impossible to cover every single issue. This raises questions of reliability. In that respect, data triangulation and theoretical sampling (see also 1.3.) should guarantee serious results. Additionally, particular attention is paid to making the research process as transparent as possible. It needs, finally, to be noted that the discourse which is produced in this paper has the same attributes as the one which is analysed. It is, thus, in itself

\footnotetext{
${ }^{19}$ Lexis means the vocabulary or total stock of words.

${ }^{20}$ A metaphor is the use of a vehicle to describe a specific topic. Lakoff and Johnson (1980) have found that metaphors are not a pure characteristic of language alone, but they are pervasive in everyday life, that is in thought and action. As they remark, metaphors can create realities. Their significance lies in their manipulative power. "New metaphors, like conventional metaphors, can have the power to define reality. They do this through a coherent network of entailments that highlight some features of reality and hide others. The acceptance of the metaphor, which forces us to focus only on those aspects of our experience that it highlights, leads us to view the entailments of the metaphor as being true" (Lakoff and Johnson 1980, 157).

${ }^{21}$ Metonymy is the replacement of an expression by a factually related term. The semantic connection is of causal, spatial, or temporal nature and is therefore narrower than metaphor (e.g. using 'Napoleon instead of France') (Bußman 1996 in Lerner 1999, 310).

${ }_{22}$ A synonym is a word or phrase with a meaning similar to that of another in the same language (Pollard and Liebeck 1994, 814).
} 
influenced and shaped by the personal physical and social environment. From a meta-level perspective, the results which are produced can be regarded as 'secondary-order discourse'.

After a brief summary of the Austrian mental health policy since the 1960s and an outline of the Austrian mental health care planning documents, in the subsequent parts the introduced analytical framework will be applied for the analysis of mental health care reform discourse in documents and interview texts.

\begin{tabular}{|c|c|c|}
\hline \multicolumn{3}{|c|}{ Analytical framework } \\
\hline 离 & $\begin{array}{l}\text { Dimensions of analysis } \\
\text { (adopted from } \\
\text { Fairclough 1995) }\end{array}$ & $\begin{array}{l}\text { Analytical categories } \\
\text { (questions to be asked) }\end{array}$ \\
\hline \multirow[t]{2}{*}{ Language } & $\begin{array}{l}\text { Text and language } \\
\text { (adopted from Mautner 2000) } \\
\text { (text analysis) }\end{array}$ & $\begin{array}{l}\text { a) Formal features: Text, lexis, non- } \\
\text { verbal modes } \\
\text { b) Content features: motives, } \\
\text { strategies }\end{array}$ \\
\hline & $\begin{array}{l}\text { Text production } \\
\text { and interpretation processes } \\
\text { (processing analysis) }\end{array}$ & $\begin{array}{l}\text { How is discourse constructed and } \\
\text { how is it constructive? } \\
\text { Who produces the text? Who } \\
\text { consumes the text? } \\
\text { Immediate institutional, political, } \\
\text { societal, economic context } \\
\text { Issues of transparency }\end{array}$ \\
\hline Society & $\begin{array}{l}\text { Relationship between } \\
\text { discourse } \\
\text { and societal context } \\
\text { (social analysis) }\end{array}$ & $\begin{array}{l}\text { Genealogy of terms, definitions } \\
\text { (what, who) } \\
\text { What is not said in the text? } \\
\text { Broader societal, political, economic } \\
\text { and historical context of discourse } \\
\text { formations and terms; } \\
\text { Tendencies of discourse } \\
\text { developments in the light of welfare } \\
\text { state transformation; } \\
\text { Explicit and implicit financing } \\
\text { arguments }\end{array}$ \\
\hline
\end{tabular}

Table 15: Analytical framework; own table 


\subsubsection{Mental Health Care Policy in Austria since the 1960s: A Brief Historical Overview}

Compared to other Western European countries (e.g. outlined in Bennett 1995; Goodwin 1997), in Austria mental health care reform initiatives started late. Around 1970, mental health care was characterised by a 'two-component' type of service provision. This included hospital care in mental hospitals and treatment by specialist doctors. Furthermore, the system around 1970 can be described as a two-tier system with better equipped or private service provision for affluent persons and stigmatised mental hospital care for less well-off persons (Forster 1994). As the author remarks, there were significant reasons for the time-lag, such as the slow process of appreciating the problem within the medical profession, the political arena and the overall climate within the Austrian society.

Nevertheless, since the 1970 s, substantial changes have taken place within Austrian mental health care (e.g. Meise, Hafner and Hinterhuber 1991). This is most significantly apparent in decreasing numbers of hospital beds in mental hospitals and utilisation of hospital beds as has been outlined in chapter 3. At the same time, chapter 3 also demonstrated that outpatient and community services (particularly for accommodation, employment related services, mobile and ambulatory psychiatric services) have been increased, resulting in a rising number of occupational groups involved (Forster 1997). However, unlike other countries, within the first 20 years of reform initiatives, strategically planned reform measures have not taken place. According to Forster (1994), endeavours within that period of time can at best be described as the beginnings of a reform process and have more or less, been the product of single actor's initiatives resulting in a kind of patchwork-scenery of various community mental health care services. The author has summarised this type of reform procedure as 'micropolitics'. That apart, from around the 1970 s, public awareness of the appalling psychiatric conditions rose and a critical civil movement named 'Demokratische Psychiatrie' emerged (Hermann 1979). Several activities such as under-cover journalism in psychiatric hospitals revealed bad conditions and discriminating effects of the legal system and made psychiatry a public issue. Yet the movement lost publicity during the 1980s.

Since the mid-80s, discussions about the future provision of mental health care services have once more been intensified on the professional and political level. In 1990, two legislative changes mark the beginning of a new era: firstly the law of 'Civil Commitment Act' (Unterbringungsgesetz) and secondly the 'Psychotherapy Act' (Psychotherapiegesetz) were formulated. Over the last ten years, reform initiatives broadly focussed on further decentralisation and deinstitutionalisation. In the following chapters the latest reform era is addressed in further detail. 


\subsubsection{Mental Health Care Plans in Austria: Development and Contents}

The first official document which was concerned with mental health care in Austria was the 'Zielplan für die Krankenversorgung und Altenhilfe in Wien'. It was established by the City Councillor Alois Stacher in 1975 (Schmidl and Rudas 1999). The publication was followed by several discussions with respect to the reorganisation of mental health care in large cities resulting in some further planning documents in the late 1970s (Schmidl and Rudas 1999). The majority of documents were however only written from 1990 onwards. In 1992, the Ministry of Health (Bundesministerium für Gesundheit 1992) published the first federal mental health care planning document which has been written by a group of experts. Furthermore, in 1994, hospital mental health care was, for the first time, separately covered in the federal hospital plan (ÖBIG 1994) and in 1997, a federal document including suggestions for the overall Austrian mental health care service provision was published (ÖBIG 1997) with follow-ups in the years 1998 and 2000. Additionally, mental health care was addressed in all of the subsequently following hospital plans (Katschnig, Denk and Scherer 2004).

Apart from those federal activities, planning initiatives have mostly been undertaken on the provincial level. All of the provincial governments have commissioned mental health care reform projects and several reform documents have been produced. Meanwhile, all of the nine provinces have published at least one mental health care plan. In some provinces (e.g. Lower Austria, Styria) revisions and/or evaluations of the initial documents have been made. The first provincial plan was published in 1993 (Meise et al. 1993), the latest one is from 2003 and addresses the revision of mental health care in Lower Austria. Since these documents include reform objectives and priorities, they play a significant role for future mental health care provision.

From a CDA-perspective mental health care plans can be described as discursive occurrences and narratives, shaped by different social groups and interests and their different forms of practice and strategies. It is on the one hand of interest, to address the process of document development and the actors included. On the other hand, it will be intriguing, to see how reality is constructed by the plans through structuring complex situations in a specific way. Finally it is interesting how different actors might be constituted by the plan and how specific attributes and aspects of theses groups of actors are defined in that processes, while some actors may be neglected entirely. Not least, as stated earlier, reform documents are political documents and therefore reflect broader ongoing politicaleconomic processes and dynamics. Although planning projects have not been carried out by politicians personally, they have been commissioned by public bodies and final responsibility for publication of the documents has rested with the according political actors. This is not always clearly visible. Thus, in some cases the researchers that have developed the plans are named as authors on the 
front page, thereby transporting the impression of a research document whilst other examples state the authors as public and private organisations which were involved in producing the plans, herewith reflecting the notion of a policy document (table 16). In summary, reform documents reflect policy objectives, however precisely they are stated. As a member of a provincial government put it: "The mental health care plan defines the cornerstones for future policies" (Landesregierung Oberösterreich 2002, 3; I.Z. translation).

\section{Mental Health Care Reform Documents since 1990}

\begin{tabular}{|c|c|c|}
\hline $\begin{array}{c}\text { Year of } \\
\text { publication }\end{array}$ & Authors & Title \\
\hline 1992 & $\begin{array}{l}\text { Bundesministerium für } \\
\text { Gesundheit, Sport und } \\
\text { Konsumentenschutz }\end{array}$ & $\begin{array}{l}\text { Empfehlungen für die zukünftige psychiatrische } \\
\text { Versorgung der Bevölkerung Österreichs. } \\
\text { Mitteilungen der Österreichischen Sanitätsverwaltung }\end{array}$ \\
\hline $1993 *$ & Meise, U. et al. & $\begin{array}{l}\text { Bürgernahe Psychiatrie: Leitlinien für die Reform der } \\
\text { psychiatrischen Versorgung in Tirol }\end{array}$ \\
\hline 1994 & ÖBIG & $\begin{array}{l}\text { Ôsterreichischer Krankenanstalten- und } \\
\text { Großgeräteplan } 1994\end{array}$ \\
\hline 1996 & Katschnig, H. et al. & Der Niederösterreichische Psychiatrieplan 1995 \\
\hline $1997 \mathrm{a}$ & ÖBIG & $\begin{array}{l}\text { Struktureller Bedarf der psychiatrischen Versorgung in } \\
\text { Österreich }\end{array}$ \\
\hline $1997 \mathrm{~b}$ & ÖBIG & $\begin{array}{l}\text { Österreichischer Krankenanstalten- und } \\
\text { Großgeräteplan } 1997\end{array}$ \\
\hline 1998 & ÖBIG & $\begin{array}{l}\text { Struktureller Bedarf der psychiatrischen Versorgung in } \\
\text { Österreich. Wartung und Fortführung }\end{array}$ \\
\hline 1998 & Landesregierung Steiermark & $\begin{array}{l}\text { Konzept für die Psychosoziale Versorgung in der } \\
\text { Steiermark }\end{array}$ \\
\hline 1999 & ÖBIG & $\begin{array}{l}\text { Österreichischer Krankenanstalten- und } \\
\text { Großgeräteplan } 1999\end{array}$ \\
\hline 2000 & Dantendorfer, $K$. & Der ,Psychiatrieplan Burgenland 2000“ \\
\hline 2000 & ÖBIG & Planung Psychiatrie Fortschreibung \\
\hline 2000 & $\ddot{O B I G}$ & Kärntner Psychiatrieplan \\
\hline 2000 & $\begin{array}{l}\text { Püringer, U., M. Trutschnig and } \\
\text { P. Konstantinuik }\end{array}$ & $\begin{array}{l}\text { Bedarfsgerechte psychosoziale Versorgung in der } \\
\text { Steiermark }\end{array}$ \\
\hline 2001 & ÖBIG & $\begin{array}{l}\text { Österreichischer Krankenanstalten- und } \\
\text { Großgeräteplan } 2001\end{array}$ \\
\hline 2002 & $O ̈ B I G$ & $\begin{array}{l}\text { Grundlagen fü die integrierte psychiatrische } \\
\text { Versorgung in Wien }\end{array}$ \\
\hline 2002 & Landesregierung Oberösterreich & Psychiatrieweiterentwicklungsplan \\
\hline 2002 & Landesregierung Salzburg & $\begin{array}{l}\text { Leistungen für psychisch kranke Menschen. Bedarfs- } \\
\text { und Entwicklungsplan }\end{array}$ \\
\hline 2002 & $\begin{array}{l}\text { Arnold, M., P. König and A. } \\
\text { Lingg }\end{array}$ & $\begin{array}{l}\text { Die Weiterentwicklung der psychiatrischen } \\
\text { Versorgung in Vorarlberg }\end{array}$ \\
\hline 2003 & $\begin{array}{l}\text { Katschnig, H., P. Denk and B. } \\
\text { Weibold }\end{array}$ & $\begin{array}{l}\text { Der Niederösterreichische Psychiatrieplan. } \\
\text { Evaluierung }\end{array}$ \\
\hline
\end{tabular}

Table 16: Mental Health Care Reform documents since 1990; own table 
The content of provincial documents which are now going to be analysed in detail shows several characteristics from a synchronic and diachronic perspective. Firstly, since the publication of the first document in 1993, the central reform aims have been deinstitutionalisation and decentralisation. Thus, providing mental health care outside (psychiatric) institutions and on the local level where people live and work appears to be the unchanged main objective of the reform texts. These core aims are linked to various sub-goals such as changing priorities treatment pathways which should render institutional care secondary to outpatient and mobile care ('ambulant vor stationär'). Additionally, since the first document it has been stressed to transform mental health care from supply-oriented to person-oriented and needs-based care. In other words, individual persons' needs should be at the heart of any question of service supply and development. In that context, concepts of 'normalisation',24 and 'individualisation' 25 are emphasised which, in turn, require that more attention is paid to integration and co-ordination of services as well as to establishing arrangements for continuing care. Finally, in most of the documents from 1995 onwards 'participation' of people with mental illnesses and their relatives in treatment and service planning appears as an aim.

From a diachronic perspective the core aims have remained unchanged since the beginning of the 1990s. In addition to structural changes in quantitative terms, the younger texts increasingly pay attention to quality of services and forms of measuring quality.

In summary, evaluations show that despite several changes in service structure and provision, the overall aims of mental health care reform have not been achieved so far (e.g. Landesregierung Steiermark 2001; ÖBIG 2002; Pühringer 2000), which is similar to the experiences of other countries (e.g. Bramesfeld 2003). Documents show that mental health care at present consists of various types of services and institutions which are still largely uncoordinated and geographically unequally distributed.

\footnotetext{
${ }^{24}$ 'Normalisation' refers to providing services in a way which enables persons with a mental illness to live their lives as 'normally' as possible. Hence, to enable them to live a life which is not different from generally accepted ways of life of citizens (Land Oberösterreich 2002).

25 'Individualisation' refers to the right of self-determination and individuality (Land Oberösterreich 2002).
} 


\subsubsection{Analysis of Reform Discourses and Processes}

"It is a hopeless condition that - when using well-worn language for suggesting innovations - even the most honest reformer, via taking over an established apparatus of categories and the bad philosophy lying behind, enforces the power of the existing which he/she wants to brake." (Horkheimer and Adorno 2001, 4; I.Z. translation)

\subsubsection{The Different Faces of Community Mental Health Care}

When addressing not only manifest but also latent contents and formal features of the documents, several characteristics can be identified. First of all, the plans differ considerably in their outer appearance. Some of them are simple 'Worddocuments' (e.g. Dantendorfer 2000), while others mirror a professional and graphic-design layout (e.g. Landesregierung Salzburg 2002). On the cover page, some plans show paintings by mentally ill artists. Documents also differ in their length, ranging from 39 pages up to 671 pages. The appearance gives an impression of a different significance or purpose of the documents. The cheaper and plain documents appear to have been written in order to fulfil an agreement or for internal administrative use only, whilst others seem to address a broader audience, showing greater effort with a sense of taking the issue more seriously. Although the reform plans are public documents, public knowledge of their existence and their contents seem to be low and access is often linked with bureaucratic obstacles. A social worker who has been working in the mental health field for years states:

"Schauen Sie, was geplant ist in Wien, weiß ich gar nicht. Es wird ja nirgendwo veröffentlicht. Man hat nirgendwo Einblick." (I1)

("Look, I don't know what is planned in Vienna. It is nowhere published. One cannot gain insight.")

Similarly, a former user of psychiatric services notes:

"Das Problem ist einfach, dass die Öffentlichkeit nicht weiß, was der Psychiatrieerweiterungsplan ist." (I3)

("The problem is simply that there is no public awareness of the mental health care reform plan.")

Concerning overall strategies for changing the priority of care from inpatient to community and outpatient care, there are some subtle contradictions. Within plans 
covering overall mental health care, inpatient hospital care still seems to be the primary issue or the norm. It is used as a standard against which other service elements are compared. On the one hand, this is apparent in the order of topics, where hospital care heads the table of contents and the related chapters of the documents but it is also apparent in several terms which reflect hospital care as the norm, whereas community services are 'the other', 'the deviant' or the 'hospital's complement'. Community services and related issues are summarised with terms like 'außerstationäre Versorgung' (service provision outside the hospital), 'extramural', 'komplementäre Versorgung' (complementary service provision), 'nicht-stationäre Versorgung' (non- inpatient care) (e.g. Dantendorfer 2000; Katschnig et al. 1996; Landesregierung Oberösterreich 2002). The hospital's dominance also appears in the utterance of a member of the managerial board in a mental hospital. When he describes mental health care plans as

“...Dokumente, die die Grundsatzposition einer gemeindenahen Psychiatrie beziehen, die in die Spitäler der somatischen Medizin integriert werden soll,“ (I2)

("...documents that outline the core aims of community psychiatry, which is to be integrated in hospitals of somatic medicine"),

he restricts reformed mental health care to reformed hospital care. This is underpinned by the characteristically dominant feature in reform discussions which is numbers of hospital beds.

"Ich bin ja einer von denen, die nicht so furchtbar auf den Betten herumreiten, aber andererseits hab ich es natürlich leichter...weil wir eh genügend Betten da haben." (I2)

("I am not one of those who only discuss numbers of beds; on the other hand it's also easier for me because we have enough beds anyway.")

"In Niederösterreich gehört noch allerhand umversorgt, da wird halt gestritten um Betten." (I1)

("Lower Austria still needs a lot of restructuring, commonly it's beds which are fought for.")

“...im Bezug auf Experten - auf Chefärzte - spielt die Macht eine große Rolle und es ist halt von alters her so, dass der der Größte ist, der die meisten Betten hat." (I4)

("...concerning experts - the heads of a clinic - power plays a significant role and it has traditionally been the case that those who have the highest number of beds are the most important ones. ") 
The spatial metaphor of a hospital's employee which symbolises hospital care as safe space in contrast to the demanding and threatening space 'outside' similarly underlines the picture of hospital dominance:

“... die absolute Narrenfreiheit, die so ein bisschen belächelt wird, die hab ich da herinnen schon ... ich weiß nicht, ob ich in einem Amtshaus draußen - sag ich jetzt auch draußen - irgendwie so lernen hätte können ... wir stehen hier nicht unter dem Druck, nämlich wie draußen, gemma, gemma, schnell, schnell.“(I1)

("...inside I've got the freedom to do whatever I want, this kind of freedom which is sometimes a bit smiled at...I don't know whether I would have been able to learn all this outside - now I also say outside - in an office...we are not under pressure like outside, hurry up, quick, quick.")

The statements demonstrate that the self-perception of key actors, including that of decision-makers is not generally identical with the definition of 'community care' in reform plans. Some of them address decentralisation but neglect deinstitutionalisation. Prior (1993) has made the point that a confusion between these two processes can be traced back to the first publications about community care in the 1950s. It may be linked to these inaccuracies that the movement from mental hospitals to community care can in Austria be described as transinstitutionalisation rather than a move into an independent world of community life (Forster 2000).

The discourse, additionally, mirrors hierarchical structure within mental health care. In overall listings the common custom is to use terms such as 'ärztliches und nicht-ärztliches Personal' (medical and non-medical personnel), 'medizinische und außermedizinische Fachdisziplinen' (medical and non-medical disciplines) which renders areas that are not part of the medical field subordinate (e.g. Arnold et al. 2002; Dantendorfer 2000; Katschnig et al. 1996; Meise et al. 1993; Landesregierung Salzburg 2002). This is similarly visible in descriptions and metaphors of organisational structures:

"Die nördlichen PSD-Beratungsstellen (psychosozialer Dienst) sollten fachlich der zukünftigen Abteilungsleitung [für Psychiatrie] in Eisenstadt unterstellt werden, die südlichen PSD-Beratungsstellen der zukünftigen Abteilungsleitung in Oberwart." (Dantendorfer 2000, 17)

("The offices of ambulatory and mobile psychiatric services (Psychosozialer Dienst) of the northern area should be professionally subordinated to the head of the department of psychiatry in Eisenstadt and the offices of the southern area should be subordinated to the head of the department of psychiatry in Oberwart.") 
"Was ich in der Psychiatrie als starken Hemmschuh erlebe, ist die Schnittstelle zwischen stationärem und extramuralem Bereich und zwar aus dem Grund, weil es da um Machtpositionen geht. Da geht's um die Machtposition, dass der stationäre Bereich bestimmt, was außerhalb der Mauern passiert, also dass sozusagen die Fänge nach außen gehen." (I6)

("For me the separation between hospital and community care is one of the major obstacles because it's associated with power-relations. The powerrelation is structured in that way that the hospital sector defines what should happen outside the walls, the [literally] tentacles go from the inside to the outside.")

"Ich glaube, dass die Entwicklung, so wie sie jetzt ist, dass die Intramuralen den extramuralen Bereich definieren, dass das ein Handicap darstellt." (I7)

("I think that the current development, where the hospitals define what is outside the hospital, is a handicap.")

One gets a similar picture of the situation in another province, where various psychiatric social services are run like ambulatories, according to medical patterns (ÖBIG 2002). This indicates that 'the social' is rather inferior to 'the medical'.

\subsubsection{Actor-relationships and Discourse Struggles}

Taking the perspective that mental health care plans are political documents, they are the result of negotiation processes between different interest groups with varying degrees of power. From that point of view, the role of actors becomes significant, with some groups of actors having better opportunities to organise their interests in order to shape politics than others (Jessop 1999). The analysis of the given process shows that in terms of shaping policies the profession of psychiatrists is in a dominant position. Firstly, although expert involvement has been extended to different disciplines, there are a greater number of psychiatrists represented as authors in the documents than other occupational groups. The dominant position is additionally underpinned by more subtle features.

"Man muss schon sagen, der rechtliche Anspruch [des Psychiatrieplanes] ist bescheiden, aber trotzdem wird das ja doch - und das ist der wesentliche Teil - von einem Großteil der ... Psychiater schon auch gewollt und auch getragen.“(12)

("It has to be noted that the legal power of the mental health care plan is minimal but it is supported - and this is most important - by the majority of psychiatrists.") 
The significant issue in that statement is not that psychiatrists are involved in planning but that it is primarily the psychiatrists who are ascribed that role while other groups of interests are not mentioned at all. This is similar when controversies about existing plans are described:

"[Psychiater] $\mathrm{X}$ hat kritisiert ...; [Psychiater] $\mathrm{Y}$ hat sehr massiv die , $\mathrm{Z}$ [Psychiater]-Pläne' kritisiert.“ (I2)

("[Psychiatrist]X has criticised...; [Psychiatrist] Y has severely criticised the planning document of [Psychiatrist] Z.")

These prevailing patterns mirror a hierarchical stratification within occupational groups as well as between medical professionals and users or their relatives. The inherent logic is also noticeable in utterances of other interviewees. An involved relative states:

"Es wär ganz gut wenn wir mitreden könnten, jetzt nicht im Sinne von bestimmen, sondern einfach nur, ah, unsere Meinung zu den Dingen kundtun können, als Korrekturmöglichkeit. Das ist aber nicht geschehen, und das war die Schwierigkeit. Es ist besser geworden im Lauf der 90er Jahre dann, aber so richtig einbezogen sind die Users eigentlich nie worden, ah, und das ist also schade." (I4)

("It would have been nice if we had been able to join the discussion, not in the sense of making decisions but simply, ah, to state our opinion, as a way to correct things. This has not happened and this was the difficulty. It has improved over the 1990s but users have not been really involved, ah, and this is a pity.")

When paralleled with sociological literature about the status of the medical profession, medical dominance has to be seen in the light of the history of medicine and its relation to the state (Annandale 1998; Elston 1991; Freidson 1970). With regard to mental health care planning in Austria, the phenomenon of psychiatrists' dominance is not a new one. In fact, already the first major changes can be traced back to the initiative of single psychiatrists while politicians have played a secondary role.

"Es hat mir einmal einer [Psychiater] erzählt, dass sie in Innsbruck in einer bestimmten Gasthaus-Hinterstube in den schönen alten Gasthäusern beim ,Goldenen Dachl', dass sie sich da sozusagen fast verbrüdert haben, fast gelobt haben, wir wollen die österreichische Psychiatrie verbessern.“ (I4)

("A psychiatrist told me that, once, they were meeting in the back room of one of these beautiful old pubs next to the 'Goldenen Dachl' and were 
almost allying themselves, almost swearing - we want to improve psychiatry in Austria.")

This role is still ascribed to them. As a politician states:

“... und da haben wir wirklich mit dem Prof. X. [Psychiater] - Sie werden ihn sicher kennen - einen herausragenden Experten, der hat uns den Psychiatrieplan gemacht, mit allen Vernetzungsansätzen." (I5)

("...and with Prof. X [psychiatrist] - I'm sure you know him - we have really got an excellent expert who has produced the mental health care plan for us; including all aspects of co-ordination.")

The war-metaphor in the following utterance seems to underpin the logic. The interviewee describes a situation in one province where hitherto no planning document has existed:

“...da ist der Prof. X [Psychiater] dann angesetzt worden, dann hat er das sozusagen mit einer Armee von Panzern in Ordnung gebracht." (I4)

("...then they have put on Prof. X [psychiatrist] and he has put things in order with [literally] a division of tanks.")

It seems very likely that the dominant position of psychiatrists impacts on the mental health care discourse. In fact, medical terminology dominates the rhetoric, yet discourse struggles which question prevailing concepts are clearly visible. Thus, a former user notes:

"Ich hab natürlich nicht gewußt, wenn ich sie [die Medikamente] jetzt absetze, dass es dann zu einem sogenannten Rückfall kommen kann, was die Ärzte dann wieder als Psychose bezeichnen." (I3)

("Of course I didn't know that I will get a so-called relapse if I stop taking the drugs, which doctors then call 'psychosis'.")

Additionally, dissatisfaction and uncertainty with prevailing terms in psychiatry are apparent.

"Es wundert mich nicht, ahm, wie viele wirklich, ahm, irgend eine Störung also ich habe noch kein passendes Wort für mich gefunden - aber wie viele Leute dann ausbrechen oder flüchten müssen." (I3)

("I am not surprised, ahm, how many people, ahm develop some kind of disorder - I haven't found the right word for myself so far- I mean how many people finally have to escape.") 
It is, however, characteristic that discourse struggles are restricted to psychiatry in a narrow sense. They primarily concern concepts of mental illness, diagnoses or treatment while broader issues of mental health care such as the financing discourse are not contested. This suggests that addressing the discourse which is beyond medicine and the traditional realm of psychiatrists seems to be of even more interest.

\subsubsection{Mental Health Care between Economisation and Changing Patterns of Governance}

The previous statements are already associated with another central issue in the documents which is the emphasis on involving people who have experienced a mental disorder and/or their relatives in planning activities. From a diachronic perspective, user involvement appeared for the first time as a definite objective in the Lower Austrian planning document in 1996 (Katschnig et al. 1996). Since then, 'user involvement' or 'user participation' have been stressed in most of the following documents. Generally, however, the terms seem to be used as a catchphrase, rather than a clearly defined concept. Addressing the issue of 'participation' is usually restricted to single sentences like the following:

"In diese Evaluation und die aus ihr folgenden Entscheidungen sollen Patienten, Angehörige und/oder Patientenvertreter einbezogen werden.“ (Arnold et al. 2002, 24)

("Patients, relatives and/or representatives of patients should be involved in evaluation of services and in subsequently following decision making.")

In its original meaning, 'participation' is understood as a constitutive element of democratic or republican forms of societies. It can mean both, taking part in political processes and decision making ('teilnehmen') or taking part in the results of politics, for instance in national wealth ('teilhaben') with the current usage focussing on the former rather than on the latter (Schnurr 2001). In terms of social planning, user participation has developed from an approach of overall 'citizen participation' (Ortmann 1976) to an increasing focus on 'user participation'. The rationale for participation is based on two rather different theoretical foundations. From a democracy-theoretical perspective the purpose of participation has on the one hand been defined as providing conditions for legitimised power and on the other hand - according to the so-called 'participatory democracy theories' - as mode for political and social integration which should eventually result in selftransformation of participants into responsible citizens (Schmidt 1995). As a second theoretical strand, participation has been addressed in theories of social service production and consumption where it has been regarded as an integral part 
of any service provision/consumption process (Schnurr 2001). A case in point is that production and consumption of social services take place at the same time which always involves the user. Concerning social planning, user participation based on democracy theories is proposed as a means to finally develop democracy, while from the perspective of service production and consumption theory it has been argued that increasing participation of users in planning and providing services is conditional for successful and effective service provision (Schaarschuch in Schnurr 2001).

Thus, form and level of 'participation' can be multifaceted. In its prevailing meaning in social planning as "the ways in which ordinary citizens can or do take part in the formulation or implementation of policy decision", the meaning of 'taking part' varies according to ideological perspectives and values of its users. (Richardson in Rowe and Shepherd 2002, 278). For example, Hickey and Kipping (1998) illustrate different forms of user involvement in mental health care on a continuum with 'information' at the one end and active involvement in the form of 'user control' at the other. In between, participation can mean 'consultation' and 'partnership'. Therefore, various patterns of user involvement, ranging from a consumerist approach to a democratic approach can be termed 'participation', correlating to the different theoretical foundations which I have mentioned above. Concerning the level, 'participation' can take place on the individual level (where issues concerning personal care are influenced), the service level (where organisation and service provision are influenced) or the strategic level (where users are involved in local and national policy development) (Scottish Development Centre for Mental Health Care 2001). Despite this substantial diversity, contradictory understandings of the term 'participation' are not addressed in the documents, nor are practical considerations visible in the texts, as to how different perspectives among interest groups and the likely conflicts this entails might be handled. That different concepts of participation do exist among actors, becomes apparent when analysing their statements. While planners and payers mainly follow the consumerist approach, users and relatives wish for more user control. Yet, in the end they accept the passive role ascribed to them.

"Ahm, der Prof. X [Psychiater] hat das ja immer wieder versichert, dass die Angehörigen eingebunden sind, dass sie auch in jeder Region Mitspracherecht haben sollen usw. Ah, er hat mir auch immer wieder etwas geben zum Durchschauen und Lesen, mehr kann und konnte man auch gar nicht erwarten und gar nicht verlangen." (I4)

("Ahm, Prof. $X$ [psychiatrist] has always made sure that relatives are involved, that they should have a say in every planning region and so on. Ah, he has also given me something to read through now and then. You cannot expect more than that and you cannot demand more than that.") 
When asked about 'participation' a politician gave the following answer:

"Auch das haben wir gemacht, wir haben im Vorfeld der Erstellung zwei größere Landesveranstaltungen gemacht, wo wir alle Betroffenen alle Institutionen, Vereinigungen, eingeladen haben und sie gebeten haben uns ihre Bedürfnisse in dem Zusammenhang mitzuteilen, sodass die einfließen können, und wir haben dann auch den Psychiatrieplan wieder in der selben Form präsentiert vor diesem Forum, das ist eigentlich ganz gut ankommen." (I5)

("We have done that, too. Before the plan was written we organised two quite large events where we invited all institutions and users and where we asked them to tell us their needs so that they can be incorporated. And then we presented the plan in the same way in front of this audience. This was actually quite appreciated.")

Among payers, the focus on the 'advisory-concept' is not only visible in terms of user-participation but also in terms of other actors' involvement in the planning process. In one province, selection of an applicant for the planning project was described in the following way:

"Wir [Sozialabteilung] sind dann hergegangen und haben einen Landesarbeitskreis einberufen mit diesem partizipativen Prinzip,...der Landesarbeitskreis hat dann Stimmen abgegeben...und wir haben uns dann eigentlich für jemanden anderen entschieden, als was das Stimmungsbild dort war, haben wir aber begründet; also wir haben das als beratendes Gremium gesehen." (I7)

("What we [department of social affairs] did next is to call a meeting according to the principle of participation...the team there voted but we actually decided that someone else should carry out the project which was contrary to the results of the voting; but we justified our decision; we had perceived the group as consulting body.")

Additionally, a representative of a social services provider describes the form they were involved in as

“...Befragung - und dann aber ohne Korrekturlesen, was mir nicht taugt. Aber sonst is des einfach über Befragung der Anbieter abgelaufen." (I7)

(“...interview - but without proof reading later on which I don't like. It was simply interviewing providers.")

From a comparative perspective, in Upper Austria 'participation' played a considerably more significant role during the planning process than in the other 
provinces. Thus, the planning project was commissioned on condition that regular collective meetings with representatives of the numerous actors were an integral part of the planning process. While similar forms of participatory processes have already happened in other planning fields in Austria for several years (e.g. in urban development processes) (Albrechts 2002), it is a novel experience in mental health care that participation is stipulated by the commissioning politicaladministrative body. Despite the controversies in definition and perception, the experience of participation seems to bear potential for developing new processes of communication. An actor who was involved in this 'participatory process' emphasises the valuable experience she has gained:

“...wie geht man damit um, wenn ein Mitarbeiter das [eine Maßnahme] so super findet und der Betroffene sagt, das ist ein Blödsinn,...also das war für mich beeindruckend...und da sag ich, sind wir bei weitem noch nicht so weit, dass ich sage, das nimmt man ernst...aber ich denke mir, da sind wir in einem Entwicklungsprozess.“(I7)

("...how should you deal with the situation where a professional employee says that something is a perfect service and the user disagrees.... I was impressed by this process... and I have to say, we still don't take everything seriously what they say but I think this is a learning process.")

Furthermore, an involved user, somehow surprised, mentions:

"Eigentlich, alles was ich gesagt habe (lacht) mehr oder weniger ist schon eingebunden worden, steht in diesem schriftlichen Dings drinnen."(I3)

("Actually, everything I said (laughs) has more or less been incorporated, is part of this written thing.")

The results indicate that in the mental health care planning field forms of collective learning are developing, however they differ considerably in scope and form. When undertaken in larger scale, participation appears to be mainly experimental, yet strongly controlled by the contracting political authority.

In addition to leaving the definition of 'participation' unaddressed, there is only token acknowledgement in the documents of how participation may be affected by social factors, social inequalities and power imbalances and what strategies are planned to overcome these inequalities. One of these social factors is the socially constructed demarcation between the 'normal' and the 'abnormal' discourse and associated inequalities concerning opinions of people with mental disorders, which users experience.

"Leider darf ich das [Träume, Visionen] nach wie vor nicht sagen, weil sonst wird alles wieder als psychiatrisch eingestuft...ich habe gelernt zu schweigen 
und auch, zu reden, nur - ich schweige oft nach wie vor, weil ich einfach das Gegenteil kenne." (13)

("Unfortunately, I still don't feel allowed to talk about my dreams, my visions, because anything is easily categorised as psychiatric...I have learned to be silent but also to talk, however, I am still silent in many situations because I simply have experienced the opposite.")

Furthermore, participating users are constructed as a homogenous group. The statement below gives an example of how the concept of 'a generic service user' neglects power-relations and specific obstacles which certain groups of users may face. A female user who is involved in planning and campaigning observed:

"Was ich immer wieder sage, ich bin die Jüngste und ich bin eine Frau...und das war am Anfang immer so, dass das was ich gesagt habe die anderen [männlichen Betroffene] in eigenen Worten noch einmal wiederholt haben und dann hat es gepasst..... Ich hab schon oft die Erfahrung gemacht, ja so quasi, was möchte uns denn das junge Mädchen erzählen" (I3)

("What I constantly tell people is that I am the youngest one and that I am a woman... and at the beginning the typical pattern was that anything I said was repeated by the others [male users] and then it was fine. I have learned that people sort of ask who does this young girl think she is?")

In general, participation in any form may be restricted due to limited material resources which is acknowledged in only one document (Land Oberösterreich 2002). There is little in the proposals that acts to enhance the users' material resources. The discourse of different actors, however, reflects that material resources are a vital issue.

"Sehr viele Betroffene haben kein Internet, haben nicht diesen Zugang zu Informationen...es nutzt mir nichts, wenn ich Betroffene selbst anspreche und es scheitert dann wieder an der Mobilität." (I3)

("A lot of users don't have internet, they don't have the same access to information...it's useless to address users when lack of mobility makes participation impossible.")

“...und was absolut nicht angegangen wird, ist dass immer mehr an der Armutsgrenze leben...das heißt zum Krankheitsbild kommt noch das Finanzielle und das geht soweit, dass dann gesagt wird, wenn z.B. Betroffenenvertreter angestellt werden ... sie sollen ehrenamtlich arbeiten." (I7) 
("...and what is absolutely left unaddressed is their increasing poverty risk...that means that in addition to the image of illness there is the financial issue. When users are, for example, being employed it is suggested that they should work voluntarily.")

The results are similar to an analysis of user participation in Scotland by Lewis (2003). The author concludes that ,the rhetoric of user involvement often appears to have more to do with incorporation and control than democratisation and empowerment" (Lewis 2003, 8). Users are ascribed the role of consumers who learn to articulate needs but who are otherwise in a passive role. Extension of the consumer status to people who are using public services has been described earlier in other countries (e.g. Barnes 1999; Keat, Whitely and Abercrombie 1994). That 'consumerism' has also been transferred to Austrian mental health care, is illustrated by further discursive elements in the documents. While in older documents the term 'patient' is predominately used for service users, in more recent ones a diversification of terms occurs where notably, the term 'customer' appears. This term is usually accompanied with the logic of 'freedom of choice'.

"Nicht das Angebot darf länger über die Kund/innen, sondern die Kund/innen müssen über ihr Angebot entscheiden." (Landesregierung Oberösterreich 2002, 3)

("Customers must no longer be selected according to available supply, but customers must decide on their supply.")

In that context, Hugman (1994) has identified two sets of relationships between users and providers/payers. One form he has termed "market consumerism" which aims at consumers' ability to choose between different options in a 'market place'. The other one he calls "democratic consumerism" which means developing products rather than choosing between finished products. Similarly Barnes (1999, 84) distinguishes between " 'making and creating' the services...rather than simply 'consuming' them." In stressing freedom of choice, the mental health discourse seems to reflect the latter rather than the former. However, some elements of 'product-development' occur.

"Die Kund/innen wählen künftig nicht nur ihr Angebot aus, sondern (mit)entscheiden über neue Konzepte und beurteilen und bewerten bestehende Angebote." (Landesregierung Oberösterreich 2002, 3)

(,. Customers not only choose their service but they (partly) decide on new concepts and assess existing supply.")

When relating these results to general developments within the welfare state, they fit well with a common trend of transformation which Bröckling, Krasmann and 
Lemke (2000) have called 'economisation of the social'. Roughly speaking, 'economisation' means that market principles, their logic and concepts are transferred to the public sector. The starting point of this process can be dated back to the 1980s, when the public sector in Western European welfare states became increasingly described as being in a crisis (e.g. Ferrara and Rhodes 2000). Arguments of overspending and under-serving, demographic changes or technical progress have initiated major restructuring processes since the end of the 1980s in various parts of the public sector. On the one hand, privatisation and deregulation occurred. However, apart from changing ownership from public to private, another pattern of 'economisation' has been to transform the remaining public services through internal rationalisation and adoption of the market-logic. Characteristics of this logic are firstly, 'commodification', which means transforming health and social care services into 'buyable' goods. Secondly, creating business-like structures within organisations similar to private companies and finally, establishing competition between institutions and their activities (Novy 2002). This form of 'economisation' has particularly taken place within health and social sector services. For instance, in the UK, 'economisation' was clearly visible when the National Health Service (NHS) was changed into the so-called 'internal market' which meant that market-principles were introduced in a still publicly financed health care system. One example for the Austrian health care sector which mirrors this development is the DRG-related hospital financing system (Leistungsorientierte Krankenanstalten-finanzierung) which was des-cribed in the previous chapter 4. A vital characteristic of this financing model is that it introduces competition between hospital care providers and between departments within hospitals. The aim is to contain costs by forcing hospital administrators towards higher technical efficiency ${ }^{26}$.

Apart from those fairly obvious restructuring processes, transformation is also visible in more subtle forms. Thus, in order for the constructed 'quasi-market' to function, services which are provided have to be defined and constructed as single 'packages'. Pelizzari $(2003,9)$ remarks that "once it has been accepted that all services can be clearly separated from each other, they can be quantified according to market prices". This process of segregation is, again, visible in the mental health care discourse. One document, for example, has re-named services as 'products' and uses the term 'Ist-Produkte' (available products) or 'SollProdukte' (products which are needed) (Landesregierung Salzburg 2002).

\footnotetext{
${ }^{26}$ Technical efficiency refers to the physical relation between resources (capital and labour) and health outcome. A technically efficient position is achieved when the maximum possible improvement in outcome is obtained from a set of resource inputs. An intervention is technically inefficient if the same (or greater) could be produced with less of one type of input (Palmer and Torgerson 1999, 1136). This efficiency level is focused on the individual person and organisation and does not address the societal level.
} 
"Der im Mittelpunkt jedes Verwaltungshandelns stehende Kunde hat erstmals die Garantie, Leistungen - auf Grund der in den Produktbeschreibungen festgelegten inhaltlichen Kriterien - in bestimmter Mindestqualität zu erhalten.“ (Landesregierung Salzburg 2002, 29)

("The customer, who comes first in every activity of public administration, is for the first time guaranteed to receive services of defined minimum quality, according to the criteria which have been determined in the descriptions of the products.")

As the quote shows, 'economisation' is not restricted to the level of health or social care provision but has to be embedded in a wider context of public administration sector restructuring. Public sector reforms have been triggered by the introduction of 'New Public Management' (NPM), which meant transferring the market logic to the general public administration level. The theoretical basis for NPM is firstly, the theory of 'New Political Economics' which applies the concept of 'methodological individualism' for the analyses of actors' behaviour in the field of politics (Pelizzari 2001). As a second theoretical root, Hood (1991) identified 'The New Institutional Economics' with the focus on contestability, user choice, transparency and incentive structures. Mental health care has adopted the NPM-logic as it is, for example, visible in the aims of a project entitled 'KundeLeistung-Qualität-Steuerung' (customer-performance-quality-control), which accompanied the establishment of the mental health care plan in Upper Austria (Landesregierung Oberösterreich 2003). According to Atzmüller and Redak (2000), one central characteristic of NPM is that it changes public administration into a service industry and re-constructs citizens into consumers of public services. Equally, Barnes $(1999,85)$ notes that "changes in the system of governance associated with new public management provided opportunities for users to play a more active role in influencing the nature of health and social care services. However, those changes emphasized the creation of more effective consumers as a spur to increase service responsiveness, rather than community development as a basis for collective empowerment." 'Participation' in mental health care is therefore likely to be framed within a NPM perspective.

With NPM, a new language - the language of accounting - has entered the public sphere and has since then dominated the discourse. In that context, technical efficiency has become a primary goal in public services. As Rowe and Shepherd (2002) observe, user views in NPM are sought to make services more responsive to consumers' needs and preferences so that public resources are used more efficiently and effectively. Consequently, as Fairclough (1994) remarks, the 'consumer-discourse' is not only be understood as the frequent use of the term 'consumer', but as the growing development of specific discursive forms which he calls 'hybrid discursive forms'. They emerge, for example, when elements of 
former authoritative discourses are combined with promotional modes of appropriately addressing customer-oriented discourses.

Another central feature in this restructuring process of public services has been the strong focus on quantitative indicators, be it for quality control or for planning purposes (Rowe and Shepherd 2002). These indicators are crucial instruments for making activities comparable and subsequently, competitive. The importance of quantitative indicators seems also to be prevalent in mental health care.

"Die [Evaluation der psychiatrischen Versorgung] wurde halt einfach notwendig, weil man gesagt hat, die Zahlen stimmen nicht mehr." (I2)

("Evaluation of mental health care was found to be necessary because the figures were not correct any more.")

A professional employee critically observes:

"Der Schlüssel [Bettenschlüssel, Personalbedarfsschlüssel] muss passen und darüber hinaus gibt es nichts." (I1)

("The only concern is to find the correct quantitative indicator for bed numbers and numbers of personnel; apart from that, there is no discussion.")

According to Rose's (1999) critical analysis of using numbers within the technologies of government, figures are not to be seen as neutral or objective, as their quantitative nature might suggest. On the contrary, they are implicitly political if one, for example considers the choice of what to measure, or how to measure something. Similarly, MacKenzie (1981) remarks that despite their apparently unambiguous nature, numbers can neither be ideologically nor theoretically innocent which, most importantly, is grounded in the process of their development. When describing the unmet need of mental health care services, the majority of authors in the plans state figures for hospital beds, places in different types of accommodation, day structure and employment related services per 1000 inhabitants. When tracing back the origins of the figures in the reform documents, it becomes clear that the history of their development is intransparent. Two documents of 1992 and 1993 provided the source from which figures were adopted for the following plans (Zechmeister 2002). The development of the original figures, however, lacks intelligibility in terms of methods and data used for their calculation. Critics have argued that despite their seemingly precise nature, the figures published are to a great extent based on values and estimates (e.g. Rössler 1998). Authors of more recent documents have tried to use other methods of defining met and unmet needs for services, such as expert interviews, or utilisation data (e.g. Püringer et al.). Others have particularly stressed the shortcomings of using figures for service components as a means to define future 
needs (e.g. Landesregierung Oberösterreich 2002) without, however, abandoning the figures in the actual plan.

This result has to be embedded into the broader context of social policy. Rose $(1999,197)$ remarks that "numbers have achieved an unmistakable political power within technologies of governments." Not only do they reduce complexity, but they make governments judgeable and confer legitimacy. For public spending on mental health care they are undoubtedly a valuable instrument to operationalise reform objectives and to justify resource allocation to an area of social policy which has never belonged to the most 'popular' ones. Additionally, national fiscal policy has come under pressure by regulations on the supranational level. Under the headline 'quality of public finance', national policies are obliged to justify their types and amounts of spending which increases the demand for quantifiable indicators for spending public money (BEIGWUM 2000). Furthermore, Porter (1996) has pointed out that the recourse to quantification is linked to a climate of distrust and suspicion. The allure of numbers increases when authority is mistrusted and when experts are met with scepticism. People respond to the climate by referring to figures, thus trying to justify their judgements on the grounds of objectivity. Psychiatry, as an unpopular part of social policy, may be exposed to such pressure. With psychiatrists being seen as 'stepchildren' within medical profession they may be particularly prone to such patterns of behaviour.

In a way, numbers de-politicise the areas of political judgement. The formalistic systems ignore the extent to which they are politically constructed. Rose $(1999,208)$ remarks that " 'the power of a single figure' is here a rhetorical technique for 'black boxing' - that is to say, rendering invisible and hence incontestable - the complex array of judgements and decisions that go into a measurement, a scale, a number." In that sense, the concepts of care as transported via figures in the reform plans become subtle and difficult to identify. Consequently, this underlying data, decisions and concepts are not easily challenged from actors other than the producers of the reform documents.

Weber (2001) has analysed that the rising significance of quantitative indicators in the NPM model not only leads to de-politisation but also to dedemocratisation. He argues that decision-making takes place increasingly informally and shifts away from formal democratic processes. Thus, the restructuring process changes the role of health policy. Similarly, Sheldrick (2003, 149) notes that "the restructuring of health care systems...has made it more difficult for people to participate in allocation decisions and to hold decision makers accountable. The adoption of the internal market in the UK, for example, resulted in greater autonomy for health authorities, while limiting individual participation and parliamentary and ministerial oversight." Additionally, due to the argument of scarce resources, decisions about which services to provide for are increasingly being made according to principles of cost-minimisation. This procedure reduces experts' responsibility to a technical problem of minimising 
costs. Consequently, the impression appears to be that political conflicts don't exist or that every conflict is related to scarce resources which can be solved technically and rationally.

\subsubsection{Towards a Liberal Model of Mental Health Care?}

Against the backdrop of the previous chapter it is finally of interest to address some further significant terms in the planning documents, which are 'needsbased' and 'person-oriented' services. The focus on person-oriented needs in mental health care originates in increasing dissatisfaction with existing services, particularly in the field of social care. It has been criticised that services have not been provided according to users' needs but providers have, on the contrary, defined their own type of mental health care resulting in inflexible and fragmented types of different services being established. This has led to the users' shifting between services whenever their needs were changing. The situation has been particularly difficult for people with multiple needs. As a matter of fact, those people usually have had to be institutionalised because this has been the only place where multiple needs have been able to be met. Mental health care planners regard the shift to a person-oriented and needs-based service as solution to overcome fragmentation of service provision, because focussing on the individual's needs requires co-ordination and integration of services such as integration of primary and secondary care or health and social care (Bundesministerium für Gesundheit 1999). From that perspective, needs-based service provision goes hand in hand with the aim to establish an adequate community-based system of care.

Viewed through the 'CDA-lens', however, some further dimensions of the 'needs-based'-'person-oriented' discourse formation need to be addressed. Firstly, questions to be asked in that context are what the documents say concerning how needs are assessed, how they are rated and what the plans indicate about the measures which are planned to meet needs. As with participation, there exist some terminological problems with the term 'need'. Thus, two terms, namely the German 'Bedürfnis' and 'Bedarf' are randomly used in the documents, usually without explicitly outlining what meaning they refer to. According to the definition by Heinze and Priebe (1995), 'Bedürfnisse' are the subjective needs which are those needs users personally experience and articulate. 'Bedarf', on the contrary, is politically determined or normatively postulated. 'Needs-based service provision' in documents (randomly expressed as 'bedürfnisorientiert' and 'bedarfsorientiert') therefore involves both dimensions, a subjective one and a normative one. Assessment of needs can take place in various ways. Subjective needs can, for instance, be assessed via institutionalised 'quality of life-research', via informal conversations between user and professionals or via individual 
standardised interviews, to name just a view options. Comparably, normative needs can also be defined through different modes. These range from a democratic formulation process to a 'technical process' of experts' evaluation and calculation, such as cost-efficiency evaluations. The mental health care discourse, though not explicitly outlining, seems to reflect a specific amalgam of these two categories. On the one hand, the 'consumer discourse' transports a specific approach of individual needs assessment. Thus, mental health care consumers are asked to articulate their individual needs in analogue to market research. This appears to be visible in the development of specific instruments for individual needs-assessment in order to predict resources.

"[Es ist] daher erforderlich, ein geeignetes standardisiertes Instrumentarium zu entwickeln, das sowohl den individuellen Hilfebedarf ermitteln als auch in weiterer Folge den daraus resultierenden notwendigen Ressourceneinsatz prognostizieren kann.“(Landesregierung Oberösterreich 2003, 2)

("It is therefore required to develop an adequate standardised instrument in order to assess individual needs and to predict resulting resource implication.")

Elements of normative needs-assessment can be considered to be the same as the previously mentioned quantitative indicators, thus needs are defined and/or calculated by experts or according to the listings of further normative experts' criteria.
"Gerade für eine fachlich richtige und menschlich adäquate, also eine bedürfnisgerechte Versorgung dieser Patientengruppe ist es erforderlich, eine entsprechende Planung zu betreiben." (Katschnig et al. 1996, 14)
("Particularly to provide professionally correct and humanly adequate, hence needs-based services for this specific group of patients, mental health care planning is required.")

Overall, this discourse formation seems to be an additional component of previously explored key orientations in the social sector. Hence, the described form of individual needs-assessment is one crucial element of the NPM understanding of public service provision. The same is true for the applied methods of needs-assessment on the population-level. With respect to the prevalent type of individual needs-assessment, Mayer (1982) criticises that simply asking individuals about their needs is problematic in several ways. Firstly, it is usually carried out during an artificial situation of an interview. Secondly, needs will typically be stated according to the specific experience and living situation. Thus, responses are mainly oriented towards the status quo of individuals and usually consist of issues which seem generally attainable for the individual 
person. Results from socially disadvantaged groups will, thus, be influenced by their usual living conditions and their adaptation to them. This type of needsassessment, furthermore, restricts the problem of 'need' to a problem of communication, leaving structural hegemony unaddressed. As Heinze and Priebe (1995) put it, sufficient communication between actors is then regarded as automatically removing hitherto existing disadvantages of specific social groups. Put differently, the focus on individual needs constrains political awareness of how needs have been developed. An individual needs-based focus is then just another dimension of the medical-oriented approach in health care, which is traditionally characterised by the emphasis on the individual person and her/his disease. In that respect, Lewis (2003) has expressed concerns about the potentially paternalistic nature of the concept. The 'needy individual', she considers, symbolises a passive and dependent individual.

Furthermore, Sayce $(2000,81)$ remarks that a person-oriented and need-based mental health care service may aim to establish a 'perfect' system of community care, that is a community care system which effectively changes places and organisation of services and ceases to resemble institutions. But she goes on to say: "It fails to set as an aim changes in the whole social environment, that would break down the barriers of exclusion from economic and social life. It fails to require that one role of mental health services should be to facilitate social inclusion." From that perspective, users may contribute towards the development of service provision, when they are asked to list some of their unmet service needs in mental health care plans, yet this does not automatically guarantee conditions which facilitate the participation of a mentally ill person as a full citizen. In Sayce's (2000) words, it does not guarantee full social inclusion of the mentally ill. Thus, focus on training and support for users in order to contribute to improve services leaves broader social dimensions uncovered. These dimensions are not addressed in the planning documents.

Bonell and Hilton (2002) have, furthermore, outlined that consultation-types of 'needs assessment' exercises may be carried out by service managers or planners in order to inform or merely legitimize their decisions. Similarly, Mayer (1982) notes that a market-research type of needs-assessment is unlikely to shape planning processes, but it rather provides information for planners as to how citizens' expectations might be controlled.

Articulating needs can, additionally, be influenced by specific discursive norms which need not necessarily be located within the mental health care field. One example is the 'zero-deficit spending' discourse which dominated discussions on public spending in the period between 2000 to 2002 and the prevailing discourse of public cost-containment. The climate of fiscal imperative affects the notion of public resources and entitlements. 
"Ich meine, die Euroumstellung haben wir auch gehabt, es ist wirklich alles teurer geworden, und jeder versucht zu sparen, und des merkt man halt schon auch bei Subventionen.“ (I3)

("There was the new currency, everything has really become more expensive, everyone tries to save money and this can be noticed when it comes to subsidies “)

In such an environment, having to bear a considerable proportion of costs privately becomes a much easier fact to be accepted.

"Wir waren in der unglücklichen Lage sag $\mathrm{i}$ iazt amal, letztes Jahr, dass uns eben im Frühjahr versprochen worden is, dass wir eben Vereinssubvention bekommen, dann hat sich die Lage geändert, dann war auf einmal kein Geld mehr da. Jetzt haben wir das Jahr 2002 mit Eigenkapital von 7000 Euro finanziert."(I3)

("We were in this unlucky situation that we were promised subsidies in spring. Then the situation changed and suddenly, no more money was left. Thus, we covered the costs for the year 2002 with 7,000 $\epsilon$ of private capital.")

Support from the government then turns into something outstanding for which gratefulness is expressed.

"Die [Personen der Sozialabteilung] sind sehr nett, die rufen auch immer wieder an und so...und sind auch immer mit Rat und Tat zur Seite gestanden, und wir haben von ihnen die bestmögliche und großzügigste Unterstützung erhalten und das darf man auch nicht vergessen." (I3)

("The people from the department of social affairs are very kind, they call now and then... and they have given advice several times. We have received the best possible and most generous support from them and one must not forget this.")

The financing discourse is, moreover, important in context with the measures to meet defined needs and provision of services.

"Grundsätzlich sollen sich Menschen mit psychosozialem Betreuungsbedarf sowie deren Angehörige frei entscheiden können, welche angebotenen und bedarfsgerechten Leistungen sie von wem in Anspruch nehmen wollen. Entsprechend dieser Wahlmöglichkeit sollen innerhalb der finanzierbaren Möglichkeiten möglichst vielfältige und variable Angebote zur Verfügung stehen. (Landesregierung Oberösterreich 2002, 11) 
("In principle, people with psycho-social needs for care and their relatives should be able to choose from those services which are supplied and regarded as adequate. According to this freedom of choice, the variety of supplied services should be as large as possible. They need, however, to be provided within a limit of available financial resources.")

While freedom of choice is transported as being paramount, there is an important appositive saying that within the limit of available financial resources, the variety of supplied services should be as large as possible. Noticeably, 'financial resources' are constructed as something fixed and naturally predetermined. This runs contrary to the fact that the amount of 'available financial resources' is determined in budgetary policy processes (BEIGEWUM 2000; BEIGEWUM 2002). Particularly in the social sector, where sources of financing are predominately taxes, the proportion which is allocated to mental health care is eventually subject to negotiation. The rhetoric of predetermined resources, on the contrary, signals the impression that financial resources are an unchangeable natural fact, something which is not directly related to political actors and processes. This shapes individual perceptions and reduces possibilities and degrees of action.

It is, furthermore of interest that the concepts of needs-based and personoriented services are usually accompanied by the term 'individualisation'. Although referring predominately to the right of 'self-determination' and 'individuality', the concept implies yet another aspect which is the notion of individual responsibility:

"Wir wollen eigentlich den betroffenen Menschen in den Mittelpunkt stellen...und aufgrund dessen müssen wir die Betroffenen stärken, dass sie sich auch um ihre Rechte sozusagen kümmern. Damit übernehmen sie aber auch mehr Selbstverantwortung. Also, net nur Rechte fordern, sondern auch mehr Selbstverantwortung.“ (I7)

("We actually want to follow a person-oriented approach... and this means we have to strengthen the users so that they can look after their rights. But then they also have to take over self-responsibility. As I said, they cannot just demand rights but they also have to bear responsibility.")

This approach has also been adopted by several international user organisations. The activist Ron Thomson, for example, stresses that "in order to get...rights, people have to take responsibility. They cannot maintain their 'secret unwillingness to be held at least in part accountable for some of their actions while mentally ill." (Thompson in Sayce 2000, 118).

Remarkably, these utterances go in line with liberal arguments from both the Right and the Left, who have claimed that individual autonomy and responsibility has to be strengthened and that individuals have to adopt an active part in 
governing. That kind of discourse has started to become dominant with the emergence of social-liberalism in Western Europe. In Austria, this was the case from 1986 onwards, when the Great Coalition superseded the social democratic hegemony. For Jessop (2000) this policy change is accompanied by the shift from the 'Keynesian welfare national state' (KWNS) to the 'Schumpeterian workfare post-national regime' (SWPR). While welfare policies are premised on rights attached to national citizenship, he argues that workfare policies are premised on mobile workforces and active integration into labour markets, accompanied by emphasising the individual's responsibility. In Jessop's view, this cannot simply be regarded as continuity of the welfare state but it is associated with a wide range of re-visionings of a new welfare society.

With respect to mental health care, this shift is particularly interesting, since it involves some strategies which sound very similar to mental health care reform goals. One of them is the emphasis on the 'local', the 'community', notably the focus on empowering community groups (Brodie 2000). The 'community' is therefore not only emphasised among mental health care reformers but, as Brodie (2000) remarks, also neo-liberalism has re-invented the community. Even more, she argues, community and individualism have been conflated. Notably, within the community, the individual subject has become more responsible and emotionally linked with other individuals of her/his community (Rose 2000). Governance, through activating the engagement of individuals, their strengths and readiness for decision making, has become the contrasting picture to the centralist and paternalist state which inhibits the individual.

The fact that different fields of problems are linguistically defined (such as community mental health care), at the same time constructs a field where political strategies are to be implemented. Communities become the geographical or virtual territory through which governance takes place. They become classified, documented and interpreted. Governance through communities requires several strategies which define the new dimensions and the individuals as part of them. It additionally requires strategies for integrating, instrumentalising or mobilising individuals. Rose (2000) points out that through the terminus 'community' an 'ethnographic sociology' entered the language of public authorities which replaced the initial discourse of critical activists who advocated for a less paternalistic welfare state. The movement of resistance has thus turned into a discourse of experts and has been consolidated into a professional field. Finally, Rose points out that through inventing the community, 'the social' as an overarching space has been fragmented into different communities. Put differrently, governance has ceased to address collective social issues and is tailored to defined and demarcated communities and their individual members within. Individual rights and responsibilities are stressed while reciprocal responsibilities of society for providing equal opportunities for the individual person are barely addressed. Not surprisingly, in the Austrian mental health care reform processes, 
'the social' in terms of addressing collective social complexities, plays a minor role compared to discussions concerning individual measures for individual persons in the mental health care community. An empirical indication for this in the reform documents may be that mental health care issues which are more concerned with 'the social' have received comparably low attention. For example, employment related initiatives and services have been addressed in much less detail and which much lower priority than hospital care.

Not least, during that transformation process the mode of governance changed. For the Austrian case, Novy and Hammer (2002) point out that social policy between the 1970s and the mid-1980s was characterised by a dialectic and open approach, leaving room for experiments and social innovation. Notably, during that period concepts of participation, empowerment and self-help were strongly supported, yet compared to the current situation, they were embedded in a different ideological context. With the onset of the social-liberal period, a shift towards a more technocratic and social engineering style of governance occurred. Understanding of politics changed from a dialectic to a positivist form that operates with clear and logical relationships between means and ends. Embedded in that context, the meaning of core-concepts has inevitably undergone substantial changes.

\subsection{Conclusion}

In this chapter, mental health care and current reform initiatives have been addressed. For the Austrian case, reform processes and the content of reform objectives have been analysed in detail, following the approach of a critical discourse analysis. I have aimed to demonstrate some of the linguistic aids which are used in the current mental health care discourse and the controversies which are linked to them. This chapter has additionally shed some light on the process of mental health care discourse development whilst the various social dimensions to which the discourse is linked to have also been explored. Furthermore, I have learned about the rhetorical aids which are used to define and portray actors in mental health care. In that context, it has been particularly focussed on the discourse about the mentally ill and attempted to exemplify what these findings indicate about the roles and status of the mentally ill within mental health care planning and provision. The findings provide a picture about the position of mental health care in general and that of the mentally ill in particular within the overall welfare state and society.

Although the plans differ in appearance and detail, core discursive strands can be observed collectively. Most importantly, mental health care planning tends to be influenced by overall welfare state transformation processes. Although core aims remain unchanged, they become a different meaning in the broader 
transformation context. This is particularly the case when concepts are not clearly defined and thus can be used differently in changing ideological climates.

Generally, the plans focus on the content-dimension, while the process dimension is largely neglected both in the planning documents themselves and in the planned measures and procedures. Planning processes are rather intransparent. A case in point is that existing conflicts are not addressed, nor are proposals stated as to how conflicts might be handled in future. This gives the impression of existing consensus. Another example is that rather than valuing participation as a process in its own right, participation is mainly seen in instrumental terms; as a means to hearing public views on their health care needs. As Rowe and Sheperd (2002) put it, this is rooted in the NPM focused approach to participation.

When it comes to actor-relationships, on the one hand, hitherto privileged statuses remain unchanged. Thus, the medical profession still has a dominant role in mental health care planning and provision. At first glance, I tend to agree with Barnes (1999) who concludes for the British case that a fundamental shift in power seems not to happen. However, the previous ten years of planning processes have taken place under specific circumstances and social changes. Thus, when addressing the discourse-societal relation, the question of actors and powerrelations becomes another dimension. Firstly, existing forms of participation provide a challenge and force those in positions of power to reconsider their practices. Moreover, involvement of further occupational groups and already existing forms of dialogue imply the potential for transformation and change. Yet, the transformation is itself a discursive hegemony. Standards and normative principles in the documents which go beyond psychiatry in a medical sense are part of a larger discourse formation. This is the discourse formation of welfare state restructuring, which is evidently invested by liberal ideologies. One example of that is the economisation discourse and the associated re-construction of the status of users. The analysis, therefore, suggests that medical dominance in terms of shaping and defining the discourse is in fact restricted to a very narrow 'playing field' which is equally true for the potential of the mentally ill to shape planning and provision.

Let me recur back to discourse theory which notes that social identities, roles, attitudes and value systems are transported via discourse, whilst users of discourse are not necessarily conscious of those processes. In mental health care this might be especially likely, because the rhetoric of several core elements has remained unchanged since the 1970s. Terms that have been used by psychiatrists in the 1970s are still observable in the documents. However, 30 years ago they were embedded in a different context. When looking at more subtle elements and linking them to broader socio-political changes, a transformation of meaning can be observed. This indicates that power is diffuse and cannot be ascribed to some single actors. It seems rather to be interwoven in the amalgam of knowledgepower formations. 
When embedded in that context, the key-concepts of mental health care plans become multidimensional connotations. The deconstruction of the concepts has shifted the focus away from mental health care per se and has turned the attention to the relation between mental health care and social policy and the political economic context. While the discourse mirrors that, overall, financing issues play a minor role in mental health care discussions, the deconstruction process should in the following chapters allow for the identification of links between mental health care reform programs and financing issues and demonstrate how financing questions are addressed indirectly in many cases. 


\section{Mental Health Care Financing in the Light of Reform Objectives and Discourse}

The previous chapter has shown that the mental health reform discourse mirrors a transformation process of mental health policy which is part of a larger process of welfare state transformation. In this chapter it will be analysed which role mental health care financing plays in both reflecting and shaping this development and vice versa which role discourse transformation plays in influencing and shaping (future) financing arrangements. Additionally, it will be shown how the interdependency between financing and discourse impact on the overall mental health care structure and on individuals affected by mental illness and/or their relatives. In doing so, not least the interrelation between financing and service provision will become more transparent.

The chapter is based on the approach that mental health care financing is a political process and bears considerable potential to shape societal structures and relationships. Thus, any mental health care financing system mirrors a specific social-policy concept of mental health and illness by the way, mental health care is financed in quantitative and qualitative terms and by the way, mental health care financing is embedded in the overall welfare state context.

The objective of this chapter is to make the central role of financing for mental health policy formation and processes of policy development more visible and to make transparent processes of transformations which are already taking place or which are likely to occur. It is to be expected that the link between financing and discourse and their impact on the mental health care structure are not always obviously visible, the more so if no major mental health financing reforms are taking place. Therefore, attention will particularly be paid to more subtle elements of change and the role of financing herein.

\subsection{Analytical Framework}

In order to make the complexity more tangible an analytical framework is required which allows for a structured analysis of mental health care financing and its policy dimensions. The analytical framework which will be used has been adapted from Daly and Lewis (2000) who have developed a framework for the purpose of analysing social care (financing) arrangements (table 17). Similar to their concept of social care, mental health care takes place at the intersection of state, market, family and the voluntary sector and is, as Daly and Lewis (2001, 286) put it for social care, "an activity that crosses spheres". In mental health care, this is not least due to the encounter of traditionally separated policy domains of health and social care with their individually characteristic involvement of 
different societal sectors (see chapter 3 and 4). It is precisely the complexity resulting from that which is at the centre of the framework.

Overall, the analysis focuses on three dimensions of 'mental health care' which are found to be closely linked to financing and discourse. The first one is the 'responsibility dimension', which draws attention to how financing arrangements and discourse reflect responsibilities and obligations for mental health care. This brings also in a normative element concerning social relations in mental health care and the state's role in shaping these relations. The second dimension is 'labour' which draws attention to how financing and discourse are linked to the nature of work and activity (paid or unpaid work, formal or informal work). Finally, the third dimension is the 'cost-dimension' which addresses the question how financing arrangements are linked to the division of costs between families, individuals and within societies at large.

The analytical framework used addresses two levels as demonstrated in the two columns of table 17. Firstly, it will be analysed how financing shapes a specific mental health care system landscape on the macro-level. Thus, I seek to examine how financing arrangements form the division of mental health care between the sectors 'state', 'market', 'family' and 'voluntary/community'. Secondly, the framework addresses the micro-level and analysis effects for individuals by who I mean people who are affected by a mental illness and/or their relatives. Furthermore, as it is outlined in the two rows of table 17, the framework addresses the current situation as well as the dynamics of change by analysing the shifting of boundaries on both, the macro-and the micro-level. Thus, it will be identified if relationships within mental health care are shifted between the sectors on the macro-level and between individuals on the micro-level. For this task, I will specifically use the results from the discourse analysis in chapter 5 as an empirical indicator of processes of change. Overall, the empirical material for answering the analytical questions will be used from the sources provided in the previous chapters 3,4 and 5, as outlined in the third row of table 17 .

The framework has been found appropriate for several reasons. Firstly, it puts mental health care financing at the centre of interest rather than following traditional differentiations into either health or social care financing. Consequently, it draws particular attention to the balance between the health and social sector in mental health care and financing. It has additionally been found adequate because it enables me to capture the broad spectrum of financing arrangement and is, for example, not restricted to one selected form such as cash benefits or to one financing element such as sources of financing. Even more, it makes transparent the interplay between certain elements of financing arrangements and their effects on mental health service provision. 


\begin{tabular}{|c|c|c|}
\hline \multicolumn{3}{|c|}{ Analvtical Framework } \\
\hline & Macro-level & Micro-level \\
\hline $\begin{array}{l}\text { Implications of mental health } \\
\text { care financing on... }\end{array}$ & $\begin{array}{l}\text {...the division of mental } \\
\text { health care (labour, } \\
\text { responsibility and cost) } \\
\text { between the state, market, } \\
\text { family and community }\end{array}$ & $\begin{array}{l}\text {...the distribution of mental } \\
\text { health care (labour, } \\
\text { responsibility and cost) } \\
\text { among individuals within the } \\
\text { family and community and } \\
\text { the character of state support } \\
\text { for the mentally ill and for } \\
\text { carers }\end{array}$ \\
\hline Trajectories of change & $\begin{aligned} & \text { more/less: } \text { state } \\
& \text { market } \\
& \text { family } \\
& \text { community }\end{aligned}$ & $\begin{array}{l}\text { - alteration in the distribution } \\
\text { of mental health care activity } \\
\text { - alteration in the identity of } \\
\text { carers } \\
\text { - alteration in the conditions } \\
\text { under which mental health } \\
\text { care is carried out and the } \\
\text { nature of the state's role } \\
\text { herein } \\
\text { - alteration in the relations } \\
\text { between mental health care } \\
\text { giver and receiver }\end{array}$ \\
\hline Empirically indicated by & $\begin{array}{l}\text { chapter } 3,4, \text { and } 5 \\
\text { - the mental health care } \\
\text { reform discourse } \\
\text { - mental health care financing } \\
\text { arrangements } \\
\text { - the distribution of } \\
\text { expenditure and costs } \\
\text { between sectors } \\
\text { - the distribution of provision } \\
\text { between sectors }\end{array}$ & $\begin{array}{l}\text { chapter } 3,4 \text { and } 5 \\
\text { - who performs mental } \\
\text { health care? } \\
\text { - who is the recipient of } \\
\text { which type of mental health } \\
\text { care benefits and services that } \\
\text { are available } \\
\text { - who has access to which } \\
\text { type of mental health care - } \\
\text { which kind of relations exist } \\
\text { between the mental health } \\
\text { care giver and receiver? } \\
\text { - under what economic, social } \\
\text { and normative conditions is } \\
\text { mental health care carried } \\
\text { out? (e.g. who bears the costs, } \\
\text { what is the discursive } \\
\text { context) }\end{array}$ \\
\hline
\end{tabular}

Table 17: Analytical framework; own table adapted form Daly and Lewis (2000) 
Most importantly, the framework allows for addressing how mental health care financing shapes the complex relationships between state, market, family and the voluntary sector in mental health care or vice versa how financing is shaped by this relation. Thus it makes visible the social and political economy within mental health care financing and service provision are embedded. Similar as Daly and Lewis (2001) have observed for social care, I argue that this issue has remained underdeveloped in mental health care so far. Notably, the framework incorporates the role of the informal sector which has all too often been neglected in current welfare state reforms and their analyses (Österle 2001). Not least, the framework's beauty lies in the fact that it connects the changes on the macro level with the micro level, thus making visible the relationship between financing arrangements and individual social relations within mental health care provision. In that respect it allows for example for making transparent the gendered nature of these relations. Overall, the framework furnishes a rich picture about possible directions of mental health policy, thus eventually reflecting the policy dimension of the financing-reform discourse conglomerate.

\subsection{Mental Health Care Financing and Impacts on the Macro Level}

\subsubsection{The Changing Role of the State}

Chapter 3 has shown that in terms of service provision, the role of the state has decreased while the sectors 'private non-profit', 'private for-profit', 'family' and 'voluntary/community' have played an increasingly important role over the last decades. Furthermore, within the health care sector, the state's role as a provider is mainly restricted to hospital mental health care. Outside the health care system provision is to a large extent carried out by various private sector providers.

However, those who provide services needs not necessarily to be identical with those who are financially responsible. Data from chapter 4 gives an insight into this issue. When analysing the data, it turns out that mental health services which are provided within the health care system in Austria are characterised by relatively high public financial responsibility. This is shared between the state and the social insurance funds. Although some private responsibilities in the form of co-payment for the identified health care sector services exist, they are rather moderate in size compared to other services. Yet, co-payments have been raised over the last years and some new forms of out-of-pocket payments have been introduced but it needs to be noted that exemptions from co-payments for low income groups exist which may particularly apply to the mentally ill. An exception to this financing pattern is the financing of psychotherapy which is 
characterised by a relatively high overall private share. In general, the described public-private payment pattern is not only characteristic for Austria but can also be observed in a similar form in the German or the UK case, although responsibility of the private sector in the form of private insurance seems to be higher or even expanding in these countries.

Furthermore, within the health care sector public responsibility is highest for hospital mental health care in the Austrian model. For mental health care services which are provided within the health care sector but outside hospitals such as psychiatric specialist services, private financial responsibility for the sector 'family' tends to be more likely (e.g. in the form of prescription fees or travelcosts etc.). In that respect, Austria does not differ much from the German or the UK case. For example, according to the Mental Health Foundation (1995), in the early 1990 s, it was estimated that on average $80 £$ per person per day was spent publicly on those in English mental hospitals and just $£ 1$ per person per day was spent on those in the community. Likewise, in a review of costs in one area in Germany in 1983 it was found that of the amount paid from social insurance sources, around 70 percent went towards the costs of hospital mental health care (Cooper and Bauer 1987). However, the gap may have narrowed with ongoing reform processes.

For mental health care services which are covered outside the health care sector, the state's financial responsibility is tendentially lower. The Lower Austrian case has shown that public responsibility is more likely to be restricted to coverage of only a proportion of costs with the person affected or even his/her relatives having to pay for the other share. Moreover, when the principle of subsidiarity is applied, private sources account for the primary basis of funding, while only the remainder is covered publicly (e.g. in the case of residential care). In summary, the extent to which the state bears financial responsibilities for mental health care services in Austria correlates very much with the extent to which mental health care services are covered within the health care system, more exactly, within hospitals. Again, this is also a typical pattern in the two other countries which have been described.

In addition to the range of services covered, one has to take into account the level of coverage which is quantitatively indicated by the level of expenditure and its development (in relation to other expenditure). Unfortunately, specific quantitative empirical data on that matter are hardly available for Austria. Nevertheless, some data which I have presented earlier seem to indicate that overall expenditure for mental health services within the health care system has increased which is for example demonstrated by rising health insurance expenditure on psychotropic drugs and on psychotherapy. Increasing expenditure is also suggested by the figures on rising costs for psychiatric hospital care (at least until 1995) or by the increasing number of specialist psychiatrists. However, most of the data cannot be segregated into public and private expenditure shares 
or they are available for one point in time only. In that respect, the general health care expenditure trend for Austria may provide a rough picture (see 4.4.). It shows increasing health care expenditure in absolute terms. In relative numbers, public expenditure has decreased while private expenditure has increased at an annual rate of $4.5 \%$ over the last years (Hofmarcher and Röhrling 2003).

For mental health services outside the health care system, currently available Austrian data doesn't allow for a calculation of the share of expenditure levels. Generally, chapter 5 has provided some evidence that public financial responsibility is more subject to discretionary decisions and, thus, rather volatile and that private responsibility can be substantial. A case in point is the unstable public subsidy of specific services in the self-help sphere which can be associated with high individual private investments. A rough indicator concerning the publicprivate share for services outside the health care system is the data on social assistance expenditure. In that respect, since 1998 the increase of gross expenditure has been accompanied by a constantly rising private share (see 4.4.).

Apart from that, it is important to address the development over time in terms of service structure and organisation of mental health care as outlined in the planning documents. As demonstrated in the framework in table 17, it will be asked how these changes affect the relationships between different societal sectors. One common feature of all documents is the aim of deinstitutionalisation. Although this is related to major restructuring processes, financing issues are hardly addressed. For example with respect to sources of financing, the reform discourse does not explicitly address any changes in the payer-relationship, be it the relationship between different public payers, between public and private payers or between various private payers. Yet, given the Austrian payer scene and the legal responsibility patterns, the community care paradigm with its increasing service provision outside the health care sector makes a change in the payer relationship inevitable.

A shift to service provision outside the health care system, firstly incurs changes within public sector responsibilities with growing local or provincial public responsibilities. Secondly, due to the different legal situation (e.g. characteristic of cost-sharing), it also involves higher private responsibilities for the sectors 'family' and 'voluntary/community'. This has been a general concern. To quote Goodwin $(1997,62)$ : "What the shift towards community care does allow for is increased scope for the shifting of the costs of care from the state on to informal carers. It also allows for the neglect of at least some patients, who, following discharge, my not receive any community support services whatsoever. Community care policy creates the possibility of cutting costs in a way that institutional care does not allow, and, there is some evidence of governments having chosen this route."

Notably, increasing mental health care obligations for service providers outside the health care system do not necessarily correspond to equally increasing 
resource allocations. The UK example shows that, although government funding for general social services has increased in recent years, the amounts available for mental health have been constrained and the mental health grant given by central government to local authorities has not been increased at all in the latest period, despite the fact that mental health care had been given a priority status (Sainsbury Centre for Mental Health 2003). Furthermore, the empirical data from chapter 4 demonstrates that in absolute terms, the mental health budget which is allocated to the health care sector is significantly higher than that transferred to the social sector in the UK.

Although Austrian data are not available for a similar investigation, there are some indications for an analogous pattern. Firstly, the amount of money which was used in 1997 for financing long-stay wards has been 'frozen' and has since then been used for financing the rising number of other psychiatric services outside the hospital (Zechmeister and Österle 2001). Hence, even though financial sources for some services have been increased (e.g. for MAPS in Lower Austria), this is mainly due to a re-allocation from former long-stay wards which had been financed by the same payer. Secondly, many of the former 'long-stay' mentally ill have been transferred to long-term care institutions which are paid much lower daily flat rates than the original hospital wards. What there is no evidence for, is an official transfer from resources stemming from within the health care system to payers which are responsible for services outside the health care system. Although without doubt the number of services outside the health care sector has been increased, it is unlikely that the overall amount of resources has increased to the same extent.

Furthermore, raising resources in the 'non-health care sector' has been particularly difficult, as the scope of action in terms of public budgets and the resources available have been considerably restricted for provinces and communities and, thus, for those payers which are primarily responsible for mental health services outside the health care sector. The financial situation of provinces and communities has been severely affected by federal measures of zero-budgeting in context with the EU-stability pact (Smutny 2002). Thus, shifting public responsibility to the provincial and/or local level seems not least to be associated with less flexibility for raising additional resources for mental health care.

Considering that an aim of the reform has been to primarily locate treatment and care not only outside the hospital but to a high extent outside the health care system, a resource allocation debate which addresses re-allocation of former health care resources is vital. In other words, if overall resources are not increased for the non-health care services, increasing service capacity will have to be financed with the same amount of money which raises the question of who has to bear the financial burden? As mental health care services are very personnelintensive, it seems obvious that cost-containment measures will primarily affect 
the workforce. Highly qualified people might be paid less or their salary may stagnate, jobs might as well be increasingly carried out by less qualified personnel or by an increasing number of voluntary workers. The latter has been characteristic for many of the non-profit organisations which are involved in mental health care outside the health care sector. This may as well impact on the quality of care. As the study by Denk and Weibold (2002) has demonstrated, despite the high number of persons with mental illness in nursing homes, only a small number of specifically qualified psychiatric nurses has been available to care for these persons so far.

Another scenario is that the diversity of services provided will be reduced, thus concentrating financing on some singly priorities. Indeed, while MAPS in Lower Austria have been expanded over the last years (related to the quantitative figures of the mental health care plan), employment related services have received increasingly lower financing priority (Durstberger 2004), which may not least be related to the fact that the latter have received only minor attention in mental health care planning documents (see 5.2.). Notably, the criteria for focussing on MAPS rather than employment related services have neither been made transparent nor discussed publicly nor have there been research activities which would legitimise such a prioritisation from an academic point of view.

Not least, the development has to be embedded into the context of overall health and social care sector restructuring. Firstly, it has been demonstrated in chapter 5 that the political context has changed from a social liberal to a more market-liberal ideology. Similar to other Western European countries, a key issue in the Austrian social policy discourse has been the cost containment aim which has also an impact on mental health care. In the international debate it has been noted that the desire to save public money has been key to the process of deinstitutionalisation. For example, Ungerson $(1995,39)$ remarks: "In many European countries these policies [deinstitutionalisation] are driven largely by ideas of reducing expenditure - namely that it is cheaper and more cost-effective to care for people in the "community"'. Although professional arguments have played an important role for framing the deinstitutionalisation goal, the costcontainment context has probably been another factor of influence. Yet, as it has been shown, the term 'cheaper' is likely to be related to public sector costs only, while in terms of overall economic costs, deinstitutionalisation needs not necessarily to be cheaper (Fakhoury and Priebe 2002), but in some cases simply masks a shift of costs from the sector 'state' to the sectors 'family' and 'community'.

In conclusion, though not explicitly made transparent in restructuring processes, the financial impact in terms of payer relationship and financial responsibility within society at large can be substantial and it seems almost paradoxical that there is only token acknowledgement of this particular financing issue in the mental health care discourse. There may be one specific explanation 
why the question of financial responsibility has been mostly neglected so far. In chapter 5 , it has been outlined that several dimensions of the discourse reflect a social engineering type of governance which suggests a positivist approach to mental health care, stressing the logical relationship between means and ends. Transferred to financing, this approach perceives financing primarily as a technical instrument which is located somewhat outside the mental health care sphere and its actors. Thus, the notion of what the subject 'mental health care financing' covers is actually restricted to allocation of available resources. Mental health care financing, from that point of view, is then mainly concerned with increasing allocative efficiency within given resource constraints but widely ignores the more political dimensions such as distributional effects.

\subsubsection{The Rising Position of the 'Market'}

Shifting of boundaries on the societal level in context with mental health care financing can also be observed in another, more subtle, form. It has been demonstrated in chapter 5.2., that, even where sources of funding are public, the role of the 'market' has become increasingly important. This trend has been termed 'economisation of the social' referring to the transfer of market principles, their logic and concepts to the public sector. Some of these discourse developments are closely linked with financing issues. They are particularly related to the reimbursement level of financing and require some fundamental discussion of reimbursement methods in mental health care.

According to the discourse, financing instruments to be preferred are those which support commodification and individualisation, thus allowing for the consumer-concept to be implemented. In order to establish conditions for 'buying' services according to individual preferences, cash benefits rather than benefits in kind are to be preferred. Examples for such a transformation are the 'Personal Budget' or the 'Voucher System' which have been described in the German example. The role of the state is in that case perceived as one of enabling or supporting rather than providing and being fully responsible. This can either mean that provision of services is left to 'free market forces', hence, services are expected to evolve according to market principles of demand and supply. Such a situation has been described in the area of long-term care after the introduction of monetary long-term care allowances (Hammer 2002). For mental health care specifically, the mentally ill would receive some type of cash benefit which they can use autonomously to buy their preferred services. As the German example has shown, this is a realistic future scenario and discussions of that model have also started in Austria, specifically in context with disability allowances. Notably, 'Personal Budgets' do not necessarily change the overall level of resources allocated to mental health care. In the German examples budgets are legally based 
on the social assistance act and are thus, related to the same patterns of costsharing as in traditional financing arrangements (Schröder 2004). Hence, unless the level of the cash benefit is high enough to cover total costs of professional care, the sectoral shift to 'family' and 'voluntary/community' equally occurs with 'Personal Budgets' or any other modified type of cash-benefit.

Another less radical scenario might be that services are continued to be regulated publicly. This means that public and/or private service provision is planned and legally regulated on the provincial or on the federal level, thus ensuring adequate distribution of services. In that case, it is likely that the overall aim of cost-containment requires some form of rationing. Considering the discourse, a typical approach would be that experts in the field of mental health care establish a pre-defined service catalogue without much public discussion about priorities. Responsiveness, in such a model, would be assured via assessing individuals' needs using an elaborate type of assessment instrument.

Furthermore, the economisation model requires that the financing system needs to support competition in mental health care. With the introduction of the LKF- reimbursement system in 1997, this has already happened in the Austrian hospital sector (see chapter 4.4.). In contrast to other countries with DRG systems, in Austria psychiatry is included in the LKF-system. Yet, the competitive element of the LKF system may have some specific effects for the treatment of persons with mental illness. In that respect, several critical arguments have been raised in context with DRG reimbursement for mental health care. Firstly, the criterion which is used for the level of reimbursement is the diagnosis. This is inappropriate in mental health care because the same diagnosis can be related to considerably differing severities of a mental illness and, consequently, to different lengths of stays and resource needs (e.g. Lercher 1998; Lien 2003). As a result, the money providers receive is not always related to actual costs. Reimbursement may either be less than costs (when treating severe cases) or income exceeds actual costs (in less severe cases). The incentive works in a way that providers need to prefer less severe cases in order to avoid deficit spending. In other words, the method bears the potential of 'cream skimming'. This is specifically related to small scale providers which are not able to pool risks. Secondly, DRGs show shortcomings for long-term diseases, as financing is to the advantage of shorter episodes rather than longer stay periods. In turn, this bears the incentive for repeated readmissions known as the 'revolving door effect' (Lien 2003). Thirdly, DRGs in mental health care bear the risk to reduce quality of care which may not appear at the point of discharge but rather in the long run (Frick and Cording 2004). Whether these effects occur will not least depend on the details of the single systems. For example, the first generation of the Austrian LKF system was heavily criticised by psychiatrists because treatment of people with severe mental illness was related to considerable financial disadvantages for hospital providers (Meise and Hinterhuber 1998). One reason for that was that only data from one 
mental hospital was used for calculating average resource needs per diagnosis. As a consequence, the first generation of the 'LKF system' has been remodelled by introducing a 'severity-factor' which means that reimbursement does not solely depend on the diagnosis but also on the severity of the diagnosed illness (Katschnig, Denk and Scherer 2004). This has been regarded as more appropriate for mental health care (Lercher 1998). Yet, in some cases the incentive has now the reverse effect. As the admission of persons with severe psychiatric diagnoses is currently associated with quite high income, providers have an interest in high admission numbers. This can even have the side-effect that the existence of a psychiatric ward in a general hospital prevents hospital providers from closure of hospital wards (Gross 2000). As public providers on the community level increasingly need to justify the existence of their hospital in numerous discussions about hospital closure, the competitive element of DRGs is not least associated with highly political dimensions.

That the DRG system makes profitable parts more visible, thus reflecting the market-logic, may not just be interesting in terms of deficit spending. As Pelizzari (2003) remarks, it can also be related to other consequences. Given that there is an overall tendency in favour of privatisation which is also increasingly being discussed for the health care sector (Davis and Fairbrother 2003; Wirtschaftsblatt 2003; Rümmele 2005), full privatisation of profitable parts of mental health care services becomes a realistic option, as those become attractive for capital investment. Consequently, only those parts of mental health care which are nonprofitable may then remain publicly provided and financed. Indeed, the UK case in chapter 4 has shown evidence for that development.

Systematic empirical data of the long-term DRG impact in mental health care have been rare for the Western European context. In terms of short term effects for psychiatry in Austria, Frick, Barta and Binder (2001) demonstrated for the province of Salzburg that the 'revolving door effect' did not occur as a consequence of the LKF system in the first two years. Furthermore, they showed that LKF reimbursement was not the primary factor of influence for length of stay and hospital frequency. On the other hand, the Austrian mental health report from 2004 (Katschnig, Denk and Scherer 2004) states the average length of stay in psychiatric hospitals and/or departments has decreased considerably since the hospital reform. Thus, it dropped from 41.2 days in 1996 to 27.2 days in 2002. Furthermore, Katschnig et al. (2001) remarked that constantly increasing hospital admissions are to a large extent due to re-admissions. One explanation for that contradiction could be that the effects have been triggered by the prospective budget rather than by the LKF system. Overall, the issue is generally discussed controversially. As scholars have pointed out, research from other countries shows that many effects may only be visible in the long run (Kunze 2001; Russel 1989; Theurl 1996). Notably, there have been countries such as the USA, where DRG reimbursement has been abolished for psychiatric hospital services after a 4-year 
period with the justification of inappropriateness. Furthermore, the German case has shown that in some countries psychiatry has been excluded from DRGs per se. On the other hand, Lien (2003) points to the rather contradictory concern that the exemption of mental health care will in the long run draw funds away from the mental health care sector. There is also some apprehension that mental health care might become an idiosyncratic service with its own rules and regulations if it is exempted from general health care reforms. In summary, what all these debates make clear is that there is a lot more research required with respect to the specific impact of health sector reimbursement reforms on mental health care.

Concerning competition, the introduction of competitive elements by means of financing is not restricted to the hospital sector but there is some evidence that a similar transformation process has also started in other fields including services outside the health care system. Thus, even where service provision remains primarily publicly financed, the form of financing is likely to change. Indeed, as Gerlinger (2002) has shown for the German health care sector, an increasing tendency to introduce a type of DRG-related reimbursement in the ambulatory sector might be a reasonable future scenario.

Another example for such a transformation process is demonstrated by the shift from public subsidies to performance-based contracts for privately provided social services (e.g. Schneider and Trukeschitz 2003). With respect to mental health care, a US-study has demonstrated some advantages of performance-based contracting showing that this type of reimbursement has reduced the possibilities for non-profit organisations to select patients. In particular, the contracts forced providers to supply integrated services for persons with complex needs (Smith and Lipsky 1993). Put differently, performance-based contracting has supported the implementation of community care especially for severely ill persons or people with long-term illness. However, others have demonstrated that performance-based contracting in mental health is also associated with several problems. For instance, Ashton (1998) has identified that negotiation for mental health services was more complex than in other cases. Compared to other fields of health care, this not least resulted in higher transaction costs leaving eventually less resources for treatment and care. Additionally, Simpson (1998) remarks for the British context that difficulties with contracting arose in the field of mental health care because performance criteria are much more difficult to define than in other fields of health care. For example, there exists an irreducible uncertainty about treatment results. Furthermore, most contracts are ,activity-based' which is inadequate for mental health care. For instance, rather than the number of treated persons, optimal coordination of services for persons is relevant for the outcome. Additionally, contracts don't guarantee adequate spending levels. As the UK case shows, the ratio 'actual expenditure/initial allocation for mental health' varies considerably between the different spending bodies and is not necessarily related to the needs index of the various regions (see 4.2.). This suggests that in the 
contracts some providers haven't received the same proportion of money which has originally been allocated to mental health care. As the Ashton $(1998,358)$ summarises: "When transactions involve highly specific assets and are associated with considerable uncertainty and/or problems of measurement, contracts between purchasers and providers tend to be incomplete and therefore open to opportunism. Because this increases the costs of monitoring and enforcement, some form of vertically integrated organisational arrangements tends to be more efficient than markets".

For the Austrian case, several critical issues can be raised in context with contracting for mental health care services outside the health care sector. It has been shown that non-profit providers in mental health care have usually a quasimonopsonist status which means that very few single providers are responsible for a large population and for providing a large number of services. It has been criticised that this gives providers considerable power to choose 'their own' patients. All in all, this constellation constitutes an obstacle for person-oriented community based care as it makes supply of adequate services for people with complex needs particularly difficult (Zechmeister et al. 2002). As a matter of fact these people have been likely to be cared for in nursing homes because this is the location where all service elements can easily be provided in one place. With performance-based contracts, similar to the US case, providers could be influenced as to provide integrated services especially for people with complex needs. For example a contract with the 'Caritas' as one of the main providers in Lower Austria would then stipulate that service provision has to integrate accommodation, labour oriented and treatment oriented services via mobile and flexible teams. There could even be a specific clause in the contract in order to guarantee that persons with complex needs are not automatically referred to longterm care institutions. However, several problems appear when addressing the issue in more detail.

Firstly, although responsibility for most of the services affected rests on the provincial level, it is split between different administrative areas. For example, the administrative part which is responsible for nursing home issues differs from the one which covers matters of MAPS (see 4.4.). Thus, several contracts would have to be concluded with several purchasers. This seems to be as much an obstacle for coordination and integration of services as it would be a means to enhance coordination.

Another crucial question is, whether it is actually in the interest of the purchasers to enable community care for severely ill patients with complex needs, as these people will require considerably more resources than persons with common mental disorders (Beecham, Fenyo und Knapp 1991; Kavanagh 1996). Facing the pressure of cost-containment it seems unlikely that purchasers on the public administration level are advocating the treatment and care of severely mentally ill in the community. This financing mechanism can therefore as well 
encourage a segregation of patients into 're-institutionalised' and 'marketable' (Priebe 2003) ones, the more so, as the demand for community integration has traditionally come from professionals or users rather than from the political or public administration level. Moreover, the issue of defining adequate performance criteria which has been described earlier is equally true for Austria.

To sum up, the economisation processes which are observable in the discourse and its consequences for financing show, as Daly and Lewis $(2000,295)$ outline, that "welfare state transformation is more complex than is generally conceived and that state support may be in the process of taking a new form rather than being appropriately characterized as being 'cut-back' ". Detailed consequences for mental health care have yet to be analysed in further empirical research.

\subsection{Mental Health Care Financing and Impacts on the Micro Level}

This part of the analysis focuses on impacts of financing arrangements on the individuals affected and the changes of these effects over time which can be observed. When analysing the effects of financing arrangements on the microlevel, the nature of mental illness and the related characteristics of people with mental illness need to be remembered. To sum up the information from previous chapters, these are firstly, the high prevalence of poverty, secondly, the high degree of unmet needs, thirdly, the high degree of stigma, and, finally, the often lifelong nature of the mental diseases. Additionally, people with mental illness also have poorer physical health than the general population (e.g. Harris and Barraclough 1998). Due to these characteristics the impact from financing arrangements for individuals with a mental illness differs from that for people with a somatic illness. In the following parts these specific features will be addressed.

\subsubsection{Shifting of the Financial Burden on the Individual Level}

It has been outlined in the previous part that the private expenditure share for services which are provided within the health care system is low compared to those covered outside the health care sector, suggesting that the burden on the individual level is also low. However, the micro-level needs to be addressed in a more differentiated way. Firstly, individuals may be affected differently by the way public sources for financing health care are levied. Drawing attention to the Austrian health care system, social insurance premia are regressive which means that people with lower income have to pay a disproportionately higher rate than those in higher income groups (Guger 1996; Wendt 2003). Given that there is a 
high prevalence of low income among individuals with mental illness, regressive revenue raising places a higher burden on this group.

Furthermore, although user charges for health care services are low compared to services provided outside the health care sector they still can have some significant effects for individuals with mental disorders. To quote Dixon (2002, 27): "Most studies show that charges deter access particularly amongst the low income, the unemployed, the elderly and the chronically ill. Any increase in user charges or individual risk rated private insurance is likely to adversely affect access for those with mental health problems, due to a combination of their chronic state, the stigma attached to their illness and the impact on their employment opportunities and earning capacity." In that context, Frank and McGuire (1999) found in their empirical study that demand for outpatient mental health care is more sensitive to cost-sharing than for outpatient care in somatic medicine. In Austria, cost-sharing is particularly characteristic in the outpatient sector. Notably, it is exactly the outpatient sector which is to receive higher priority in mental health care as treatment in primary care settings and by specialist psychiatrists and other professionals in the field are to be prioritised according to the reform aims. Yet, if user charges deter individuals from service utilisation, it may compound the documented low utilisation of services attributed in part to the stigma associated with mental health problems. Due to the comparatively poorer physical health status of people with mental illness, the financial burden of user charges is even more substantial.

Access-problems associated with cost-sharing are even more virulent for services which are provided outside the health care sector. As it has been outlined earlier, the likelihood for private cost-sharing is considerably higher for those services. Since these services have become more significant during the reform process, individual financing responsibility plays an ever more important role. For the affected individuals this is related to a specific distribution of costs. While treatment is primarily borne by the state, caring is 'off-loaded' by placing people in cheaper residential accommodation or discharging them into the local community. This is often related to higher private financial responsibilities as well as caring responsibilities for relatives or friends. As Goodwin $(1997,85)$ remarks: "The result is an increasingly stark divide in the pattern of expenditure on mental health services. Statutory financing of services has tended to be concentrated upon the provision of treatment services, while financial responsibility for the care of people with mental health problems concerning their need for accommodation, employment, transport, and so on, has tended to be delegated to non-statutory and informal sources of care."

As this shows, the individual financial burden has also an impact on relatives. For example, in a German study-population $63 \%$ of spouses and $69 \%$ of parents of people with schizophrenia had to bear private costs which result from the illness only (Mory, Jungbauer and Angermeyer 2002). Although objectively the 
existing burden is very often marginalized, not addressed or played down, burden is explicitly expressed by parents who have children with early onset of illness and who still live with them as well as by spouses with low income. Moreover, the higher private costs for professional care, the higher the incentive for informal care. Not only is this related to further costs for the carer (loss of income, loss of qualification, loss of long-term social security) but carers may develop mental disorders themselves (e.g. depression) resulting in some further need for mental health care resources (e.g. Rainer et al. 2002; Wittmund, Wilms and Angermeyer 2002; Wittmund and Killian 2002). While in some countries, carers' support has been established, this has only marginally been the case in Austria.

From a gender perspective it has to be noted that informal care is largely carried out by women. Similar to the case of long-term care for elderly or child care, associated loss of financial independency and reduced social security may constitute a long-term risk factor for female poverty. Moreover, another scenario may be that the high private costs for professional carers result in black or grey market arrangements with illegal employment. In the case of long-term care for elderly people this is a known phenomenon (Hammer and Österle 2001). Not only is this arrangement related to precarious financial situations for the carer but it also may impact on the employment situation in the formal labour market. Professional carers who are again mainly women (Zechmeister 2004) may face increasing pressure concerning wage levels. Especially for the lower qualified this may result in difficulties to find an adequately paid formal employment arrangement. In summary, these scenarios demonstrate - as outlined in the framework in table 17 - how financing arrangements strongly influence the nature of work and activity. Although the reform discourse does not particularly address this issue, with unchanged financing structures, unpaid and informal work will inevitably have to play an important role in future caring relations.

More generally, it needs to be noted that the individual financial responsibility is distributed rather unevenly among individuals, which results from the patchy distribution of professional service provision and the diversity of financing arrangements. Thus individual responsibility is higher in those areas where no (publicly funded) professional services are available. This is for example the case in areas where few specialist psychiatrists with a social insurance contract are available or in provinces with lower public funding of psychotherapy. Thus, even if public expenditure is rising overall, financial responsibility for some individuals will remain high.

From an economic point of view, the individual financial burden and its consequences for service utilisation do not least have an impact on the overall economic costs. For example, poor mental health of adults can have consequences for their children and they can have a negative impact on social capital in the community. Thus, not treating mental problems and guaranteeing access to services is likely to result in various negative externalities. In the case of mental 
health problems further adverse impacts can include loss of productivity and poor long-term health outcomes, as well as impacts on education or on criminal justice. As Dixon $(2002,4)$ puts it: "Any positive externalities of mental health service utilisation by those with mental health problems cannot therefore be ignored when evaluating the extent to which different health care financing arrangements affect the mental health sector. The incentives for people with mental health problems to utilise mental health care under different financing arrangements may have crucial implications for achieving levels of use that more closely reflect a socially efficient resource allocation." [original emphasise]

Another possible effect may be that individuals eventually use those services which are related to the lowest financial burden. So far, this has been hospital mental health care. Moreover, this is compounded by other issues. Firstly, the analysis of reform documents and interviews in chapter 5.2. has shown that hospital mental health care holds either implicitly or explicitly a priority status in the perception of various actors in the mental health care field. Additionally, Zechmeister et al. (2001) have shown that several incentives in the financing system result in hospital focused mental health care. Firstly, although the hospital reimbursement system sets incentives to reduce lengths of stays, it still contributes to hospital-centred provision of services by simultaneously setting incentives to increase admission rates. The more cases a single hospital administers the more 'points it can earn', hence the more income it can generate. Although the prospectively fixed hospital budget means that a higher number of overall administered points decreases the value of a single point for each hospital, it has been shown that hospitals effectively tend to employ a point-maximising strategy (Lercher 1998; Stepan and Sommersguter-Reichmann 2001). Furthermore, the health insurance has no interest in setting incentives against this hospital-based supply of services, since any service consumed in the primary care sector means additional expenditure for the insurance fund, whereas hospital over-expenditure has to be born by hospital providers themselves. Many of these are provincial or local public bodies who do not exercise strict budget limits. Thus, although mental health care is de facto shifted to other services and durations of single hospital episodes for the mentally ill have decreased substantially since the 1997 hospital financing reform, hospital care is likely to remain the highest priority in referral processes and treatment decisions. This may firstly, not always meet the real preference of the individual person and secondly, it is actually contrary to the core aims of the reform according to which deinstitutionalised care should receive the highest priority.

A final financial issue on the individual level is implicitly raised with the 'participation discourse'. The discourse analysis has demonstrated that involvement of representatives of user groups or self-help groups in planning is primarily viewed as support in a market research type of assessment. Consequently, their contribution is not regarded as type of work equivalent to the 
professionals' one and these persons need not necessarily be allocated remuneration. Hence, those people either will have to work voluntarily or may be given some symbolic monetary recognition. Evidence for such a development is provided by the draft of the 'Upper Austrian Equal Opportunity Act' (Chancengleichheitsgesetz Oberösterreich), which outlines that participation of user representatives in planning bodies has to take place on a voluntary basis (Landesregierung Oberösterreich 2002a).

\subsection{2. 'Consumers' of Mental Health Care: Opportunities and Pitfalls}

The discourse analysis has shown that the mental health service users are ascribed a 'new' role in the mental health care field which is the role of a mental health service consumer or customer. Under 6.2.2., it has already been mentioned that the 'consumer approach' in mental health care requires new forms of financing arrangements, in particular a shift from benefit in kind to cash benefit, for example in the form of a 'Personal Budget'. Undoubtedly, such financing arrangements transform persons with mental illness into 'consumers' who buy the 'mental health product' on the 'mental health market'. On the one hand, this type of financing arrangement may increase freedom of choice, empowerment and selfdetermination. Additionally, Speicher (2004) remarks in context with 'Personal Budgets' that they are a means to enhance participation, which transforms the person with a mental disorder into a citizen. On the other hand, however, some deficits of cash-benefits have been found. Firstly, access to care is not guaranteed for the individual person by providing a cash benefit only. Hammer and Österle (2001) noticed for the area of long-term care that unlike an ideal market, the supply-demand mechanism does not work in the field of social care. Unless supply of services (especially in deprived areas) is assured by legal stipulations, access to care will be distributed unequally and in some (particularly rural) areas there may not be services available at all. Furthermore, access to services is dependent on the level of the budget. If the level is too low to cover at least a high proportion of costs for professional care, access to high quality mental health care is not guaranteed. Indeed, as Speicher (2004) observes for the German case of 'Personal Budgets', only a small proportion of people with mental illness can afford professional services.

Secondly, even if people can afford services, individual cash benefits do not guarantee that the services offered meet their needs. In analysing a similar case in the Italian region Lombardy, Bifulco and Vitale (2004) note that in the existing arrangement providers are not obliged to offer services for any of their 'customers'. They can as well refuse requests without facing some form of sanctions. As the scholars put it: "The position of the citizen-consumer is asymmetrical regarding the provider. There is a strong power disparity, grounded 
in the consumer condition of hardship, urgent need, or deprivation" (Bifulco and Vitale 2004, 14). Thus, services are not tailored to individual needs but users can only 'consume' pre-defined service elements. Regarding freedom of choice, this is a freedom of exit but not a freedom of voice which would allow users to co-define services according to their needs (Bifulco and Vitale 2004 referring to Berlin). Considering the Austrian mental health care situation in particular, it needs to be noted that the monopsonic status of providers in the field of social and employment related services contradicts the notion of freedom of choice. Unless the number of service providers increases considerably, freedom of choice for those services (which are expected to play an increasingly important role) exists only in theory and would largely be restricted to urban areas.

In terms of service provision, responsibility of the state is reduced to quality control of accredited providers but the state does not bear responsibility for service users in terms of support for choice and decision making and in terms of guaranteeing that users receive services according to their needs. This part of mental health care is either left to relatives or other informal support or - if such forms of help are not available - individuals have to make decisions on their own and also are left to themselves to find services which best meet their needs, if such services exist at all. Considering the numerous psychological and material barriers mentally ill people can face, it is questionable if such an arrangement will be to the benefit of the affected persons.

A crucial question in that context seems to be, if and how affected individuals or representatives are involved in the diverse contracting processes between providers and payers. More general, which actors define performance criteria, service quality and quantity and where do these negotiations take place? As Simpson (1998) has criticised for the British case, contracting negotiations between providers and payers primarily take place between the responsible purchasers and the managerial boards of the providers. Usually, they don't involve those professionals who actually carry out the service and have direct contact with users, nor do they systematically involve user representatives. Furthermore, due to the focus on market logic and related technical efficiency it is to be expected that quantitative indicators will play an important role, especially those which allow calculations and discussions of technical efficiency issues (see chapter 5). In such circumstances it is highly questionable whether services will really meet the needs of service users. Related to the Austrian situation, the consumerist participation approach in the reform discourse seems to result in a similar tendency on the individual level as mentioned for the British case. 


\subsection{Conclusion}

With the shift towards provision in community settings, services have been increasingly provided outside the health care sector. While medical mental health care is usually associated with universal or almost universal access, this is not the case for non-medical services. The trend seems to be that private responsibility for the sectors 'family' and 'voluntary/community' and, thus, for the individuals affected and/or their relatives is increasing. However, the analysis has shown that apart from expenditure levels and financial responsibility some more subtle changes can be observed when analysing developments in terms of resource allocation and reimbursement methods. Regardless of the source of finance, 'privatisation' occurs in terms of introducing market principles into the public and family sector which is related to various financing scenarios with their own specific consequences for the affected individuals. In general, methods used tend not to take into full account the specific characteristics of mental disorders. However, empirical research which addresses the impact of these changes in reimbursement and resource allocation has been very limited so far. Apart from that, the analysis has shown that mental health care (financing) - because of its complexity - is an interesting example for indicating broader welfare state developments.

With regard to the situation for the mentally ill and their relatives, the picture which has been drawn appears to be rather bleak. This should not leave the impression of pessimism but should rather motivate and stimulate further debates, in particular, discussions about alternative approaches to finance mental health care in Austria. The following and final chapter intends to conclude the thesis with some material for a structured discussion on those issues which have turned out to be most relevant. 


\section{Concluding Remarks: What Financing for Mental Health Care?}

After having outlined the impact of mental health care financing arrangements against the backdrop of (mental health) policy tendencies which have arisen from the discourse analytical part, I will finally provide some concluding thoughts on the question how to finance mental health care. However, the aim of this chapter is not, as one might infer from the title, to present an alternative model for financing mental health care in Austria. Rather than 'designing' a financing model I will, firstly, seek to provide some suggestions concerning a potential process of developing an alternative financing approach. Put differently, some ideas will be offered as to how a process for developing such a model could be organised, and which issues would have to be taken into account.

The second aim of this chapter is to suggest some fundamental subjects to be covered in the discussions of such a development process. For that purpose I have tried to define core criteria which have evolved from the thesis, against which alternative financing arrangements can be assessed. The criteria are intended as a discussion tool for practitioners, planners and politicians. Most importantly, they should make the linkage between service provision, service financing and the overall political-economic context more transparent in future mental health policy discussions.

\subsection{Recommendations for the Development Process}

The most striking result of the thesis turns out to be the numerous scenarios and consequences which arise from more or less excluding financing issues in mental health care reform discussions and thus, missing to link questions of mental health care service provision with financing aspects. Regarding the major restructuring processes which have either occurred already or which are inevitably required, should the reform plans be fully implemented, it is indeed surprising that financing aspects have received so little attention. Neither the quantity of monetary resources required nor the mode of financing has been addressed in detail in most documents or in political discussions. Not addressing this issue, however, re-shapes the perception of what is regarded a priority in mental health care restructuring. It transports the impression that financing issues play a minor role, that financing is separated from mental health care or that financing is something that is predetermined and cannot be changed anyway.

The scenario which results from that is that restructuring of service provision takes place within the current mental health care financing structures. As a consequence of decentralisation and deinstitutionalisation, service provision 
outside the hospital and even outside the health care sector will play an increasingly important role. By implication, financial responsibility will be based on different legal regulations, it shifts to different sectors and to different payers with an increasing focus on the sectors 'family' and 'voluntary/community'. Not least, this is linked to growing responsibilities for individuals and/or their relatives. This is compounded by the introduction of several market-style instruments which particularly increase individual responsibility on various levels. Although the mental health care reform aims at social inclusion, for some persons affected this may actually result in social exclusion. Moreover, as it has been shown, the current financing system entails several incentives which run contrary to the reform goals. As a result, implementation of some specific reform aspects is hindered.

Overall, the analysis makes clear that mental health care reform processes lack substantial transparency in terms of financing and implications from various financing arrangements. It is therefore required to put the financing discussion on the (mental) health policy agenda and to strongly connect issues of service provision and financing. This is even more of relevance, as neuropsychiatric disorders account for $20 \%$ of disability adjusted life years and $43 \%$ of years lived with a disability in Europe (see chapter 2) and are associated with high individual and economic burden.

Besides discussing financing issues more generally, there are at least two reasons which may actually call for developing an alternative financing model: Restructuring mental health care financing will firstly be needed if social exclusion of people with mental illness is to be prevented or mitigated and it will secondly be required if full reform implementation is to be achieved. However, if a financing model is to be developed the question is how this will take place. In the expert dominated style of health and social policy formulation this matter sounds probably somewhat odd. Indeed, it seems to be self-evident that, similar to other recent projects such as the pension or health care reform, some expert(s) in the field need to be found to design a model. The answer to the question of how to develop a new model would then simply be to present a list of disciplines and experts to be considered.

Yet, I want to contest this approach for two reasons. The first one is based on my own experience with designing a 'ready-made' financing model for mental health care financing in Lower Austria. During the first stages of the development process, the commissioners of the project made clear that the financing issue should no longer be addressed in the remaining project period. Considering that an alternative financing model will inevitably address very sensitive questions of resource distribution and challenge existing power-relations, I doubt that any financing approach which will be developed on the initiative of single experts without a clear political mandate has a great chance to be implemented.

The second reason why I contest the expert-driven approach is simply to demonstrate that there may be other ways to find solutions for social problems in 
society than the one we have experienced over the recent decades. In other words, I want to challenge what has been taken for granted by arguing that it may be worth to experiment with unorthodox and even utopian sounding forms of developing a financing model.

Thus, my claim for an alternative way of planning is based on two lines of argument. The first one is a pragmatic one, which simply focuses on finding a mode which guarantees implementation, whereas the second one is a rather visionary one, which addresses not only mental health care financing issues per se but uses them as an example for discussing general social visions and ideas for mental health policy formulation.

For the development process, I basically propose to continue or adapt one of the outlined core aims of mental health care plans, which is the "participation principle'. In other words, I suggest developing a future financing model via a participatory approach, involving various actors and/or their representatives in the process. From the pragmatic point of view, this might be one option to find a financing method which has a broad majority among decision makers. The argument is based on general social planning literature which suggests that the best way to guarantee reform implementation is to involve those who will be affected by the reform in the planning process (e.g. Herrmann 2001; Markert and Wieseler 2001). Furthermore, as Hart and Pommerehne (1994) point out in context with 'Nimbys' ${ }^{26}$, acceptance of a solution is very often dependent on how the solution was found and how decisions were made.

However, it has been pointed out under 5.2. that 'participation' has several meanings. In contrast to the 'consumerist approach' which has been dominant so far, I suggest a participation approach on the other end of the continuum, which has been termed the 'democratic approach', thereby addressing the visionary dimension of my arguments. Concerning the level of participation, formulating a financing approach would address the strategic level of participation (see 5.2.). In contrast to the prevailing perception of participation, one requirement for organising an alternative participation process would firstly be that actors and/or their representatives are involved actively rather than passively. In the given case this means that participants develop the financing model together from scratch rather than being asked retrospectively whether or not they like an already finalised model. A second requirement would be that the project results in empowerment, education and emancipation of those involved. Thus, according to the empowerment definition by Kieffer $(1984,9)$, it would actually result in "the construction of multidimensional participatory competence" in the form of a "development from socio-political illiteracy or 'infancy' to socio-political 'adulthood' ", or, as Nelson, Lord and Ochocka $(2001,127)$ have defined empowerment, it would create "opportunities for and conditions that promote

${ }^{26}$,Nimby' means ,not in my backyard'. 'Nimby-goods' are to the benefit of a large majority but the group which is affected by establishing them is rather resisting such an undertaking. 
choice and control, community integration and valued resources." Another requirement would be that the process is organised in a way which guarantees participation regardless of individual material or mental resources. This implies two challenges. Firstly, how can people be motivated to participate at all and secondly, how can it be guaranteed that, once people are part of the participation process, everybody has the same chances to influence decision making. In other words, how can it be avoided that the same power-relations which are pertinent in society in general are not simply transferred into the participation processes, thus, neglecting the views and claims of the traditionally more powerless.

Chapter 5 has shed some light to the problems of participation which may be helpful for this experiment of thoughts. In that context, the following issues are relevant to be taken into account. Firstly, people with low material resources must receive enough material support. This can range from support for transport, child care or income to adequate payment for the time they spend for participating. Secondly, during the actual discussions and dialogs, methods need to be used which make sure that less articulate or less educated participants have the same chance to express their views, to present their proposals and to be taken serious as the eloquent ones. In that respect, traditionally existing power-imbalances need to be taken into account such as gender relations (Lewis 2004). Furthermore, the language of those meetings needs to be comprehensible for all participants. In some cases this may simply require an interpreter, in other circumstances it may even be necessary to organise some lessons for knowledge transfer and education because if people should seriously discuss financing matters they need to understand the basic concepts and the context of financing. Overall, it will be paramount that experts who have internalised technical terms and specific disciplines' languages prepare or 'translate' their inputs in a way so that it is understandable for every participant.

With respect to organising such a process, different types of 'democratic participation' are to be taken into account. According to Fichtner (1986), one can distinguish democratic participation along two lines which are firstly, formal types and, secondly, more informal types of participation. Both types include representative forms and more direct forms of involvement. When organising such a process in detail, representatives as well as direct forms of involvement may be necessary in different stages of development. However, there is no need to re-invent the wheel. A lot can be learned from the experience of such approaches in other areas. For example, increasing activity in terms of participation experiments can be observed in the area of budgeting where nationally and internationally some projects have been undertaken to involve the general public in budgeting (see for example BEIGEWUM 2000; BEIGEWUM 2002; Jäger, Leitner and Tomassovits 2002; Klatzer 2002). Furthermore, participation projects have been organised for local area management and urban planning in Austria and internationally (see for example Diebäcker 2004 for Austria). 
Overall, the quality and success of such a project must not just be assessed in terms of its results, precisely whether or not the new financing model solves the problems, but also in terms of the process itself. The latter includes for example criteria concerning what people have learned both, 'technically' and 'socially' or concerning whether conflicts of interests have been discussed openly and transparently or whether they have been concealed. On a meta-level, the aim of such a process is in fact developing a new understanding of democracy.

\subsection{Guidelines for Discussing Financing Options}

In addition to the general process of developing a financing model, the final parts of this chapter address the subjects which will be important to be covered during such a project. Put differently, while 7.1. has been concerned with the procedure of how a financing concept can be established, this sub-chapter addresses issues which are concerned with financing options per se and their various characteristics. As I have mentioned earlier, I am not going to bring forward final versions of alternative financing arrangements for discussion at this stage, but I seek to summarise core issues which have evolved during the writing process and present them in the form of a 'discussion guideline' which can be used in the debates. The discussion tool is based on the following considerations.

In chapter 4 various forms of financing arrangements have been demonstrated. In particular, three case-studies have been presented. They have been selected and described according to the criterion of 'overall health care system type', which is a very common typological criterion. From a pragmatic point of view, this criterion could as well be used for discussing alternative mental health care financing arrangements for Austria. However, the empirical material shows that with respect to the effects on the macro and micro level of mental health care, broad trends and tendencies seem to be similar in all three countries, regardless whether the health care system is a 'Beveridge' or a 'Bismarck' type. Apart from various differences in detail (e.g. in terms of regressivity with respect to raising sources of financing), a common pattern in all of the three countries is that the more mental health services are provided within the health care sector, the higher is public financial responsibility. With the shift towards provision in community settings, services in all of the three countries have been increasingly provided outside the health care sector. While medical mental health care is usually associated with universal or almost universal access, this is not the case for services provided outside the health care system. Similar to the Austrian case, in the remaining two countries the development is associated with some increasing private responsibility for the sectors 'family' and, 'voluntary/community' and, thus, for the individuals affected and/or their relatives (Zechmeister and Österle 2004a). Equally, in all three countries the role of the market is becoming more 
important, for example in terms of rising significance of private insurance such as in the UK or in terms of introducing market principles in the form of 'Personal Budgets' such as in Germany.

Consequently, the criterion 'health care system type' which mainly characterises differences in the sources of financing seems to bear some shortcomings for discussing alternative financing scenarios for mental health care. Furthermore, it is rather unrealistic that the health care system type would be changed if Austrian mental health care system representatives came to the conclusion that a tax based 'Beveridge system' should be preferred for financing mental health care.

Quite conversely, the previous chapters have shown that rather than the type of resources it is firstly the level of resources spent on mental health care, secondly, the way resources are allocated and thirdly, the mode how providers are reimbursed which primarily shapes the impact on the individual and on the macro level on the one hand and which creates incentives or disincentives for reform implementation on the other hand. In that respect, it is not uncommon that slight variations in regulations within the same method of financing can be associated with rather different impacts for the individuals. For example, variations in the level of 'Personal Budgets' in Germany are associated with substantial differences in terms of individual financial burden. Another example is the DRG system in Austria. The first generation was clearly related to disadvantages for providers who were treating patients with a psychiatric diagnosis, whereas this was avoided in the following generations by simply increasing the value for treating severe forms of illness. If such variations make a difference, this also means that there exist in fact many alternative ways of financing mental health care. Moreover, these alternatives may be more realistic in terms of implementation because they don't necessarily require changes of the central type of health care system.

Taking these results into account, I have tried to summarise the core criteria on the resource allocation and reimbursement level which may be more appropriate to indicate implications of mental health care financing than the criterion 'health care system type'. They may be helpful for discussing alternative financing scenarios, although I need to state that they are by no means exhaustive and can surely be extended to further criteria.

Overall, two different dimensions can be addressed in discussing financing options. The first one is the 'content dimension' which is concerned with questions about different elements of financing and their effects - in the given case the effects on the individual and macro level. The 'content dimension' mainly addresses 'material' issues. Yet, it has been found, that this dimension leaves several issues untouched. Therefore, a second dimension for discussing alternative financing arrangements has found to be important, which is the 'process dimension'. In contrast to the 'content dimension', the 'process dimension' is concerned with issues of decision making and actor involvement in defined alternative financing scenarios. 


\subsubsection{Content Dimension}

With respect to the content level, the following categories for addressing the effects of financing have been found to be useful. These are, firstly, the effect of financing on the nature of mental health care services, secondly, the consequence for the role of the beneficiaries, thirdly, the impact on service providers, fourthly, the impact on the role of the state and finally, the implication for the role of public administration. To explain how these variables can be used for discussions, I will demonstrate the concept by using financing examples from the thesis. One important issue in the financing discussions which has been neglected in debates so far will finally be to make transparent which political dimensions different financing scenarios reflect. For that purpose it has been tried to relate the core characteristics which have been described in earlier parts to general political ideologies which they seem to reflect. Table 18 provides a summary of these issues.

\begin{tabular}{|c|c|c|}
\hline \multicolumn{3}{|c|}{ Interdependency between financing and mental health policy } \\
\hline Variables to consider: & \multicolumn{2}{|c|}{ Characteristics observed } \\
\hline $\begin{array}{l}\text {...nature of mental health } \\
\text { service }\end{array}$ & Form of 'public good' & Product \\
\hline ...role of beneficiaries & Users & Customers, consumers \\
\hline ...role of providers & (Uncoordinated) actors & Competitors \\
\hline ...role of the state & Public responsibility & Public support \\
\hline \multirow[t]{2}{*}{$\begin{array}{l}\text {...role of public } \\
\text { administration }\end{array}$} & $\begin{array}{l}\text { Financier (and provider); } \\
\text { Responsibility for } \\
\text { providers and users }\end{array}$ & $\begin{array}{l}\text { Purchaser; } \\
\text { Guidance and control } \\
\text { of providers }\end{array}$ \\
\hline & $\begin{array}{c}->\text { Social democratic } \\
\text { oriented mental health } \\
\text { policy }\end{array}$ & $\begin{array}{l}\rightarrow \text { Liberal oriented } \\
\text { mental health policy }\end{array}$ \\
\hline
\end{tabular}

Table 18: Interdependency between financing and mental health policy; own table

With respect to the nature of services, it has been shown that financing can transform mental health care services into a form of 'public good' (e.g. in the case 
of financing universal benefits in kind) or into 'buyable' products (e.g. in the case of cash benefits only).

Correspondingly, through financing arrangements, beneficiaries are ascribed different roles which range from that of 'users' on the one hand to the role of 'consumers' on the other hand. In the latter case, beneficiaries may be free to choose between services, however their cash limit and the number of available providers restrict the quantity and/or quality of services to be 'consumed'. Thus, if a 'product-consumer' character is constructed by mental health care financing using services is dependent on purchasing power. By contrast, the former role is more associated with collective provision of goods rather than products and using goods according to needs rather than buying them. An example for the former is the financing of hospital mental health care in Austria, whereas the latter situation results for instance from the 'Personal Budgets' in Germany.

Thirdly, financing arrangements shape the role of the providers which, according to chapter 6 has also an effect on affected individuals. Currently, the role of providers resembles those of uncoordinated actors on the one hand and those of competitors on the other hand. Examples for the latter are the DRG related reimbursement in Austrian hospital mental health care and the introduction of performance based contracting in the UK. An example for the former role is the traditional situation in Lower Austria, where different providers outside the health care field act in a rather uncoordinated manner. This pattern has been more common in bureaucratic and state-led forms of service supply.

This leads fourthly to how financing arrangements are linked with a certain role of the state. While there are some arrangements which represent full or at least high public responsibility there are others where the role of the state is reduced to that of providing support. High public responsibility is characteristic for benefits in kind which can be accessed universally according to needs rather than after means testing. Furthermore, in the case of cash benefits, public responsibility is higher the more costs can be covered with the public monetary transfer. An example for high responsibility of the state is hospital mental health care in the UK, whereas low public responsibility can for instance be observed in the case of psychotherapy in Austria or in the case of residential care.

The fifth criterion is the extent of public administration responsibility. Thus, different financing arrangements are associated with different public administration involvement within the whole process of financing and service provision. While involvement can on the one hand be related to responsibility sharing with different players who represent collective goals and interests, in other cases the role of public administration is reduced to guiding and controlling a market transfer similar to some fields of economic policy. The latter role is reflected in the approaches of performance based contracting which have been demonstrated earlier. The former has traditionally been the case where public financing has been linked with public provision of mental health care arrangements, for example nursing homes in Lower Austria. 
Related to general mental health policy ideologies the observed characteristics seem to reflect two core strands, which is a more social democratic oriented mental health policy style on the one hand and a more liberal oriented mental health policy approach on the other. Notably, the term ,social democratic' is here to be understood in the sense of primarily rights-based entitlements to mental health care, whereas 'liberal' denotes a policy strand which is ruled by market principles with limited welfare rights. Of course this is only a crude typology, since features cannot always be clearly attributed to one specific ideology-type. For example, in the category 'role of the state' the feature 'public support' would also be typical for a conservative mental health policy ideology. Nevertheless, this form of portrayal fulfils the function of making the political dimension of financing more transparent.

From a historical perspective, the trends in mental health financing seem to mirror a mental health policy shift from a more social democratic oriented towards a more liberal oriented policy style in all three countries under investigation or vice versa, the liberal oriented policy discourse leads to a specific choice for mental health financing arrangements which support a liberal rather than a social democratic approach. In the Austrian case, the shift towards a liberal mental health policy discourse has been demonstrated in more detail in the discourse analysis which shows, once more, the interrelation between financing and discourse (see 5.2.). However, while I would describe the trend towards a liberal approach as being quite evident, typifying former approaches as clear cut social democratic is less obviously indicated. On the one hand, the argument is supported by the fact that hospital financing can traditionally be attributed to a social democratic policy strand in all three countries under investigation. Even in the UK, where the overall welfare system has always mirrored a liberal approach, the health care system has shown typical social democratic elements (Badelt and Österle 2001). With shifting mental health care from hospitals to other service elements, the social democratic elements become less apparent. Yet, especially in the Austrian case, I would say that there have always been other policy elements, especially more conservative ones. For example the role of the family in mental health care has always been important. Overall, these policy strands impact on individual responsibility in terms of organising and financing mental health care and on access to professional services. Needless to say that individual responsibility is higher and access is more likely to be restricted in a financing system which mirrors a liberal policy approach.

While the liberal mental health policy approach seems to increasingly dominate, it has to be noted that this is not something which needs to be taken for granted. Indeed, for a broad financing discussion, it will be paramount that the current development is not perceived as strict and exclusive. On the contrary, when discussing the effects of various financing arrangements, some alternative policy strands may be detected or vice versa, alternative policy aims can be 
defined in the first place which may be achieved by other and even unprecedented forms of financing approaches. As an example I would like to mention a financing model which has been introduced as a pilot project in the Italian region of Campagnia. Notably, concerning the financing approach the model differs only slightly from the 'Personal Budget' model in Germany, yet the impact is a completely different one. Bifulco and Vitale (2004) describe this arrangement as a form of 'Individual Health Care Budget' which is intended for people affected by social disabilities derived from psycho-organic illnesses or socio-environmental marginality. The central aim of the financing strategy is to reduce hospital referrals. In order to achieve this, the costs of public expenditure for institutional services are transferred into individual budgets to be spent on the three basic functions of housing, work and socialization. In other words, the cost of a bed in an inpatients institution is converted into a budget which can be used by the individual person to develop his/her living and working capabilities. However, in contrast to the 'Personal Budget' in Germany, individuals do not receive the budget themselves, but it is managed by a non-profit organisation according to an individual care project. In order to choose the non-profit organisation and to develop the personal care plan, the individual is supported by a publicly financed interdisciplinary team of professionals. Furthermore, providers of services are involved in negotiating the care project. The professional support team is also responsible for observing the provider organisations' compliance with the project. As an incentive for reducing the level of medical care, the care budget is increased by $10 \%$ at each step of decreasing medical intensity.

Applied to the framework in table 18, under such a financing arrangement, the nature of the mental health services would have to be characterised as public good because using services is not directly restricted to purchasing power. Furthermore, as Bifulco and Vitale $(2004,13)$ point out, "the beneficiary in this case is not recognized as a consumer, but as a player in his/her own individualized rehabilitation therapy plan, a player with his/her social ties and resources. ... Above all, the bargaining competence (and power) of the citizen is not considered as a starting-point, but as the intervention purpose. The idea is to support the ability of the frail citizen to choose on the project he/she is implied with, but without requiring that this capability should be fully developed [from] the beginning" (own emphasise). Additionally, with respect to providers, their role would be most correctly described as partners in a network rather than as competitors or uncoordinated actors. Finally, the role of public administration is also rather specific. Although it does not provide services themselves, it takes part in the whole process of service provision and responsibility is not just restricted to quality control. Related to mental health policy ideologies, this model does not really fit into traditional mental health policy approaches. It rather includes characteristics of several approaches or can even be described as an alternative one. In terms of individual responsibility, it resembles, however, a social democratic type. 
Having demonstrated some subjects for discussion by using examples of financing from chapter 4, the final aim is to summarise the main issues for discussion. From my point of view the core question in any financing discussion needs to be which general mental health policy is actually wanted? Is the aim a continuation of the liberal approach, should it resemble the traditional policy approach in overall health care which has included many social democratic elements or is there another alternative? Once, there is consensus on that matter, finally those financing arrangements have to be selected, combined or even newly invented which support these aims. In summary, guiding questions for discussing alternative financing arrangements would therefore be:

What is the aim in terms of mental health policy?

Which financing arrangements support these aims by the way they shape

a) the nature of mental health services?

b) the role of the affected individuals?

c) the role of the providers?

d) the role of the state?

e) the role of public administration?

In contrast to traditional financing debates, in such a discussion, financing would not just be a technical means to increase efficiency within given resourceconstraints but it would inevitably link mental health policy and financing issues and thus, mental health service provision and financing.

\subsubsection{Process Dimension}

While several core issues for the selection of a particular financing arrangement have been covered by addressing the content dimension, this still leaves an important aspect of financing unaddressed. The issue which has yet to be covered is concerned with the processes within a particular financing arrangement. Basically, from the process perspective, questions need to be asked which are mainly concerned with decision making in terms of resource allocation. These either address resource allocation directly, for example decision making about the level of hospital budgets, or they address resource allocation more indirectly in terms of criteria according to which resources are allocated. In that context, the first crucial question is where decisions about resource allocations or about indicators concerning resource allocation are to be made. For example the location can be the traditional parliamentary representative process but decision making about resource allocation can also be more directly transferred on to the mental health care arena where a committee is responsible for decision making. This leads to another vital issue for discussion namely who are the actors who make the decisions? The group of actors may involve politicians, civil servants on the administration level, experts, providers or representatives of users and/or their 
relatives. Finally, discussions are required about what is being decided on which level? I will, again, demonstrate this more precisely by using several illustrations from the thesis which mirror different levels of decision making.

Take for instance the 'Mental Health Care Budget' which has been introduced in the German case study (see 4.3.). According to this arrangement, several monetary sources are pooled into a single mental health budget. While various expectations have been expressed how this arrangement allows more flexible choice between forms of treatments, no information has been provided concerning who actually decides about the resource use and where these decisions are made. The location of decision making could be the hospital but also some 'independent' location or it could even be the users' place of living. Correspondingly, several alternatives in terms of decision makers are possible. One can think of a multiprofessional team including professionals from all provider types involved or the decision makers can be a form of representative board involving also users but it can also be a single psychiatrist. What I want to stress is that these decisions determine very much how resources will finally be distributed and to who's benefit they are. If decision making is for example located at the hospital or if it is dominated by medical doctors, existing incentive structures will very likely result in using a higher proportion of financial resources for hospital mental health care.

Another example is the formulation of performance indicators for performance based contracting. Under 5.2. and subsequently under 6.3., it has been outlined that existing types of performance indicators are not always appropriate for mental health care. Moreover, they are very much related to technical efficiency concerns and thus, influenced or even defined entirely by managers and accountants. Defining these performance criteria will, again, have an impact on resource distribution. Most importantly, they determine quality and quantity of service supply and, consequently, costs of services. Not least, if people receive a cash benefit, spending these resources and, hence, final resource allocation will be considerably influenced by the quality and quantity of service availability. Principally, one can ask the same questions as in the above example, which is, firstly, which actors are involved in deciding about contract criteria and contract negotiations and, secondly, where do these negotiations take place?

The final example relates to resource allocation according to pre-determined formulae. By nature, the formulae determines very much the flow of resources to different areas and providers and, eventually, to users. Considering the problems which are associated with establishing formulae, I suggest that this must not be reduced to a mathematical task. Taking, additionally, into account the critical issues which have been raised under 5.2. concerning figures, it seems to be required that the mathematical task is accompanied by a political dialog, where it is not only explained what the figures are based on but where, additionally, amendments and adjustments are discussed publicly and transparently. Again, these debates can involve various actors and representatives. 
Overall, this subject is closely related to 7.1 . because the questions very much address the issue of participation and democracy. Thus, any approach which involves various actors and/or their representatives and, hence, transforms decision making on resource allocation more into a public process, reflects the 'democracy-participation' principle. Consequently, for details on organising such processes within a certain financing model the same issues will have to be taken into account as outlined earlier under 7.1. for the procedure of establishing a financing model.

To conclude, guiding questions for the process dimension within a specific financing approach would be:

a) Where are decisions about resource allocations made?

b) Who makes decisions on which issue of resource allocation?

c) How are decisions made?

\subsection{Closing Statement}

One of the central aims of the thesis has been to further integrate the fields of mental health care and social policy in an interdisciplinary manner for the Austrian context. The specific quality of this approach has been that it has made the interrelations between mental health care financing and reform more transparent. Additionally, it has indicated various challenges with respect to (future) financing approaches and their interdependencies with mental health care service provision. In providing, on the one hand, a description of mental health care financing arrangements in Austria and selected European countries, the thesis has shown that due to the specific characteristics of mental illness and mental health care, these financing arrangements are more complex than it is the case in overall health care financing. In the following in-depth analysis of the mental health reform discourse, it has, on the other hand, been demonstrated how central concepts of the reform are characterised by different meanings which is, for example the case for the 'participation principle'. Moreover, although core objectives themselves have remained broadly unchanged, the underlying meaning has been transformed in the context of overall welfare state restructuring, notably resulting in a more liberal oriented mental health care approach. Within that processes of change mental health care financing has received little attention. Yet, even if not explicitly addressed, the analysis has demonstrated several examples how reform discourse and financing are implicitly linked to each other. Not least, the impact of these relations in terms of responsibility for (financing) mental health care on the level of the individual persons affected and on the general society level has been demonstrated. In summary, the trend seems to be that private responsibility for the societal sectors 'family' and 'voluntary' and thus for the affected individuals or their relatives is increasing while the state's role in 
terms of mental health care responsibility is on the decline. While reform concepts themselves may aim at social inclusion of persons with mental disorders, it has been shown that more subtle elements of change bear the danger of social exclusion. The thesis finishes with some suggestions for establishing an alternative mental health care financing approach including guidelines for discussing alternative financing scenarios.

Not least, this piece of research has just as well raised many more questions which are yet to be answered in future research projects. These questions are very much related to the currently developing sub-discipline 'mental health economics' at the European level. It remains to be hoped that, as one impact of the thesis, the specific Austrian situation will play an important role in future research activities on these issues. This should not least foster planning and development in Austrian but also international mental health care. 


\section{References}

Aktion Psychisch Kranke, Deutsche Krankenhausgesellschaft, Spitzenverbände der Krankenkassen. (eds.) 1998. Bundesweite Erhebung zur Evaluation der Psychiatrie-Personalverordnung. Baden-Baden: Nomos.

Albrechts, L. 2003. Planning and Power. Towards an Emancipatory Planning Approach. Environment and Planning 21: 905-924.

Andreasen, NC. and DW. Black. 2001. Psychiatry. Introductory Textbook. $3^{\text {rd }}$ ed. Arlington: American Psychiatric Publishing.

Annandale, E. 1998. The Sociology of Health and Medicine: A Critical Introduction. Cambridge: Polity Press.

Arnold, M., KW. Lauterbach and K-J. Preuß. 1997. Managed Care. Ursachen, Prinzipien, Formen und Effekte. Stuttgart: Schattauer.

Arnold, M., P. König and A. Lingg. 2002. Die Weiterentwicklung der psychiatrischen Versorgung in Vorarlberg. Bregenz: Landesregierung.

Ashton, T. 1998. Contracting for Health Services in New Zealand: A Transaction Cost Analysis. Social Science and Medicine 46: 357-367.

Astbury, J. 2002. Mental health: gender bias, social position, and depression. In: G. Sen, GA. George and P. Östlin. (eds.) Engendering international health. The Challenge of Equity. Massachusetts: MIT Press.

Atzmüller, R. and V. Redak. 2000. Analyse des Strategieplans der Wiener Stadtregierung: ,Strategieplan für Wien - 'Qualität verpflichtet Innovationen für Wien ". Wien: Grüne Bildungswerkstatt.

Badelt, C. and A. Österle. 2001. Grundzüge der Sozialpolitik. $2^{\text {nd }}$ ed. Wien: Manz.

Balk, L. (ed.) 1998. Grundlagen der Bedarfsermittlung in der psychiatrischen Versorgung. Bocholt: Eicanos Verlag.

Bargetz, B. 2002. „Lassen wir doch die Männer Männer sein und die Frauen Mütter. “ Zur diskursiven Formationslogik der Gestaltung von „,Mutter" dargelegt am Kinderbetreuungsgeld. Universität Wien: Diplomarbeit. 
Barnes, M. 1999. Users as Citizens: Collective Action and the Local Governance of Welfare. Social Policy \& Administration 33: 73-90.

Barnes, M. and R. Bowl. 2001. Taking over the asylum. Empowerment and mental health. Hampshire: Palgrave.

Bauer, M., R. Engfer and J. Rappl. 1991. Psychiatrie-Reform in Europa. Bonn: Psychiatrie Verlag.

Becker, GS. 1991. A Treatise on the Family. Cambridge: University Press.

Becker, T. 1999. Qualität und Steuerung in der regionalen psychiatrischen Versorgung - Erfahrungen aus England. In: V. Kauder and H. Kunze. (eds.) Qualität und Steuerung. Köln: Rheinland Verlag.

Beecham J., A. Fenyo and M. Knapp. 1991. The mixed economy of mental health care. PSSRU Bulletin 8: 8-9.

BEIGEWUM. 2000. Mythos Nulldefizit. Alternativen zum Sparkurs. Wien: Mandelbaum.

BEIGEWUM. 2002. Frauen Macht Budget. Staatsfinanzen aus Geschlechterperspektive. Wien: Mandelbaum.

Bennett, D. 1995. Entwicklung und Praxis der Gemeindepsychiatrie auf verschiedenen Kontinenten. In: T. Bock. (ed.) Abschied von Babylon. Bonn: Psychiatrieverlag.

Bifulco, L. and T. Vitale. 2004. Contracting of Social Policy in Local Welfare: A Change in Position of the Recipients? Conference paper presented at the II ESPAnet Conference, Oxford September $9^{\text {th }}-11^{\text {th }} 2004$.

Bindman, J., A. Beck, G. Glover, G. Thornicroft, M. Knapp, M. Leese and G. Szmukler. 1999. Evaluating mental health policy in England. British Journal of Psychiatry 175: 327-330.

Bindman, J., G. Glover, D. Goldberg and D. Chisholm. 2000. Expenditure on mental health care by English health authorities: a potential cause of inequity. British Journal of Psychiatry 177: 267-274.

BMFG. 2003. Mental Health in Austria. Wien: BMFG.

BMSG. 2001. Alten- und Pflegeheime in Österreich. Wien: BMSG. 
BMSG. 2003. Datenbank für Angebote zur beruflichen Integration für Menschen mit Behinderung in Österreich. Online available under

http://www.wegweiser.bmsg.gv.at

(October 2003)

Bolognese-Leuchtmüller, B. 1994. Heilung und Krankenpflege im Spiegel sozialkultureller Entwicklung. Menschenbild, Lebensverständnis und Weltsicht als Schlüsselkategorien. Beiträge zur historischen Sozialkunde 24: 40-50.

Bonell, C. and M. Hilton. 2002. Consumerism in Health Care: The Case of a U.K. Voluntary Sector HIV Prevention Organization. International Journal of Voluntary and Nonprofit Organisations 13: 27-46.

Bramesfeld, A. 2003. Wie gemeindenahe ist die psychiatrische Versorgung in der Bundesrepublik Deutschland? Psychiatrische Praxis 30: 256-265.

Brodie, J. 2000. Imagining democratic urban citizenship. In: EF. Isin. (ed.) Democracy, citizenship and the global city. London: Routledge.

Bröckling, U., S. Krasmann and T. Lemke. (eds.) 2000. Gouvernmentalität der Gegenwart. Studien zur Ökonomisierung des Sozialen. Frankfurt/Main: Suhrkamp.

Bundesministerium für Gesundheit. (ed.) 1996. Die psychiatrische Versorgung chronisch psychisch Kranker. Daten, Fakten, Analysen. Baden-Baden: Nomos Verlag.

Bundesministerium für Gesundheit. (ed.) 1999. Von institutions- $z u$ personenzentrierten psychiatrischen Hilfen in der psychiatrischen Versorgung. Baden-Baden: Nomos Verlag.

Bundesministerium für Gesundheit, Sport und Konsumentenschutz. 1992. Empfehlungen für die zukünftige psychiatrische Versorgung der Bevölkerung Österreichs. Mitteilungen der österreichischen Sanitätsverwaltung 9: 265-289.

Busfield, J. 1999. Mental health policy. Making gender and ethnicity visible. Policy and Politics 27: 57-73. 
Busse, E. and A. Riesberg. 2000. Health Care Systems in Transition. Germany. Copenhagen: European Observatory on Health Care Systems (EOHCS). Online available under

http://www.observatory.dk

(July 2004)

Cermele, JA., S. Daniels and KL. Anderson. 2001. Defining Normal: Construction of Race and Gender in the DSM-IV Casebook. Feminism \& Psychology 11: 229-247.

Commission for Health Improvement. 2003. What CHI has found in: mental health trusts. Sector report. London: CHI.

Con_sens. 2000. Kennzahlenvergleich der überörtlichen Träger der Sozialhilfe. "Stationäre Einrichtungen der Behindertenhilfe 1998“. Hamburg: Con_sens. Online available under

http://www.consens-

info.de/hausig/dokumenteb/ueberoertlichetraeger/Bericht98 8Stand6.3.2000.pdf (July 2004)

Cooper, B. and M. Bauer. 1987. Developments in mental health care and services in the Federal Republic of Germany. International Journal of Mental Health 16: 78-93.

Copeland, J. 1981. 'What is a „Case“? A Case for What?' In: JK. Wing, P. Bebbington and LN. Robins. (eds.) What is a Case? London: Grant McIntyre.

Daly, M. and J. Lewis. 2000. The concept of social care and the analysis of contemporary welfare states. British Journal of Sociology 51: 281-298.

Dantendorfer, K. 2000. Der „Psychiatrieplan Burgenland 2000“. Eisenstadt: KRAGES.

Davis, S. and P. Fairbrother. 2003. Private Finance Initiative (PFI) and Public Private Partnerships (PPPs): Definition and Sources. Working Paper Series No 39. Cardiff: School of Social Sciences.

Deister, A., D. Zeichner and Ch. Roick. 2004. Ein regionales Budget für die Psychiatrie. Erste Erfahrungen aus einem Modellprojekt. Psychoneuro 30: 285288. 
Denk, P. and B. Weibold. 2002. Die Situation von Personen mit psychischen Beeinträchtigungen in Pensionisten- und Pflegeheimen und betreuten Wohneinrichtungen in Niederösterreich. St.Pölten: NÖGUS.

Denzin, N. 1989. The research act: A theoretical introduction to sociological methods. $3^{\text {rd }}$ ed. New York: Prentice Hall.

Department of Health. 2002. Expenditure Plans 2000-03 to 2003-04. Departmental Report for the Health and Social Service Programmes. London: Department of Health. Online available under http://www.doh.gov.uk/dohreport/index.htm (July 2004)

Department of Health. 2003. Resource allocation. Weighted capitation formula. London: Department of Health. Online available under http://www.dh.gov.uk/assetRoot/04/02/02/72/04020272.pdf (July 2004)

Department of Health. 2004. Personal Social Service expenditure and unit costs: England: 2002-2003. London: Department of Health. Online available under http://www.publications.doh.gov.uk/public/sb0402.htm (July 2004)

De Rick, K., S. Opdebeeck, Ch.Van Audenhove and F. Lammertyn in cooperation with G. Hedebouw HIVA. 2000. De gezinsleden van personen met langdurige psychische problemen. Eindrapport onderzoek in opdracht van de Vlaamse Minister van Cultuur. Leuven: Lucas.

Der Standard. 2003. Aufmerksamkeit als Programm. 24.2., p.18. Wien.

Deutscher Berufsverband für Soziale Arbeit. 2003. Soziotherapie. Neues Feld für Soziale Arbeit. Essen: Deutscher Berufsverband für Soziale Arbeit. Online available under

http://www.dbsh.de/html/hauptteil aktuelles 13.html (July 2004)

Diebäcker, M. 2004. (ed.) Partizipative Stadtentwicklung und Agenda 21. Diskurse-Methoden-Praxis. Wien: Edition Volkshochschule.

Dilling, $\mathrm{H}$. (ed.) 2000. The ICD-10 classification of mental and behavioural disorders. Bern: Huber. 
Dixon, A. 2002. Dilemmas in financing mental health. Eurohealth 8 (1): 25-28.

Döcker, U. 1994. Vom Narren zum psychiatrischen Fall. Über den Umgang der bürgerlichen Gesellschaft mit dem Wahnsinn. Beiträge zur historischen Sozialkunde 2: 51-56.

Dörner, K. 1969. Bürger und Irre. Zur Sozialgeschichte und Wissenschaftssoziologie der Psychiatrie. Frankfurt/Main: Europäische Verlagsanstalt.

Dörner, K. 1974. Wohin sollen wir den Krankheitsbegriff der Psychiatrie entwickeln? Psychiatrische Praxis 1: 123-129.

Durstberger, A. 2004. Expert interview. Unpublished correspondence.

Eagleton, T. 2000. Ideologie. Eine Einführung. Stuttgart/Weimar: Metzler.

Elston, MA. 1991. The politics of professional power. In: Gabe J. (ed.) The Sociology of the Health Service. London: Routledge.

Emmerson, C., C. Frayne and A. Goodman. 2002. Pressures in UK Healthcare: challenges for the NHS. London: Institute of Fiscal Studies.

Fairclough, N. 1994. Conversationalization of public discourse and the authority of the consumer. In: R. Keat, N. Whiteley and N. Abercrombie. (eds.) The authority of the consumer. London: Routledge.

Fairclough, N. 1995. Critical Discourse Analysis. London: Longman.

Fakhoury, W. and S. Priebe. 2002. The process of deinstitutionalization: an international overview. Current Opinion in Psychiatry 15: 187-192.

Ferrara, M. and M. Rhodes. 2000. Recasting European Welfare States. London: Frank Cass.

Fichtner, O. 1986. Handbuch der örtlichen Sozialplanung. Frankfurt/Main: Verein für öffentliche und private Fürsorge.

Forster, R. 1994. Psychiatrische Versorgung und Psychiatriepolitik in Österreich 1970-1990. In: U. Froschauer, K. Krajic and JM. Pelikan. (eds.) Psychosoziale Versorgung und Gesundheitsberufe in Österreich. Ausgewählte Aspekte aus sozialwissenschaftlicher Perspektive. Wien: Facultas. 
Forster, R. 1997. Psychiatriereformen zwischen Medikalisierung und Gemeindeorientierung. Eine kritische Bilanz. Opladen: Westdeutscher Verlag.

Forster, R. 2000. Die vielen Gesichter der Deinstitutionalisierung - soziologisch gedeutet. Psychiatrische Praxis 27(Sonderheft): 39-43.

Foucault, M. 1967. Madness and Civilization. London: Travistock.

Foucault, M. 1973. Wahnsinn und Gesellschaft. Frankfurt/Main: Suhrkamp.

Foucault, M. 1982. Von der Subversion des Wissens. Frankfurt/Main: Ullstein.

Foucault, M. 1991. Die Ordnung des Diskurses. Frankfurt/Main: Fischer.

Fowler, R. 1991. Language in the News. Discourse and Ideology in the Press. London: Routledge.

Frank, RG. and WG. Manning. (eds.) 1992. Economics and Mental Health Care. Balitmore: Johns Hopkins University Press.

Frank, RG. and TG. McGuire. 1999. Economics and Mental Health. Cambridge: National Bureau of Economic Research. Working paper no.7052.

Freidson, E. 1970. Professional Dominance. Chicago-Aldine: Atherton.

Frick, U., J. Rehm and C. Cording. 2001. Brauchen wir eine psychiatrische Gesundheitsökonomie?- Wozu wir eine psychiatrische Gesundheitsökonomie brauchen! Psychiatrische Praxis 28 (Sonderheft): 1-6.

Frick, U., W. Barta and H. Binder. 2001. Fallpauschalen in der stationären psychiatrischen Versorgung. Empirische Evaluation im Land Salzburg. Psychiatrische Praxis 28 (Sonderheft): 55-62.

Frick, U. and C. Cording. 2004. Finanzierungsmodelle für die psychiatrische Versorgung: Konzepte, Evidenz und Erfordernisse. Psychiatrische Praxis 31:163166.

Froschauer, U. and M. Lueger. 1992. Das qualitative Interview zur Analyse sozialer Systeme. Wien: Universitätsverlag.

Garfinkel, H. 1967. Studies in ethnomethodology. New Jersey: Prentice Hall. 
Gerlinger, T. 2002. Zwischen Korporatismus und Wettbewerb: Gesundheitspolitische Steuerung im Wandel. Berlin: WZB Publication Series.

Gesundheitsreport der Techniker Krankenkasse. 2002. Depression und Krankenstände in Deutschland. Hamburg: Techniker Krankenkasse.

Glaser, BG. and AL. Strauss. 1998. Grounded Theory: Strategien qualitativer Sozialforschung. Bern: Huber.

Glover, GR., E. Robin, J. Emami and GR. Arabscheibani. 1998. A needs index for mental health care. Social Psychiatry and Psychiatric Epidemiology 33: 89-96.

Glover, GR. 2002. Allocations within allocations: How should PCTs spend their money? University of Dunham: Centre for Public Mental Health. Online available under

http://www.dur.ac.uk/mental.health/index.php

(July 2004)

Goffman, E. 1973. Asyle. Über die soziale Situation psychischer Patienten und anderer Insassen. Frankfurt/Main: Suhrkamp.

Goodwin, S. 1997. Comparative Mental Health Policy. From Institutional to Community Care. London: Sage.

Gross, R. 2000. Psychiatrische Abteilung im Allgemeinen Krankenhaus: Chancen und Probleme der Regionalisierung am Beispiel Hollabrunn. Hollabrunn: Unpublished Report.

Gröger, H. 1999. Zur Entwicklung der Psychiatrie in der Wiener Medizinischen Schule. In: B. Keintzel. (ed.) Gründe der Seele. Wien: Picus Verlag.

Guest, JF. and RF. Cookson. 1999. Cost of schizophrenia to the UK society. An incidence-based cost-of-illness model for the first five years following diagnosis. Pharmacoeconomics 15: 597-610.

Guger, A. 1996. Umverteilung durch den Staat in Österreich. WIFO Monatsbericht 10: 635-652.

Habermas, J. 1977. Erkenntnis und Interesse. Frankfurt/Main: Suhrkamp.

Hagelskamp, J. 2004. Das persönliche Budget kommt. In der Behindertenhilfe werden individuelle Hilfen erprobt - Sachstand und Ausblick. Blätter der Wohlfahrtspflege 4: 126-129. 
Hammer, E. and A. Österle. 2001. Neoliberale Gouvernmentalität im österreichischen Wohlfahrtsstaat. Von der Reform der Pflegevorsorge 1993 bis zum Kinderbetreuungsgeld 2000. Kurswechsel 4: 60-69.

Hammer, E. 2002. Die Regelung zur Pflegvorsorge in Österreich. Wien: Master Thesis.

Harris, EC. and B. Barraclough. 1998. Excess mortality of mental disorder. British Journal of Psychiatry 173: 11-53.

Hart, A. and WW. Pommerehne. 1994. Zur Standortwahl von Nimby-Gütern. Hamburger Jahrbuch für Wirtschafts- und Gesellschaftspolitik 39: 184-211.

Hauck, G. 1992. Einführung in die Ideologiekritik. Hamburg: Argument Verlag.

Haug, H-J. and W. Rössler. 1999. Deinstitutionalisation of psychiatric patients in central Europe. European Archives of Psychiatry and Clinical Neuroscience 249: 115-122.

Heinze, M. and S. Priebe. 1995. Zum Bedürfnisbegriff in der psychiatrischen Forschung. Fundamenta Psychiatrica 9: 52-60.

Henderson, K. and M. Knapp. 2003. UK. In: H. Anheier and S. Kumar. (eds.) Social Services in Europe. Frankfurt: Publisher Institut für Sozialarbeit und Sozialpädagogik on behalf of the 'Observatorium für die Entwicklung der sozialen Dienste in Europa'.

Herles, M. 1996. The language of social security. Terminological, semantic and sociolinguistic aspects on a synchronic and diachronic level. Wien: Doctoral Thesis.

Hermann, B. 1979. Dokumentaion der Demokratischen Psychiatrie Wien. Wien: Gesellschaft für Demokratische Psychiatrie.

Herrmann, F. 2001. Planungstheorie. In: H-U. Otto and H. Thiersch. (eds.) Handbuch Sozialarbeit, Sozialpädagogik. $2^{\text {nd }}$ ed. Neuwied; Kriftel: Luchterhand.

Hickey, G. and C. Kipping. 1998. Exploring the concept of user involvement in mental health through a participation continuum. Journal of Clinical Nursing 7: 83-88. 
Hofmarcher, M. and H. Rack. 2001. Health Care Systems in Transition: Austria. Copenhagen: European Observatory on Health Care Systems (EOHCS). Online available under www.observatory.dk.

(March 2004)

Hofmarcher, M. and G. Röhrling. 2003. Gesundheitsausgaben in der EU. Die Vergleichbarkeit kränkelt. Schwerpunktthema: Die Vorausschätzung der Gesundheitsausgaben in Österreich. Health System Watch IV/2003.

Hofmarcher, M. and G. Röhrling. 2003a. Cost sharing in EU health care systems. Austria. Wien: IHS.

Hood, C. 1991. A public management for all seasons. Public Administration 69: 3-19.

Horkheimer, M. and TW. Adorno. 2001. Dialektik der Aufklärung. Philosophische Fragmente. $13^{\text {th }}$ ed. Frankfurt/Main: Fischer.

Hughes, G. 1988. Words in Time. A Social History of the English Vocabulary. Oxford: Basil Blackwell.

Hugman, R. 1994. Consuming Health and Welfare. In: R. Keat, N. Whiteley and N. Abercrombie. (eds.) The authority of the Consumer. London: Routledge.

Ingleby, D. 1985. Mental Health and Social Order. In: S. Cohen and A. Scull. (eds.) Social Control and the State. Oxford: Blackwell.

Jablensky, A., N. Sartorius and G. Emberg. 1992. Schizophrenia. Manifestations, incidence and course in different cultures: a WHO ten-country study: Psychological Medicine 20 (suppl.): 1-97.

Jäger, S. 2001. Discourse and knowledge: Theoretical and methodological aspects of a critical discourse and dispositive analysis. In: R. Wodak and M. Meyer. (eds.) Methods of critical discourse analysis. London: Sage.

Jäger, J., S. Leitner and R. Tomassovits. 2002. Wege zu einem alternativen Teilhabebudget für Wien. Wien: Grüner Rathausclub.

Jessop, B. 1999. The changing governance of welfare. Recent trends in its primary functions, scale and modes of coordination. Social Policy and Administration 33: 348-359. 
Jessop, B. 2000. From the KWNS to the SWPR. In: G. Lewis, S. Gerwik and J. Clarke. (eds.) Rethinking Social Policy. London: Sage.

Jetter, D. 1982. Geschichte des Hospitals. Band 5: Wien. Von den Anfängen bis um 1900. Wiesbaden: Franz Steiner Verlag.

Johnson, S., M. Zinkler and S. Priebe. 2001. Psychiatrische Gesundheitsversorgung in Großbritannien. In: Aktion Psychisch Kranke. (eds.) 25 Jahre Psychiatrieenquette. Band 1+2. Bonn: Psychiatrieverlag.

Johnson, S., M. Zinkler and S. Priebe. 2001a. Mental health service provision in England. Acta Psychiatrica Scandinavica. 104 (suppl. 410): 47-55.

Katschnig, H., E. Etzersdorfer and M. Muzik. 1993. „Nicht nur eine minderwertige Gesundheit": Eine Untersuchung über die Einstellung der österreichischen Bevölkerung zu psychisch Kranken und zur Psychiatrie. Research report. Wien.

Katschnig, H., W. Boisl, G. Eichberger, E. Etzersdorfer, P. Fischer, R. Fliedl, A. Marksteiner, E. Tatzer, J. Wancata and J. Windhaber. 1996. Der Niederösterreichische Psychiatrieplan 1995. St. Pölten: Landesregierung Niederösterreich.

Katschnig, H. 1998. Hundert Jahre wissenschaftliche Psychiatrie: Sigmund Freud, Emil Kraeplin, Émile Durkheim und die moderne Psychiatrie. Wiener Klinische Wochenschrift 110: 207-211.

Katschnig, H., E. Ladinser, M. Scherer, G. Sonneck and J. Wancata. 2001. Österreichischer Psychiatriebericht 2001. Wien: BMSG.

Katschnig, H., P. Denk and B. Weibold. 2003. Evaluation des Niederösterreichischen Psychiatrieplans 1995. Wien: Universitätsklinik für Psychiatrie.

Katschnig, H., P. Denk and M. Scherer. 2004. Österreichischer Psychiatriebericht 2004. Wien: BMGF.

Kaufmann, F-X. 2003. Sozialpolitisches Denken. Frankfurt/Main: Suhrkamp.

Kavanagh, S. 1996. Northern Ireland Care in the Community. PSSRU Bulletin 10: 30-32.

Keat, R., N. Whitely and N. Abercrombie. 1994. The authority of the consumer. London: Routledge. 
Kessler, RC., KA. McGonagle, S. Zhao, CB. Nelson, M. Hughes, S. Eshleman, HU. Wittchen and DS. Kendler. 1994. Lifetime and 12 month prevalence of DSM-III-R psychiatric disorders in the United States. Archives of General Psychiatry 51: 8-19.

Kieffer, CH. 1984. Citizen Empowerment: A Developmental Perspective. In: JC. Rappaport and R. Hess. (eds.) Studies in Empowerment. Steps Towards Understanding and Action. New York: Haworth Press.

Klatzer, E. 2002 Engendering Budgets. Ein wichtiger Beitrag zur Demokratisierung der Wirtschaftspolitik und ein zentrales Instrument einer umfassenden Gender-Mainstreaming-Politik. Kurswechsel 1: 78-90.

Knapp, M. (ed.) 1995. The Economic Evaluation of Mental Health Care. Aldershot: Ashgate.

Knapp, M., D. Novick, L. Genkeer, C. Curran and D. McDaid. 2003. Financing health care in Europe: Context for the Schizophrenia Outpatient Health Outcomes Study. Acta Psychiatrica Scandinavica (Suppl. 416): 30-40.

Krautgartner, M., J. Berner and J. Wancata. 2001. Die Belastung der österreichischen Bevölkerung durch Demenzerkrankungen zwischen den Jahren 2000 und 2050. Gemeindenahe Psychiatrie 22: 33-49.

Kruckenberg, P. 2000. Der Mensch im Mittelpunkt: Von einem institutions- zu einem personenzentrierten psychiatrischen Hilfesystem. Sozialpsychiatrische Informationen 3: 17-21.

Krüger U. and H. Kunze. 2004. Passgenaue Hilfe. In der Psychiatrie gibt es bereits gute Erfahrungen mit persönlichen Budgets. Blätter der Wohlfahrtspflege 4: $140-142$.

Kunze, H. 2001. Diskussion zum Beitrag von Ulrich Frick. Psychiatrische Praxis 28 (Sonderheft): 63-65.

Kvale, S. 1996. InterViews. An Introduction to Qualitative Research Interviewing. London: Sage.

Laing and Buisson. 2003. Thriving private hospital market. Press release. Online available under

http://www.laingbuisson.co.uk

(April 2003) 
Lakoff, G. and M. Johnson. 1980. Metaphors we live by. Chicago: University Press.

Landesregierung Oberösterreich. 2002. Psychiatrieweiterentwicklungsplan. Linz: Landesregierung.

Landesregierung Oberösterreich. 2002a. Diskussionsentwurf für ein Landesgesetz zur Chancengleicheit für Menschen mit Beeinträchtigungen (Ö̈. Chancengleichheitsgesetz - Ö̈. ChG). Linz: Landesregierung.

Landesregierung Oberösterreich. 2003. Projekt KL-QS (Kunde-Leistung-QualitätSteuerung). Kurzbeschreibung und Zwischenbericht. Linz: Landesregierung.

Landesregierung Salzburg. 2002. Leistungen für psychisch kranke Menschen. Bedarfs- und Entwicklungsplan. Salzburg: Landesregierung.

Landesregierung Steiermark. 2001. Die extramurale Psychiatrie in der Steiermark. Graz: Landesregierung.

Launois, R., M. Tourni and J. Reboul-Marty. 1998. Cost of illness: An inextricable maze or an aid in decision making? The case of schizophrenia. Encephale 24: 83-99.

Leibenkuft, E. 2000. Women with bipolar illness: An update. Bulletin of the Menninger Clinic 64: 5-17.

Lercher, JR. 1998. Leistungsorientierte Krankenanstaltenfinanzierung. Innsbruck: Master Thesis.

Lerner, Ch. 1999. The Language of Central Banking. Terminological Aspects and Discourse Analysis with Special Focus on the Federal Reserve System and the European System of Central Banks. Wien: Doctoral Thesis.

Lesky, E. 1978. Die Wiener Medizinische Schule im 19. Jahrhundert. Graz-Köln: Böhlau.

Lewis, L. 2003. User involvement discourse in mental health policy: A critical feminist approach. Conference paper: BSA annual conference.

Lewis, L. 2004. User involvement within Scottish Mental Health Policy: Locating Power and Inequality. To be published in 'Scottish Affairs'. 
Lien, L. 2003. Financial and organisational reforms in the health sector: implications for the financing and management of mental health care services. Health Policy 63: 73-80.

Lueger, M. 2001. Auf den Spuren der sozialen Welt. Methodologie und Organisierung interpretativer Sozialforschung. Frankfurt: Peter Lang.

MacKenzie, D. 1981. Statistics in Britain 1865-1930. The Social Construction of Scientific Knowledge. Edinburgh: University Press.

Mannion, R. and N. Small. 1999. Postmodern Health Economics. Health Care Analysis 7: 255-272.

Markert, A. and S. Wieseler. 2001. Sozialberichterstattung und Sozialplanung. In: H-U. Otto and H. Thiersch. (eds.) Handbuch Sozialarbeit, Sozialpädagogik. $2^{\text {nd }}$ ed. Neuwied; Kriftel: Luchterhand.

Mautner, G. 2000. Der britische Europa-Diskurs. Methodenreflexion und Fallstudien zur Berichterstattung in der Tagespresse. Wien: Passagen Verlag.

Mayer, G. 1982. Individuelle Bedürfnisse und Gesundheitspolitik. Augsburg: Maro.

Meise, U., F. Hafner and H. Hinterhuber. (eds.) 1991. Die Versorgung psychisch Kranker in Österreich. Eine Standortbestimmung. Wien: Springer.

Meise, U., W. Rössler, V. Günther and H. Hinterhuber. 1993. Bürgernahe Psychiatrie: Leitlinien für die Reform der psychiatrischen Versorgung in Tirol. Innsbruck: VIP- Verlag.

Meise, U. und H. Hinterhuber. 1998. Leistungsorientierte Krankenhausfinanzierung- Verliert die Psychiatrie? Neuropsychiatrie 12: 177-186.

Mental Health Foundation. 1995. Annual Report. London: Mental Health Foundation.

Meyer, M. 2001. Between theory, method and politics: positioning of the approaches to CDA. In: R. Wodak and M. Meyer. (eds.) Methods of critical discourse analysis. London: Sage. 
MHEEN. 2004. Mental Health Economics European Network. Online available under

http://www.mentalhealth-econ.org

(July 2004)

MHEEN.2004a. Mental Health Economics. Final Report. Brussels: Mental Health Europe. Online available under

http://europa.eu.int/comm/health/ph projects/2002/promotion/promotion 20020

7 en.htm

(May 2005)

Michalitsch, G. 2000. Jenseits des homo oeconomicus? Geschlechtergrenzen der neoklassischen Ökonomie. In: B. Krondorfer. (ed.) Frauen und Ökonomie. Oder: Geld essen Kritik auf. Wien: Pro Media.

Ministry of Health Welfare and Sport (VWS) and T. Institute. 2000. Major challenges to Dutch Mental Health Care (Fact sheet mental health care (GGZ) No 1, August. Utrecht: Trimbos Institute.

Mory, C., J. Jungbauer and MC. Angermeyer. 2002. Finanzielle Belastungen von Eltern und Partnern schizophrener Patienten im Vergleich. Psychiatrische Praxis 29: $175-180$.

Mörchen, G., V. Pieters, A. Weicert, C. Niederle, E. Fähndrich and W. Voigtländer. 2002. Armut und soziale Unterversorgung bei stationär behandelten psychisch Kranken. Psychiatrische Praxis 29: 295-300.

Mossialos, E. and SMS. Thomson. 2002. Voluntary health insurance in the European Union. In: E. Mossialos, A. Dixon, J. Figueras and J. Kutzin. (eds.) Funding health care: options for Europe. Buckingham: Open University Press.

Mueser, KT., SM. Glynn, PW. Corrigan and W. Barber. 1996. A Survey of Preferred Terms for Users of Mental Health Services. Psychiatric Services. 47: 760-761.

Murray, C. and A. Lopez. 1996. The Global Burden of Disease in 1990: final results and their sensitivity to alternative epidemiological perspectives, discount rates, age-weights and disability-weights. In: C. Murray and A. Lopez. (eds.) The global Burden of Disease: A Comprehensive Assessment of Mortality and Disability from diseases, Injuries and Risk Factors in 1990 and projected to 2020. Havard: School of Public Health. 
Nam, H-J. 2003. Alten- und Pflegeheime in Österreich: Trägerstruktur, Angebotsstruktur und Beschäftigung. Wien: Working paper.

Nam, H-J. 2003a. Soziale Sicherungssysteme bei Pflegebedürftigkeit alter Menschen: Europäische Wohlfahrtsstaaten als Vorbild für Südkorea? Wien: Doctoral Thesis.

Nelson, G., J. Lord und J. Ochocka. 2001. Empowerment and Mental Health in Community: Narratives of Psychiatric Consumer/Survivors. Journal of Community and applied Social Psychology 11: 125-142.

Netten, A. and J. Beecham. (eds). 1993. Costing Community Care. Aldershot: Ashgate.

Novy, A. 2002. Entwicklung gestalten. Gesellschaftsveränderung in der Einen Welt. Frankfurt/Main: Brandes \& Apsel/Südwind.

Novy, A. and E. Hammer. 2002. Reflections on History and Content of Social Innovation in Austria. Unpublished project report 2002.

OECD. 2002. OECD Health Care Data. CD-Rom. Paris: OECD.

OECD. 2004. OECD Health Care Data. Paris: OECD. Online available under http://www.oecd.org/topicstatsportal/0,2647,en $2825 \quad 495642 \quad 1 \quad 1 \quad 1 \quad 11$ 1,00.htm $\underline{1}$

(July 2004)

ÖBIG. 1994. Österreichischer Krankenanstalten und Großgeräteplan (ÖKAP/GGP) 1994. Wien: BMSG.

ÖBIG. 1997. Struktureller Bedarf der psychiatrischen Versorgung in Österreich. Wien: ÖBIG.

ÖBIG. 2000. Kärntner Psychiatrieplan. Klagenfurt: Landesregierung.

ÖBIG. 2002. Grundlagen für die integrierte psychiatrische Versorgung in Wien. Wien: ÖBIG.

ÖBIG. 2004. Psychotherapie auf Krankenschein. Beschreibung und Evaluierung der bisherigen Umsetzung. Wien: ÖBIG. 
Österle, A. 2001. Equity Choices and Long-Term Care Policies in Europe. Allocating resources and burdens in Austria, Italy, the Netherlands and the United Kingdom. Aldershot: Ashgate.

Office of Fair Trading. 1996. Health insurance. London: Office of fair Trading.

Ortmann, F. (ed.) 1976. Sozialplanung für wen? Gesellschaftsstruktur, Planung und Partizipation. Darmstadt: Luchterhand.

Palmer, S. and DJ. Torgerson. 1999. Definitions of efficiency. British Medical Journal 318: 1136.

Patel, A. and M. Knapp. 1998. Costs of mental illness in England. Mental Health Research Review 5: 4-10.

Patel, V., R. Araya, M. de Lima, A. Ludemir and C. Todd. 1999. Women, poverty and common mental disorders in four restructuring societies. Social Science \& Medicine 49: 1461-1471.

Pelizzari, A. 2001. Die Ökonomisierung des Politischen. Konstanz: UVK Verlagsgesellschaft.

Pelizzari, A. 2003. Entpolitisierung des Verwaltungswissens: Ökonomisierungstendenzen am Beispiel des Züricher Spitalswesens. Unpublished conference paper.

Pereira, J., AC. Campos, F. Ramos, J. Simões and V. Reis. 1999. Health care reform and cost containment in Portugal. In: E. Mossialos and J. Le Grand. (eds.) Health Care and Cost Containment in the European Union. London: Ashgate.

Pfeil, W. 2001. Vergleich der Sozialhilfesysteme der österreichischen Bundesländer. Wien: BMSG.

Piccinelli, M. and FG. Homen. 1997. Gender Differences in the Epidemiology of Effective Disorders and Schizophrenia. Geneva: WHO.

Pijl, YJ., H. Kluiter and D. Wiersma. 2000. Change in Dutch mental health care: an evaluation. Social Psychiatry and Psychiatric Epidemiology. 35: 402-407.

Pilgrim, D. and A. Rogers. 1994. A Sociology of Mental Health and Illness. Buckingham: Open University Press. 
Polland, E. and H. Liebeck. 1994. The Oxford Paperback Dictionary. Oxford: University Press.

Porter, T. 1996. Trust in numbers. The invention of objectivity. Princeton: University Press.

Priebe, S. 2003. Zukunft psychiatrischer Versorgung - Träume und Alpträume. Psychiatrische Praxis 30 (Sonderheft): 48-53.

Prior, L. 1993. The Social Organization of Mental Illness. London: Sage.

Püringer, U., M. Truschnig and P. Konstantinuik. 2000. Bedarfsgerechte psychosoziale Versorgung der Steiermark. Graz: Landesregierung Steiermark.

Ramos, F., J. Sennfelt, MJ. Amaral and P. Valente. 1996. Economia da saùde e saùde mental: Os custos da depressao. Revista Portuguesa de Saúde Pública 14: 53-68.

Rainer, M., S. Jungwirth, Ch. Krüger-Rainer, A. Croy, G. Gatterer and M. Haushofer. 2002. Pflegende Angehörige von Demenzerkrankten: Belastungsfaktoren und deren Auswirkungen. Psychiatrische Praxis 29: 142-147.

Rechnungshof. 1998. Wahrnehmungsbericht des Rechnungshofes. Konvergenzkriterien. Psychiatrische Versorgung. Wien: Rechnungshof.

Reichert, R. 2003. Ein besseres Selbst werden. Vortragsmanuskript Armutskonferenz. Salzburg. 20.3.03.

Resch, R. 2001. Sozialrecht. $2^{\text {nd }}$ ed. Wien: Manz.

Rice, D., S. Kelman and LS. Miller. 1992. The Economic Burden of Mental Illness. Hospital and Community Psychiatrie 43: 1227-1232.

Rice, N. and PC. Smith. 2002. Strategic resource allocation and funding decisions. In: E. Mossialos, A. Dixon, J. Figueras and J. Kutzin. (eds.) Funding health care: options for Europe. Buckingham: Open University Press.

Robinson, R. and A. Dixon. 1999. Health Care Systems in Transition. UK. Copenhagen: European Observatory on Health Care Systems (EOHCS). Online available under http://www.observatory.dk

(July 2004) 
Rössler, W. 1992. Sozialpsychiatrische Dienste in der Bundesrepublik Deutschland - ein Überblick. Gesundheitswesen 54: 19-24.

Rössler, W., H-J. Salize, U. Biechele and A. Riecher-Rössler. 1994. Stand und Entwicklung der psychiatrischen Versorgung. Nervenarzt 65: 427-437.

Rössler, W. 1998. Bedarfsindikatoren einer regionalisierten psychiatrischen Versorgungsplanung. In: L. Balk. (ed.) Grundlagen der Bedarfsplanung in der psychiatrischen Versorgung. Bocholt: Eicanos.

Rössler, W. 2001. Cui bono oder wer braucht die Gesundheitsökonomie? Psychiatrische Praxis 28 (Sonderheft): 29-31.

Rose, N. 1999. Powers of Freedom. Reframing Political Thought. Cambridge: University Press.

Rose, N. 2000. Tod des Sozialen? Eine Neubestimmung der Grenzen des Regierens. In: U. Bröckling, S. Krasmann and T. Lemke. (eds.) Governmentalität der Gegenwart. Frankfurt/Main: Suhrkamp.

Rothbard, AB. and E. Kuno. 2000. The success of deinstitutionalization. Empirical findings from case studies on state hospital closures. International Journal of Law and Psychiatry 23: 329-344.

Rothschild, KW. 2003. The absence of power in contemporary economic theory. Journal of Socio-Economics 31: 433-442.

Rowe, R. and M. Shepherd. 2002. Public Participation in the New NHS: No Closer to Citizen Control? Social Policy \& Administration 36: 275-290.

Rümmele, M. 2005. Kranke Geschäfte mit unserer Gesundheit. Symptome, Diagnosen und Nebenwirkungen. St.Pölten: NP Bucherverlag.

Russel, LB. 1989. Medicare's New Hospital Payment System: Is It Working? Washington: Brookings Institution.

Sainsbury Centre for Mental Health. 2003. Money for Mental Health. A Review of Public Spending on Mental Health Care. London: SCMH. Summary online available under

http://www.scmh.org.uk/8025694D00337EF1/vWeb/fsCPIR4PDJ8T (July 2004) 
Salize, H-J. 2001. Die Kosten der Schizophrenie - was wissen wir (nicht)? Psychiatrische Praxis 28 (Sonderheft): 21-28.

Salize, H-J., W. Rössler and I. Reinhard. 2001. Kostenermittlung in einem fragmentierten psychiatrischen Versorgungssystem. Gesundheitswesen 58 (Sonderheft): 10-17.

Salize, H-J. 2004. Expert interview. Unpublished correspondence.

Saraceno, B. and C. Barbui. 1997. Poverty and Mental illness. Canadian Journal of Psychiatry 42: 285-290.

Sayce, L. 2000. From Psychiatric Patients to Citizens. Overcoming Discrimination and Social Exclusion. London: Macmillan.

Schmidl, F. and S. Rudas. 1999. Die Entwicklung organisierter psychiatrischer Hilfen in Wien. In: B. Keintzl. (ed.) Gründe der Seele. Wien: Picus Verlag.

Schmidt, MG. 1995. Demokratietheorien. $3^{\text {rd }}$ ed. Opladen: Leske + Budrich.

Schneider, U. and B. Trukeschitz. 2003. Was leisten Leistungsverträge? Erste Ergebnisse einer Befragung unter NPO PraktikerInnen. Wien: Working paper.

Schnurr, S. 2001. Partizipation. In: H-U. Otto and H. Thiersch. (eds.) Handbuch Sozialarbeit/Sozialpädagogik. $2^{\text {nd }}$ ed. Neuwied; Krieftel: Luchterhand.

Schröder, C. 2004. Die Selbstbestimmung fördern. Anforderungen an die Kommunen zur Einführung persönlicher Budgets - Beispiel Niedersachsen. Blätter der Wohlfahrtspflege 4: 143-144.

Schülein, J. 1987. Theorie der Institution. Opladen: Westdeutscher Verlag.

Schülein, JA. 1994. Homo oeconomicus und soziologische Theorie. In: JA. Schülein and G. Bohmann. (eds.) Ökonomie und Gesellschaft. Wien: Springer Verlag.

Schülein, JA. and S. Reitze. 2002. Wissenschaftstheorie für Einsteiger. Wien: Universitätsverlag.

Schulenburg, v. d. JM. 2000. Die Entwicklung der Gesundheitsökonomie und ihre methodischen Ansätze. In: O. Schöffski und JM. v. d. Schulenburg. (eds.) Gesundheitsökonomische Evaluationen. $2^{\text {nd }}$ ed. Berlin: Springer. 
Scottish Development Centre for Mental Health Care. 2001. Route Map to User and Carer Participation. Part 1: Introduction and Guide to Using the Route Map. Edinburgh: Socttish Development Centre for Mental Health. Online available under

http://www.sdcmh.org.uk/publications.htm

(September 2003)

Scull, A. 1979. Museums of madness. The social organization of insanity in the $19^{\text {th }}$ century England. London: Allen Lane.

Scull, A. 1985. Humanitarism or Control? Some Observations on the Historiography of Anglo-American Psychiatry. In: S. Cohen and A. Scull. (eds.) Social Control and the State. Oxford: Blackwell.

Sheldrick, BM. 2003. Judical Review and the Allocation of Health Care Resources in Canada and the United Kingdom. Journal of Comparative Policy Analysis: Research and Practice 5: 149-166.

Shelton, G. 1998. Zu den jüngsten Psychiatriereformen in England. Sozialpsychiatrische Informationen 3: 19-22.

Simpson, CJ. 1998. Contracting in mental health. British Journal of Psychiatry 172: 4-6.

Smith, SR. and M. Lipsky. 1993. Services and Clients under Contracting. In: Smith SR. und M. Lipsky. (eds.) Nonprofits for Hire. The Welfare State in the Age of Contracting. Cambridge/London: Havard University Press.

Smutny, G. 2002. Haushaltswesen der Länder. In: G. Steger. (ed.) Öffentliche Haushalte in Österreich. Wien: Verlag Österreich.

Sozialministerium. 2002. Richtlinien für die Förderung von sozialpsychiatrischen Diensten. Berlin: Sozialministerium.

Speicher, J. 2004. Wechselwirkung zwischen Vergütungssystem und Patientenversorgung. Rheinland-pfälzische Erfahrungen mit dem Persönlichen Budget. Vortragsmanuskript. Konferenz ,Unternehmen Psychiatrie'. 15.-16.6.04.

Statistische Nachrichten. 2000. Sozial(hilfe)leistungen der Bundesländer 1998. Statistische Nachrichten 6: 433-439. 
Statistische Nachrichten. 2004. Sozial(hilfe)leistungen der Bundesländer 2002. Statistische Nachrichten 8: 762-769.

Statistisches Bundesamt. 2002. Gesundheitsausgaben nach Ausgabenträgern. Online available under http://www.destatis.de (July 2004)

Stepan, A. and M. Sommersguter-Reichmann. 2001. Analyse des neuen leistungsorientierten Krankenanstalten-Finanzierungssystems in Österreich. Wien: Working paper.

Stevens, A., J. Raftery and RA. Mendelsohn. 2001. Commissioners' information requirements on mental health needs and commissioning for mental health services. In: G. Thornicroft. (ed.) Measuring Mental Health Needs. $2^{\text {nd }}$ ed. London: The Royal College of Psychiatrists.

Stoppard, J. 2000. Understanding Depression: Feminist Social Constructionist Approaches. London: Routledge.

Strouhal, E. 1989. The case of W. A critical journey to the border between psychiatry and justice. In: R. Wodak. (ed.) Language, power and ideology. Amsterdam: John Benjamin.

Szasz, TS. 1974. The Myth of Mental Illness: Foundations of a Theory of Personal Conduct. New York: Harper \& Row.

Tarricone, R., S. Gerzele, R. Montanelli, L. Fattura, M. Percudani and G. Racagni. 2000. Direct and indirect costs of schizophrenia in community psychiatric services in Italy. The GISIES Study. Interdisciplinary Study Group on the Economic Impact of Schizophrenia. Health Policy 51: 1-18.

Theurl, E. 1996. Notwendige Begleitmaßnahmen einer Neuordnung der Krankenhausfinanzierung in Österreich. ÖKZ 11A: 26-35.

Thornicroft, G. (ed.) 2001. Measuring mental health needs. London: Institute of Psychiatry.

Torfing, J. 1999. New Theories of Discourse. Laclau, Mouffe and Žižek. Oxford: Blackwell.

Ungerson, C. 1995. Gender, cash and informal care. Journal of Social Policy 24: $31-52$. 
Verband der privaten Krankenversicherung. 2002. PKV Zahlenbericht 2001/2002. Köln: Verband der privaten Krankenversicherung. Online available under http://www.pkv.de/downloads/Zb02.pdf (July 2004)

Von Cranach, M. 2000. Housing for psychiatric patients inside and outside of hospitals. Psychiatrische Praxis 27 (Sonderheft): 59-63.

Wancata, J., B. Kaup and M. Krautgartner. 2001. Die Entwicklung der Demenzerkrankungen in Österreich in den Jahren 1951 bis 2050. Wiener Klinische Wochenschrift 113: 172-180.

Warner, R. 1994. Recovery from Schizophrenia. Psychiatry and Political Economy. New York: Routledge.

Weber, B. 2001. Öffentlich/Privat - neue Grenzziehungen im Übergang zum Postfordismus. Kurswechsel 4: 24-37

Weber, M. 1980. Wirtschaft und Gesellschaft. Grundlagen einer verstehenden Soziologie. Tübingen: Mohr.

Weintraub, R. 2002. How Economics became a Mathematical Science. Duke: University Press.

Weiss, G. and R. Wodak. 2003. Introduction: Theory, Interdisciplinarity and Critical Discourse Analysis. In: G. Weiss and R. Wodak. (eds.) Critical Discourse Analysis. Theory and Interdisciplinarity. Hampshire/New York: Palgrave Macmillan.

Weiß, U. 1995. Macht. In : D. Nohlen. (ed.) Politische Theorien. München: Beck.

Wendt, C. 2003. Krankenversicherung oder Gesundheitsversorgung. Gesundheitssysteme im Vergleich. Wiesbaden: Westdeutscher Verlag.

WHO. 2000. World Health Report. Geneva: WHO.

WHO. 2001. The Mental Health Report. Geneva: WHO.

WHO. 2001a. Atlas. Mental Health Resources in the World. Geneva: WHO. Online available under

http://www.who.int/mental health/evidence/atlas/

(June 2004) 
Williams, R. and DP. Doessel. 2001. Economics of Mental Health Care. Industry, Government and Community Issues. Aldershot: Ashgate.

Wilson, J. 2000. Mental health services in New Zealand. International Journal of Law and Psychiatry 23: 215-228.

Wirtschaftsblatt. 2003. Spitalskonzern KRAGES soll ab 2004 von privatem Betreiber geführt werden. 16.5.2003.

Wittmund, B., HU. Wilms and MC. Angermeyer. 2002. Depressive Disorders in Spouses of Mentally Ill Patients. Social Psychiatry and Psychiatric Epidemiology 37: 177-182.

Wittmund, B. and R. Killian. 2002. Welche Kosten tragen Angehörige für die Betreuung psychisch kranker Familienmitglieder. Psychiatrische Praxis 29: 171172.

Wodak, R.1989. (ed.) Language, Power and Ideology. Amsterdam: John Benjamin.

Wodak, R. 2001. What is CDA about - a summary of its history, important concepts and its developments. In: R. Wodak and M. Meyer. (eds.) Methods of critical discourse analysis. London: Sage.

Wolff, S. 2000. Dokumenten- und Aktenanalyse. In: U. Flick, E. Kardorff and I. Steinke. (eds.) Qualitative Forschung: Ein Handbuch. Hamburg: Rowohlt.

Zechmeister, I. and A. Österle. 2001. Finanzierungsstrukturen der psychiatrischen Versorgung in Niederösterreich. Wien: Unpublished report.

Zechmeister, I. 2002. Bedarfsplanung für die psychiatrische Versorgung im außerstationären Bereich: Eine Reflexion über Bedarfszahlen als adäquate Planungsrichtlinie zur quantitativen Dimensionierung des außerstationären Versorgungsbedarfs. Unpublished report commissioned by Grillich, Scheucher \& Dressel GmbH.

Zechmeister, I., A. Österle, P. Denk and H. Katschnig. 2002. Incentives in financing mental health care in Austria. Journal of Mental Health Policy and Economics 5: 121-129.

Zechmeister, I. 2004. Frauen und Psychiatrie: Eine polit-ökonomische Perspektive. ,Neuropsychiatrie' 17: 106-112. 
Zechmeister, I., J. Meichenitsch and J. Hagleitner. 2004. Analyse und Empfehlungen zur zukünftigen Finanzierbarkeit des Gesundheitswesens. Wien: Grüner Klub im Nationalrat.

Zechmeister, I. and A. Österle. 2004. Herausforderungen und mögliche Neuansätze für die Finanzierung einer gemeindenahen psychiatrischen Versorgung. Endbericht zum Jubiläumsfondsprojekt (Nr. 9710). Wien: Unpublished research report.

Zechmeister, I. and A. Österle. 2004a. Mental Health Care Financing in Europe in the Light of Health Policy Trends: Distributional Issues in the UK, Germany and Austria. Conference paper presented at the II ESPAnet Conference, Oxford September $9^{\text {th }}-11^{\text {th }} 2004$. 


\section{Forschungsergebnisse der Wirtschaftsuniversität Wien}

Herausgeber: Wirtschaftsuniversität Wien vertreten durch ă.o. Univ. Prof. Dr. Barbara Sporn

Band 1 Stefan Felder: Frequenzaliokation in der Telekommunikation. Ökonomische Analyse der Vergabe von Frequenzen unter besonderer Berūcksichtigung der UMTS-Auktionen. 2004.

Band 2 Thomas Haller: Marketing im liberalisierten Strommarkt. Kommunikation und Produktplanung im Privatkundenmarkt. 2005.

Band 3 Alexander Stremitzer: Agency Theory: Methodology, Analysis. A Structured Approach to Writing Contracts. 2005.

Band 4 Günther Sedlacek: Analyse der Studiendauer und des Studienabbruch-Risikos. Unter Verwendung der statistischen Methoden der Ereignisanalyse. 2004.

Band 5 Monika Knassmüller: Unternehmensleitbilder im Vergleich. Sinn- und Bedeutungsrahmen deutschsprachiger Unternehmensleitbilder - Versuch einer empirischen (Re-)Konstruktion. 2005.

Band 6 Matthias Fink: Erfolgsfaktor Selbstverpflichtung bei vertrauensbasierten Kooperationen. Mit einem empirischen Befund. 2005.

Band 7 Michael Gerhard Kraft: Ökonomie zwischen Wissenschaft und Ethik. Eine dogmenthistorische Untersuchung von Léon M.E. Walras bis Milton Friedman. 2005.

Band 8 Ingrid Zechmeister: Mental Health Care Financing in the Process of Change. Challenges and Approaches for Austria. 2005.

www.peterlang.de 